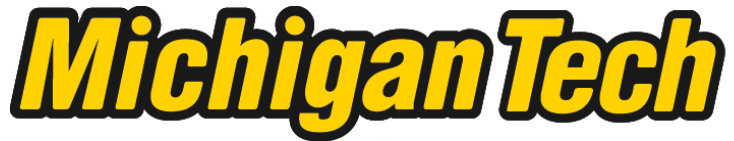 \\ Michigan Technological University Create the Future Digital Commons @ Michigan Tech
}

Dissertations, Master's Theses and Master's Reports - Open

Dissertations, Master's Theses and Master's

Reports

2012

\section{Model to describe the mode I fracture of steel fiber reinforced ultra-high performance concrete}

Eric L. Kreiger

Michigan Technological University

Follow this and additional works at: https://digitalcommons.mtu.edu/etds

Part of the Civil and Environmental Engineering Commons

Copyright 2012 Eric L. Kreiger

\section{Recommended Citation}

Kreiger, Eric L., "Model to describe the mode I fracture of steel fiber reinforced ultra-high performance concrete", Master's Thesis, Michigan Technological University, 2012.

https://doi.org/10.37099/mtu.dc.etds/248

Follow this and additional works at: https://digitalcommons.mtu.edu/etds

Part of the Civil and Environmental Engineering Commons 


\title{
A MODEL TO DESCRIBE THE MODE I FRACTURE OF STEEL FIBER REINFORCED ULTRA-HIGH PERFORMANCE CONCRETE
}

\author{
By \\ Eric L. Kreiger \\ A THESIS \\ Submitted in partial fulfillment of the requirements for the degree of \\ MASTER OF SCIENCE \\ (Civil Engineering) \\ MICHIGAN TECHNOLOGICAL UNIVERSITY \\ 2012
}

(C) 2012 Eric L. Kreiger 

This Thesis, "A Model to Describe the Mode I Fracture of Steel Fiber Reinforced UltraHigh Performance Concrete," is hereby approved in partial fulfillment of the requirements for the Degree of MASTER OF SCIENCE IN CIVIL ENGINEERING.

Department of Civil and Environmental Engineering

Signatures:

Thesis Advisor

Dr. Theresa M. Ahlborn

Department Chair

Dr. David Hand

Date 



\section{Table of Contents}

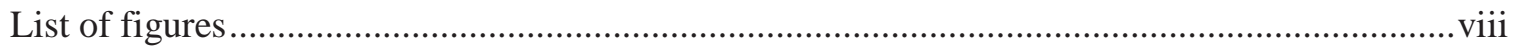

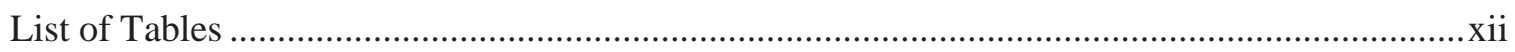

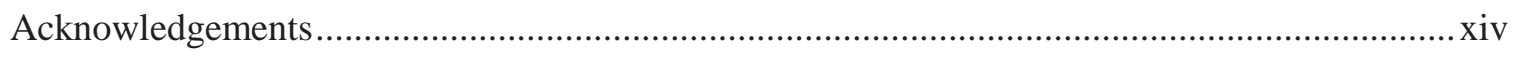

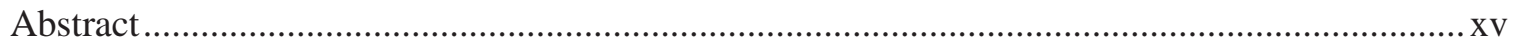

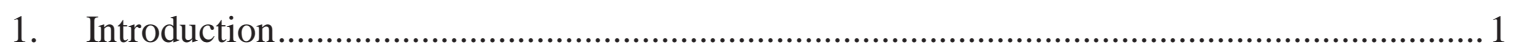

1.1 Introduction to Ultra High Performance Concrete (UHPC) .............................................. 1

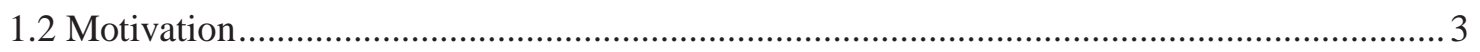

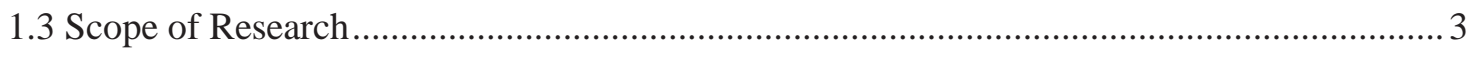

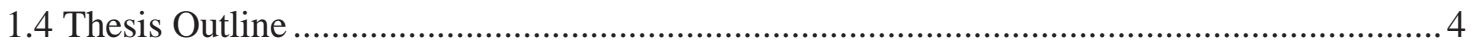

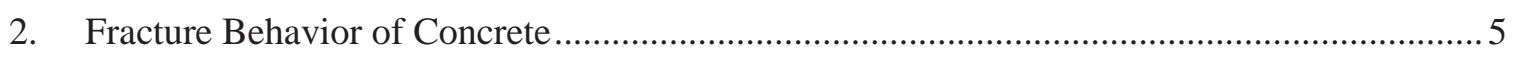

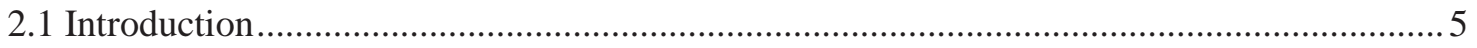

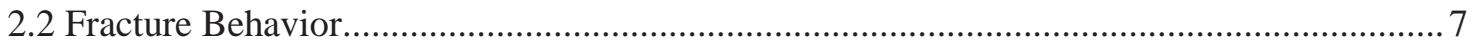

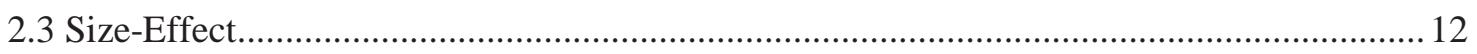

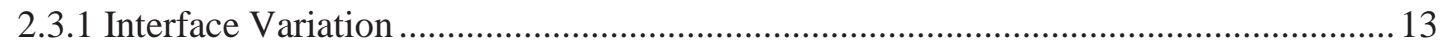

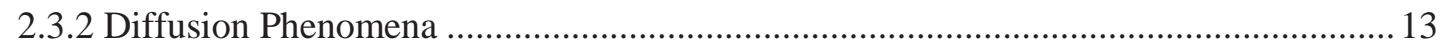

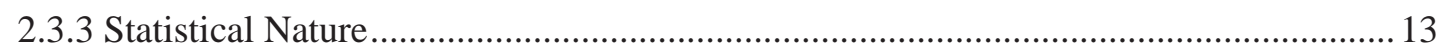

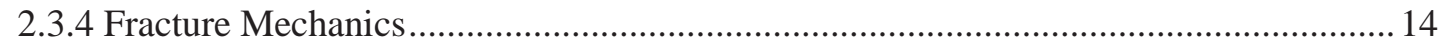

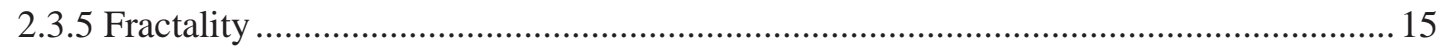

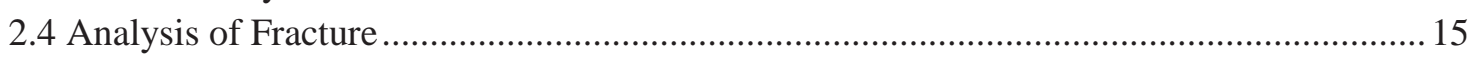

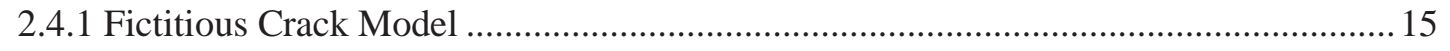

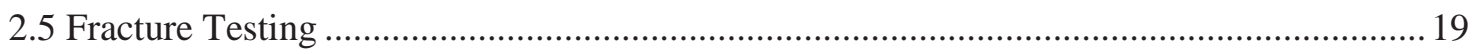

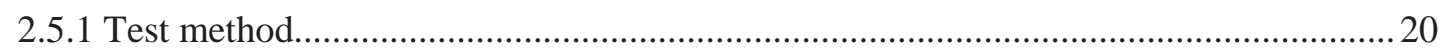

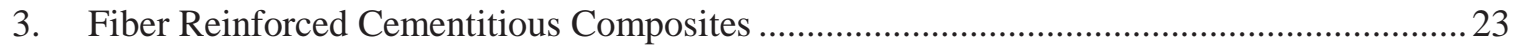

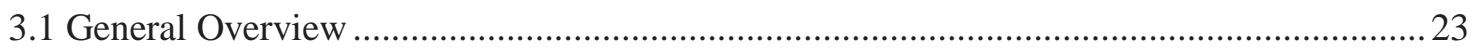

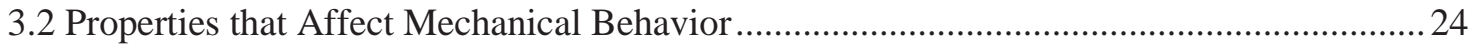

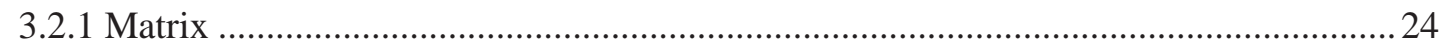

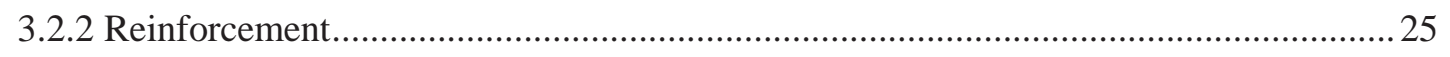

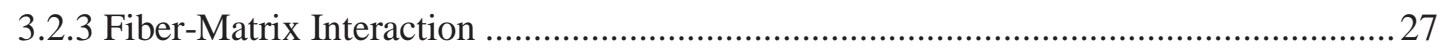

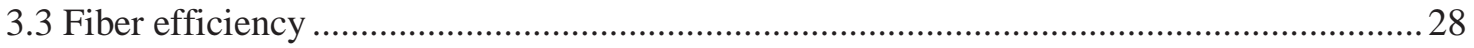

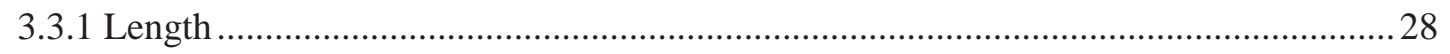

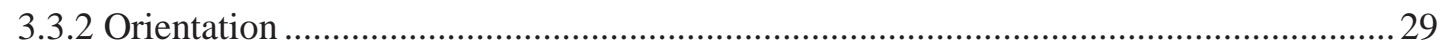

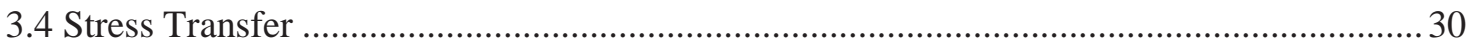

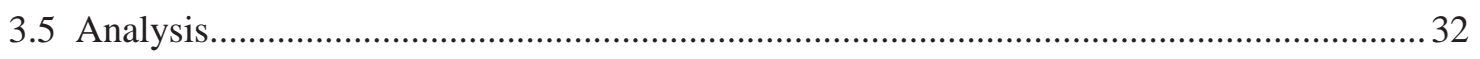

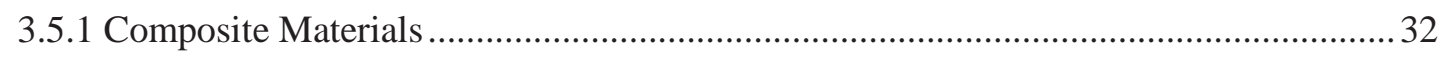

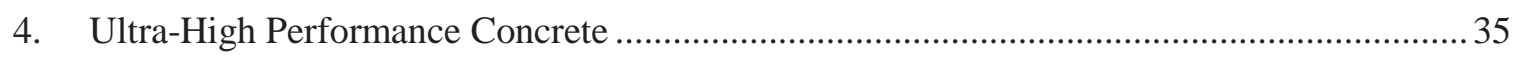

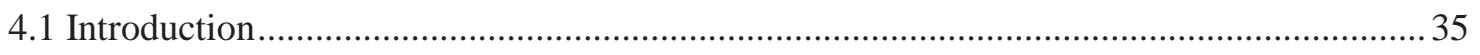

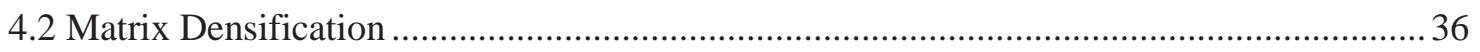




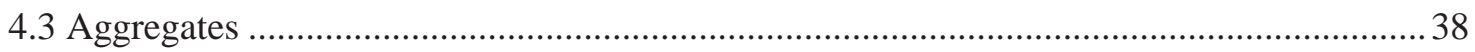

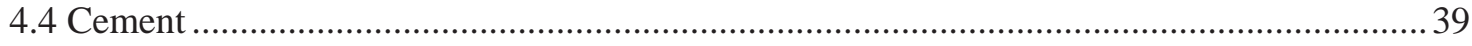

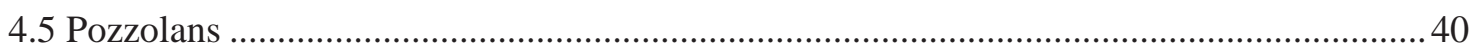

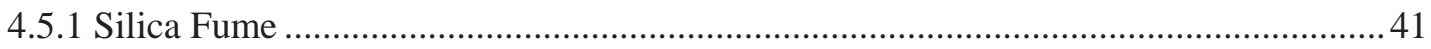

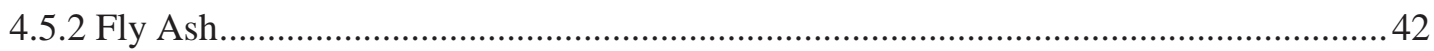

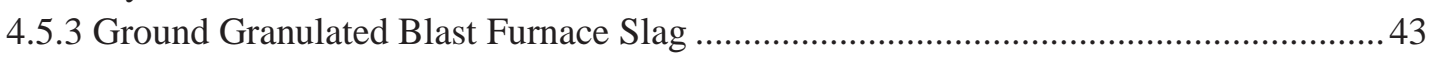

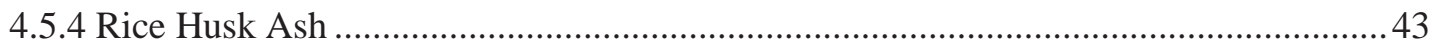

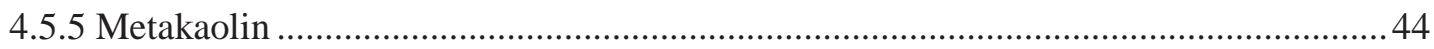

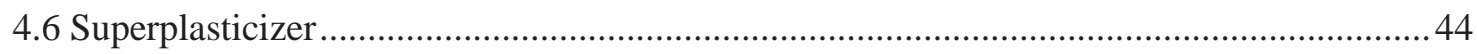

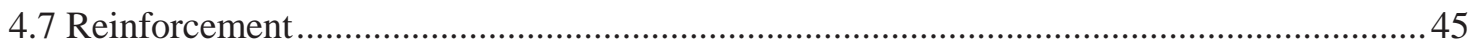

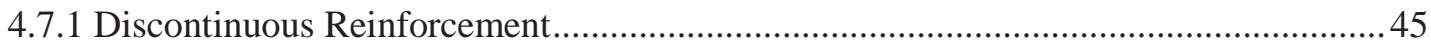

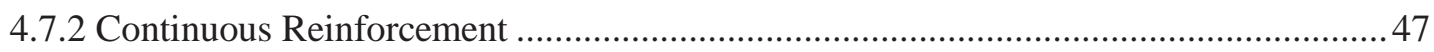

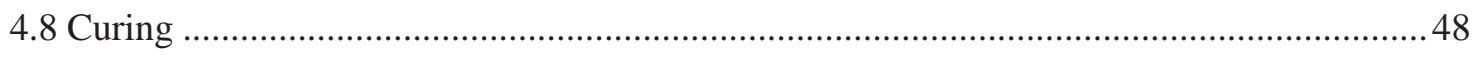

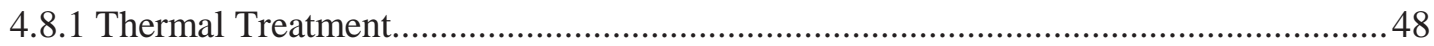

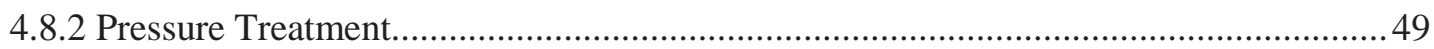

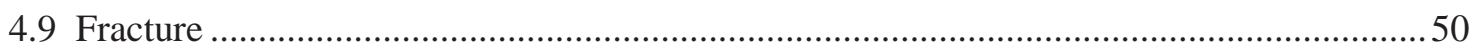

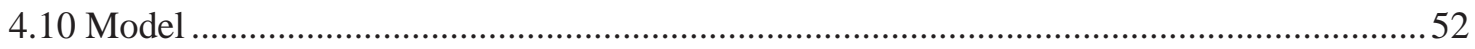

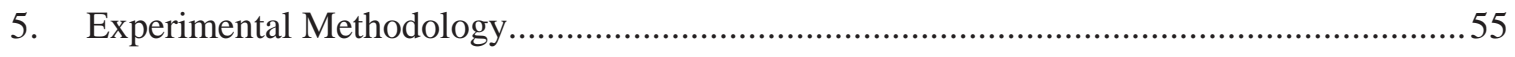

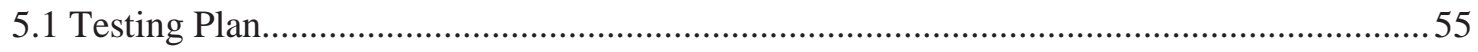

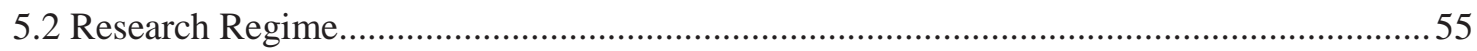

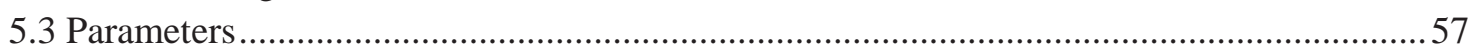

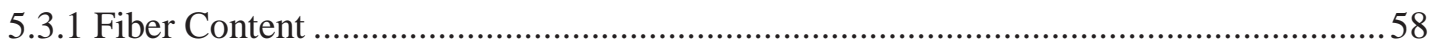

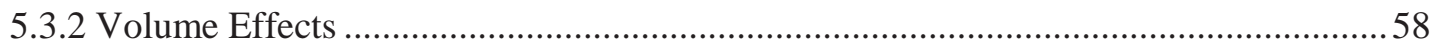

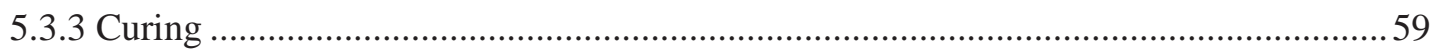

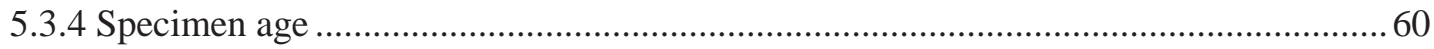

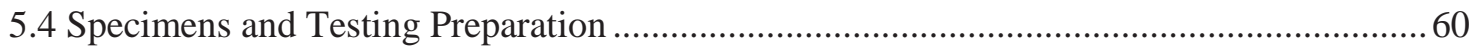

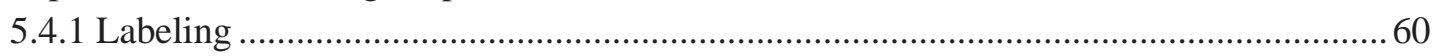

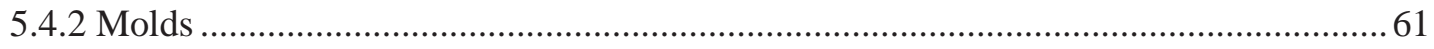

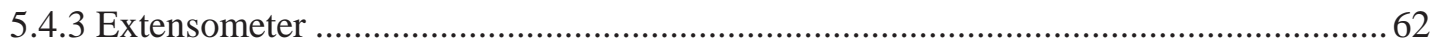

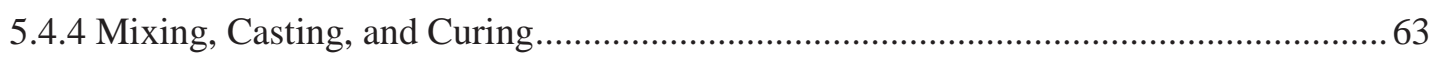

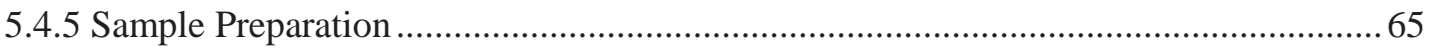

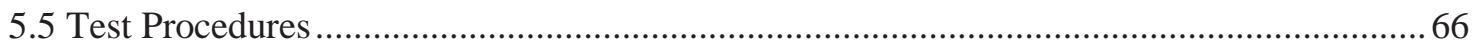

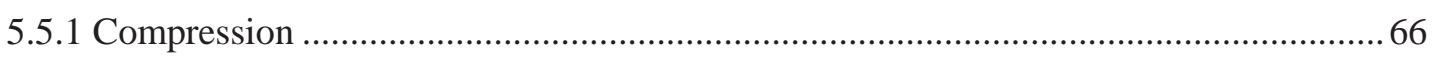

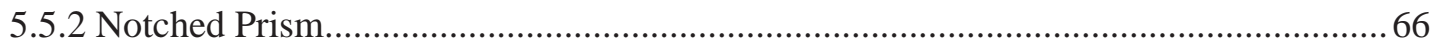

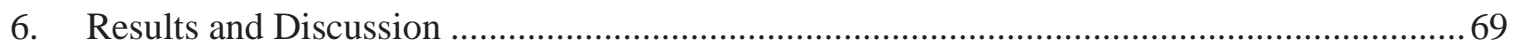

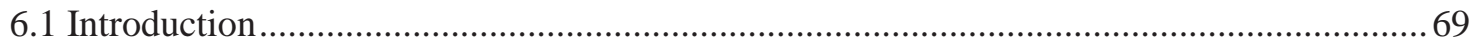

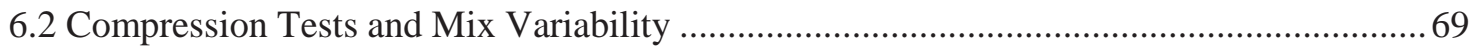

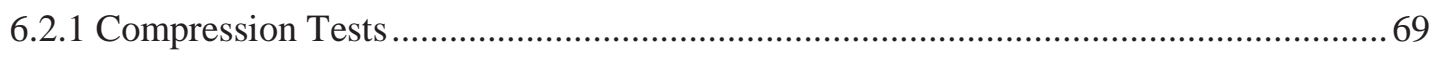

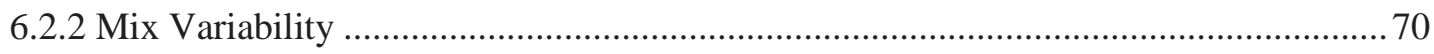

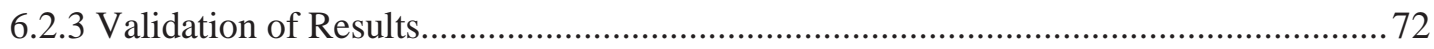

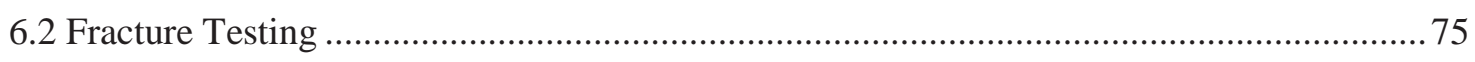

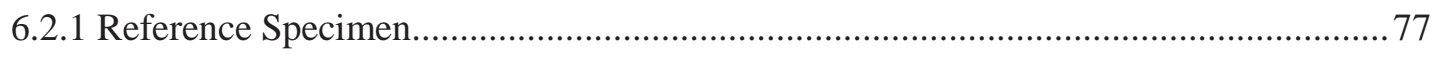




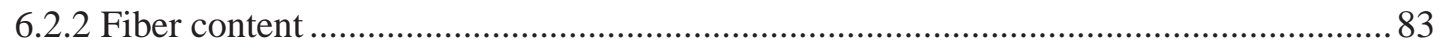

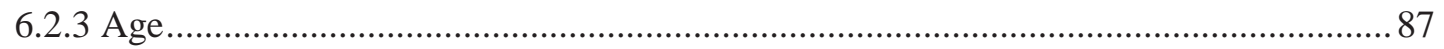

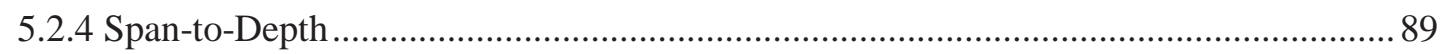

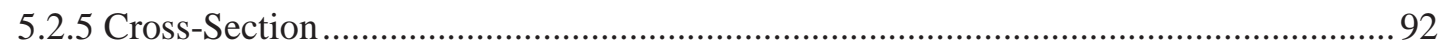

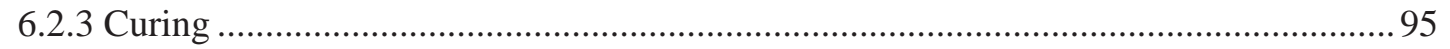

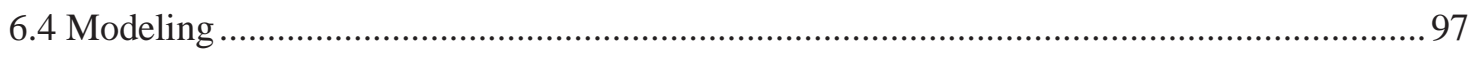

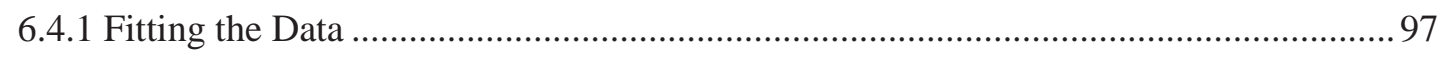

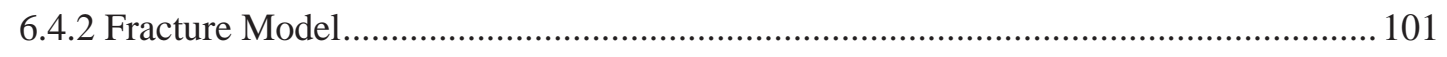

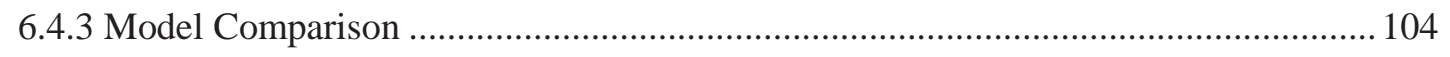

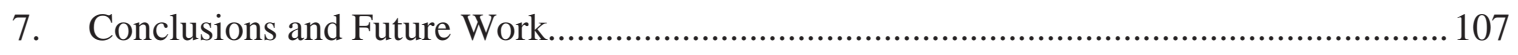

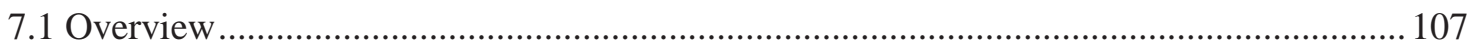

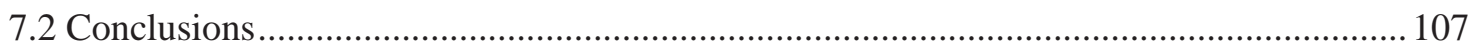

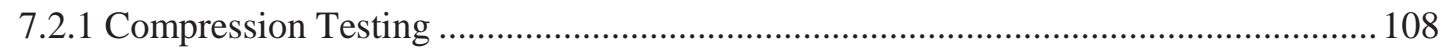

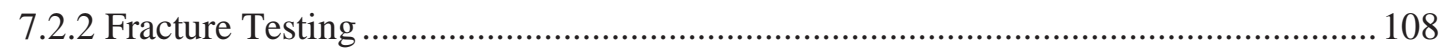

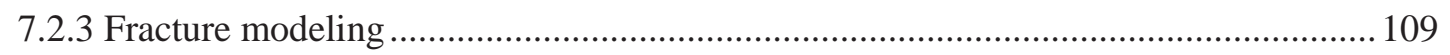

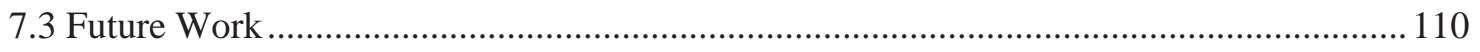

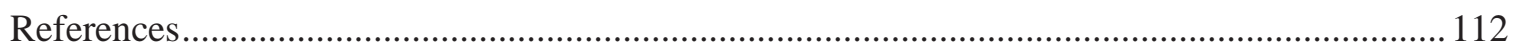

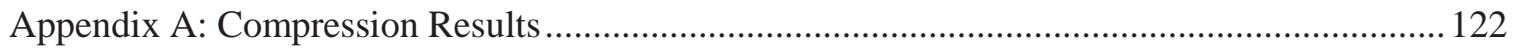

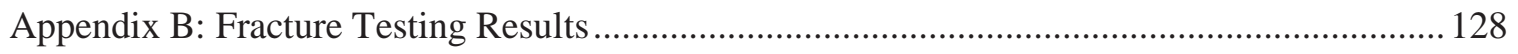

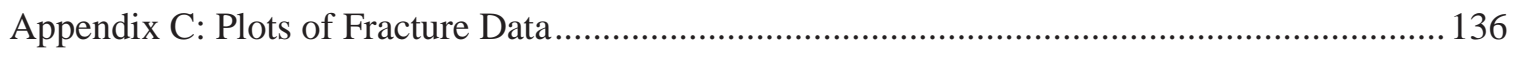

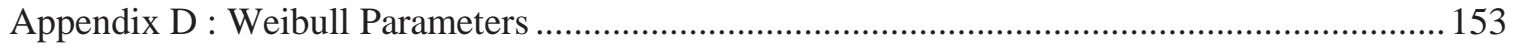

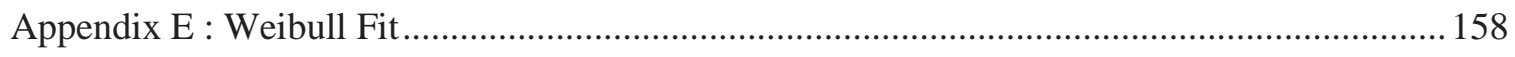




\section{List of figures}

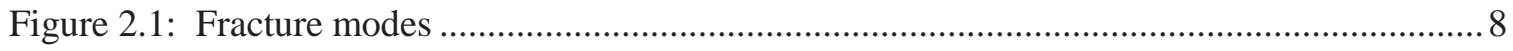

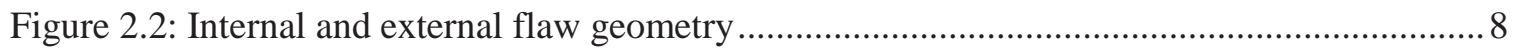

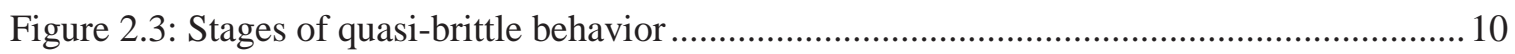

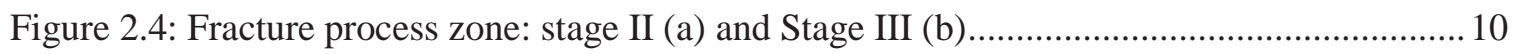

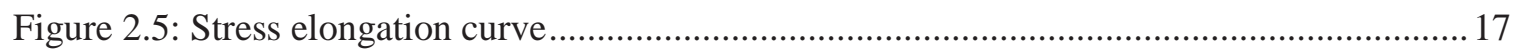

Figure 2.6: Constitutive models: linear (a), bi-linear (b), exponential (c), power (d)................... 18

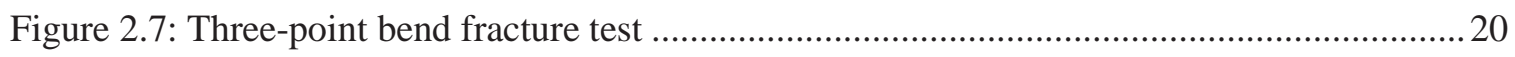

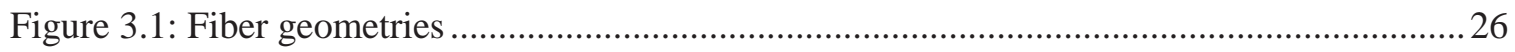

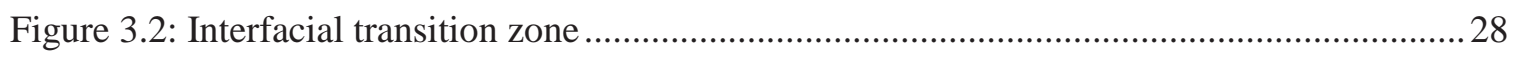

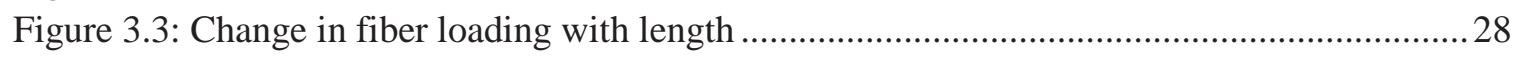

Figure 3.4: Local bending of fibers: ductile fibers (a) and ridged fibers (b)................................2

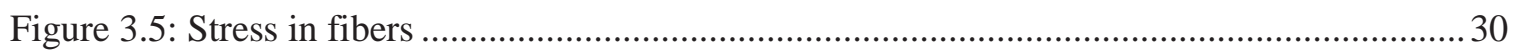

Figure 3.6: Debonding process: pre-fracture debonding (a) and post fracture debonding (b) ....... 31

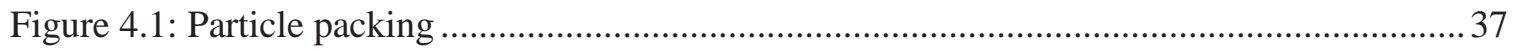

Figure 4.2: AFGC/SETRA strain hardening curve for UHPFRC ..............................................53

Figure 5.1: Curing chamber: external view (left) and internal view (Right) ...............................59

Figure 5.2: Molds: compression, 2580-4.5 prism, 2580-6.75 prism, 2580-9 prism, (left) , 5180-4.5

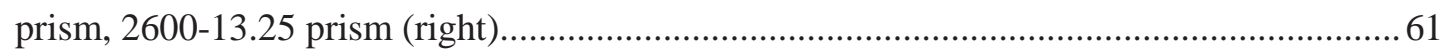

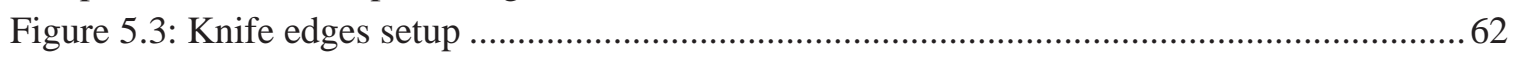

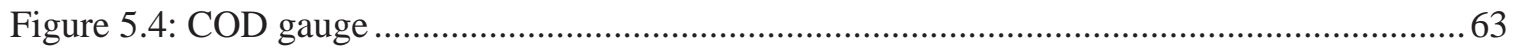

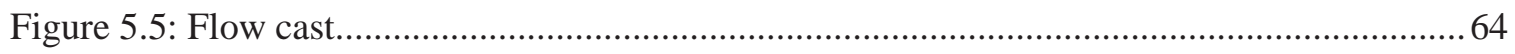

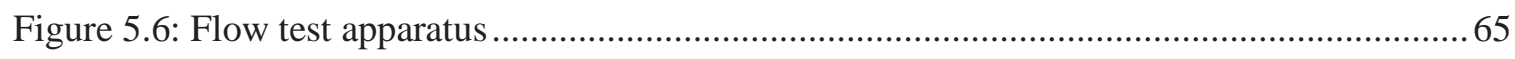

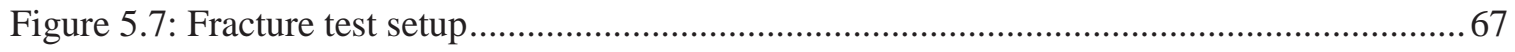

Figure 6.1: Effect of fiber content on compressive strength................................................... 74

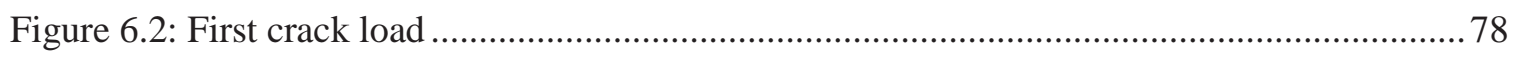

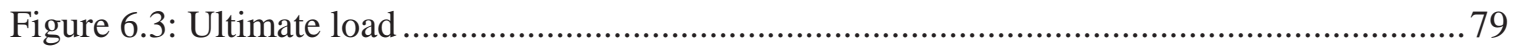

Figure 6.4: P-w curve and fracture energy curve for reference specimen .................................. 82

Figure 6.5: First crack and ultimate strengths at various fiber contents .................................... 83

Figure 6.6: Average P-w curve for NP-A-28d-f0-2580-4.5 …................................................ 85

Figure 6.7: Average P-w curve for NP-A-28d-f2-2580-4.5 …............................................... 85

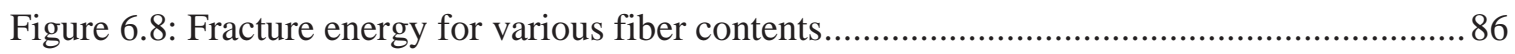

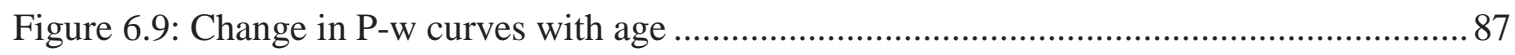

Figure 6.10: Time development of first crack strength for various fiber contents........................ 88

Figure 6.11: Time development of ultimate strength for various fiber contents.......................... 88

Figure 6.12: Time development of fracture energy for various fiber contents ............................. 89

Figure 6.13: Change in P-w curve with length ..................................................................... 90

Figure 6.14: Time development of first crack strength for various S/D ratios and fiber contents.91

Figure 6.15: Time development of ultimate strength for various S/D ratios and fiber contents.... 91

Figure 6.16: Fracture energy with change in S/D ratio for various fiber contents and ages..........92 
Figure 6.17: First crack strength with change in depth for various fiber content and ages .......... 93

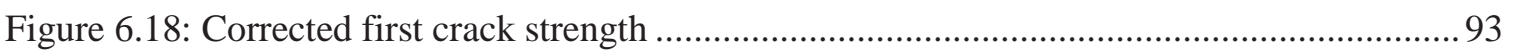

Figure 6.19: Ultimate strength with change in depth for various fiber content and ages ............. 94

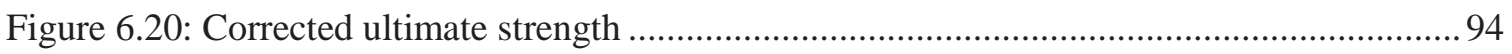

Figure 6.21: Fracture energy with change in depth for various fiber content and ages ................95

Figure 6.22: First crack strength with different curing ........................................................... 96

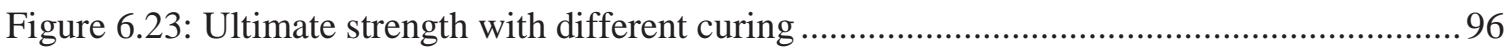

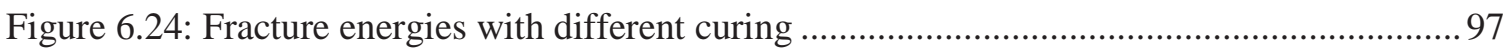

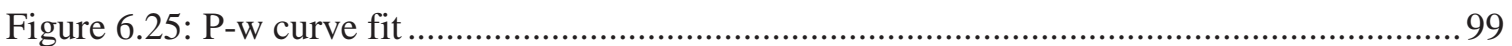

Figure 6.26: Modified Weibull best fit for NP-A-28d-f2-2580-4.5 specimen............................. 103

Figure 6.27: Plot of the Beta parameter with fiber content for several specimens ...................... 104

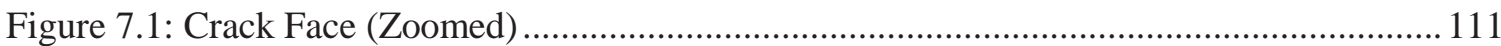

Figure C.1: NP-A-3d-f0-2580-4.5 data (Left) and NP-A-7d-f0-2580-4.5 data (Right)...........136

Figure C.2: NP-A-28d-f0-2580-4.5 data (Left) and NP-A-56d-f0-2580-4.5 data (Right)........136

Figure C.3: NP-A-3d-f1-2580-4.5 data (Left) and NP-A-3d-f1-2580-9 data (Right)............137

Figure C.4: NP-A-3d-f1-5180-4.5 data (Left) and NP-A-7d-f1-2580-4.5 data (Right)...........137

Figure C.5: NP-A-28d-f1-2580-4.5 data (Left) and NP-A-28d-f1-2580-9 data (Right)..........138

Figure C.6: NP-A-28d-f1-5180-4.5 data (Left) and NP-A-56d-f1-2580-4.5 data (Right)........138

Figure C.7: NP-A-3d-f2-2580-4.5 data (Left) and NP-A-3d-f2-2580-6.75 data (Right).........139

Figure C.8: NP-A-3d-f1-2580-9 data (Left) and NP-A-3d-f1-2580-13.75 data (Right)..........139

Figure C.9: NP-A-3d-f2-5180-4.5 data (Left) and NP-A-7d-f2-2580-4.5 data (Right)...........140

Figure C.10: NP-A-7d-f2-5180-6.75 data (Left) and NP-A-7d-f2-2580-9 data (Right)..........140

Figure C.11: NP-A-7d-f2-2580-13.75 data (Left) and NP-A-7d-f2-5180-4.5 data (Right)......141

Figure C.12: NP-A-28d-f2-2580-4.5 data (Left) and NP-A-28d-f2-2580-6.75 data (Right)......141

Figure C.13: NP-A-28d-f1-2580-9 data (Left) and NP-A-28d-f1-2580-13.75 data (Right).....142

Figure C.14: NP-A-28d-f2-25180-4.5 data (Left) and NP-A-56d-f2-2580-4.5 data (Right)......142

Figure C.15: NP-A-56d-f2-2580-6.75 data (Left) and NP-A-56d-f2-5180-9 data (Right).......143

Figure C.16: NP-A-56d-f2-5180-4.5 data........................................... 143

Figure C.17: NP-A-3d-f3-2580-4.5 data (Left) and NP-A-3d-f3-2580-9 data (Right)..........144

Figure C.18: NP-A-3d-f3-5180-4.5 data (Left) and NP-A-7d-f3-2580-4.5 data (Right).........144

Figure C.19: NP-A-28d-f3-2580-4.5 data (Left) and NP-A-28d-f3-2580-9 data (Right)........145

Figure C.20: NP-A-28d-f3-5180-4.5 data (Left) and NP-A-56d-f3-2580-4.5 data (Right)......145

Figure C.21: NP-TT-7d-f0-2580-4.5 data (Left) and NP-TT-28d-f0-2580-4.5 data (Right)......146

Figure C.22: NP-TT-7d-f1-2580-4.5 data (Left) and NP-TT-7d-f1-2580-9 data (Right)........ 146

Figure C.23: NP-TT-7d-f1-5180-4.5 data (Left) and NP-TT-28d-f1-2580-4.5 data (Right)......147

Figure C.24: NP-TT-7d-f2-2580-4.5 data (Left) and NP-TT-7d-f2-2580-6.75 data (Right).....147

Figure C.25: NP-TT-7d-f2-2580-9 data (Left) and NP-TT-7d-f2-5180-4.5 data (Right)........148

Figure C.26: NP-TT-28d-f2-2580-4.5 data (Left) and NP-TT-28d-f2-2580-6.75 data (Right)...148

Figure C.27: NP-TT-28d-f2-2580-9 data (Left) and NP-TT-28d-f2-5180-4.5 data (Right).....149

Figure C.28: NP-TT-7d-f3-2580-4.5 data (Left) and NP-TT-7d-f3-2580-9 data (Right)........149

Figure C.29: NP-TT-7d-f3-5180-4.5 data (Left) and NP-TT-28d-f3-2580-4.5 data (Right).....150

Figure C.30 NP-DTT-28d-f0-2580-4.5 data........................................ 150

Figure C.31: NP-DTT-28d-f1-2580-4.5 data (Left) and NP-DTT-28d-f3-2580-4.5 data (Left)..151 
Figure C.32: NP-DTT-28d-f2-2580-4.5 data (Left) and NP-DTT-28d-f2-2580-6.75 data

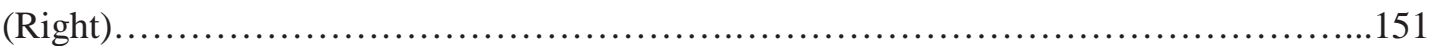

Figure C.33: NP-DTT-28d-f2-2580-9 data (Left) and NP-DTT-28d-f2-5180-4.5 data (Right)...152 Figure E.1: NP-A-3d-f1-2580-4.5 best fit (Left) and NP-A-3d-f1-2580-9 best fit (Right).......158 Figure E.2: NP-A-3d-f1-5180-4.5 best fit (Left) and NP-A-7d-f1-2580-4.5 best fit (Right).....158 Figure E.3: NP-A-28d-f1-2580-4.5 best fit (Left) and NP-A-28d-f1-2580-9 best fit (Right).....159 Figure E.4: NP-A-28d-f1-5180-4.5 best fit (Left) and NP-A-56d-f1-2580-4.5 best fit (Right)...159 Figure E.5: NP-A-3d-f2-2580-4.5 best fit (Left) and NP-A-3d-f2-2580-6.75 best fit (Right)...160 Figure E.6: NP-A-3d-f1-2580-9 best fit (Left) and NP-A-3d-f1-2580-13.75 best fit (Right).....160 Figure E.7: NP-A-3d-f2-5180-4.5 best fit (Left) and NP-A-7d-f2-2580-4.5 best fit (Right)......161 Figure E.8: NP-A-7d-f2-5180-6.75 best fit (Left) and NP-A-7d-f2-2580-9 best fit (Right).....161 Figure E.9: NP-A-7d-f2-2580-13.75 best fit (Left) and NP-A-7d-f2-5180-4.5 best fit (Right)...162 Figure E.10: NP-A-28d-f2-2580-4.5 best fit (Left) and NP-A-28d-f2-2580-6.75 best fit

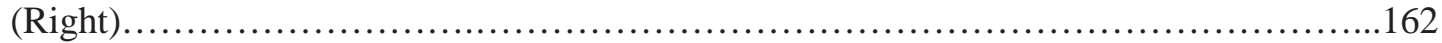

Figure E.11: NP-A-28d-f1-2580-9 best fit (Left) and NP-A-28d-f1-2580-13.75 best fit

(Right) ............................................................ 163

Figure E.12: NP-A-28d-f2-5180-4.5 best fit (Left) and NP-A-56d-f2-2580-4.5 best fit

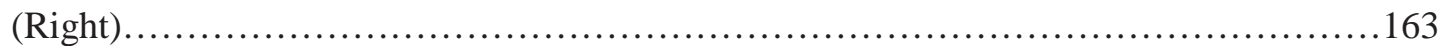

Figure E.13: NP-A-56d-f2-2580-6.75 best fit (Left) and NP-A-56d-f2-5180-9 best fit

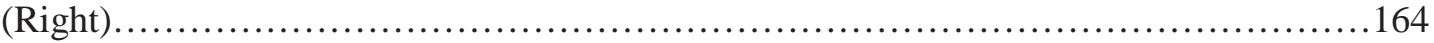

Figure E.14: NP-A-56d-f2-5180-4.5 best fit............................................164

Figure E.15: NP-A-3d-f3-2580-4.5 best fit (Left) and NP-A-3d-f3-2580-9 best fit (Right)..... 165

Figure E.16: NP-A-3d-f3-5180-4.5 best fit (Left) and NP-A-7d-f3-2580-4.5 best fit (Right)....165

Figure E.17: NP-A-28d-f3-2580-4.5 best fit (Left) and NP-A-28d-f3-2580-9 best fit (Right)...166 Figure E.18: NP-A-28d-f3-5180-4.5 best fit (Left) and NP-A-56d-f3-2580-4.5 best fit

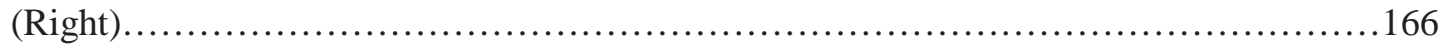

Figure E.19: NP-TT-7d-f1-2580-4.5 best fit (Left) and NP-TT-7d-f1-2580-9 best fit (Right)...167 Figure E.20: NP-TT-7d-f1-5180-4.5 best fit (Left) and NP-TT-28d-f1-2580-4.5 best fit

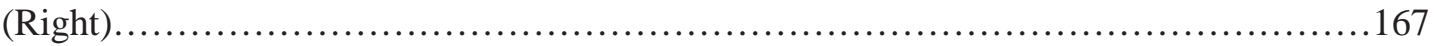

Figure E.21: NP-TT-7d-f2-2580-4.5 best fit (Left) and NP-TT-7d-f2-2580-6.75 best fit

(Right) ............................................................ 168

Figure E.22: NP-TT-7d-f2-2580-9 best fit (Left) and NP-TT-7d-f2-5180-4.5 best fit

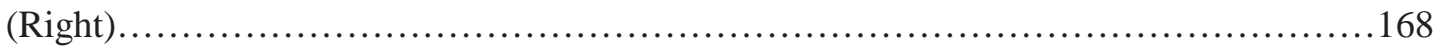

Figure E.23: NP-TT-28d-f2-2580-4.5 best fit (Left) and NP-TT-28d-f2-2580-6.75 best fit

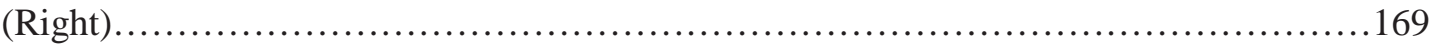

Figure E.24: NP-TT-28d-f2-2580-9 best fit (Left) and NP-TT-28d-f2-5180-4.5 best fit

(Right) ............................................................. 169

Figure E.25: NP-TT-7d-f3-2580-4.5 best fit (Left) and NP-TT-7d-f3-2580-9 best fit

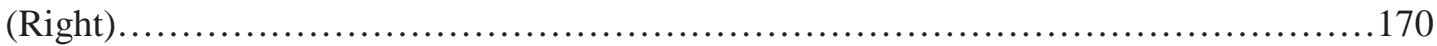

Figure E.26: NP-TT-7d-f3-5180-4.5 best fit (Left) and NP-TT-28d-f3-2580-4.5 best fit

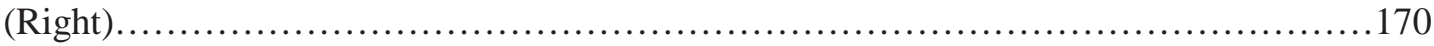

Figure E.27: NP-DTT-28d-f1-2580-4.5 best fit (Left) and NP-DTT-28d-f3-2580-4.5 best fit

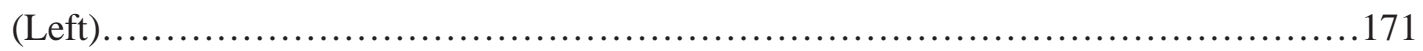


Figure E.28: NP-DTT-28d-f2-2580-4.5 best fit (Left) and NP-DTT-28d-f2-2580-6.75 best fit

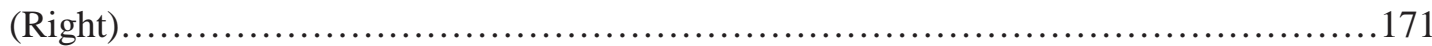

Figure E.29: NP-DTT-28d-f2-2580-9 best fit (Left) and NP-DTT-28d-f2-5180-4.5 best fit

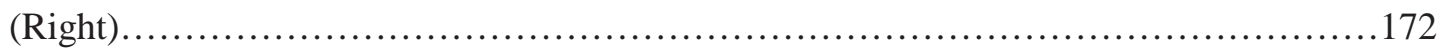




\section{List of Tables}

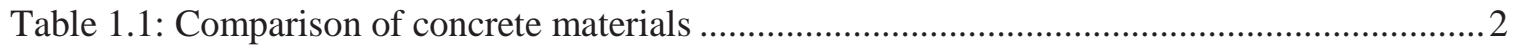

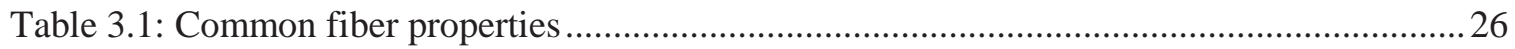

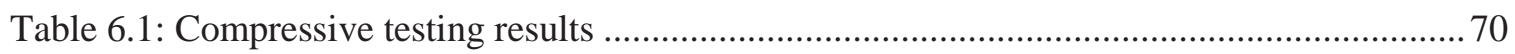

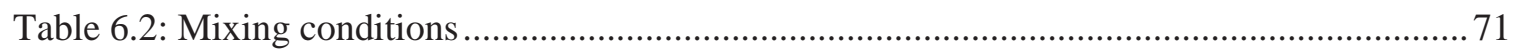

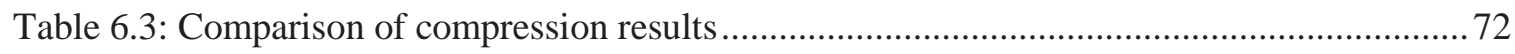

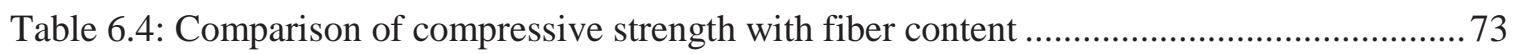

Table 6.5: Comparison of compressive strength with type of curing .......................................... 75

Table 6.6: Results for ambient 28-day flexural specimens with $2 \%$ fibers................................... 77

Table 6.7: Results from fracture tests for reference specimens ................................................. 79

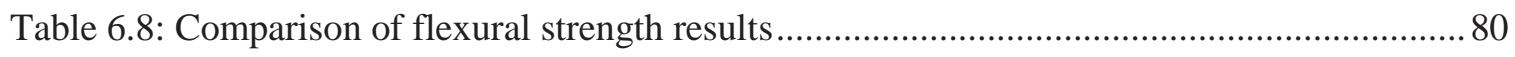

Table 6.9: Incremental fracture energies of the reference data set.............................................. 81

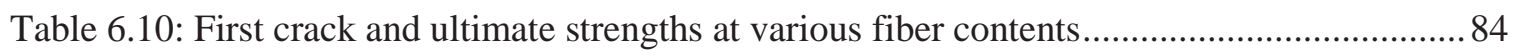

Table 6.11: First crack and ultimate strength with fiber content .............................................. 86

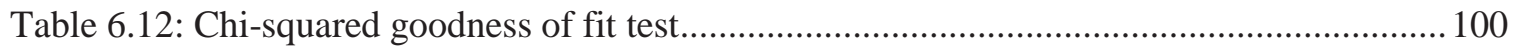

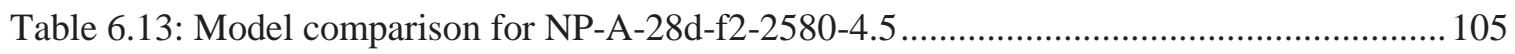

Table 6.14: Model Comparison for NP-TT-28d-f2-2580-4.5 ….............................................. 105

Table A.1: Results from compression testing (ambient cured specimens) ....................122

Table A.2: Results from compression testing (thermally treated specimens)...................123

Table A.3 Table of means an standard deviations for compression results....................123

Table A.4: Hypothesis testing of fiber content for ambient cured specimens...................124

Table A.5: Hypothesis testing of fiber content for thermally treated specimens.................124

Table A.6: Hypothesis testing of fiber content for delayed thermally treated specimens........ 125

Table A.7: Hypothesis testing of curing for $0 \%$ fiber specimens.......................... 125

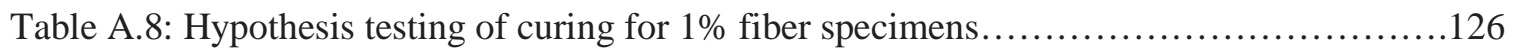

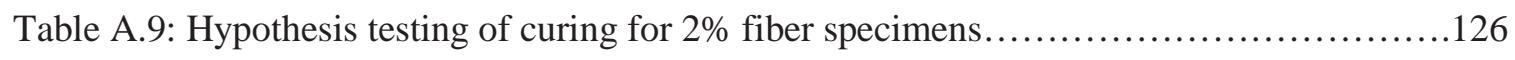

Table A.10: Hypothesis testing of curing for 3\% fiber specimens............................ 127

Table B.1: Fracture test results for $0 \%$ fibers under ambient conditions.......................128

Table B.2: Fracture test results for $1 \%$ fibers under ambient conditions.......................128

Table B.3: Fracture test results for 3\% fibers under ambient conditions......................128

Table B.4: Fracture test results for 2\% fibers under ambient conditions......................129

Table B.5: Fracture test results for delayed thermally treated specimens.....................129

Table B.6: Fracture test results for thermally treated specimens............................130

Table B.7: Statistics for first crack strength with $0 \%$ and $1 \%$ fiber contents (ambient

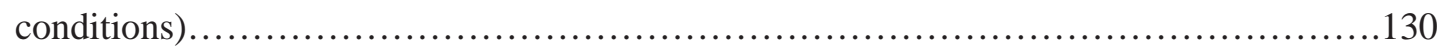

Table B.8: Statistics for first crack strength with 2\% fiber content (ambient conditions)........131 
Table B.9: Statistics for first crack strength with 3\% fiber content (ambient conditions)........131

Table B.10: Statistics for first crack strength (thermal treatment)............................132

Table B.11: Statistics for first crack strength (delayed thermal treatment)....................132

Table B.12: Statistics for ultimate strength with $0 \%$ and $1 \%$ fiber contents (ambient

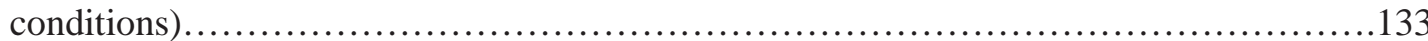

Table B.13: Statistics for ultimate strength with 2\% fiber contents (ambient conditions)........133

Table B.14: Statistics for ultimate strength with 3\% fiber contents (ambient conditions)........134

Table B.15: Statistics for ultimate strength (thermal treatment)............................134

Table B.16: Statistics for ultimate strength (delayed thermal treatment) ......................135

Table D.1: Model parameters $\left(\mathrm{W}_{\mathrm{F}}, \beta\right)$ for $1 \%$ fiber content and ambient curing (includes $95 \%$

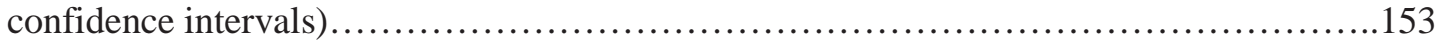

Table D.2: Model parameters $\left(\mathrm{W}_{\mathrm{F}}, \beta\right)$ for $2 \%$ fiber content and ambient curing (includes $95 \%$

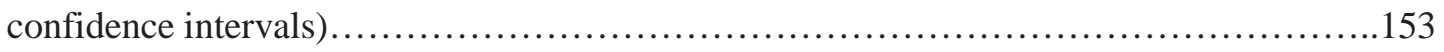

Table D.3: Model parameters $\left(\mathrm{W}_{\mathrm{F}}, \beta\right)$ for $3 \%$ fiber content and ambient curing (includes $95 \%$

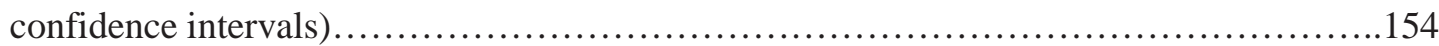

Table D.4: Model parameters $\left(\mathrm{W}_{\mathrm{F}}, \beta\right)$ for thermal treatment (includes $95 \%$ confidence

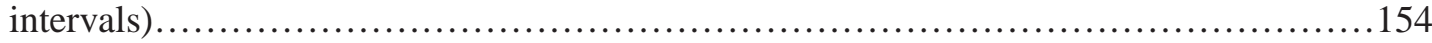

Table D.5: Model parameters $\left(\mathrm{W}_{\mathrm{F}}, \beta\right)$ for delayed thermal treatment (includes $95 \%$ confidence

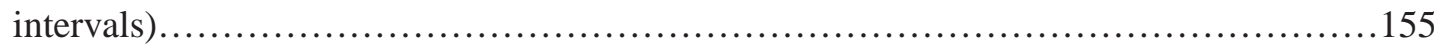

Table D.6: Model parameters $\left(\mathrm{m}, \mathrm{w}_{\mathrm{i}}\right)$ for $1 \%$ fiber content and ambient curing (includes $95 \%$

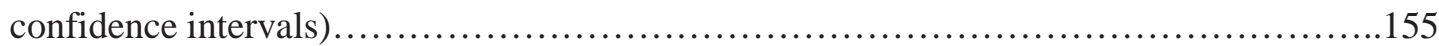

Table D.7: Model parameters $\left(\mathrm{m}, \mathrm{w}_{\mathrm{i}}\right.$ ) for $2 \%$ fiber content and ambient curing (includes $95 \%$

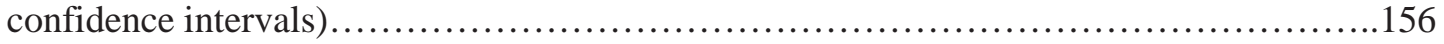

Table D.8: Model parameters $\left(\mathrm{m}, \mathrm{w}_{\mathrm{i}}\right.$ ) for $3 \%$ fiber content and ambient curing (includes $95 \%$ confidence intervals) .......................................................... 156

Table D.9: Model parameters $\left(\mathrm{m}, \mathrm{w}_{\mathrm{i}}\right)$ for thermal treatment (includes $95 \%$ confidence intervals)

Table D.10: Model parameters (m, wi) for thermal treatment (includes $95 \%$ confidence intervals) 


\section{Acknowledgements}

This Researcher would like thank Lafarge North America for providing Ductal (

UHPFRC materials. Thank you to the University Transportation Center for Materials in Sustainable Transportation Infrastructure (UTC-MiSTI) at Michigan Tech for supporting these research activities. I would like to acknowledge my advisor Dr. Tess Ahlborn, and committee members Dr. Stephen Kampe, Dr. Qingli (Barbara) Dai for all of their help and advice. Thank you to Dr. Devin Harris, Kiko, Mike Yokie, and my fellow graduate students for their assistance and the sharing of ideas.

A special thank you to my family, whose patience and dedication made this possible. 


\begin{abstract}
Ultra-high performance fiber reinforced concrete (UHPFRC) has arisen from the implementation of a variety of concrete engineering and materials science concepts developed over the last century. This material offers superior strength, serviceability, and durability over its conventional counterparts. One of the most important differences for UHPFRC over other concrete materials is its ability to resist fracture through the use of randomly dispersed discontinuous fibers and improvements to the fiber-matrix bond. Of particular interest is the materials ability to achieve higher loads after first crack, as well as its high fracture toughness. In this research, a study of the fracture behavior of UHPFRC with steel fibers was conducted to look at the effect of several parameters related to the fracture behavior and to develop a fracture model based on a non-linear curve fit of the data. To determine this, a series of three-point bending tests were performed on various single edge notched prisms (SENPs). Compression tests were also performed for quality assurance. Testing was conducted on specimens of different cross-sections, span/depth (S/D) ratios, curing regimes, ages, and fiber contents. By comparing the results from prisms of different sizes this study examines the weakening mechanism due to the size effect. Furthermore, by employing the concept of fracture energy it was possible to obtain a comparison of the fracture toughness and ductility. The model was determined based on a fit to P-w fracture curves, which was cross referenced for comparability to the results. Once obtained the model was then compared to the models proposed by the AFGC in the 2003 and to the ACI 544 model for conventional fiber reinforced concretes.
\end{abstract}





\section{Introduction}

\subsection{Introduction to Ultra High Performance Concrete (UHPC)}

Concrete is the most used construction material in the world, but it has weaknesses when exposed to certain environments and loading conditions (Mindess et al. 2003). In recent years the need for stronger and more durable materials has become ever more apparent with the degradation of North America's infrastructure. Due to an advanced understanding of concrete materials and utilization of concrete composites, solutions for many of these problems now exist. These advanced materials are achieved through modifications of the concrete matrix, as well as the use of chemical additives, and reinforcing fibers (Bentur and Mindess 2007; Mindess et al. 2003). Some of the common types are ultra-high performance fiber reinforced concrete (UHFRPC) (Rossi 2001), engineered cementitious composites (ECC) (Li 2003), slurry infiltrated fiber concrete (SIFCON) (Lankard 1985), and slurry infiltrated mat concrete (SIMCON) (Hackman et al. 1992). The preceding discussion will focus primarily on UHPFRC, as it is the focus of this research. There are several commercially available UHPFRC brands. Of these Ductal ${ }^{\circledR}$ is the only commercial product currently available in North America, and therefore the following research was performed using a Ductal ${ }^{\circledR}$ brand BS 1000 UHPFRC.

Although UHPFRC is an improved concrete material, the upfront cost and lack of a North American design standard are its major limiting factors. Additionally, life cycle cost analysis (LCCA) has shown that compared to conventional concrete the lifetime cost is much less, due to that discussed above. Also as the material is used more and more commercially available materials are produced, the upfront costs should substantially decrease (Ahlborn et al. 2008). In 2011, ACI 239 committee was established with the purpose to develop a design standard, which should also improve its applicability as a major construction material (ACI 2011). The benefit of using UHPFRC over conventional concrete depends on the application. The material has the potential to be used as structural elements, non-structural/architectural elements, as well 
as repair material (Respiendino 2012). A few of the major North American structures can be found in (Peuse 2008).

One of the draws of UHPFRC is that it offers improved mechanical behavior, as well as improved durability (Graybeal and Hartmann 2003). Table 1.1 shows a comparison between some material properties for common types of concrete: normal strength concrete (NSC), high performance concrete (HPC), steel fiber reinforced concrete (SFRC) and UHPFRC. This table shows that with UHPFRC there is an improvement to all the material properties listed. Some of the strength improvements to note are a compressive strength that is nearly seven times greater than NSC, a tensile strength that is three times greater, and a flexural strength that is 10 times greater. The improved properties under tension/flexure are primarily due to UHPFRCs inherent composite behavior, which arises from the dispersion of discontinuous fibers throughout the material (Orange et al. 2000). Aside from strength, another important tensile/flexural property is fracture energy. This property is a measure of the materials ability to resist fracture, which is taken as the area under the strength-displacement curve after cracking (Hillerborg 1985) and will be discussed in future chapters.

Table 1.1

Comparison of concrete materials

\begin{tabular}{|l|l|l|l|l|}
\hline Material Property & NSC & HPC & SFRC & UHPFRC \\
\hline Compressive Elastic Modulus (GPa) & $13.8-41.4$ & $31-55.2$ & $13.8-41.4$ & $50-60$ \\
\hline Compression $(\mathrm{MPa})$ & $20.7-41.4$ & $27.6-96.6$ & $20.7-41.4$ & $179.4-227.7$ \\
\hline Tension $(\mathrm{MPa})$ & $2.5-3.1$ & $3.5-5.5$ & $2.0-4.0$ & $8.3-9.7$ \\
\hline Flexural $(\mathrm{MPa})$ & $2.8-4.1$ & $5.5-8.3$ & $6.5-13.5$ & $29.7-40$ \\
\hline Fracture Energy $\left(\mathrm{J} / \mathrm{m}^{2}\right)$ & $30-190$ & $110-310$ & $1300-7000$ & $20000-40000$ \\
\hline Poisson's Ratio & $0.11-0.21$ & $0.19-0.22$ & $0.11-0.21$ & $0.19-0.24$ \\
\hline Creep Coefficient & 2.35 & $1.6-1.9$ & $0.43-0.69$ & 0.3 \\
\hline
\end{tabular}

Note: Fracture energies were compiled from (Wittman 2002), (Muralidhara et al. 2011), (Tamrakar 1999), (Bencardino et al. 2010), (Einsfeld and Velasco 2006), (Zhang 2011). All other values were based on (Peuse 2008), (ACI 544 2001) 


\subsection{Motivation}

The strength of unreinforced concrete under tension or flexure reaches a maximum just before unstable cracks begin to form in the material (Shah et al. 1995). In UHPFRC the introduction of fibers leads to increased strength and improved post cracking behavior (Naaman 2003). Currently, AFGC/SETRA has proposed a model for UHPFRC based on a multi-linear relationship (AFGC, 2002). Alternatively, ACI Committee 544 has proposed a model for the first crack and ultimate strengths of laboratory sized fiber reinforced concrete specimens based on the rule of mixtures (ACI 544 2001).

The objective of this research was to study the mode I fracture of UHPFRC, and develop a general mathematical model to describe the fracture behavior of a steel fiber reinforced ultra-high performance concrete (UHPC) under flexural loading. It is proposed that the fracture process of UHPFRC can be described by one simple equation, which is to be developed through the following research initiative. This model could be used by designers to determine design parameters, by inspectors to determine the expected capacity of a cracked structure, or by researchers to predict the behavior of tested specimens beyond normal testing ranges.

\subsection{Scope of Research}

The effects of flexural design parameters on the mode I fracture of UHPC were tested using a variety of single edged notched prisms (SENPs). These parameters include type of curing, age of curing, amount of fibers, and prism size. Based on recorded measurements of the load and crack mouth opening displacement (CMOD or w), a load-CMOD (P-w) curve and fracture energy curve could be developed. Compression cylinders were also tested for quality assurance of mixes, and to compare the results from this research to previous work. Several mixes were required to complete this research, and were conducted over a 4 month period. Following testing and data analysis, a model was developed by fitting a modified Weibull equation to the P-w curve. This model was then compared to the existing models proposed by

AFGC/SETRA for UHPFRC and ACI 544 for fiber reinforced concrete. 


\subsection{Thesis Outline}

This thesis will begin in chapter 2 by providing the reader with a background of the fracture process of concrete and the application of fracture mechanics to concrete materials. Then chapter 3 will discuss the composite behavior of fiber reinforced cementations composites (FRCCs). An introduction to ultra-high performance concrete follows in chapter 4 . The testing methodology is laid out in chapter 5. Chapter 6 contains the analysis and discussion of the data and modelling of the fracture curves. Finally, chapter 7 completes the thesis with conclusions and future work. 


\section{Fracture Behavior of Concrete}

\subsection{Introduction}

Concrete cracks; to the average person this is common knowledge. It becomes obvious as one drives to work on the freeway, walks to the office on city sidewalks, and looks closely at the office structure as they make their way through the doors. This is because cracking in ceramic composites, such as concrete, is inevitable due to their brittle nature. However, most people may not know that although these structures have cracks they usually have not failed. This is due to strengthening mechanisms within the material, to be discussed, and the ability of the reinforcement to carry the load, even after the formation of cracks. It is for these reasons that current design practices allows for some amount of cracking in concrete structures (Wight and MacGregor 2009).

As a means for design, fracture mechanics is a common method to analyze the failure of ceramic, steel, and polymer based materials (Anderson 2005). However, from a concrete design standpoint, the use of fracture mechanics is a relatively new concept. Even though fracture mechanics has been available since the 1950s, in its original form it was found to be not applicable to concrete structures. It wasn't until the 1970s and 1980s that a valid formulation for concrete was available (Bažant and Planas 1998). One of the generally accepted reasons for using fracture mechanics is that strength based failure designs require modifications to account for the occurrence of premature failure, such as safety factors (Anderson 2005). Another example of a modification in design is the use of the Whitney stress block in the flexural design of concrete, in place of the more complicated softening behavior (Hawkins 1985). The use of fracture mechanics has the ability to account for effects that are not addressed in current design practices, to be discussed, by approaching the problem using energy criterion (Bažant and Planas 1998).

It has been previously pointed out that even if a theory is applicable to concrete design, ACI 318 is disinclined to incorporate such design methods unless it provides insight to non-existent provisions or improvement upon current public safety provisions 
(Hawkins 1985). However, it has been predicted that the inclusion of fracture mechanics could be the next big revolution in concrete design (Bažant and Planas 1998). The use of fracture mechanics would allow for a rational and deterministic understanding of the failure behavior in concrete structures (Tassions 1985), as well as design protocols that do not rely solely on empirical data (Hawkins 1985). According to ACI committee 446-Fracture mechanics of concrete, there are five reasons that fracture mechanics can improve some aspects of structural concrete design (ACI 446 1991).

\section{Crack formation energy}

Fracture mechanics is an energy based method, in which the formation of cracks requires that the material must absorb some amount energy (Bažant and Planas 1998) associated with the resistance of that material (Anderson 2005). This energy requirement is important, because it implies that if it is not met the material will not fracture even after the design strength is met (Bažant and Planas 1998).

2. Analysis must be objective.

The example provided by ACI 446 is a problem that occurs in finite element models of concrete fracture, known as spurious mesh sensitivity. It arises when using the smeared crack approach, in which the results of the model and method of analysis depends primarily on the mesh selection (ACI 446 1991).

3. Absence of a yield plateau

In some instances the use of a plastic limit analysis, as is often done, cannot account for the existence of softening or hardening behavior in the absence of a yield plateau (Bažant and Planas 1998).

4. Fracture toughness

The fracture toughness of the structure is approximated by the area under the load displacement curve. As mentioned, plastic limit analysis does not account 
for any softening behavior in the material due to the energy dissipated during fracture. This softening behavior leads to a finite amount of fracture toughness in the structure, whereas the fracture toughness using plastic limit analysis is, in theory, unlimited (Bažant and Planas 1998).

\section{Size Effect}

As will be discussed, concrete falls victim to the size effect, which is a phenomenon that occurs when comparing strengths of structures that exhibit geometric similitude. It follows that as the size of the structure increases the strength and ductility decrease. This effect is not accounted for in plastic limit analysis, but could be with the inclusion of fracture mechanics (Bažant and Planas 1998).

In the past few decades the development of concrete fracture mechanics and the determination of testing methods has become a large area of research. Several papers have looked at fracture energy (Guinea et al. 2002; Hillerborg 1985; Wittman 2002), the size effect (Bažant and Kazemi 1991; Jueshi and Hui 1997) and the development of constitutive models to describe the fracture process (Gopalaratnam and Shah 1985; Roelfstra and Wittman 1986). As the addition of fibers in UHPC leads to a noticeable increase in fracture resistance without conventional reinforcement (Bentur and Mindess 2007), the use of fracture mechanics is of great interest, and therefore will be the focus of this study.

\subsection{Fracture Behavior}

The mechanism of fracture can be defined as one of three modes or a combination of these modes (Anderson 2005), which appear in Figure 2.1. Mode I is defined as the opening mode, which occurs under direct and indirect tension loading. The other two modes are a result of shear in the material. Mode II arises from in plane shear, which leads to a sliding action between fracture surfaces. Mode III is a tearing action due to out-of-plane shearing (Anderson 2005). For simplicity this study will only focus on mode I type fracture. 


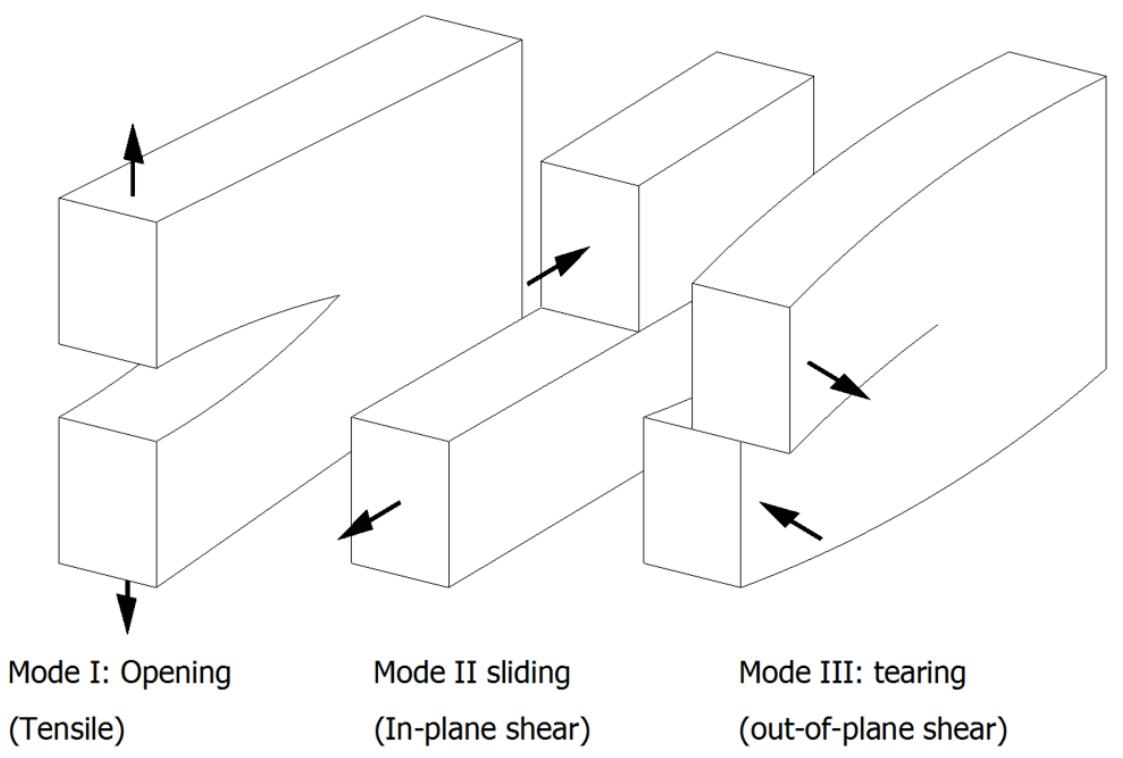

Figure 2.1: Fracture modes

Any of these modes of fracture are typically assumed to initiate at the point of greatest stress concentration, which is commonly assumed to be at a flaw in the material. As shown in Figure 2.2 this flaw can be internal of length $2 a$ or external of length $a$ (Callister 2005).

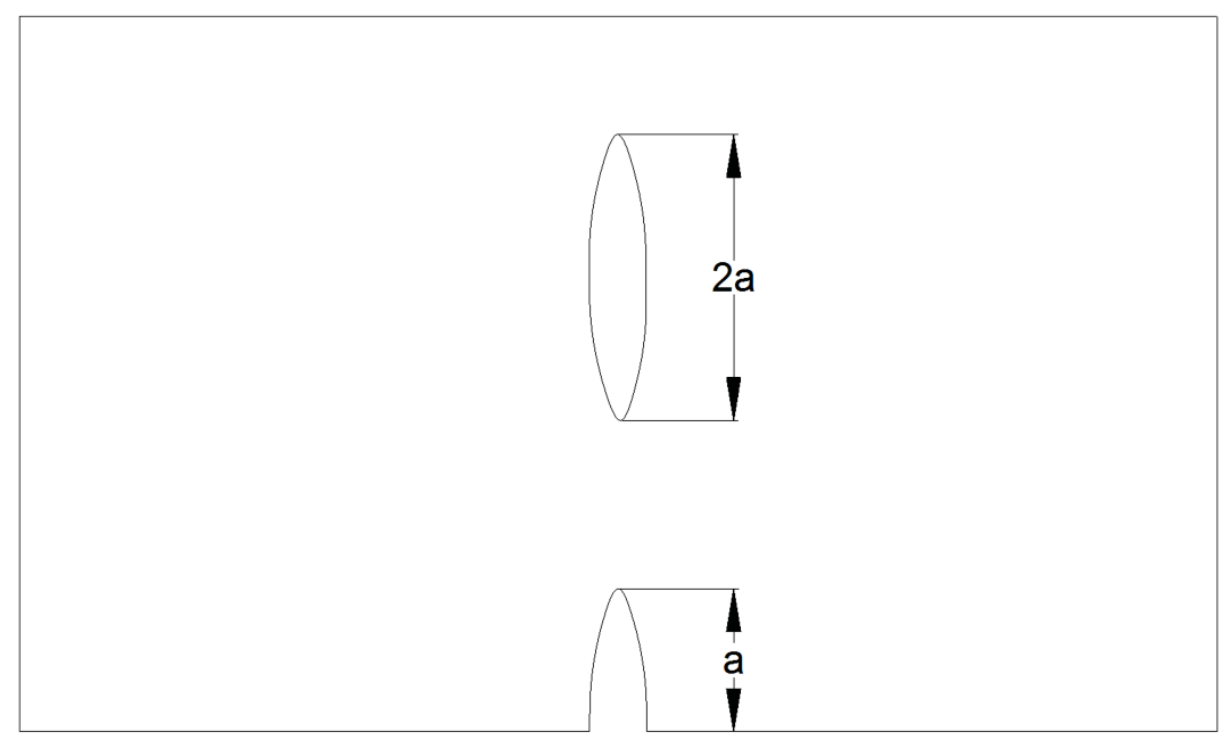

Figure 2.2: Internal and external flaw geometry 
The fracture of a material can be explained in one of the following ways: purely elastic, elastic-plastic, or quasi-brittle (Shah et al. 1995). Purely elastic (brittle) behavior is associated with a sudden and abrupt crack propagation, which leads to catastrophic failure. Alternatively, if a material exhibits elastic-plastic behavior the elastic portion is followed by a yield plateau. This plateau implies that the structure is able to sustain a constant load, without further crack propagation (Shah et al. 1995).

The quasi-brittle behavior of concrete can be best explained by the following five stages (Shah et al. 1995) as depicted graphically in figure 2.3 and with the use of figure 2.4.

I. Elastic

The material exhibits elastic behavior until the proportional elastic limit (PEL) is reached. The PEL in concrete is typically assumed to be the point of first crack (Shah et al. 1995).

II. Micro-cracking

Random micro-cracking occurs ahead of a flaw (Figure 2.4.a) leading to a toughening behavior (Shah et al. 1995).

III. Damage localization

The micro-cracks will localize forming a macro-crack, which occurs at the point of initial crack localization (figure 2.4.b). At which point the material undergoes stable crack growth (crack propagates only when load increases) and a softening behavior occurs (Shah et al. 1995).

IV. Unstable crack growth

Once the ultimate strength is reached at a critical crack length the crack will undergo unstable growth (crack propagates even though load decreases) (Shah et al. 1995).

V. Failure

The crack will continue to propagate until failure, which occurs when the stress is equal to zero (Shah et al. 1995).

The region ahead of the initial flaw location is termed the fracture process zone (Shah et al. 1995). This zone can be separated into the crack wake process zone and the crack tip process zone. As shown in Figure 2.4.b, the crack tip process zone is the region ahead of the crack where micro-cracking occurs during the fracture process and the 
crack wake process zone is the region in which the macro-crack resides (Shah et al. 1995).

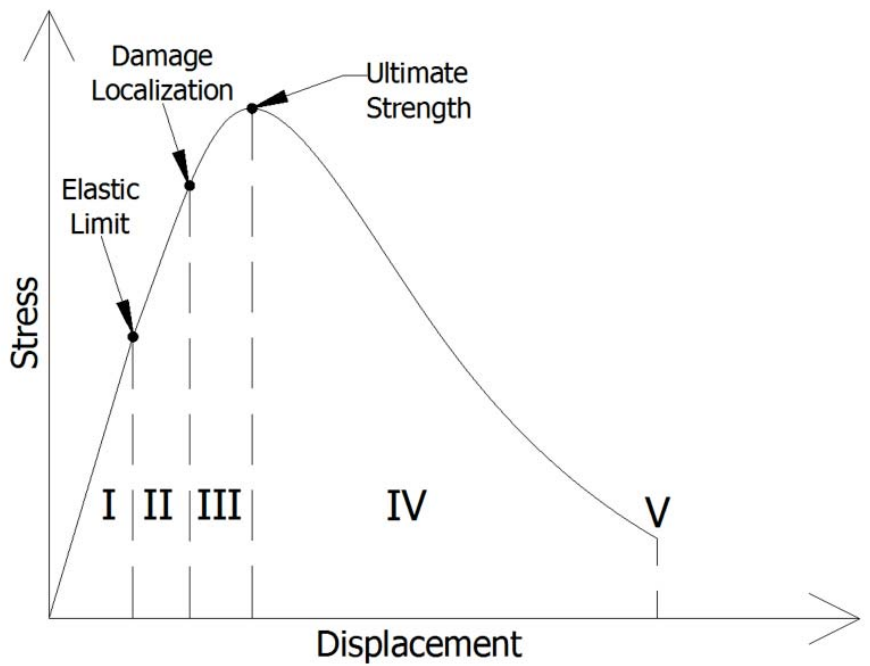

Figure 2.3: Stages of quasi-brittle behavior

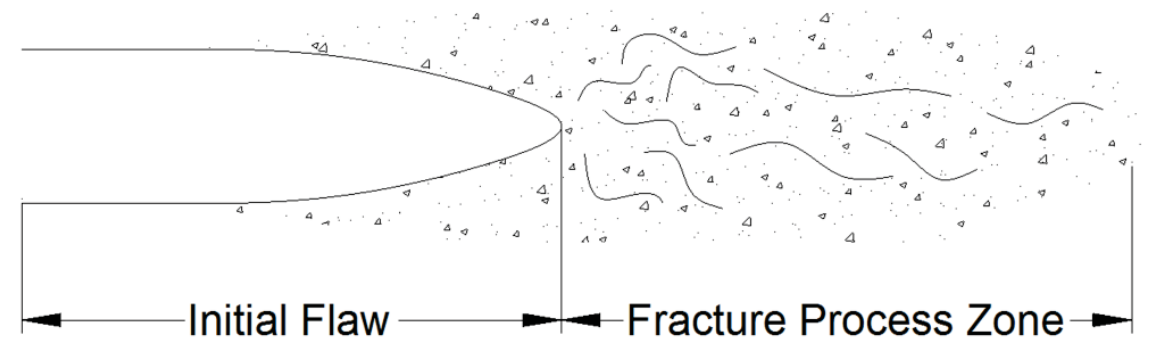

(a)

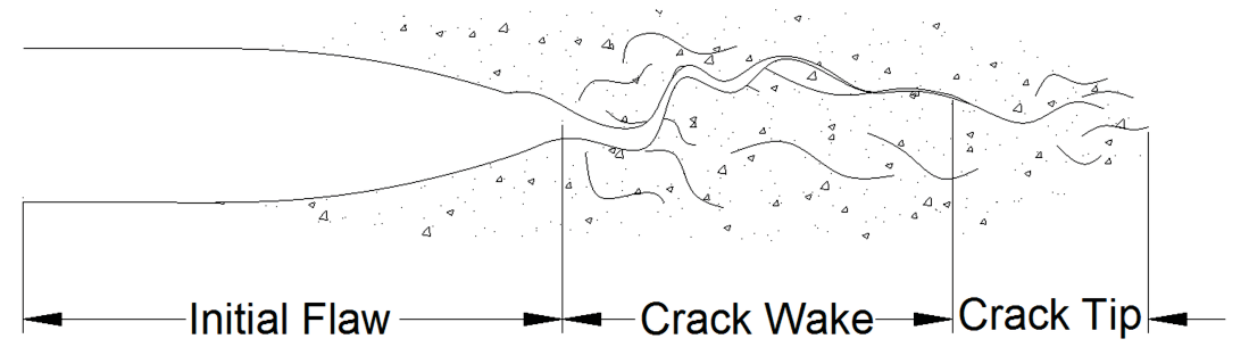

(b)

Figure 2.4: Fracture process zone: stage II (a) and Stage III (b) 
For analysis purposes it is commonly assumed that a crack propagates in a linear fashion. However, concrete is a composite material so cracks tend to propagate along non-linear or chaotic crack paths due to the heterogeneity of the material. This can be associated with several toughening mechanisms that occur within the fracture process zone as pointed out by Shah et al. (1995).

1. Microcrack Shielding

Randomly oriented micro-cracks occur at flaws ahead of the crack tip. The micro-cracking is caused by the high stress concentration near the crack tip (Shah et al. 1995). The formation of micro-cracks releases energy, which increases the amount of energy required to form unstable cracks (Anderson 2005).

2. Crack Deflection

This occurs when an inclusion (i.e. aggregates or fibers) is strong enough to divert the path of least resistance around the inclusion (Shah et al. 1995).

\section{Crack Bridging}

If an inclusion is bonded to the concrete at both crack faces the inclusion has the ability to transfer stress across cracks (Shah et al. 1995). It has been stated that fiber bridging is the most effective toughening mechanism for brittle materials (Anderson 2005).

4. Surface friction

Surface interlock can cause energy dissipation due to friction between fracture surfaces. (Shah et al. 1995).

5. Crack tip blunting 
This commonly occurs when a crack reaches a void (Shah et al. 1995). This is a form of crack arrest which occurs when the energy required to produce a crack is insufficient to overcome the materials resistance to fracture (Broek 1986).

6. Crack Branching

Crack branching in concrete occurs due to the heterogeneity of the material (Shah et al. 1995). In an ideal situation the bifurcation of cracks will occur, theoretically, when the fracture energy is twice that of the energy to resist fracture (Broek 1986).

These toughening mechanisms are all sources of variability in the fracture behavior of concrete, and may explain the source of size effect (Shah et al. 1995).

\subsection{Size-Effect}

The size effect is a term used to describe a phenomenon that occurs in materials that exhibit brittle behavior, where the strength of the material decreases with increasing size. The size effect arises from the concept that as the size increases it is more probable that flaws or intentional inclusions will be present within the material (Chawla 1993). This promotes stress concentrations in the vicinity of the flaws, which, as discussed, leads to cracking within the material. However, in the case of concrete structures, where unstable crack propagation occurs after initial crack formation, this concept has been shown to only be applicable in certain situations (Bažant and Planas 1998) According to Bažant and Planas (1998) the primary sources that could explain the size effects are interface variations, diffusion phenomena, statistical fracture, fracture mechanics, and fractality. 


\subsubsection{Interface Variation}

At interfaces, such as the walls of forms or near inclusions, the material properties may differ from the bulk structure. In large structures the earlier will have less of an effect, but the latter will still be present (Bažant and Planas 1998).

\subsubsection{Diffusion Phenomena}

Heat, pore water, and chemical diffusion can cause the properties in the structure to vary, which produces residual stresses. The diffusion half-time is dependent on the size of the structure, which means that larger structures will behave differently (Bažant and Planas 1998).

\subsubsection{Statistical Nature}

It is common to represent the statistical nature of brittle materials with a Weibull distribution, which was developed by Waloddi Weibull, to describe the nonlinearity in engineering materials (Weibull 1951). The cumulative distribution function (CDF) and probability distribution function (PDF) appear in the following forms, respectively.

$F_{x}(x)=1-e^{-\left(\frac{x-x_{u}}{x_{0}}\right)^{m}}$

$f_{x}(x)=\frac{m}{x_{o}}\left(\frac{x-x_{u}}{x_{o}}\right)^{m-1} e^{-\left(\frac{x-x_{u}}{x_{o}}\right)^{m}}$

The variables $\mathrm{m}, x_{o}$, and $x_{u}$ are all constants related to the shape of the distributions, and $\mathrm{x}$ is an a user defined input.

The distribution for the strength at a certain volume, $\mathrm{V}_{0}$, can be described by a simplified CDF as given by equation 2.3 , which is the probability of failure (Chawla 1993). 
$P\left(V_{o}\right)=1-e^{\left(-\left(\frac{\sigma}{\sigma_{o}}\right)^{m}\right)}$

Equation 2.3

where $\sigma_{0}$ and $\mathrm{m}$ are material-relevant constants to be determined and $\sigma$ is the stress in the specimen. From this it can be determined that $\sigma=\sigma_{0}$ at $P\left(V_{0}\right)=1 / e$ or 0.37 , which means that $\sigma_{0}$ is the stress value, which occurs when the probability of survival is equal to 0.37 and effects the skewness. The parameter $m$ is known as the Weibull modulus, which determines the change in slope of the curve as the stress increases. In order to account for the scale effect, the ratio between the volume under consideration and the previous volume can be incorporated into the Weibull CDF as follows (Chawla 1993).

$P\left(V_{o}\right)=1-e^{\left(-\frac{V}{V_{o}}\left(\frac{\sigma}{\sigma_{o}}\right)^{m}\right)}$

Equation 2.4

where $\mathrm{V}$ is the volume under consideration and $\mathrm{V}_{\mathrm{o}}$ is the volume used to determine the Weibull parameters.

The Weibull interpretation generally works well for small specimens and can explain the failure of a long concrete bar under direct tension. However, it has been shown that the statistical size effect has limitations with respect to other types of concrete failures, where the fracture behavior leads to a more dominant effect (Bažant and Planas 1998).

\subsubsection{Fracture Mechanics}

It has been said that this is the most important source of the size effect (Bažant and Planas 1998). As mentioned the fracture process of concrete is complicated by various toughening mechanisms, which caused the formation and propagation of macro-cracks to be delayed. The fracture mechanics size effect has been addressed by (Bažant 1985), and can be explained using Bažant's size effect law. This is a law which utilizes two commonly defined measures of fracture behavior; fracture energy, $G_{f}$, and the brittleness number, B, which is further explained in the following section. For more on the size effect law, please reference Bažant and Planas (1998). 


\subsubsection{Fractality}

Fractality is a mathematical concept, which can model complicated surfaces or shapes as a series of self-similar objects on all scales. Although fractals may explain the nature of fracture of concrete at laboratory sized test specimens, it has been shown that for large structures (large scales) the effect of fractals is less important (Bažant and Planas 1998).

\subsection{Analysis of Fracture}

The analysis of fracture is best explained by applying the first law of thermodynamics (energy conservation) (Anderson 2005). There are two forms of fracture mechanics: linear elastic fracture mechanics (LEFM) and non-linear fracture mechanics (NLFM). The use of LEFM, as it only applies to purely elastic materials, is only valid to describe the onset of fracture in concrete, due to concrete's quasi-brittle behavior. In addition, LEFM is not applicable to concrete due to its large fracture process zone, chaotic crack propagation, and difficulty determining crack tip due to crack bridging (Shah et al. 1995). Therefore, the post-fracture analysis requires the use of non-linear fracture mechanics.

Within the realm of NLFM there exist several methods of analysis. The common methods are the R-curve analysis, J-Integral analysis, the fictitious crack approach, the effective elastic crack approach, and finite element models. The J-Integral analysis is not typically done because it is not applicable for concrete (Shah et al. 1995). Frequently the fracture analysis of concrete utilizes the fictitious crack model (FCM) due to its simplicity (Hillerborg et a. 1976). Therefore the following will describe FCM. Further information on LEFM and other NLFM methods as it applies to concrete can be found in Bažant and Planas (1998) and Shah et al. (1995).

\subsubsection{Fictitious Crack Model}

As discussed above in the explanation of quasi-brittle behavior, the nature of concrete leads to the existence of toughening mechanisms that resists fracture. The resistance to fracture leads to a stress concentration in the fracture process zone. This stress 
concentration is a function of the crack opening displacement (w) and can be modeled by a cohesive stress $(\sigma(w))$ acting on the fracture surfaces (Shah et al. 1995). Following this concept, the energy release rate $(\mathrm{G})$ at the tip of a mode I crack can be represented in the following manner.

$G=G_{I C}+G_{\sigma}$

Equation 2.5

Where the fracture energy release rate $G_{I C}$ is evaluated using the concepts of LEFM. The energy release rate to overcome the cohesive stress $G_{\sigma}$, is commonly calculated in the following way

$G_{\sigma}=\int_{0}^{w_{o}} \sigma(w) d w$ Equation 2.6

In equation $2.6, \sigma(w)$, is usually represented as a decreasing monotonic function that terminates at a CMOD of $w_{o}$. The fictitious crack model says that $G_{I C}=0$, as the elastic portion is assumed to be negligibly small. This leads to an energy release rate equal equation 2.6.

In the fictitious crack model, as proposed by (Hillerborg et al. 1976), it is assumed that damage localization, as discussed, occurs after the maximum strength. The initial formulation of this model was based on a direct tensile specimen. It is assumed that the elongation will be the same prior to damage localization; therefore it was proposed the pre-fracture response be measured using an elastic stress-strain relationship. After a single macrocrack has developed the elongation at the location of the crack will continue to grow, and should be represented by the stress-CMOD relationship. A depiction of this is shown in figure 2.5. Once fracture has occurred other un-fractured areas of the beam will undergo stress relief as the crack grows (Hillerborg et al. 1976).

The total fracture energy, $G_{F}$, as mentioned above, is given by the area under the stressCMOD curve (Equation 2.6). It should be stated that, as mentioned above, the portion of the materials response prior to the peak load is ignored in the evaluation of fracture 
energy as it is assumed to be negligible compared to the magnitude of the fracture energy.

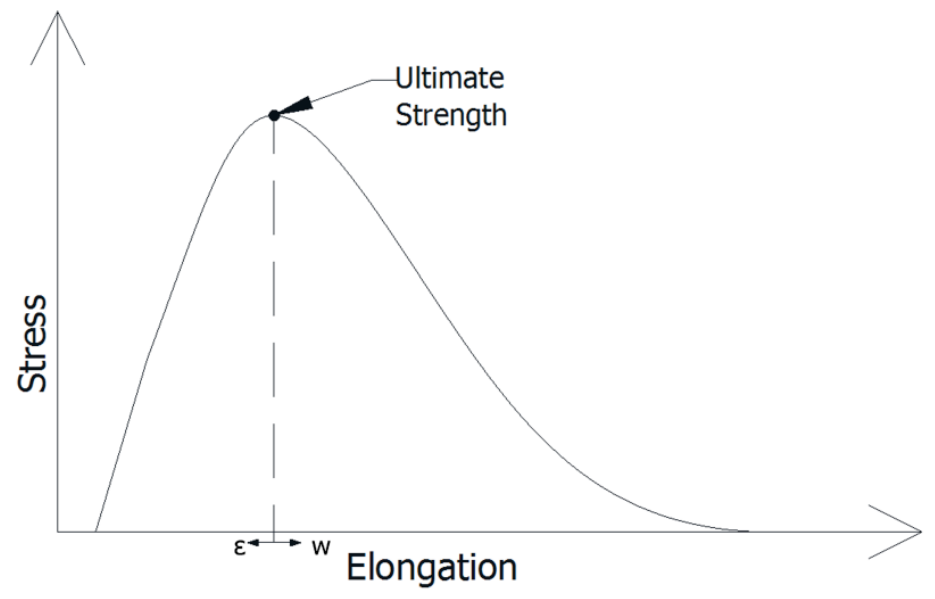

Figure 2.5: Stress elongation curve

The fracture energy is a measure of the materials fracture toughness. It is important to note that, in addition to the fracture energy, this model requires that one must know the ultimate strength, and the shape of the fracture curve (Shah et al. 1995). Some state that since the fracture energy is a material property, it should be invariant with beam size (Muralidhara et al. 2011). However, because of the size effect the value of $G_{F}$ may decrease with increasing size (Bažant and Planas 1998).

The length of the fracture process zone is termed the characteristic length and using this analysis can be estimated using the following relationship, where $E$ is Young's modulus, $G_{f}$ is the fracture energy, and $f_{t}$ is the ultimate strength.

$l_{c h}=\frac{E G_{f}}{f_{t}^{2}}$ Equation 2.7

In addition, Hillerborg has also proposes the use of the brittleness number (Bažant and Planas 1998). The brittleness number is given by equation 2.8 , where $\mathrm{D}$ is the beam 
height. This unitless number gives a comparative measure of a materials brittleness, where high brittleness is associated with a high brittleness number.

$\mathrm{B}=\frac{D}{l_{c h}}$

Equation 2.8

On an ending note, it has been pointed out that, in its formulation, FCM can be applied to un-cracked as well as cracked structures (Gustafsson and Hillerborg 1985). This gives it an advantage over other fracture models that are only applicable for post crack behavior.

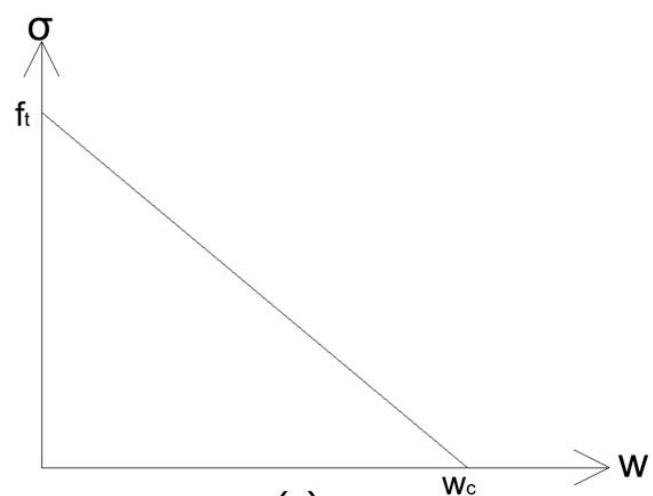

(a)

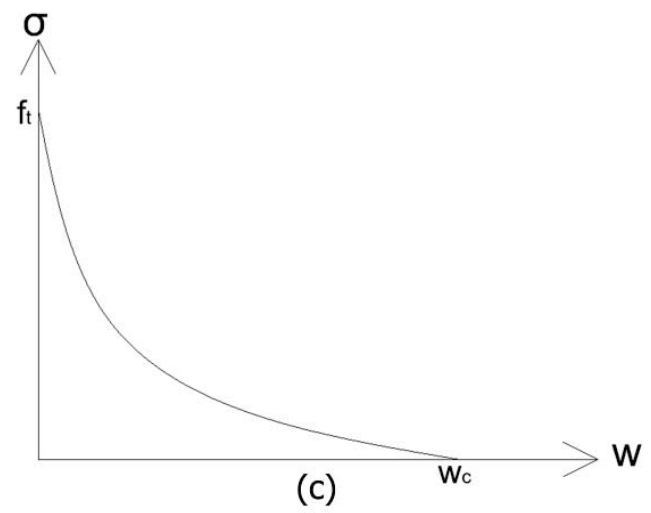

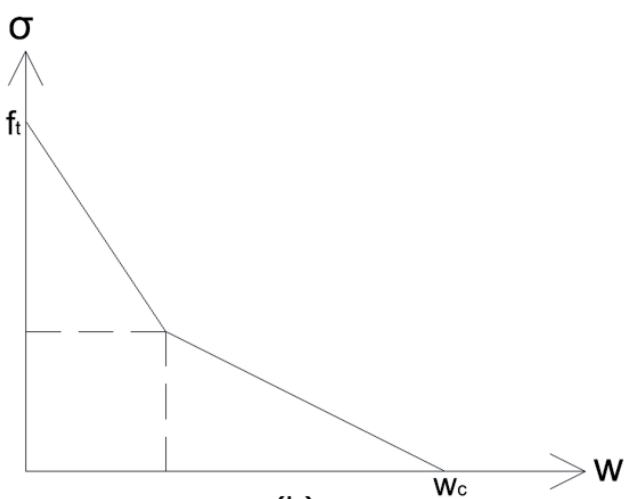

(b)

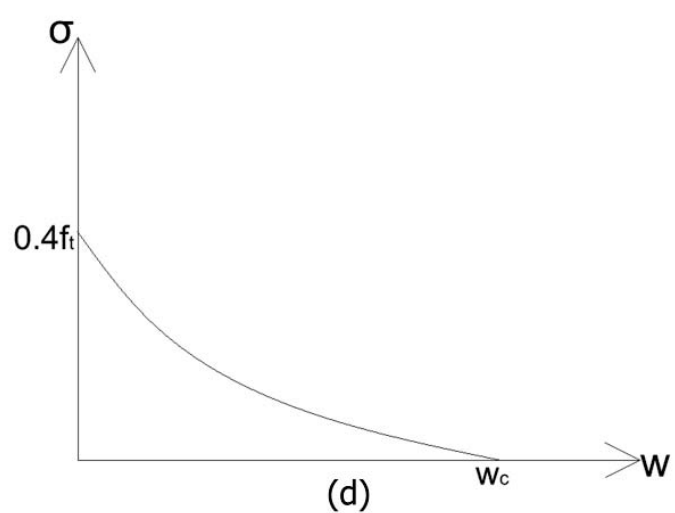

Figure 2.6: Constitutive models: linear (a), bi-linear (b), exponential (c), power (d) 


\subsubsection{Modeling Fracture Curve}

In the fictitious crack model, as mentioned, it is important to know the shape of fracture curve (stress-crack opening displacement curve) (Shah et al. 1995). Knowing the shape of the curve offers a description to the behavior of the energy dissipation process. Linear (Figure 2.6.a), bi-linear (Figure 2.6.b), exponential (Figure 2.6.c), and power curves (Figure 2.6.d) are just a few of the common shapes used to describe the nature of this process (Shah et al. 1995). Each of these curves starts with the ultimate tensile stress $f_{t}$ at a crack opening of zero, and are terminated (zero stress) at some critical crack opening $\mathrm{w}_{\mathrm{c}}$.

\subsection{Fracture Testing}

The purpose of the fracture test is to measure a material's ability to resist fracture, which is related to the fracture toughness. For plain concrete and other quasi-brittle materials, there is no test standard available. However, a variety of test methods have been proposed for measuring the fracture toughness and for analyzing the fracture process zone, as discussed in (Shah et al. 1995). There is an available ASTM test standard for the post cracking behavior of fiber reinforced concrete, but there is one difference which varies from traditional fracture tests (ASTM C1609 2007). A typical fracture test consists of notched specimen, which, when loaded, induces a crack to propagate at the tip of the notch. The principle behind this is, as discussed above, that materials will most likely fracture at a flaw or in this case a notch, which is termed notch sensitivity (Anderson 2005). 


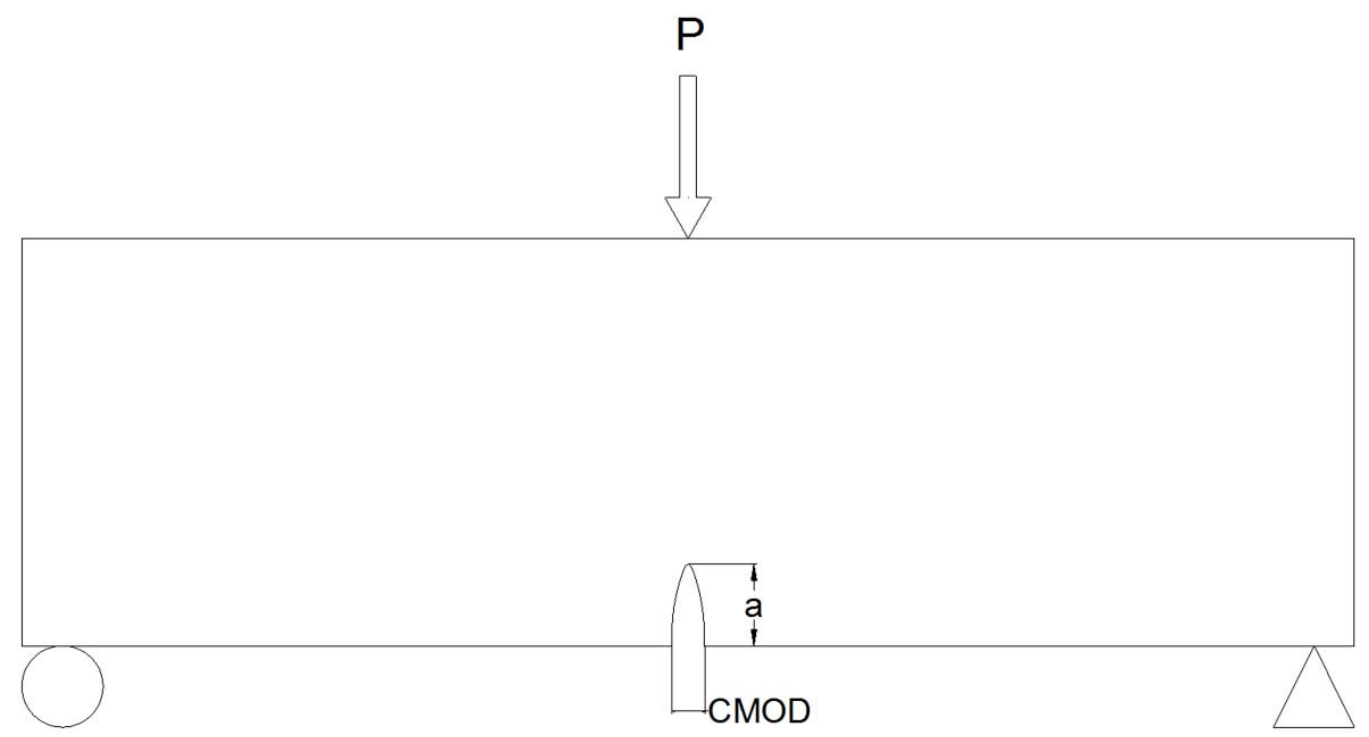

Figure 2.7: Three-point bend fracture test

\subsubsection{Test method}

The simplest and most informative fracture test is a direct tensile test, however this type of test is difficult to perform on concrete materials (Hillerborg 1985). Perhaps the most common method for testing the fracture of concrete is a notched beam Three-point bending test (Shah et al. 1995). The appeal of using a bending test is its ease in set-up and execution, as well as its familiarity in testing the indirect tensile strength of concrete (Hillerborg 1985). It is common in these tests to use a specimen with a centralized notch, which tests the materials ability to resist a mode I type fracture. However, testing under mixed mode fracture conditions has also been performed, by substituting the centralized notched specimen with an off-center notched specimen (Dai et al. 2012).

Within the realm of bending tests there are a few different procedures, depending on the results desired as discussed by(Shah et al. 1995). RILEM-International Union of Laboratories and Experts in Construction Materials, Systems and Structures has been the major authority in the investigation and proposal of various test methods for the fracture of Concrete. In 1985 RILEM technical committee 50-FMT-Fracture 
Mechanics of Concrete proposed a test method based on the fictitious crack model by Hillerborg (Hillerborg 1985), discussed above. This test recommendation uses a notched square prism under three point bending, the size of which depends on the maximum aggregate size. During the test, measurements of load and deflection are recorded. The results of this test can only be used to determine the fracture energy, $G_{F}$, but in order to be compliant with the FCM theory it should be noted that the results must include the tensile strength, $f_{t}$, and either the shape of the fracture curve or the critical crack separation displacement $w_{c}$ (Shah et al. 1995). One method to do this is to use an extensometer to measure the crack mouth opening displacement ( $\left.\mathrm{w}_{\mathrm{CMOD}}\right)$. Based on this type of test, two different methods for determining the fracture energy have been proposed. The first uses the area under the load-deflection curve (Hillerborg 1985), and the second is the area under the load-CMOD (Chen and Qiao 2011; JCI 2003) curve. Excluding the weight of the specimen the fracture energy can be estimated using Equation 2.9.

$G_{f}=\frac{W_{F}}{b(h-a)}$

Equation 2.9

The fracture energy is given by the area under the load-displacement curve divided by the fracture area, which is given by the product of the beam width, $b$, and the height, $h$, subtracted by the notch depth, a.

A similar test has been recommended to describe the fracture behavior of fiber reinforced cementitious materials (RILEM TC 162-TCF 2002). There are also several other fracture test methods, which have been discussed by Shah et al. (1995) In addition to strength testing, crack detection methods, which analyze the geometry and/or behavior of cracks also exist (Shah et al. 1995). 



\section{Fiber Reinforced Cementitious Composites}

\subsection{General Overview}

This section is included in order to summarize the key points of an intensive literature review on the composite behavior of fiber reinforced cementitious composites (FRCC), which aided an understanding of the mechanics behind the mode I fracture of steel fiber reinforced ultra-high performance concrete (UHPC). This section will provide the concepts key to understanding the mechanics behind the tensile/flexural behavior of UHPC.

The mechanical properties of composites can be attributed to the combination of the properties held by the constituents and their interaction (Bentur and Mindess 2007). The constituents are commonly considered to be either part of the matrix or reinforcement to the matrix. In the case of FRCCs the matrix is the bulk of the composite and the reinforcement is added as an enhancer to the matrix. A variety of composite types exist, however, they are usually categorized by matrix type, which can be polymer, metal, or ceramic. Reinforcements can come in many forms, including but not limited to particles, flakes, whiskers, fibers, and sheets (Chawla 1987). As composites, FRCCs are considered fiber reinforced ceramic matrix composite (FRCMC), where the matrix is considered to be a particle reinforced composite.

According to previous work (Naaman 2003), FRCCs can be further classified into two types, conventional FRCCS and high performance FRCCs. Conventional FRCCs are typically made of a normal strength concrete (NSC), and exhibit a softening behavior. Whereas, high performance FRCCs exhibit strain hardening (tension) and/or deflection hardening (flexure) behavior (Bentur and Mindess 2007). Where hardening in a material can be defined as an increase in capacity following the occurrence of firstcrack (Naaman 2003). Hardening can usually be achieved in one of two ways: increasing the fiber content, or engineering the matrix in such a way that improves the composite behavior. 


\subsection{Properties that Affect Mechanical Behavior}

The selection of both the type of matrix and reinforcement is important to the mechanical behavior of the composite (Bentur and Mindess 2007). When designing a mix one must consider the material properties of the matrix, aggregate sizes, as well as the chemical reactions that occur. This is because the aggregate size and chemistry of the matrix can be detrimental to behavior of the composite. Additionally, poor fiber selection can lead to poor interaction between the fibers and the matrix.

\subsubsection{Matrix}

In the case of FRCCs the matrix in itself is a composite, with particulate reinforcement (aggregate), held together by cement paste (Bentur and Mindess 2007; Chan and Li 1997). As mentioned, this is known as a particle reinforced composite. The matrix, in its basic most form, is formed by combining water, portland cement, and aggregates. The purpose of the aggregate is to decrease cost, provide stability, and improve wear resistance (Mindess et al. 2003). In the case of concrete, these particles are usually large in size, and may be up to 2in in diameter. Therefore, from Figure 3.1, concrete can be termed a large particle reinforced ceramic matrix composite (Callister 2005). However, many FRCCs do not use such large particles, as there is a relationship between fiber distributions and maximum particle size (Hannant 1978). For larger particles there is decreased movement of fibers in the matrix, which leads to bunching or interlock of the fibers. Therefore aggregate sizes are often limited to about 70 percent finer than $5 \mathrm{~mm}(0.2 \mathrm{in})$ and 30 percent between $5 \mathrm{~mm}(0.2 \mathrm{in})$ and $10 \mathrm{~mm}(0.4$ in) (Hannant 1978). For this reason many engineered FRCCs, such as UHPFRC, remove the larger sized aggregates and optimize the particle gradation (Richard and Cheyrezy 1995).

The mixture of water and the cement leads to hydration reactions, which are influential to the mechanical properties (Taylor 1997). In addition, chemical admixtures and pozzolan cements are often added to obtain specific properties or outcomes. The chemical reactions that occur are particularly important when discussing the interaction between the fiber reinforcement and the matrix. The major reactants present are alite 
$\left(\mathrm{C}_{3} \mathrm{~S}\right)$, belite $\left(\mathrm{C}_{2} \mathrm{~S}\right)$, aluminate $\left(\mathrm{C}_{3} \mathrm{~A}\right)$, ferrite $\left(\mathrm{C}_{4} \mathrm{AF}\right)$, gypsum, and water $\left(\mathrm{H}_{2} \mathrm{O}\right)$. The most prominent products that form within the matrix are portlandite $(\mathrm{CH})$ and calcium silicate hydrates (CSH) from the hydration of $\mathrm{C}_{3} \mathrm{~S}$ and $\mathrm{C}_{2} \mathrm{~S}$, and calcium sulfoaluminates (C $\underline{\mathrm{S}} \mathrm{A})$, such as ettringite from the hydration of $\mathrm{C}_{3} \mathrm{~A}, \mathrm{C}_{4} \mathrm{AF}$, and gypsum (Taylor 1997). The formation of $\mathrm{CH}$ reacts further with water and sulfate to increase the amount of CSH, which is attributed to much of concrete's strength (Chan and Li 1997).

\subsubsection{Reinforcement}

A variety of fibers exist, which can be used as reinforcement (Table 3.1). Fibers are generally added as secondary reinforcement, where conventional reinforcing bars are the primary (Bentur and Mindess 2007). The purpose for adding fibers is to prevent cracks from occurring, and once cracked, impede further propagation. After fracture, the fibers will also bridge cracks and transfer stresses from one fracture surface to the other leading to improved post-crack toughness. In some cases, depending on the fibers and their interaction with the matrix, the fibers will typically add some amount of additional strength to the material (Bentur and Mindess 2007).

With the addition of fibers the most influential aspects are the fiber type, fiber geometry, and volumetric percentage of fibers within the matrix (Bentur and Mindess 2007). The fiber's mechanical properties, as well as its affinity to bond to the matrix can greatly affect the ability of the fiber to interact with the matrix. The geometry of the fiber can also have an effect due to the amount of surface area, surface roughness, and fiber modifications used to improve mechanical anchorage (Bentur and Mindess 2007). Figure 3.1 shows the way in which steel fibers, as well as polymer fibers can be manufactured to improve mechanical anchorage within the matrix (ACI 544 2001). The length of the fibers can affect mobility of the fibers within the matrix, which can lead to fiber interlock (Hannant 1978). The amount of fibers in a composite is generally

defined as some fiber percentage, which has been shown to increase strength with increased percentage (Bache 1987). 
Table 3.1

Common fiber properties

\begin{tabular}{|l|c|c|c|}
\hline \multicolumn{1}{|c|}{ Fiber Types } & $\begin{array}{c}\text { Tensile } \\
\text { Strength } \\
(\mathbf{M P a})\end{array}$ & $\begin{array}{c}\text { Young's } \\
\text { Modulus } \\
(\mathbf{G P a})\end{array}$ & $\begin{array}{c}\text { Diameter } \\
(\boldsymbol{\mu m})\end{array}$ \\
\hline Natural Fibers & $600-1000$ & $83-138$ & $1.5-20$ \\
\hline Asbestos & $250-350$ & $26-32$ & $100-200$ \\
\hline Jute & $228-800$ & $11-27$ & $80-300$ \\
\hline Sisal & $345-3000$ & 200 & $150-1000$ \\
\hline Metallic Fibers & 4000 & $230-240$ & - \\
\hline Steel & $1000-2600$ & $70-80$ & $5-150$ \\
\hline Ceramic Fibers & \multicolumn{3}{|l}{} \\
\hline Carbon & $3500-3600$ & $65-133$ & 10 \\
\hline Glass & $900-1600$ & $23-40$ & $27-660$ \\
\hline Synthetic Fibers & $720-860$ & 8.3 & $20-400$ \\
\hline Aramid & $760-820$ & 4.1 & $20-400$ \\
\hline Polyvinyl Alcohol (PVA) & $200-760$ & $3.5-15$ & $20-1000$ \\
\hline Polyester & $200-300$ & 5.0 & $25-1000$ \\
\hline Nylon &
\end{tabular}

Note: Condensed from(ACI 544 2010).
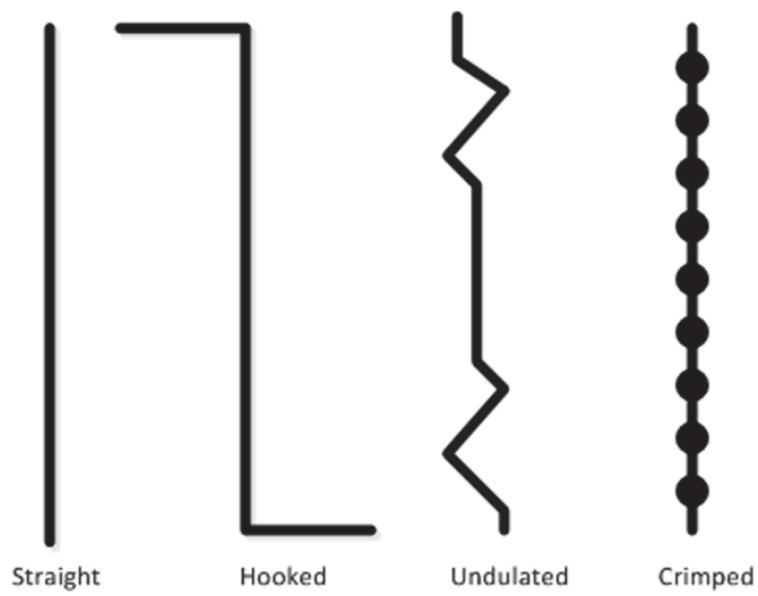

Figure 3.1: Fiber geometries 


\subsubsection{Fiber-Matrix Interaction}

The interfacial interaction or bond between the fibers and the matrix is of great importance to the behavior of FRCCs. A key factor to the strength of this bond is the structure of the fiber-matrix interface, which tends to differ from the bulk matrix (Bentur et al. 1985). Between this interface and the bulk matrix, lays a boundary which is known as the interfacial transition zone (ITZ). As described by (Bentur et al. 1985), this zone is less dense with normal strength concretes, because $\mathrm{CH}$ will develop during the hydration process in the vicinity of the fibers in the form of a thin duplex film, as well as, large crystals (Figure 2.2). During hydration the $\mathrm{CH}$ crystals will further be converted to $\mathrm{CSH}$, due to bleeding of water and insufficient packing of cement grains, leaving behind a porous region consisting primarily of CSH and ettringite (Bentur and Mindess 2007). This can lead to a weakness in the bonding between the fibers and the matrix, which ultimately affects the mechanical behavior of the composite. As hydration progresses the porosity of the ITZ decreases (Bentur and Mindess 2007). It has been concluded based on previous work (Diamond 1977, Chan and Li 1997) that the formation of $\mathrm{CH}$ is promoted by a high water-to-cementitious ratio and unfilled cavities.

As mentioned, the fiber type and geometry affect the performance of the bond. In the case of fiber type, the properties of the fiber can affect the strength of the composite based on the strength and ductility of the fiber (Bentur and Mindess 2007).

Furthermore, the fiber type can change the way in which the fiber bonds to the matrix. With Steel fibers the bond is generally more efficient if the fiber has a rough surface and/or some deformation to improve mechanical anchorage. In the case of fibers consisting of bundled filaments, as with alkali resistant glass fibers, it is difficult for large cement grains to penetrate into the spaces between filaments. This leads to uneven stress transfer from stiff external fibers to more flexible interior fibers. For hydrophilic natural fibers (i.e. sisal, jute, or wood pulp) with low moisture contents, the bond is stronger than with identical fibers at higher moisture contents (Bentur and Mindess 2007). 


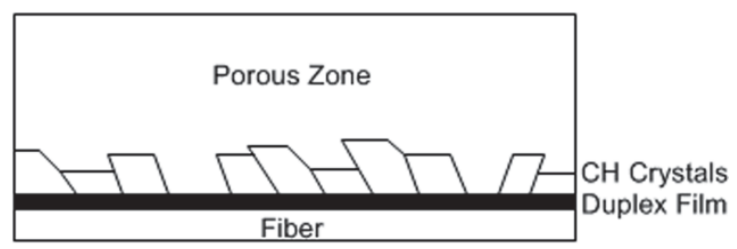

Figure 3.2: Interfacial transition zone

\subsection{Fiber efficiency}

The performance of FRCCs in tension relies on the efficiency of the fibers to interact with the matrix. Two common considerations that effect the efficiency are the length of the fibers and there preferred orientation within the matrix (Bentur and Mindess 2007).

\subsubsection{Length}

For straight fibers the geometry is usually categorized by the aspect ratio, which is the ratio between its length and diameter (L/D), the effects of which have been described by (Bentur and Mindess 2007). Macrofibers (low L/D) require manufactured deformations, as discussed above, because their interfacial bond strength is inadequate. Whereas, small diameter (high L/D) straight fibers generally have a large enough bond strength to allow for proper fiber efficiency. In the case of straight fibers, the stress carried by the fiber varies with fiber length, as shown in figure 3.4. In order to achieve the full loading capability of the fiber $\left(\sigma_{\mathrm{fu}}\right)$, the fiber must be of some critical length. This is the length at which the fibers will fail prior to pull-out (Bentur and Mindess 2007).

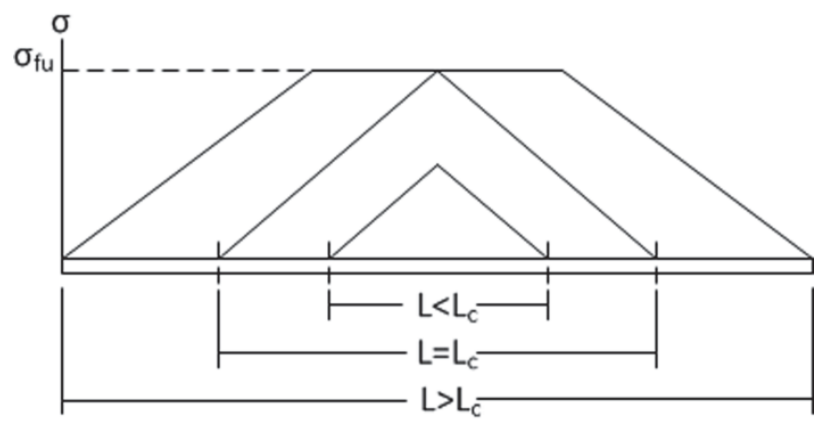

Figure 3.3: Change in fiber loading with length 


\subsubsection{Orientation}

Similar to length, the strengthening efficency changes with a change in fiber orientation. In general, orientation will follow one of the following three cases: one dimensional (1D), two dimensional (2D), or three dimensional (3D) (Bentur and Mindess 2007). Most models assume a 1D fiber orientation, where the fibers are loaded in direct tension. In design of conventional reinforced concrete which uses continuous reinforcement, engineers typical design for 1D (tension steel in beams and one-way slabs) or 2D (tension steel in two-way slabs) orientations (Wight and MacGregor 2009). However, in the case of discrete fibers it is more common to assume $2 \mathrm{D}$ or $3 \mathrm{D}$ orientations, because the short discontinuous fibers tend to rotate during pouring and/or curing processes (Bentur and Mindess 2007). This often leads to reduced fiber efficiency in uncracked and cracked situations. However, in a cracked section, orientation leads to local bending in the fiber, which can lead to improved efficiency.

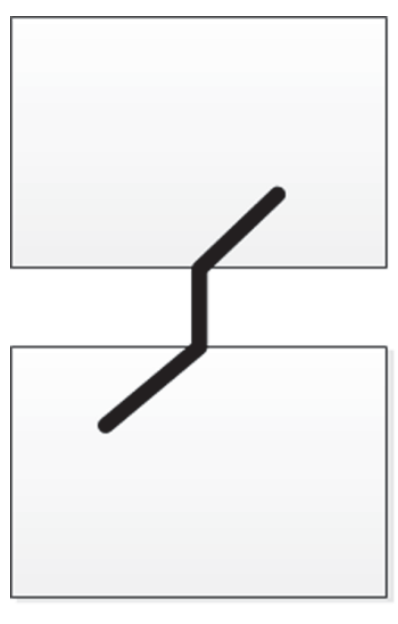

(a)

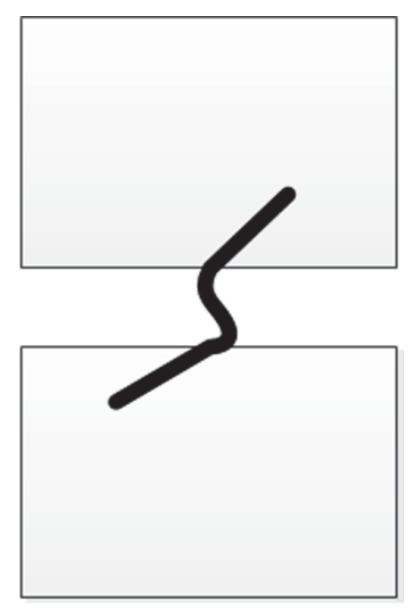

(b)

Figure 3.4: Local bending of fibers: ductile fibers (a) and ridged fibers (b) 
If subjected to local bending, ductile fibers will easily bend, which leads to induced mechanical anchorage and higher efficiency (Bentur and Mindess 2007). However, brittle fibers will lead to a build-up of stresses, which may cause fiber failure and lower fiber efficiency. Conversely, too much bending without debonding may cause damage to flexible fibers, and the lack of bending in rigid fibers may lead to damage of the ITZ.

\subsection{Stress Transfer}

The bond between fibers and the matrix is represented by the interfacial shear stress $(\tau)$, which is initially due to the fibers ability to adhere to the matrix (Bentur and Mindess 2007). Once this adhesional stress $\left(\tau_{\mathrm{a}}\right)$ is exceeded at an ultimate value, $\tau_{\mathrm{au}}$, a transition will occur from adhesional to frictional stress $\left(\tau_{\mathrm{fu}}\right)$. This process is commonly referred to as debonding, and can be represented analytically by a variety of methods, which vary from the simple to the complex (Greszczuk 1969; Lawrence 1972; Naaman et al. 1991). In the case where the FRCC is un-fractured and the fibers are adhesionally bonded to the matrix, the load is carried by the composite (matrix and fibers) (Bentur and Mindess 2007). As the specimen is loaded the load carried by the fiber will increase until either the fiber fails or debonds. Figure 3.6 shows that if the fiber lays in an unfractured section the maximum stress $\left(\sigma_{\mathrm{fu}}\right)$ in the fiber will occur in the center and the maximum bond strength $(\tau)$ will occur at the ends of the bonded section.

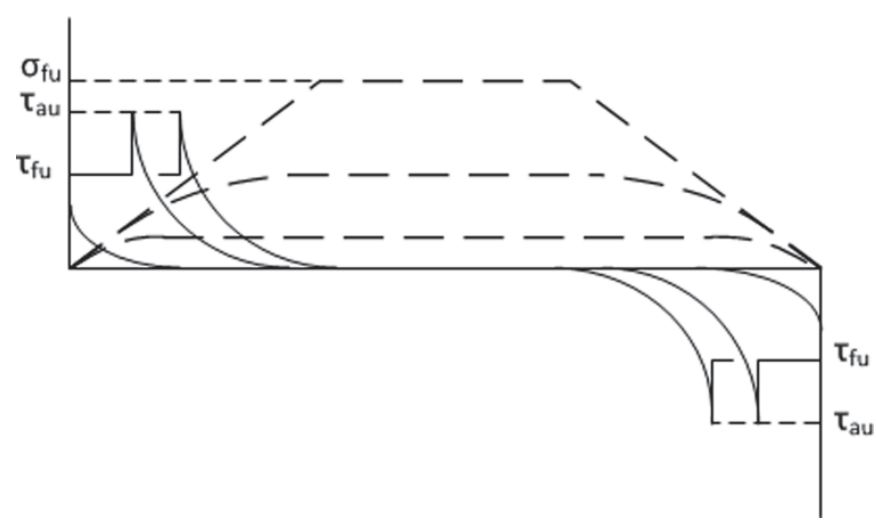

Figure 3.5: Stress in fibers 
This is at the ends for a fiber undergoing full adhesion, and since a decrease occurs when transferring from adhesional to frictional bonding this occurs at the ends of the remaining adhesionally bonded portion of the fiber. When fractured, the load will be transferred from one side of the crack to the other by the fibers, which is termed fiber bridging. Of course, this is only true if the fiber is not fractured prior to cracking. Once debonding is initiated the bonding begins to transfer from adhesional to frictional. During this stress transfer the bonding should be treated as a mixture between the two.

Figure 3.6.a depicts the case where fiber debonding occurs prior to fracture, and figure 3.6.b depicts the case where the fiber is not yet debonded after fracture. It should be noted that once fracture occurs the bonding occurs near the fracture surface and not on the ends. Once fracture occurs the stress transfer should be analyzed depending on the bonding present.

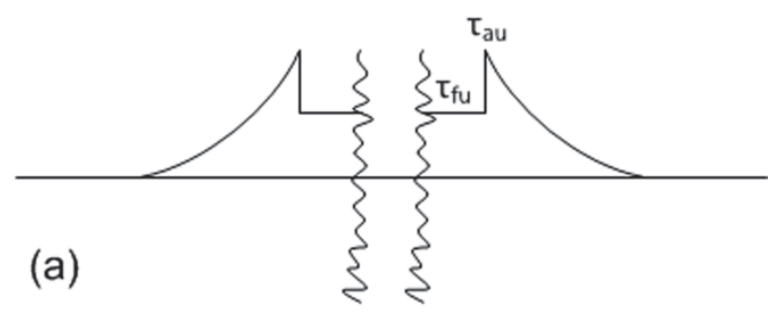

(b)

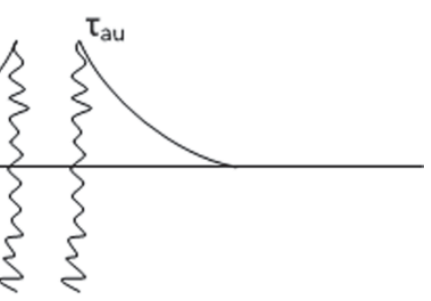

Figure 3.6: Debonding process: pre-fracture debonding (a) and post fracture debonding (b) 


\title{
3.5 Analysis
}

As mentioned the fibers are of primary importance in tension. With regards to FRCCs in tension there are three common analyses, which are as follows: composite materials, fracture mechanics, and multiple cracking (Bentur 2007). Of these only the composite materials will be discussed, as it is relevant to the ACI 544 model, which will be included in the model comparison section of chapter 6. The fracture mechanics approach is based on the information provided in chapter 2 , and relies on the use of a non-linear hinge design (Pedersen 1996). This analytical method was not included as it is beyond the scope of this research. Similarly, the multiple crack analysis also does not pertain to this research and is therefore not discussed. For more information on multiple cracking, please reference the Aveston, Cooper, and Kelly (ACK) approach (A. Aveston 1971).

Similar to quasi-brittle behavior discussed in Chapter 2, the mechanical behavior of FRCCs under tension follow the same five stages, where the fibers offer a strengthening mechanism. With the addition of fibers there are four considerations for mechanical behavior (Bentur and Mindess 2007)which are as follows.

\author{
Crack Suppression - stage I \\ Crack stabilization - Stage II \\ Crack bridging - Stage III and IV \\ Fiber matrix debondoing - Stage IV
}

\subsubsection{Composite Materials}

The composite materials approach for FRCCs is based on the rule of mixtures (ROM). The concept of the rule of mixtures is that the strength of the composite is the sum of the contributions from its constituents. The use of the ROM dates back to 1910, when Voigt developed a formulation to describe the mechanical behavior of composites with reinforcement aligned parallel to the direction of loading (Chawla 1987). It should be noted that this formulation assumes strain $(\varepsilon)$ compatibility of the matrix and 
reinforcement. Following this approach the stress in the composite can be written in the following form.

$\sigma(\varepsilon)=\sigma_{m}(\varepsilon) V_{m}+\sigma_{f}(\varepsilon) V_{f}$ Equation 3.1

The basic concepts of composite behavior, as discussed in previous sections can be easily described using this equation. The stress $(\sigma)$ in the composite, at a given value of strain $(\varepsilon)$ is a function of the contribution due to the matrix (first term) and the contribution due to the fiber reinforcement (second term). The stress in the matrix and stress in the fiber are given by $\sigma_{\mathrm{m}}$, and $\sigma_{\mathrm{f}}$, respectively. The amounts of the constituents by volume are given by $\mathrm{V}_{\mathrm{m}}$ for the matrix and $\mathrm{V}_{\mathrm{f}}$ for the fibers. This is typically the case for composites with continuous reinforcement (Swamy et al. 1974), but FRCCs usually have discontinuous fibers which may not be oriented in a 1D orientation. To account for fiber length and orientation effects in FRCCs a modified version of ROM is used, which incorporates the interface and orientation effects as discussed in the previous section (Swamy et al. 1974). Based on this theory, the equation for stress in fiber reinforced composites can be modified to the following equation.

$\sigma(\varepsilon)=A \sigma_{m}(\varepsilon) V_{m}+B \sigma_{f}(\varepsilon) V_{f}$ Equation 3.2

The values of A and B are constant, where A is commonly taken to be 1 and B is related to the length and orientation efficiency. Prior to fracture the strength in the composite is commonly approximated as, (Laws 1983), where $\sigma_{m}$ is the strength of the matrix and $\sigma_{f u}$ is the ultimate strength of the fiber.

$\sigma_{c}=\sigma_{m} V_{m}+B \sigma_{f u} V_{f}$ Equation 3.3

For discontinuous fibers it is common, in the case of FRCCs, to assume that de-bonding occurs after fracture and that the matrix has no significant contribution to the strength (Laws 1983). The post-cracking strength is often written as: 
In the case of bending, because the fibers are being loaded in indirect tension ROM is often written as (Bentur and Mindess 2007; Swamy et al. 1974).

$\sigma_{b}=E \sigma_{b m} V_{m}+F V_{f} \frac{l}{d}$

In this equation the value of $\mathrm{F}$ is a constant, which in addition to accounting for fiber efficiency also accounts for the fiber-matrix bond, $\tau$, as it is often unknown and difficult to determine for the case of bending. The inclusion of the shear stress term is recognized, from the use of the fiber aspect ratio $l / d$ to account for the efficiency of the bond. Also, it has been previously shown that in the case of bending $\mathrm{V}_{\mathrm{f}}$ can be reduced, as there is an increased strength in comparison to direct tension (Hannant 1978). Furthermore, it has been stated that the above equation for bending is more of an empirical result than a rule of mixtures formulation (Laws 1983).

There are a variety of models developed from ROM, including that by ACI 544 (ACI 5442001 ) and an approach developed by (Naaman 2003) for FRCCs that exhibit strain/deflection hardening behavior. The approach by Naaman will not be discussed as it will not be addressed in future chapters. In the case of FRCCs without conventional reinforcement (Fibers only), ACI 544 reports that based work by (Swamy et al. 1974) the following equations can be used for first crack and ultimate strength of the composite, respectively.

$\sigma_{c f}=0.843 f_{m} V_{m}+425 V_{f} \frac{l}{d_{f}}$ Equation 3.22

$\sigma_{c u}=0.97 f_{m} V_{m}+494 V_{f} \frac{l}{d_{f}}$ Equation 3.23

The values of $\mathrm{f}_{\mathrm{m}}$ and $\mathrm{V}_{\mathrm{m}}$ are the unreinforced matrix strength and matrix volume fraction, respectively. The fiber content is given by $V_{f}, 1$ is the length of the fiber, and $d_{f}$ is the diameter of the fiber. 


\section{Ultra-High Performance Concrete}

\subsection{Introduction}

Ultra-high performance concrete is a densely packed cementitious material with compressive strength above $150 \mathrm{MPa}$ (Schmidt et al. 2003). With the addition of fiber reinforcement it is often generally termed UHPFRC (Rossi 2001). For structural applications it is common to add discontinuous steel fibers, in which case the composite has in the past been termed steel fiber reinforced UHPC (Schmidt et al. 2003). The concept for UHPC was developed in Denmark in the 1980s (Bache 1981), but its potential was not realized until the mid-1990s in France (de Larrard and Sedran 1994; Richard and Cheyrezy 1995; Rossi 1997). Around the world this material is rapidly gaining popularity and is utilized for structural and non-structural elements alike. There exists several buildings, bridges, and iconic works of art made from this material. Currently in North America there are only a handful of UHPC applications, which have been previously mentioned (Peuse 2008). This lag in implementation is due to unfamiliarity with the material and lack of a North American design standard, an issue being currently addressed by the newly established ACI Committee 239 -Ultra High Performance Concrete (ACI 2011).

To promote widespread use in North America it is essential that the engineering community be introduced to the material. In previous work the composition of UHPC has been summarized (Kollmorgen 2004; Richard and Cheyrezy 1995) However, since then there has been much research in alternative mix compositions. In the past ten years UHPC, which has been a largely a proprietary endeavour, is now becoming more public with researchers beginning to developing mix designs made from local and alternative materials (Quiroga and Fowler 2004; Yang et al. 2009). The material selection and mix designs for UHPC comes from a deep understanding of the complex nature of cementitious materials, which arose from the culmination of several concepts developed over decades of research (Bache 1981; de Larrard and Sedran 1994; Richard and Cheyrezy 1995; Rossi 1997), as follows 
1. Densification of the matrix

2. Use of cement low in $\mathrm{C}_{3} \mathrm{~A}$

3. Use of pozzolans

4. Addition of fibers

5. Use of superplasticizers to promote self-consolidation

6. Thermal treatment and pressure treatment

\subsection{Matrix Densification}

The densification of the matrix, or particle packing (Figure 4.1), is perhaps the most important concept in UHPC, as it leads to high compressive strengths (Rossi 2001), increased durability (Graybeal and Hartmann 2003), and improved fiber-matrix bond characteristics (Bentur and Mindess 2007). This is partly because the densified matrix and low water to binder ratio promotes the formation of the stronger calcium silicate hydrate $(\mathrm{CSH})$ phase over the weak calcium hydroxide $(\mathrm{CH})$ phase (Chan and Li 1997; Reda et al. 1999). The concept of densification was based on geometric and kinematic principles, which led to the development of densified small particulate (DSP) concrete (Bache 1981). The densification of the matrix is due to the omission of large aggregates, and optimized gradation of the fines (Richard and Cheyrezy, 1995). Optimization is typically done through the use of particle packing models (de Larrard 1999).

In North America particle packing has been addressed through the use of aggregate gradation models, such as the widely used Fuller-Thompson model ( 0.45 power curve, maximum density curve, ideal curve) or the Andreassen model (Kumar V and Santhanam 2003). However, these types of models do not account for the packing of the fine grain constituents (cement, pozzolans, etc.) (Kumar V and Santhanam 2003; Sobolev 2004)). This may lead to improper optimization (de Larrard 1999). It has been suggested that this may be the cause of durability issues leading to the degradation in concrete materials (Quiroga and Fowler 2004). 


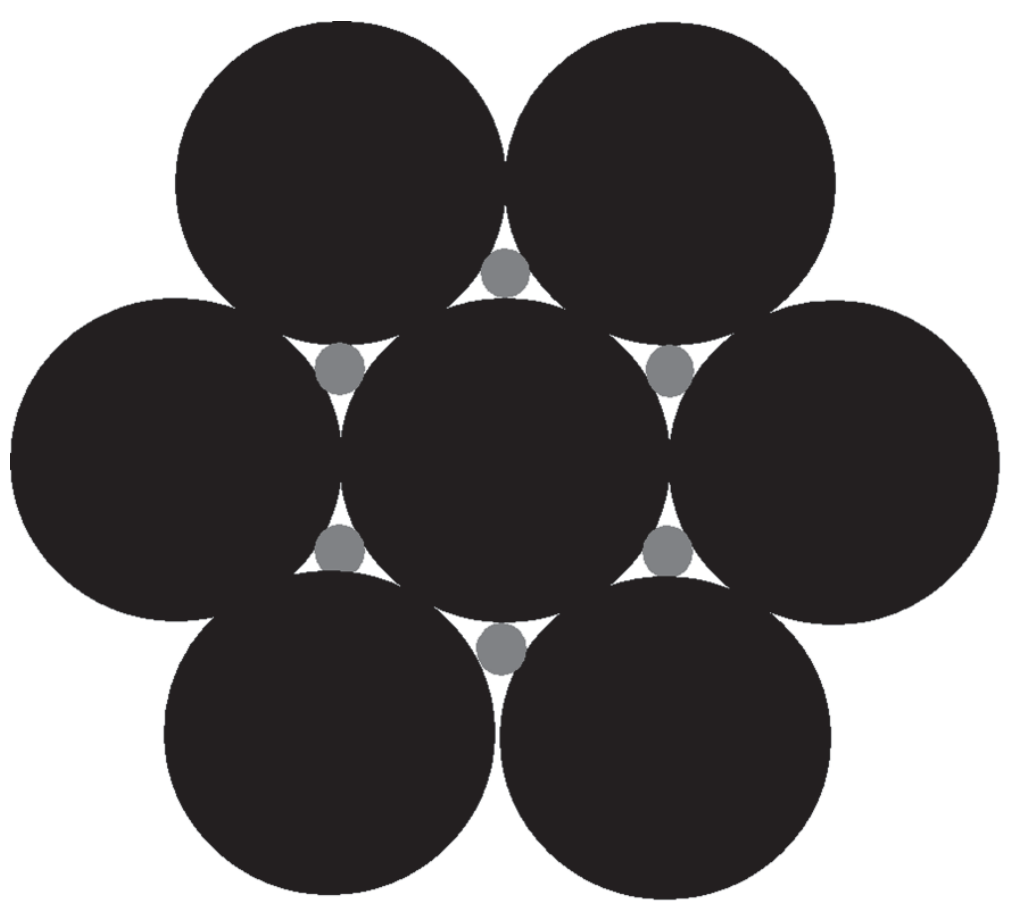

Figure 4.1: Particle packing

The above models have been termed continuous models, as they assume a continuous distribution of particles. By definition these models do not account for the fact that the particle sizes used in concrete are not continuous. Therefore, to properly proportion UHPC, many have turned to the use of discrete packing models. Those developed by de Larrard are commonly used for UHPC mix design (de Larrard 1994; Richard and Cheyrezy 1995), such as the linear packing density model (LPDM), solid suspension model (SSM), and compressible packing model (CPM). Of these a modified LPDM and CPM account for all of the following considerations (Kumar and Santhanam 2003).

In addition to modeling the particles as discrete elements, these models also consider, as hoped by Bache (1981), the geometric and kinematic effects (de Larrard, 1999). The primary considerations which must be addressed are the wall effect, the loosening effect, and the compaction effect (Kumar and Santhanam, 2003). The wall effect is the occurrence of larger voids when adjacent same size particles come in contact with a singular larger particle or wall which does not provide enough surface area to account 
for an evenly distributed number of the smaller particles. The loosening effect is the displacement of particles or expansion of the material due to the existence of particles that are not small enough to fit in the interstitial regions of a group of larger particles. Again, this leads to an increase in the size of voids in the material. The compaction effect is the densification of a material through externally applied pressure, which decreases the size of voids (Kumar and Santhanam, 2003).

In addition, if fibers are added as is the case with ultra-high performance fiber reinforced concrete (UHPFRC) then the fibers will offset the packing density, and therefore should be accounted for in the model. This has been done using a mean packing density model, which calculates the mean packing density of a fiber in a sea of mono-dispersed particles (de Larrard 1999).

Many recent studies have looked at applying 3D particle packing models (Ballani et al. 2006; Fu and Dekelbab 2003; Siiriä and Yliruusi 2007; Sobolev and Amirjanov 2007). $3 \mathrm{D}$ models look at particle sizes as a series of spheres, where the ultimate gradation is determined by optimizing the arrangement of these spheres within a cube to achieve the maximum density.

\subsection{Aggregates}

The selection of aggregates and other fillers is based on four criteria: chemical composition, particle shape, particle sizes, and particle distribution (Richard and Cheyrezy 1995). Knowing the chemical composition will prevent unwanted reactivity. The shape of fine aggregates only affects workability, whereas larger aggregates affect mechanical behavior (Mindess et al. 2003). To effectively engage the aggregate it is essential to increase the amount of bonded surface area and roughness. With regards to particle shape, rounded grains are preferred for improved rheology. The diameter of aggregates should be minimized, but should also be large enough to reduce the wall effect between the next smaller particle, and fibers. It has been said that monodispersed (mostly comprised of same size particles) sand offers the best solution in either case. (de Larrard and Sedran 1994; de Larrard 1999). 
As mentioned for UHPC, the larger aggregates are omitted, which is intended to increase particle packing and reduce the occurrence of microcracking (Richard and Cheyrezy 1995). Accordingly, the maximum aggregate size should be 600 microns and the minimum size should be limited to 150 microns so as to not interfere with the next largest particle size, cement grains (Richard and Cheyrezy 1995). Others have obtained UHPC strengths using even larger aggregates. Schmidt et al. (2003) recommended aggregate sizes of 0.5-2 mm, Reda et al. (1999) used sizes up to 4-6 mm, and Collepardi et al. (1997) used diameters up to $8 \mathrm{~mm}$.

It has been said that the aggregates should be comprised of natural sands or crushed sands with low powder content with strengths greater than $100 \mathrm{MPa}$ and good bonding capabilities (Schmidt et al. 2003). Many studies have used calcined bauxite (Bache 1987; Reda et al. 1999), but this material has high costs associated with manufacturing (de Larrard and Sedran 1994). For this reason many have turned to silica sand (crushed quartz) (Richard and Cheyrezy 1995; Collepardi et al. 1997; de Larrard and Sedran 1994), a material noted for its availability (France), low cost, high strength, and good interfacial bond (Richard and Cheyrezy 1995). Yang et al (2009) have reported that silica sands can be expensive compared to local ordinary sand alternatives. With the use of local sands, it is possible to produce mixes with equivalent compressive strength, flexural strength, and fracture energy. Yang et al. (2009) also researched the use of crushed recycled glass, which showed some success. Recycled glass does, however, lead to a decrease in mechanical behavior and pull-out behavior, which has been associated with the smooth texture of the glass. The use of recycled glass could offer an economical and environmentally friendly alternative that may lead to further implementation of UHPC. Some of the other viable aggregates are limestone (Reda 1999), granite (Rossi 2001), and basalt (Schmidt et al. 2003).

\subsection{Cement}

Cements with low tricalcium aluminate $\left(\mathrm{C}_{3} \mathrm{~A}\right)$ content give better results as they do not dissociate from the superplasticizer (Richard and Cheyrezy 1995). According to ASTM C150, these cements would be Type II-moderate sulfate resistance and Type V-high 
sulfate resistance. Additionally, Type II and Type V have lower water demand due to the lack of $\mathrm{C}_{3} \mathrm{~A}$ (Kosmatka et al. 2008). In fact both Type II used by (Möser et al. 2010), and Type V used by Richard and Cheyrezy (1996) have successfully been used to create a UHPC materials.

\subsection{Pozzolans}

The Greeks used volcanic ash as a cementitious material. The Romans continued its use and improved the technology. In fact pozzolan is derived from Pozzuoli, a city near a reputable source of weathered Mt. Visuvian ash. Although there are several sources of these natural pozzolans, the majority of those used today are by-products of industrial processes (Mindess et al. 2003). Common by-product pozzolans are fly ash (FA), silica fume (SF), ground granulated blast furnace slag (GGBFS), and rice husk ash (RHA), and calcined clays.

The primary purpose for using pozzolans in the formulation of UHPC is to improve the matrix hydration through pozzolanic reactions, compressive strength gain, bonding capabilities, rheology, as filler between cement grains, and replacements to portland cement (Richard and Cheyrezy 1995). The primary pozzolanic reaction introduces a source of silica, which reacts with calcium hydroxide $(\mathrm{CH})$ and hydroxides, to form the much stronger calcium silicate hydrates (CSH). Depending on the reactivity and composition of the pozzolan, secondary pozzolanic reactions may also occur (Mindess et al. 2003). In the case of highly reactive pozzolans, such as SF and RHA this leads to further improvement of the microstructure.

Historically, silica fume has been the primary pozzolan source for UHPC (Richard and Cheyrezy 1995). However, in the past decade there has been extensive research in using alternative pozzolans, including FA, GGBFS, RHA, and a calcined clay, metakaolin. The motivation for this is that silica fume is often expensive, and may be difficult to obtain in certain regions. In addition, the use of other pozzolans can reduce the environmental impact of concrete materials. A study looked at the environmental impact of ternary cementitious mixtures using variations of portland cement, silica 
fume, fly ash and GGBFS (Márquez et al. 2008). In comparing various mortar mix designs to a mix containing ordinary portland cement (OPC) it was possible to obtain concrete mix designs with comparable strengths and obtain a reduction in $\mathrm{CO} 2$ emissions up to $41 \%$.

Several other studies have looked at using compound cementitious mixtures (binary, ternary, and even quaternary) in UHPC (Laskar and Talukdar 2008; Longa et al. 2002; Peng et al. 2011; Yazıc1 et al. 2009; Yazıc1 et al. 2008). These studies showed that it is possible to obtain comparable, and in some cases better, results to mixes containing only SF and cement. Performance in using various pozzolans in UHPC mixtures depends on the reactivity, particle geometry (size, surface features, surface area), cement, and SP used in the mix (Laskar and Talukdar 2008).

\subsubsection{Silica Fume}

Silica fume (microsilica, or condensed silica fume) is typically a by-product of the silicon industry. However, it has been said that the best type of silica fume comes from the zirconia industry (Richard and Chayrezy, 1995). Silica fume is spherical in shape and is about 100 times smaller than the average cement particle, with an average diameter of 0.1 micrometer. Its fineness promotes the creation of a dense matrix structure, which is beneficial to the creation of high strength and low permeability concretes (Kosmatka et al. 2008). For UHPC it has been recommended for optimal particle packing and lime consumption (Richard and Chayrezy, 1995).

As stated in chapter 3, the interfacial transition zone (ITZ), is weak compared to the rest of the matrix. In early stages of hydration, the silica fume fills the regions near interfaces where the excess water resides. This leads to a reduction in the formation of $\mathrm{CH}$ in these regions, and consequently a denser ITZ due to the pozzolanic reaction (Goldman and Bentur 1986). Moreover, silica fume is a highly reactive pozzolan and therefore a secondary pozzolanic reaction will also occur (Mindess et al. 2003). The formation of CSH leads to a denser and stronger matrix, which improves the bond strength (Reda et al 1999). This has been confirmed by a study performing fiber pullout tests on fiber imbedded in concretes with various SF content (Chan and Chu 2004). The 
study showed that increasing the SF content increases the fiber bond strength and bond energy. Most improvement was seen with silica fume contents of $20 \%$ and $30 \%$ with respect to the cement content.

In addition to silica fume, silica flour or nano-silica can also be used to improve the reactivity of the material. Using silica flour along with silica fume under high temperature curing can lead to beneficial pozzolanic reaction (Reda et al. 1999).

\subsubsection{Fly Ash}

Fly ash is a by-product from the burning of coal in electric power plants, and is highly variable in particle size distribution and composition (Kosmatka et al. 2008). There are several classes of fly ash, however class $\mathrm{C}$ and class $\mathrm{F}$ are common additives for concrete. FA consists primarily of solid spheres, which range from 1 micrometer to 100 micrometers with only $10 \%$ to $30 \%$ being greater than 45 micrometers (Kosmatka et al. 2008).

With the replacement of silica fume with fly ash, a larger quantity of fly ash is required for comparable results. Hassan et al. (2000) has shown that a comparable high performance concrete (HPC) material can be obtained using 30\% fly ash replacement, whereas with silica fume only $10 \%$ cement replacement is required. Cement replacement with $20 \%$ fly ash improves packing ability of concrete and improves long term compressive strength, however increasing the replacement to $40 \%$ had less of an effect (Ha et al. 2012)

Fly ash develops slower than silica fume but tends to be comparable in permeability at later ages. However, compressive strength is less throughout the process (Hassan et al. 2000; Möser et al. 2010; Yazıcı et al. 2008). This low reactivity, which produces low amounts of reaction products at early ages, leads to a reduction in the heat of hydration and shrinkage (Yazici et al. 2008). The use of nano-limestone (CaCO3) and nano-silica ( $\mathrm{SiO} 2)$, have both been used to promote the use of fly ash as a replacement to portland cement as they exhibit high reactivity at early ages (Shah 2012). 
If the fly ash is used primarily as a partial replacement for cement, the low reactivity and spherical particles leads to an increased flow with constant water content (Laskar and Talukdar 2008; Möser et al. 2010). To develop a comparable rheology, the water and/or superplasticizer was decreased. However, when the fly ash is used as a replacement for silica fume or quartz flour the flow is decreased, which requires an increase in superplasticizer and/or water. This replacement of cement with fly ash leads to a decrease in the compressive strength. With the use of heat treatment it is possible to obtain higher compressive strengths. (Möser et al. 2010). In addition, FA improves flexural strength and toughness, while resulting in a decrease in modulus (Yazaci et al., 2009). Also, improvements in density have been seen with ternary cementitious mixtures using FA and SF with lower water to binder ratios (Longa et al. 2002).

\subsubsection{Ground Granulated Blast Furnace Slag}

GGBFS is a by-product of the steel industry during the manufacture of iron, and is typically ground to less than 45 micrometers. The grains are angular in shape with rough edges and hydrates similar to portland cement (Kosmatka et al. 2008). Its small surface area and slow reactivity lead to increased flow. To achieve flows comparable the mixes with SF, water content must be decreased. Comparable compressive strengths have been achieved with SF and a $15 \%$ replacement of cement. Higher replacement contents lead to a decrease in strength, whereas higher fineness led to lower flows and higher compressive strength (Möser et al. 2010). Results by Yazaci et al. (2008) found that similar to fly ash, GGBFS showed a reduction in the heat of hydration, shrinkage, and compressive strength. Later results showed improvements in flexural strength and toughness, but a decrease in Young's modulus (Yazaci et al. 2009).

\subsubsection{Rice Husk Ash}

RHA, as the name implies, is produced in the burning of rice husks. The typical particle sizes ranges from 5-10 micrometers with 90-96\% silica content, which leads to high reactivity (Van Tuan et al., 2011). Much of the RHA is produced in countries that are large rice producers, such as India (Laskar and Talukdar 2008). Van Tuan et al. (2011) found that with the use of RHA as a replacement to SF it is possible to produce 
comparable mixes, and even outperform SF mixes with increased fineness (3.6

micrometers). According to this research the optimum design was found using a ternary mixture of $10 \%$ RHA and $10 \%$ SF. In addition, the use of RHA increases the shear resistance and plastic viscosity of the fresh mix (increased flow), more so than fly ash (Ha et al. 2012; Laskar and Talukdar 2008). Improved compressive strength for ternary mixes with $20 \%$ FA and 10\% RHA compared to a mix with $20 \%$ FA and $10 \%$ SF at 28 and 56 days (Ha et al. 2012).

\subsubsection{Metakaolin}

Metakaolin is a highly reactive, just as with silica fume, and is used in cases when low permeability and high strength are desired (Kosmatka et al. 2008). Furthermore, it has been shown that a 1:1 replacement of silica fume with metakaolin UHPC can yield comparable flexural results for mixes with and without fibers and with and without ground quartz, regardless of thermal treatment (Tafraoui et al. 2009). Under thermal treatment, specimens with metakaolin results in a decrease in flexural strength for specimens without fibers and an increase when fibers are included when compared to similar mixes with SF. Also, if thermally treated, mixes with metakaolin tend to yield slightly higher results for compressive strengths (Tafraoui et al. 2009). If not thermally treated, the compressive results tended to be lower for mixes with metakaolin. (AlAzzawi et al. 2011; Tafraoui et al. 2009). Metakaolin also improves the rheology of the concrete with the addition of superplasticizer (Mansour et al. 2010). It should be noted that when using metakaolin as a replacement for silica fume the mixing time may be slightly increased (Tafraoui et al. 2009).

\subsection{Superplasticizer}

High range water reducers (HRWRA), also known as superplasticizers (SP), are added to UHPC mixes as dispersing and lubricating agents to increase fluidity (Bache 1987). For UHPC to achieve many of its desirable properties the w/b ratio is dramatically reduction (Roux et al. 1996). The use of superplasticizers is essential to obtain proper flow with this low water content, which can lead to particle cohesion (Bache 1987). Most water reducers belong to the following four polymer families: sulfonated 
naphthalene-formaldehyde (SNF) condensates, sulfonated melamine-formaldehyde (SMF) condensates, purified lignosulfonates, and carboxylated acrylic ester copolymers (polycarboxylates) (Mindess et al. 2003). According to previous work the superplasticizer for UHPC should be of polycarboxylate type (Schmidt 2003).

Polycarboxylate SPs offer high water reduction, and high flowability (Hirschi and Wombacher 2008). The rheology is highly dependent on the absorption of the SP by the silica fume (Schieß1 et al. 2010)), where reductions in silica fume content reduces the amount of SP required (Yazic1 et al. 2008). The addition of SF leads to lower permeability, and strength gains when compared to its high-slump high-strength concrete counterpart without SF. Without SF, large SP dosages can lead to less durable concretes, and lower compressive strengths. Also, compressive strength, flexural strength, air permeability, and Rapid Chloride Penetration are unchanged by SP dosages (Gagné et al. 1996).

\subsection{Reinforcement}

As mention in chapter 3, there are two types of reinforcement: discontinuous and continuous. Discontinuous reinforcement can be defined as either microscale reinforcement or macroscale reinforcement (Rossi 2001). Continuous reinforcement usually consists of reinforcing bars or prestressing strands.

\subsubsection{Discontinuous Reinforcement}

Microscale reinforcement is used primarily to control and stabilize microcracking, which can lead to more uniform energy dissipation. This has been demonstrated with the use of large amounts of carbon and alumina fibers. In addition to crack stabilization, the addition of micro-fibers also increases the strength of the material (Mobasher and $\mathrm{Li}$ 1996). These microfibers tend to be ineffective once an unstable crack initiates, which requires the use of longer fibers (Mobasher and Li 1996; Rossi 2001). Micro-particles, such as wollastonite or mica flakes can also be added to improve matrix toughness, and reactive fillers or polymer modifiers can be used to improve bond strength (Orange et al. 2000). 
The addition of macroscale reinforcement prevents and controls macrocracks in the matrix, as well as improves the flexural strength and toughness of the composite (Orange et al. 2000; Rossi 2001; Tafraoui et al. 2009). The length of the fibers must be enough so that the fibers are properly anchored to the matrix (Rossi 2001). These fibers are added between $1.5 \%$ and $3 \%$ by volume, but for economic reasons $2 \%$ is typically used (Richard and Cheyrezy 1995). Fibers for UHPFRC mixtures come in a variety of materials which include steel fibers (Richard and Cheyrezy 1995; Orange et al. 2000), high modulus polyvinyl alcohol (PVA) (Orange et al. 2000), and polypropelene (Schmidt et al. 2003). The ability of the fibers to control cracks depends on the embedment length and bonding characteristics (Rossi 2001). With steel fibers the best way to improve bonding is through surface roughening by means of chemical modifications or abrasion (Orange et al. 2000; Stengel 2009). PVA fibers on the other hand, chemically bonds to the matrix through the formation of organo-mineral polymercement hydrates (Orange et al. 2000). The use of deformed fibers is another way to improved peak load and pull-out work (Hamoush et al. 2010). For steel fibers of $26 \mathrm{~mm}$ in length, (Ju et al. 2009) has shown, based on pull-out tests, that that the bond strength peaks at a certain fiber percentages between $1 \%$ and $3 \%$. Bond strengths varied from $0.9 \mathrm{MPa}$ to $1.5 \mathrm{MPa}$ depending on the fiber content. The optimum peak load at first crack occurred at $1 \%$ fiber content and ultimate pullout force occurred at $2 \%$ fiber content. Based on polynomial regression it was concluded that bond performance was maximized at fiber volume of $1.5 \%$.

The addition of fibers improves ductility, but has little effect on the strength of the material in compression of UHPFRC materials (Rossi 2001), a concept that has been backed by previous research (Peuse 2008). However, others have concluded that the addition of fibers compared to unreinforced UHPC materials leads to an increase in compressive strength (Richard and Cheyrezy, 1995; Tafraoui et al. 2009). The best explanation for this is that fibers stabilize compressive stresses by means of internal confinement (Bache 1987). Work by Azzawi (2011) concluded that increasing the fiber content from $1 \%$ to $2 \%$ increased the strength by $5 \%$. 
It is the general consensus that the fibers will tend to align with the flow of the UHPC (AFGC and SETRA 2002). However, work by Barnett et al. (2009)showed that in the case of discs fibers tended to align perpendicular to the flow of the concrete. In any case, fiber orientation must be considered during structural design as it has important consequences on the strength and ductility of the composite (Barnett et al. 2009; Schmidt and Fehling 2005).

\subsubsection{Continuous Reinforcement}

The addition of continuous reinforcement to UHPC materials, whether in the form of reinforcing bars or prestressing strands, can lead to increased moment capacity (Bache 1987). UHPC's high compressive strength allows for a considerable amount of prestressing force to be added, which can further increase the moment capacity of the material (Steinberg and Lubbers 2003). In addition to adding moment capacity, continuous reinforcement is added to induce multiple cracking. The reinforcement ties together and transfers stress to sections of the beam that may normally be relieved in the occurrence of a fracture. The result is multiple cracking, which allows for larger deflections to be achieved before member failure (Bache 1987). Multiple cracking was observed with the use mild steel reinforcing bars (Yang et al. 2010) and high strength steel prestressing (Graybeal 2008). These cracks have been observed as being densely spaced and of small width (Graybeal, 2008).

Reinforced Concrete is designed so that the steel is allowed to yield. In the case of NSC, the design is limited and must account for cracking prior to yielding of the steel, because of the materials small strain capacity. The ductility of UHPFRC is increased and will allow for yielding of the steel at the development of a centralized crack (Bache, 1987). With reinforcing bars the yielding can occur using low reinforcement ratios (Yang et al. 2010). In addition the failure of prestressed UHPFRC girders was initiated by fiber pullout. After pullout the stress carried by the fibers was transferred to

the prestressing. Shortly after the added stress ultimately lead to strand failure. The use of fiber reinforcement can lead to the reduction or even the elimination of shear reinforcement (Graybeal 2006). Additionally, continuous reinforcement should be 
spaced in such a way so as not to block the flow of fibers, which may result in fiber congregation. A spacing of at least two times the fiber length has been suggested (Yang et al. 2010).

\subsection{Curing}

According to research by Habel et al. (2006)on the mechanical development of a UHPFRC under ambient conditions, the onset of hydration did not start until 26 hours after the addition of water, which was hindered by the use of superplasticizer. The mechanical properties began to develop 32 hours after the addition of water, and was 99\% completed after 90 days, whereas, the hydration of NSC can last for decades following the initial mix date. The development of flexural properties was slower than compressive properties, which is reverse from what is known about conventional concrete. Development of compressive strength is similar to that of NSC, but development of stiffness (secant modulus) is slower. Also, the fracture energy develops at a slower rate than that of NSC, which can be associated to the enhanced development of the ITZ with the use of pozzolans (silica fume). Other research shows that the mechanical properties of UHPC can be further improved through the use of thermal treatment and/or the addition of pressure (Richard and Cheyrezy 1995).

\subsubsection{Thermal Treatment}

Thermal treatment is applied during curing to improve the micro-structure of the matrix (Richard and Cheyrezy 1995). This is usually done in addition to a water bath (Yang et al. 2009) or a steam treatment within an enclosed chamber (AFGC and SETRA 2002). It is possible to achieve higher compressive strengths, higher flexural strength, and higher fracture energies with the use of thermal treatment compared to ambient conditions (Yang et al. 2009). Thermal treatment also shows improved results of $10 \%$ or more compared to curing in water bath (AFGC and SETRA 2002; Yazici 2009). Work by Richard and Cheyrezy (1995) showed that with curing temperatures up to 90 ${ }^{0} \mathrm{C}$, it is possible to achieve compressive strengths ranging from $170-230 \mathrm{MPa}$, flexural strengths from 30-60 MPa, and fracture energies in the range of 1,200-40,000 J/m². Similar results using the same curing process was achieved by Yang et al. (2009). 
Higher temperatures lead to higher bound water content, increased pozzolanic reactivity and decreased porosity, which leads to a favorable microstructure (Cheyrezy et al. 1995). Reda et al. (1999) reported that the reduction in $\mathrm{CH}$ due to increased pozzolanic reactivity by elevated temperatures eliminated the ITZ. This important finding means that the weak region near the inclusion for UHPC materials undergoing heat treatment is at the interface and not within the matrix, which leads to improved bonding. As pointed out by Kollmorgen (2004) and according to the AFGC and SETRA (2002), thermal treatment should be done after primary ettringite formation so as not to promote delayed ettringite formation, which can lead to detrimental expansion and cracking (Taylor 1997). However, Cheyrezy et al. (1995) did not observe the formation of ettringite as the cement used contained low amounts of $\mathrm{C}_{3} \mathrm{~A}$ and low water cement ratio.

\subsubsection{Pressure Treatment}

As stated by Rossi (2001), by the 1960s compressive strengths greater than $600 \mathrm{MPa}$ could be achieved using an autoclave process. Pressure is often added during curing, which improves particle packing and microstructure through the removal entrapped air, reduction of excess water, and elimination of chemical shrinkage effects (Richard and Cheyrezy 1995).

Cheyrezey et al. (1995) showed that at temperatures between $20-65{ }^{\circ} \mathrm{C}$ the addition of pressure primarily eliminates entrapped air and some free water, but has little effect on the cumulative porosity. At $80-200{ }^{\circ} \mathrm{C}$ lower porosity was obtained by the addition of pressure. However, if specimens are cooled to room temperature from $200{ }^{\circ} \mathrm{C}$ an expansion of the material was observed, which was not caused by cracking. This phenomenon can be most likely attributed to the formation of a low density hydrate (tobermorite or low density $\mathrm{CSH}$ ). For temperatures greater than $250{ }^{\circ} \mathrm{C}$ the porosity is increased due to the formation of xonotlite. The formation of xonotlite requires less water than $\mathrm{CSH}$, which leads to unused water. It was determined that the minimum porosity under pressure treatment was achieved at heat treatments between $150{ }^{\circ} \mathrm{C}$ and $200{ }^{\circ} \mathrm{C}$. Simultaneous work by Richard and Cheyrezy (1995) showed that autoclaving 
at a temperature of $250{ }^{\circ} \mathrm{C}$ to $400{ }^{\circ} \mathrm{C}$ can achieve compressive strengths of $490-680$ MPa using quartz aggregates and 650-810 MPa using steel aggregates, with flexural strengths from 45-141 MPa, and fracture energies up to $20 \mathrm{~kJ} / \mathrm{m}^{2}$. Furthermore, Richard and Cheyrezy concluded that UHPC structures undergoing pressure treatment can be up to 3 times lighter than those that did not undergo pressure treatment.

Although thermal treatment and autoclaving have demonstrated remarkable improvements on the material and physical characteristics of UHPC or UHPFRC materials, ambient temperatures may be more applicable and more acceptable for design as it does not require the use of thermal chambers or pressure vessels, which are difficult to use for large elements (de Lerrard and Sedran 1994; Yang et al. 2009). It is important to note that even without these laboratory devices it not difficult to produce results that exceed that of HPCs or FRCCs (Table 1.1, Chapter 1).

\subsection{Fracture}

In regards to material behavior it is well known that as the strength of a material increases the ductility of that material decreases. To improve ductility it is common practice to incorporate fibers in the design of UHPC members (Rossi 2001). Xiao et al. (2004) performed a wedge splitting fracture test on an unfibered ultra high strength concrete (UHSC) with a compressive strength above $140 \mathrm{MPa}$. The results of testing showed an increased brittle nature leading to high compressive and tensile strengths, but little improvement to fracture energy compared to high strength concretes (HSC). As mentioned in the previous section, work by Richard and Cheyrezy (1995) on unfibered and fibered UHPC found that it was possible to obtain fracture energies ranging from 20,000 to 40,000 J/m². Under similar curing conditions Yang et al. (2009) found that fracture energies of UHPFRCs with various aggregates ranging from 15,000 to $25,000 \mathrm{~J} / \mathrm{m}^{2}$ and Habel et al. (2006) found that after complete hydration the fracture energy was less than $25,000 \mathrm{~J} / \mathrm{m}^{2}$.

Research by Orgass and Klug (2004) found that the split tensile and flexural strengths increased with increasing fiber contents from $0 \%$ to $2 \%$. The increase for flexural 
specimens was found to be linearly related to the fiber content. In addition this research confirmed the size effect for flexural specimens and showed that the flexural strength increased with the omission of large aggregates. By increasing the fiber content from 0$5 \%$, the flexural and tensile strengths of $100 \mathrm{~mm}$ x $100 \mathrm{~mm} \times 300 \mathrm{~mm}$ UHPC prisms were shown to increase linearly with fiber volume (Kang et al. 2010). This research also showed that the rule of mixtures is applicable for UHPFRC. Stengel (2009) found that the highest fracture toughness was obtained using $2.2 \%$ fibers with $0.18 \mathrm{~mm}$ diameter and low aspect ratio (33) than for high aspect ratio (100) large diameter $(0.4$ $\mathrm{mm}$ ) undulated fibers. Large diameter straight fibers showed lowest fracture toughness, and hooked steel fibers showed comparable fracture toughness to straight fibers. Furthermore, it should be noted that there is difficulty in mixing deformed fibers as they tend to interlock during mixing.

The method of placement method is important to the flexural and fracture properties of the material as it affects the flow of UHPC (Section 4.7.1). (Ryu et al. 2010) found that the flexural first crack strength was not dependent on placement method, whereas, the ultimate flexural strength was dependent. The best results occurred when the flow was in the direction of bending and the worst case occurred when the flow was orthogonal to the direction of bending. This also applies to UHPC beams with longitudinal reinforcement. It was determined that if the material was placed at one end of the beam, rather than at the center, then it was possible to achieve higher moment capacities (Yang et al. 2010).

The use of pressure during curing (autoclaving) can also lead to improved mechanical behavior. İpek et al. (2012) found that with an increase in pressure during curing the first crack strength, ultimate flexural strength, and fracture toughness also increased (İpek et al. 2012). In addition, the use of pressure treatment eliminates cracking due to chemical shrinkage by inducing the fracture of rigid bonds, which creates microcracks that are later healed as the specimen cures (Richard and Cheyrezy 1995). 


\subsection{Model}

A possible design method developed by the French Association of Civil Engineers has been at the forefront of UHPFRC design in Europe (AFGC and SETRA 2002). This design procedure is based on French design codes and requires knowledge of the elastic and fracture curve, which is modelled using a multi-linear relationship. For strain hardening, this relationship is shown in Figure 4.1.

This method requires testing to determine estimate the $\sigma$-w relationship. The testing procedure is outlined in the document; however it will not be discussed, as it is similar to the testing method presented in chapter 2 . Once testing is completed the stress can be estimated, which is done using an iterative process, as outlined in AFGC and SETRA (2002). After the stress is obtained the first-crack stresses of bending tests are often normalized so that they match with the results of tensile tests. This is done using equation 4.1

$f_{t}=f_{f} \frac{2\left(\frac{h}{h_{o}}\right)}{\left(1+2\left(\frac{h}{h_{o}}\right)\right)^{0.7}}$

Equation 4.1

Where $f_{t}$ is the tensile stress to be calculated, $f_{f}$ is the measured flexural first-crack stress, $h_{o}=100 \mathrm{~mm}$, and $h$ is the height of the beam tested.

The calculated stresses and measured crack openings are then used to develop a curve shape. According to this analysis the first crack occurs at an elastic strain equal to

$\varepsilon_{e}=\frac{f_{t j}}{E_{i j}}$

Equation 4.2

Where $f_{t j}$ is the stress at first crack, and $E_{i j}$ is Young's modulus of the material. 


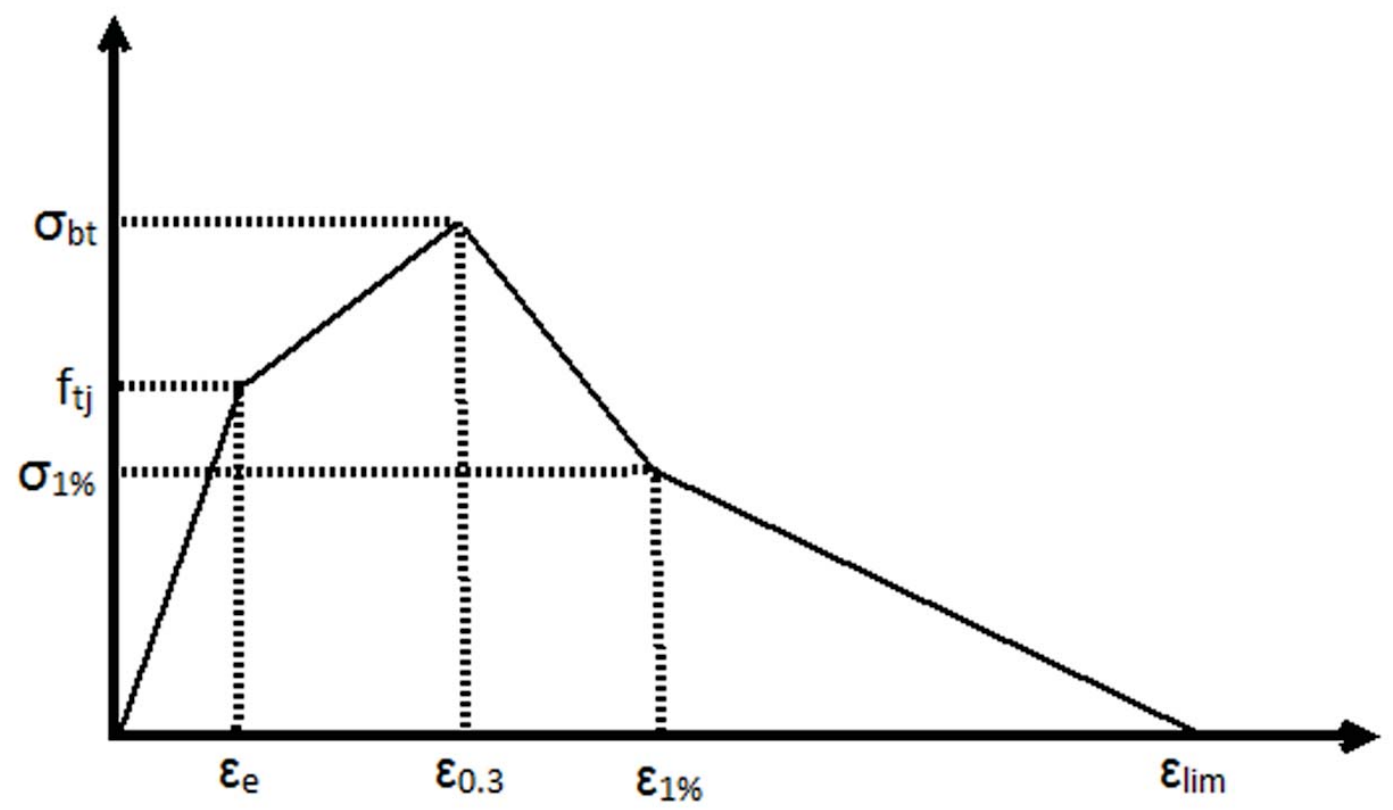

Figure 4.2: AFGC/SETRA strain hardening curve for UHPFRC

The ultimate load, $\sigma_{\mathrm{bt}}$, occurs at a crack mouth opening displacement (CMOD) value of $0.3 \mathrm{~mm}$. The stress at a CMOD of $0.01 \mathrm{H}$, where $\mathrm{H}$ is the height of the tested prism, is termed $\sigma_{1 \%}$, as shown in Figure 4.1. The value of $\varepsilon_{\text {lim }}$ can be found using Equation 4.3.

$\varepsilon_{\text {lim }}=\frac{l_{f}}{4 l_{c}}$

Equation 4.3

The characteristic length, $l_{c}$, can be estimated as $\frac{2}{3} h$, where $\mathrm{h}$ is the depth of the section. In Equation $4.3, l_{f}$, is the length of the fiber. 



\section{Experimental Methodology}

\subsection{Testing Plan}

The intended goal of this research is to develop a model to describe the mode I fracture behavior of a steel fiber reinforced ultra-high performance concrete (UHPC). All research was performed using a Ductal@ brand BS1000 UHPFRC material with high strength steel fiber reinforcement. Fibers were $12.5 \mathrm{~mm}$ in length and around $200 \mu \mathrm{m}$ in diameter.

Based on the information covered in chapters 2,3, and 4 it was decided that the fracture behavior may be affected by five variables; curing regime, specimen age, fiber content, and two different volume changes. To test these parameters, a series of single edge notch prisms (SENPs) were tested using a crack mouth opening displacement (CMOD) controlled three point bend test. In addition, compression testing was performed for quality assurance of mix consistency and as a reference to previous work. In the testing of fracture the flexure test was preferred over other types of tests, because of its acceptance in testing the mode I fracture of fiber reinforced cementitious composites fiber reinforced cementitious composites (FRCCs) (RILEM TC 162-TDF 2002). Also, the simplicity in the casting on preparation of SENP's allowed for ease of conduction in a laboratory setting.

\subsection{Research Regime}

Each specimen was categorized based on the type of curing, the age, the amount of fibers, test, and size. Figure 5.1 shows a tabulated depiction which organizes these variables with respect to the compression and SENP specimens to be tested. For curing, three types were used based upon previous work (Peuse 2008), which are as follows; ambient (A), thermally treated (TT), and delayed thermally treated (DTT). Next, with respect to the age, testing was conducted at 3, 7, 28, and 56 days for A curing, 7 and 28 days for TT, and 28 days for DTT. The compression specimens were 3 in $(76 \mathrm{~mm})$ diameter and 6 in $(152 \mathrm{~mm})$ high $(3 \times 6)$ cylinders tested at 28 days, 7 days, and 28 days for A, TT, and DTT curing regimes, respectively. 
Based on the size of prisms tested in previous research (Graybeal 2005; Kollmorgen 2004; Peuse 2008) it was decided that that notched prisms with a width of $51 \mathrm{~mm}(2$ in.), depth of $51 \mathrm{~mm}$ ( 2 in.) and span of $229 \mathrm{~mm}$ (9 in.) would be the most comparable to these studies. From this size the specimens of variable length were tested. The length increased from $229 \mathrm{~mm}$ (9 in.) to $343 \mathrm{~mm}$ (13.5 in.), $457 \mathrm{~mm}$ (18 in.), and 696 $\mathrm{mm}$ (27.5 in.). In order to simplify the presentation of the results, the change in length was reported as a span-to-depth ratio, which is the span divided by the beam depth. For the above lengths these values are 4.5 for the reference prism, and $6.75,9$, and 13.75 for the others, respectfully. Also, a change in depth and width with constant S/D ratio was tested, in which case the depth and width were increased from $51 \mathrm{~mm}$ (2 in.) to 76 $\mathrm{mm}$ (3 in), while the S/D remained 4.5. Furthermore, Figure 5.1 shows a layout of all the specimens tested, where, $X$, represents specimen to be tested and, - , represents specimen that would not tested. The reason that all prism types and compression cylinders were not tested was that the undertaking would be too large for the scope of the project. Compression cylinder were only tested at 28 days for ambient curing, 7 day for thermal treatment and 28 day for delayed thermal treatment based on the findings of previous research that found that by these ages UHPC has achieved most of its compressive strength (Habel et al. 2006; Peuse 2008). For the most part all SENPs with $2 \%$ fibers were tested, as $2 \%$ is a common fiber percentage for UHPFRC, and is recommended by LaFarge North America for Ductal ${ }^{\circledR}$. For $1 \%$ and 2 fiber contents, the prisms were only tested only a selection of the prisms were tested in order to make general conclusions about the effect of fibers on the variables tested. For $0 \%$ fibers only one specimen type was tested, which allowed for conclusions to be made about the matrix material. The following section will describe in more depth the prisms and the tested parameter. 
Table 5.1

Research regime

\begin{tabular}{|c|c|c|c|c|c|c|c|c|}
\hline \multirow[b]{2}{*}{ Curing } & \multirow[b]{2}{*}{ Age } & \multirow[b]{2}{*}{$\begin{array}{c}\text { Fibers } \\
(\%)\end{array}$} & \multirow[b]{2}{*}{$\begin{array}{c}\text { Compressive } \\
{[\mathrm{C}]}\end{array}$} & \multicolumn{5}{|c|}{ Notched Prism [NP] } \\
\hline & & & & $2580-4.5$ & $2580-6.75$ & $2580-9$ & $5180-4.5$ & $\begin{array}{l}2580- \\
13.75\end{array}$ \\
\hline \multirow{16}{*}{$: \exists$} & \multirow{4}{*}{3} & 0 & - & $\mathrm{X}$ & - & - & - & - \\
\hline & & 1 & - & $X$ & - & $X$ & $\mathrm{X}$ & - \\
\hline & & 2 & - & $X$ & $\mathrm{X}$ & $X$ & $\mathrm{X}$ & $\mathrm{X}$ \\
\hline & & 3 & - & $X$ & - & $X$ & $X$ & - \\
\hline & \multirow{4}{*}{7} & 0 & - & $X$ & - & - & - & - \\
\hline & & 1 & - & $X$ & - & - & - & - \\
\hline & & 2 & - & $\mathrm{X}$ & $\mathrm{X}$ & $\mathrm{X}$ & $\mathrm{X}$ & - \\
\hline & & 3 & - & $\mathrm{X}$ & - & - & - & - \\
\hline & \multirow{4}{*}{28} & 0 & $\mathrm{X}$ & $X$ & - & - & - & - \\
\hline & & 1 & $X$ & $X$ & - & $X$ & $X$ & - \\
\hline & & 2 & $X$ & $X$ & $X$ & $X$ & $X$ & $X$ \\
\hline & & 3 & $X$ & $X$ & - & $\mathrm{X}$ & $\mathrm{X}$ & - \\
\hline & \multirow{4}{*}{56} & 0 & - & $X$ & - & - & - & - \\
\hline & & 1 & - & $X$ & - & - & - & - \\
\hline & & 2 & - & $X$ & $X$ & $X$ & $X$ & - \\
\hline & & 3 & - & $X$ & - & - & - & - \\
\hline \multirow{8}{*}{ 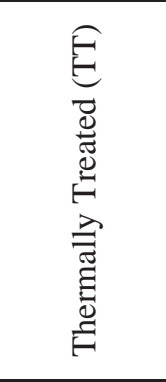 } & \multirow{4}{*}{7} & 0 & $X$ & $X$ & - & - & - & - \\
\hline & & 1 & $X$ & $X$ & - & $X$ & $\mathrm{X}$ & - \\
\hline & & 2 & $X$ & $X$ & $X$ & $X$ & $X$ & $X$ \\
\hline & & 3 & $X$ & $X$ & - & $X$ & $X$ & - \\
\hline & \multirow{4}{*}{28} & 0 & - & $X$ & - & - & - & - \\
\hline & & 1 & - & $X$ & - & - & - & - \\
\hline & & 2 & - & $X$ & $X$ & $X$ & $X$ & - \\
\hline & & 3 & - & $X$ & - & - & - & - \\
\hline \multirow{4}{*}{ 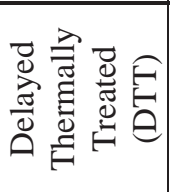 } & \multirow{4}{*}{28} & 0 & $X$ & $X$ & - & - & - & - \\
\hline & & 1 & $X$ & $X$ & - & - & - & - \\
\hline & & 2 & $X$ & $X$ & $X$ & $\mathrm{X}$ & $X$ & - \\
\hline & & 3 & $\mathrm{X}$ & $X$ & - & - & - & - \\
\hline
\end{tabular}

\subsection{Parameters}

The mentioned parameters were specifically chosen in regards to the flexural fracture behavior and not intended to change the compressive strength. Any change in the compressive strength, if noticed, was unintentional and coincidental. Compressive tests will be discussed in section 5.3. The following explanation of these parameters is devoted exclusively to prisms. 


\subsubsection{Fiber Content}

As was mentioned earlier in chapter 3, the strength of FRCCs is dependent on the matrix component and the fiber component. In this study, the percent of fibers by volume were varied from the normal $2 \%$ to include $0 \%, 1 \%$, and $3 \%$. It was suspected that as the fiber content increased, the strength of the prism would increase as well.

\subsubsection{Volume Effects}

Based on the well-established volume effect in brittle materials, it was anticipated that as the specimen volume increased, the strength in the specimen would decrease.

Therefore, two types of volume changes were tested. One was an increase in the span and the other was an increase in the cross sectional area. As the span was increased, the cross sectional area stayed a constant 2 in. $x 2$ in. (51 mm x $51 \mathrm{~mm})$, which increased the span to depth ratio. The 4 spans used were $229 \mathrm{~mm}$ (9 in.) to $343 \mathrm{~mm}$ (13.5 in.), 457 $\mathrm{mm}$ (18 in.), and $696 \mathrm{~mm}$ (27.5 in.), which gave span to depth ratios of 4.5, 6.75, 9, and 13.25, respectfully. The cross section was tested by increasing from $51 \mathrm{~mm}$ ( 2 in) to 76 $\mathrm{mm}$ (3 in), while maintaining a span to depth ratio of 4.5. For labeling purposes these changes were recorded according to the beams area in $\mathrm{mm}^{2}$ and span as 2580-4.5, 2580$6.75,2580-9,2580-13.25,5180-4.5$, which are ordered left to right in Table 5.1 from smallest volume to largest volume. It should be noted that the depths specified were for labeling purposes, because once a beam was notched the depths at the midsection decreased, which increased the span to depth ratio and decreased the prism depth just above the notch. The single notch was nominally $10 \%$ the prism height, for a prism height of $51 \mathrm{~mm}$ this decreased the depth to about $46 \mathrm{~mm}$. 


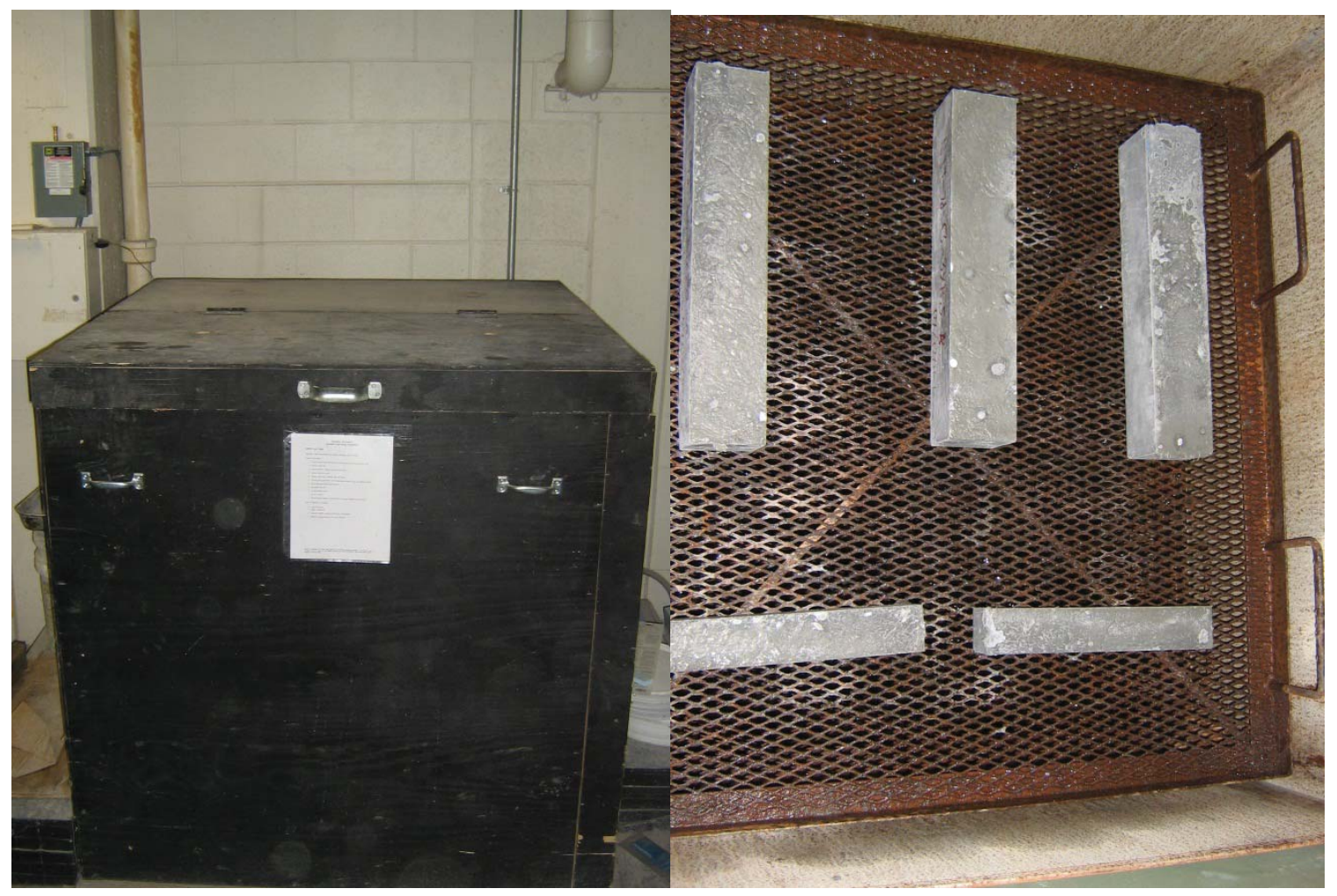

Figure 5.1: Curing chamber: external view (left) and internal view (Right)

\subsubsection{Curing}

Ambient cured specimens, after a 3 day in mold initial cure, were cured at room temperature until testing. Thermally treated specimens (TT) were cured in a steam chamber (Figure 5.1) at a temperature of $90{ }^{\circ} \mathrm{C}\left(194{ }^{\circ} \mathrm{F}\right)$, and roughly $100 \%$ humidity for 48 hours. This cure was preceded by a 6 hour ramp period starting at room temperature and climbing at a rate of $11.2{ }^{0} \mathrm{C} / \mathrm{hr}\left(20{ }^{0} \mathrm{~F} / \mathrm{hr}\right)$. Following the 48 -hour steam treatment, the chamber was shut down (2 days and 6 hrs after initial start) and specimens were left to cool overnight. After thermal treatment, specimens underwent ambient curing until the day of testing. The delayed thermally treated followed the same thermal treatment, but were treated 7 days after the initial cure, for a total of 10 days after mixing, and then cured under ambient conditions until testing. 


\subsubsection{Specimen age}

The control specimens, reference specimens and all other specimens with $2 \%$ fibers excluding the 2580-13.25prism were tested under ambient curing, thermal treatment, and delayed thermal treatment. Ambient specimens (A) were tested at 3, 7, 28, and 56 days, TT specimens were tested at 7 and 28 days, and DTT specimens were tested at 28 days. 2580-9 and 5180-4.5 specimens with $1 \%$ and 3\% fibers and 51(2)-13.25 specimens with $2 \%$ fibers were tested at 3 and 28 days for A, 7 days for TT, and 28 days for DTT.

\subsection{Specimens and Testing Preparation}

\subsubsection{Labeling}

All specimens had a primary and secondary label, which was as follows.

\section{Primary: Test -Curing-Age-Fiber Content-Area-S/D-Letter}

Secondary: Date of mix-daily batch number

where tests were labeled as C for compression, and NP for notched prism. The curing regime was shortened for ambient, thermally treated, and delayed thermally treated to A, TT, and DTT, respectfully. The age of the specimens were recorded by the testing age followed by a $d$ for days. Fiber content was labeled with the percentage of fibers used, without the percent sign, preceded by an f for fibers. Only prisms were designated with a depth and S/D value, compression cylinders had no label for the size, as all cylinders were the same. Ending the primary label was a letter A-Z to set the specimen apart from the others having the same variables. Following this primary label, a secondary label was used to keep track of when the specimen was cast and the daily batch number, which assisted in keeping track of the day that the specimen should be tested.

As an example, if a first time thermally treated $2580-4.5$ notched prism with $2 \%$ fibers, which was to be tested at 28 days was cast after the second batch on April 1, 2011, after the initial cure it would be labeled as: 


\subsubsection{Molds}

To complete this research several different mold sizes were used (Figure 5.2). All cylinder molds conformed to ASTM C470 (ASTM C 470 2008), and all prism molds conformed to ASTM C192 (ASTM C 192 2007). All prism molds were timber except for the 51 (2)-4.5 molds, which were made of steel. All pieces for timber molds were measured with a level to ensure that they were straight and securely fastened together in such a way to prevent bending due to the wet UHPC pushing on the sides during the initial cure process. It was noticed early on that if the wood was not coated to prevent leeching of moisture from the wet UHPC to the wood, that a dry area about a $1 / 16^{\text {th }}$ of an inch around the perimeter of the prism would develop. Therefore, all wood molds were coated with polyurethane_and dried prior to casting.

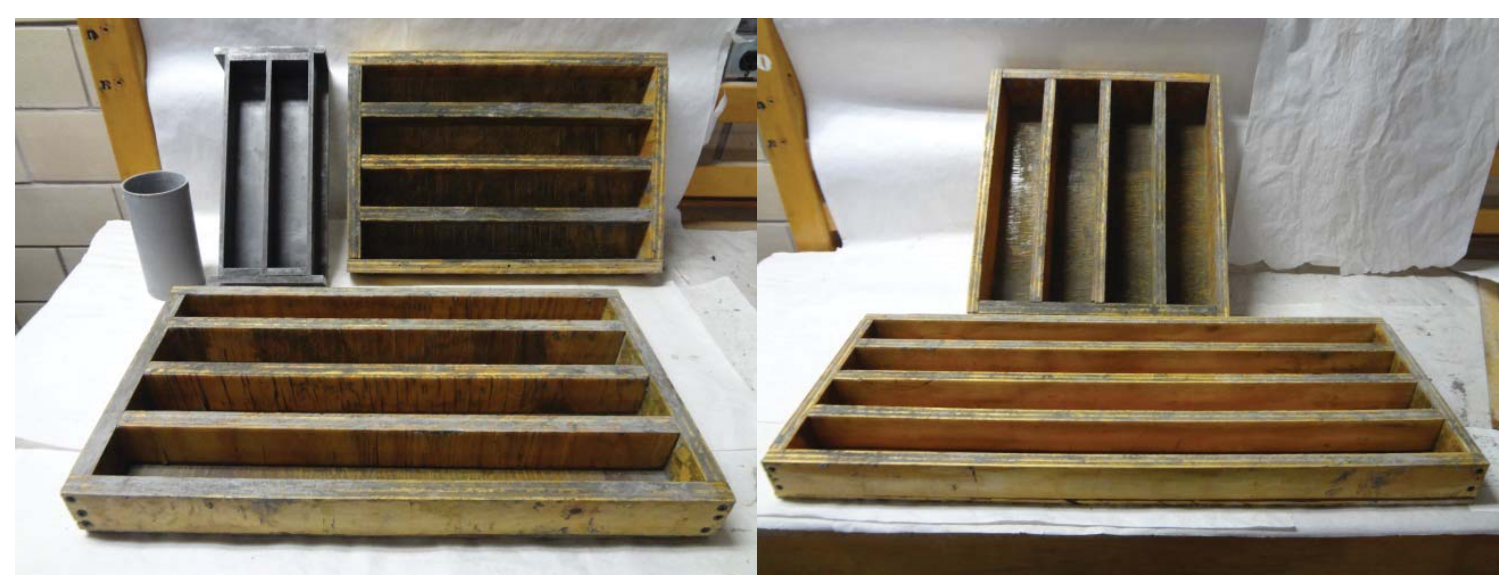

Figure 5.2: Molds: compression, 2580-4.5 prism, 2580-6.75 prism, 2580-9 prism, (left) , 5180-4.5 prism, 2600-13.25 prism (right) 


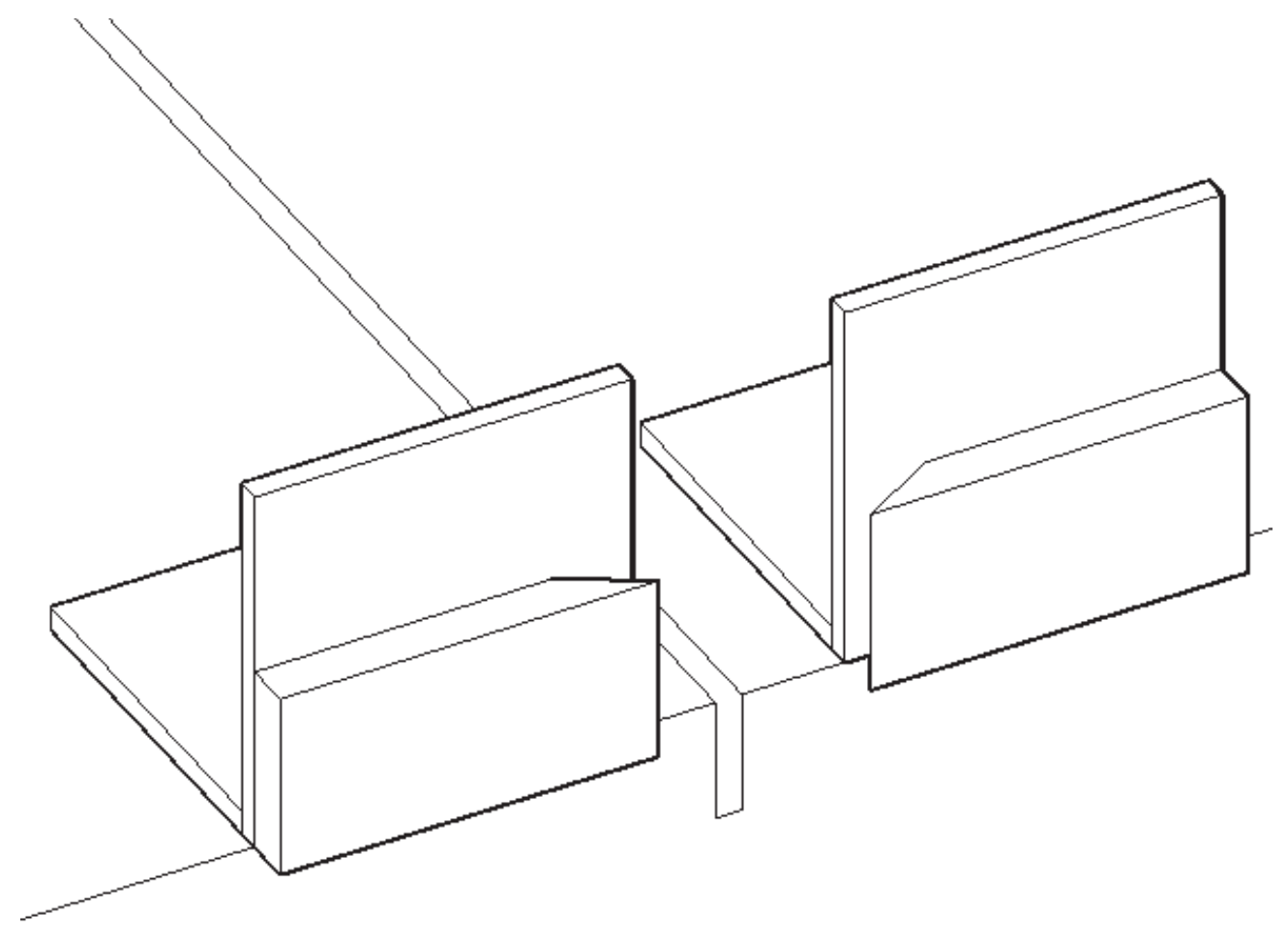

Figure 5.3: Knife edges setup

\subsubsection{Extensometer}

Knife edges as shown in Figure 5.3, were used to attach the extensometer to the beam. The dimensions of these were $1 / 4$ " $\times 1 / 16 " \times 1 / 2 "$, with a cut that is no more than 30 degrees to ensure that the extensometer could be properly attached. These were attached to an $\mathrm{L}$ bracket, which was later adhered to the prisms.

The CMOD was measured by an Epsilon brand clip on extensometer, as shown in Figure 5.4, with a $12 \mathrm{~mm}$ tensile range, a $2 \mathrm{~mm}$ compression range, and a gauge length of $20 \mathrm{~mm}$. On the end of the clip gauge, as it is commonly referred to, were grooves which prior to the test were set on to the knife edges and gauge arms were placed so that they butted up to the bottom edge of the beam. The gauge was protected in case of 
failure by stringing the wire which connected it to the machine in an elevated position so that if the prism were to fail abruptly the gauge would swing out from harm's way, which came in handy while testing prisms with $0 \%$ fibers. To maintain a level position as the testing progressed the gauge was strung in such a manner that it was tensioned enough so that it prevented gravitational effects, but not so much that it did not prevent the gauge from moving downward with the prism as it bent during the fracture process. It should be noted that in this set up it was assumed that the gauge arms were ridged in the short direction, and therefore since the gauge was in direct contact with the beam it directly measure the crack mouth opening displacement (CMOD). Also, the CMOD measurement was taken to be constant across the entire length of the notch mouth.

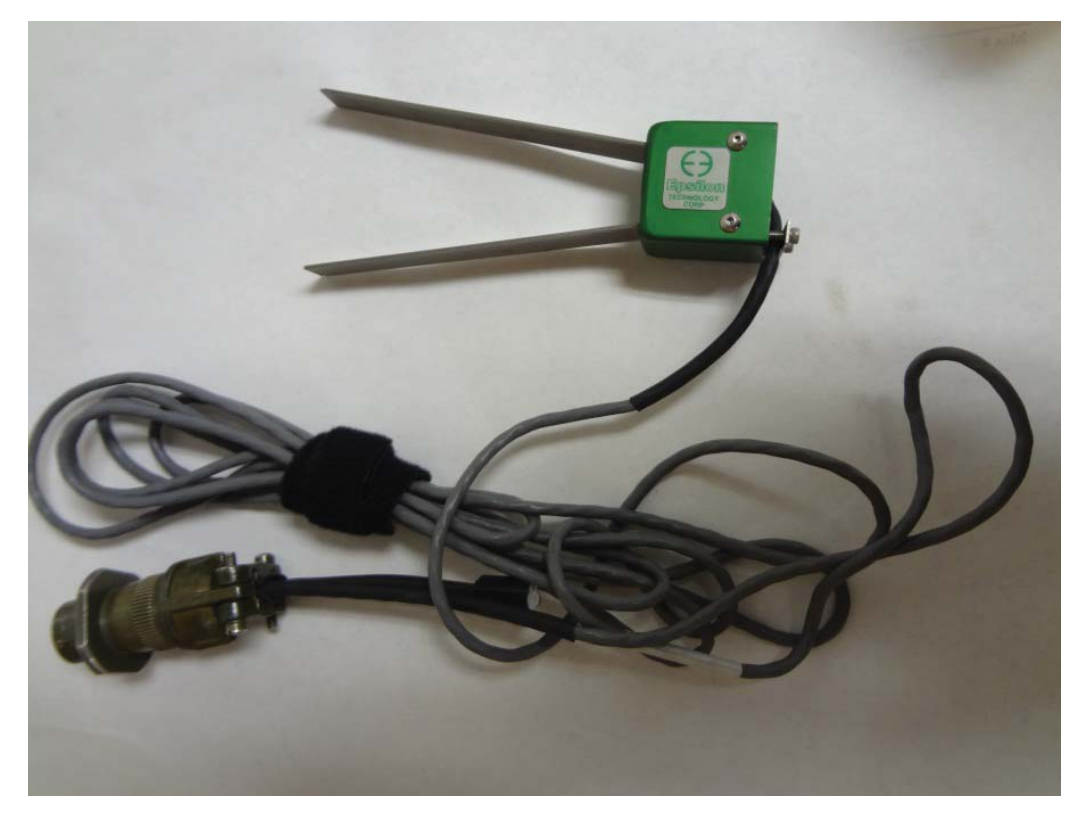

Figure 5.4: COD gauge

\subsubsection{Mixing, Casting, and Curing}

Mixing was done following a procedure and described in Kollmorgen (2004), which was suggested by LaFarge North America. After mixing a flow test was run in accordance to Ductal ${ }^{\circledR}$ Reference T 006: Operating Procedure Flow Test (Ductal® reference T 006). This test is used to verify the rheology of the mix, and is reported as a flow measurement in millimetres. 
Compression cylinders were cast according to previous work (Kollmorgen 2004, Peuse 2008). Fracture prisms were tested in a similar manner as those same works. Prisms were cast by filling the mold from one end, which due to UHPC's flowable rheology allowed the mix to travel to the opposite side (Figure 5.5). This procedure was performed in two equal volume lifts, after each lift the mix was vibrated for a short amount of time to release any entrapped air. A vibration time of 0-to-10 seconds was used, because during preliminary mixing it was noticed that if the vibration exceeded 10 seconds the fibers would settle and their distribution in the matrix would favor the bottom edge of the prism. Casting was done in this manner in an attempt to align the fibers in a one dimensional orientation along the length of the prism.

(a)

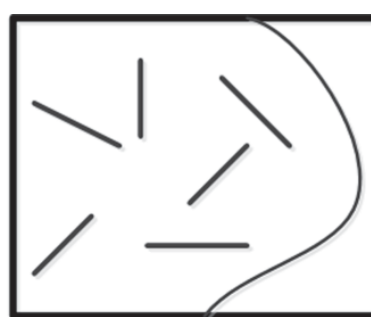

(b)
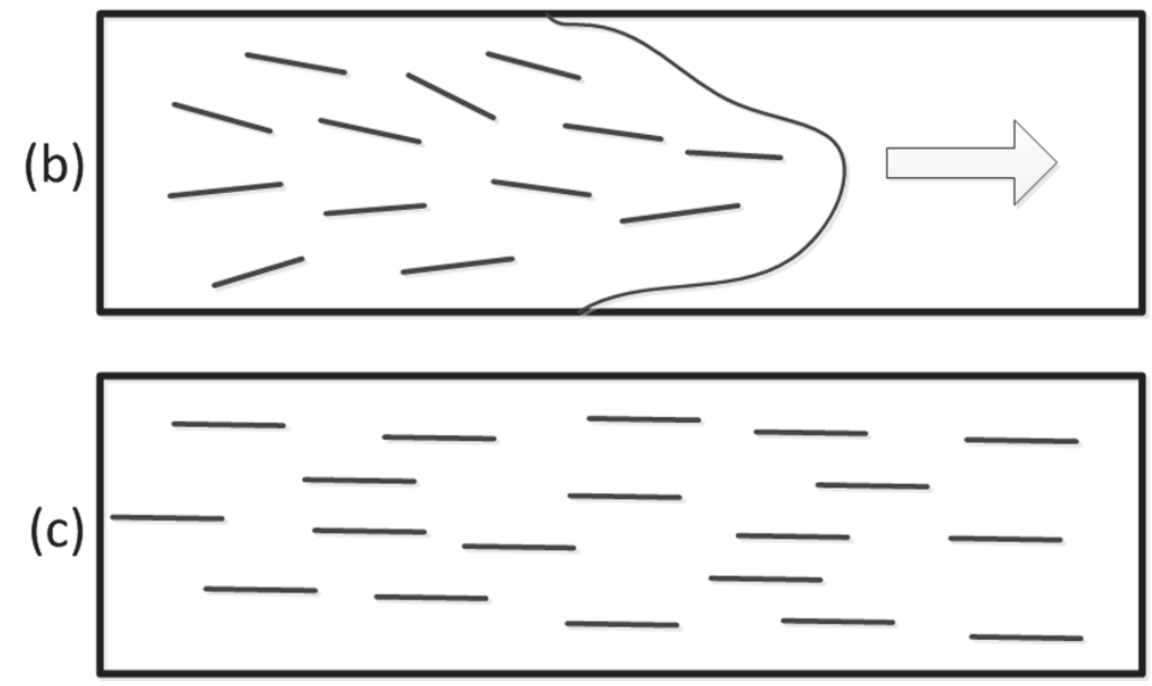

Figure 5.5: Flow cast

After specimens were filled, they were covered with plastic to ensure that the moisture from the UHPC did not escape during curing. Compression cylinders were filed in two lifts and vibrated and capped to retain moisture. All specimens, except 3 day ambient cured prisms, were cured for 3 days within the molds, after which point they were 
demolded. The 3 day ambient cured specimens were demolded after 2.5 days, so as to provide enough time to prepare the specimen for testing the next day.

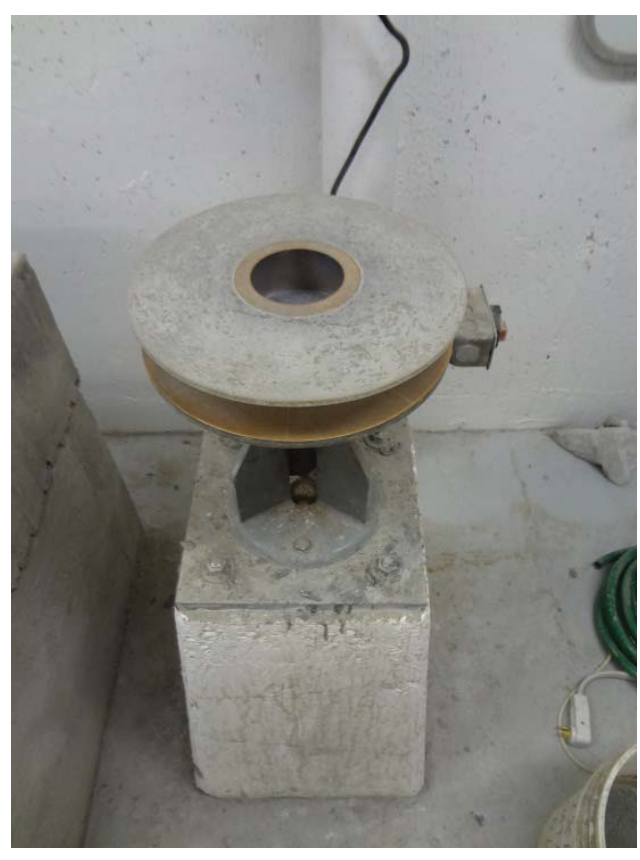

Figure 5.6: Flow test apparatus

\subsubsection{Sample Preparation}

After the specimens reached their specified curing time they were prepared in the following way. The compression cylinders were cut to 6 in using a concrete saw blade and ground to ensure that the ends were parallel. All prisms were measured to ensure conformance to (ASTM C 192 2007) 24 hours prior to testing. At this point the SENPs were notched using a diamond tip saw blade to a depth of $10 \%$ the beam height as specified by (AFGC and SETRA 2002). The two knife edge set ups were then epoxied to the beam separated by a distance equal to the COD gauge length. 


\subsection{Test Procedures}

\subsubsection{Compression}

Prior to testing the cylinder was measured to ensure that it met the requirements set forth in (ASTM C 39 2005). All compression specimens were tested on a Baldwin CT 300, using a load controlled rate of $150 \mathrm{psi} / \mathrm{s}$ as suggested by Ductal® reference T001Operating Procedure Compressive Test (Ductal ${ }^{\circledR}$ reference T 001). This load rate was used instead of the ASTM load rate, because based on previous research (Graybeal 2003; Kollmorgen 2004), it was noted that the ASTM rate would increase the time to test. The specimens were positioned and measured to ensure that they were centrally located on the bearing plate and compression head. The specimens were then manually loaded until snug, at which point the specimen was loaded at the specified rate until failure.

\subsubsection{Notched Prism}

Testing for notched prisms was based off two recommended procedures, which appear in an article by RILEM 162(RILEM TC 162-TDF 2002), and the AFGC/SETRA UHPC code recommendations (AFGC and SETRA 2002). Testing was executed as a crack mouth opening displacement (CMOD) controlled system, using an Epsilon brand COD gauge connected to a 55 kip servo-controlled hydraulic testing machine. The gauge was attached to the knife edges, which were previously attached to the UHPC specimen to be tested. The test procedure was composed of three acts; preload, initial ramp, and final ramp. The preload was controlled at an arbitrarily chosen COD rate of 0.15 $\mathrm{mm} / \mathrm{sec}$ until the load reached $100 \mathrm{~N}$, where the procedure switched to the initial ramp stage. The rate of this stage was much slower at a rate of $0.03 \mathrm{~mm} / \mathrm{min}$, due to the sensitivity of the COD gauge. Once a CMOD of $1.2 \mathrm{~mm}$ was reached, which was decided to be far enough away from the peak load that a faster load rate could be applied, the final ramp was initiated at a rate of $0.2 \mathrm{~mm} / \mathrm{min}$. This rate was continued at this rate until $10 \mathrm{~mm}$, which in most cases is where the beam strength was reduced to roughly $20 \%$ of the maximum load. Throughout the entirety of the test, the sampling 
frequency used was $5 \mathrm{~Hz}$, in the anticipation of optimizing this in the analysis of the data. The setup and testing of a notched specimen is shown in figure 5.3.

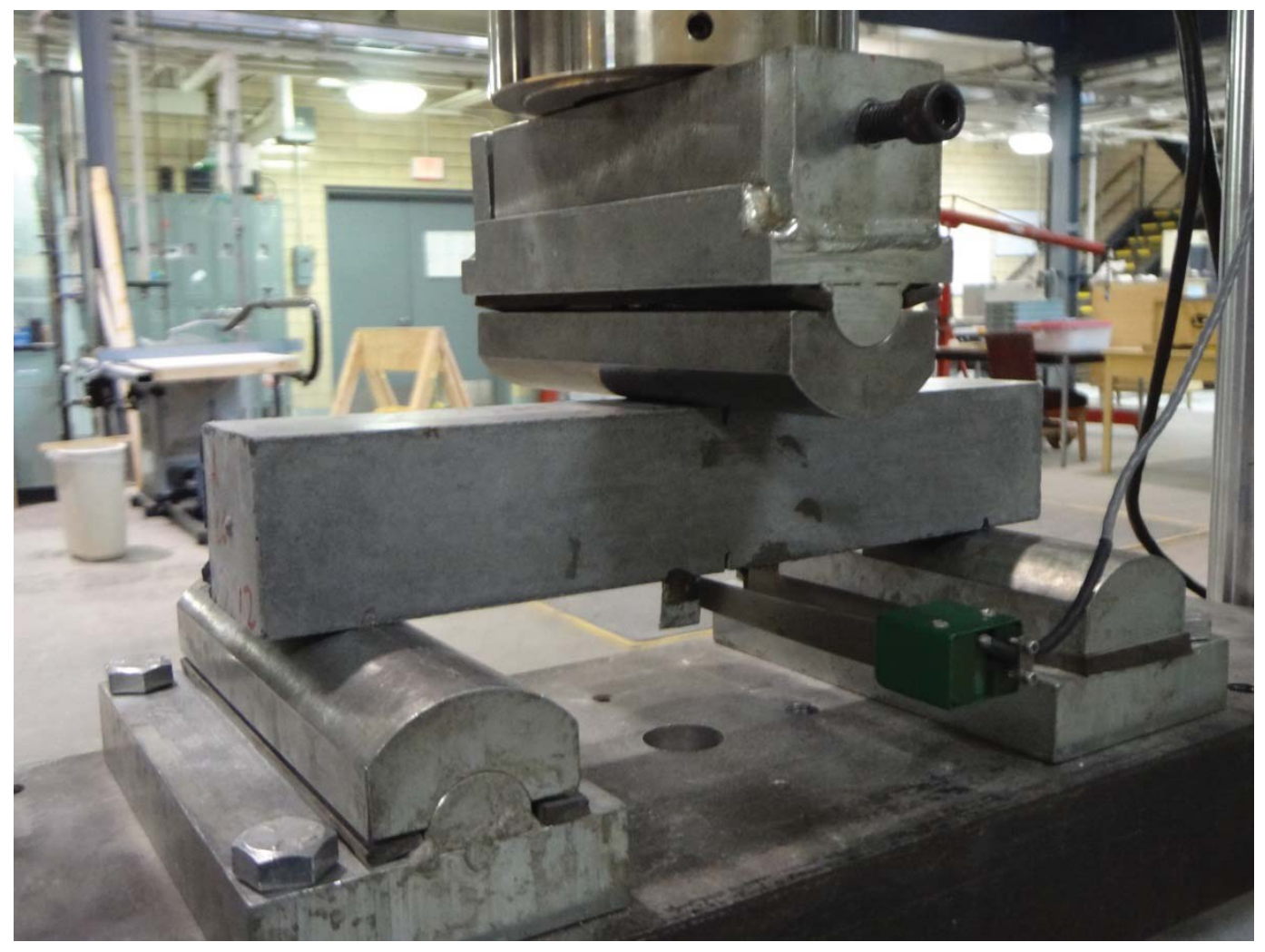

Figure 5.7: Fracture test setup

Most testing of this sort is generally only taken to a CMOD of about 3 or $4 \mathrm{~mm}$ (RILEM TC 162-TDF 2002), due to the length of testing. However, the intention of this research was to fully model the fracture behavior of UHPC, and this could only be done by attempting to reach final collapse.

The length of the test, consequently, did limit the number of beams that could be tested based on typical ASTM time windows for specimen testing (ASTM C 39 2005). The number beams that could be tested for 3, 7, 28, and 56 day are 2, 4, 6, and 12, respectfully. As is the case with this research, future fracture testing should not be as limited, because based on the models developed in this research shorter tests could be 
performed. The recorded measurements for this test were time, load, deflection, and CMOD, from which stress-deflection, and stress-CMOD curves could be developed. 


\section{Results and Discussion}

\subsection{Introduction}

Following the procedures outlined in the previous chapter several compression tests and a variety of flexural fracture tests were performed on Ductal ${ }^{\circledR}$ UHPFRC. Compression tests were performed in order to gauge the variability from mix to mix and to test the change in compressive behavior with variations in fiber content and curing regime. As mentioned previously (Chapter 5), the bulk of the research focused on the fracture behavior of UHPFRC under flexural three point bending tests. In addition to testing the fiber content and curing method this research also looked at the changes in prism depth, prism length, and the age of curing (Section 5.3).

\subsection{Compression Tests and Mix Variability}

\subsubsection{Compression Tests}

Compression tests were conducted for quality assurance and to test the effects of fiber content on the compressive strength. To verify the precision of test results, an analysis was conducted based on ASTM procedures (ASTM C 670 2003). According this analysis all specimens were accepted if they were within 2 standard deviations from the mean. If measurements were outside this range, these outliers were removed and the statistical analysis was again performed. The results for specimens that underwent ambient- 28 day, thermally treated- 7 day, and delayed thermally treated- 28 day curing with fiber contents of $0 \%, 1 \%, 2 \%$, and $3 \%$ appear in Table 6.1 . For any questions on specimen labeling, please refer to chapter 5 (Section 5.4.1). This table shows, for each specimen type, the number of sample population, the mean compressive strengths and standard deviations in MPa, and the coefficient of variation (C.O.V.). The distribution of compressive strengths for a single specimen type was assumed to follow a normal distribution. Therefore, the mean compressive strength for a single data set was calculated using an arithmetic mean. For complete compressive results the reader is referred to Table A.1 (Appendix A). 
Table 6.1

Compressive testing results

\begin{tabular}{|l|c|c|c|c|}
\hline Specimen & $\begin{array}{c}\text { Population } \\
(\#)\end{array}$ & $\begin{array}{c}\text { Mean Stress } \\
\text { (Mpa) }\end{array}$ & $\begin{array}{c}\text { Std. Dev. } \\
\text { (Mpa) }\end{array}$ & $\begin{array}{c}\text { C.O.V. } \\
(\%)\end{array}$ \\
\hline CA-28d-f0 & 3 & 86.60 & 1.08 & 1.25 \\
\hline CA-28d-f1 & 6 & 131.79 & 10.33 & 7.83 \\
\hline CA-28d-f2 & 10 & 142.33 & 12.64 & 8.88 \\
\hline CA-28d-f3 & 6 & 155.36 & 7.94 & 5.11 \\
\hline CTT-7d-f0 & 4 & 121.07 & 5.71 & 4.72 \\
\hline CTT-7d-f1 & 2 & 171.23 & 15.53 & 9.07 \\
\hline CTT-7d-f2 & 4 & 180.29 & 10.28 & 5.70 \\
\hline CDTT-28d-f0 & 2 & 121.41 & 3.60 & 2.97 \\
\hline CDTT-28d-f1 & 4 & 191.72 & 3.19 & 1.66 \\
\hline CDTT-28d-f2 & 2 & 190.12 & 7.12 & 3.74 \\
\hline CDTT-28d-f3 & 2 & 202.79 & 7.09 & 3.50 \\
\hline
\end{tabular}

Note: $1 \mathrm{ksi}=6.89 \mathrm{MPa}$

These results show that the compressive strengths increase as the material is thermally treated, which is in agreement with previous work discussed in chapter 4 (Section 4.7.1). In addition, it appears that there is an increase in compressive strength with the addition of fibers and as fiber content is increased. It has been previously mentioned (Section 4.6.1) that the addition of fibers has a definitive effect on the compressive strength, when compared to specimens without fibers. However, it has also been stated that increasing the amount of fibers does not significantly affect the compressive strength (Section 4.6.1). The coefficients of variation, other than the C-TT-7d-f1 at 9.07 $\%$, were below the acceptable value, which means that there is little variation between mixes.

\subsubsection{Mix Variability}

Any variation that does exist may be the result of variations in curing and/or mixing conditions. Table 6.2 gives an overview of the room conditions and fresh mix temperature and flow. Mixes are labeled consecutively based on the fiber content as $\mathrm{MV}_{\mathrm{f}}-\mathrm{N}$, where $\mathrm{M}$ stands for Mix, $\mathrm{V}_{\mathrm{f}}$ is the fiber content in $\%$, and $\mathrm{N}$ is a number that represents the order for each mix of a certain fiber content. Table 6.2 reports the date and time of each mix, along with the room temperature and humidity, initial and final 
mix temperatures, and the results of the flow test as discussed in chapter 5(Section 5.4.4).

Table 6.2

Mixing conditions

\begin{tabular}{|c|c|c|c|c|c|c|c|c|c|}
\hline \multirow{2}{*}{ Mix } & \multirow{2}{*}{ Date } & \multirow{2}{*}{ Time } & \multicolumn{2}{|c|}{$\begin{array}{c}\text { Room } \\
\text { Conditions }\end{array}$} & \multicolumn{2}{|c|}{$\begin{array}{c}\text { Mix } \\
\text { Temperature } \\
\end{array}$} & \multicolumn{3}{|c|}{ Flow Results } \\
\hline & & & $\begin{array}{r}\text { Temp } \\
\left(C^{\circ}\right)\end{array}$ & $\begin{array}{c}\text { Humidity } \\
(\%)\end{array}$ & $\begin{array}{c}\text { Initial } \\
\left({ }^{\circ} \mathrm{C}\right)\end{array}$ & $\begin{array}{c}\text { Final } \\
\left({ }^{\circ} \mathrm{C}\right)\end{array}$ & $\begin{array}{l}D_{\text {initial }} \\
(\mathrm{mm})\end{array}$ & $\begin{array}{r}D_{\text {final }} \\
(\mathrm{mm}) \\
\end{array}$ & $\begin{array}{l}\text { Flow } \\
(\mathrm{mm})\end{array}$ \\
\hline M0-1 & $2 / 3 / 2011$ & 9:12 AM & 23 & 20 & 22 & 27 & 204 & 236 & 33 \\
\hline $\mathrm{M} 0-2$ & $2 / 24 / 2011$ & 8:52 AM & 23 & 22 & 22 & 31 & 192 & 226 & 34 \\
\hline M1-1 & $2 / 29 / 2011$ & 10:18 AM & 22 & 25 & 21 & 29 & 204 & 235 & 31 \\
\hline M1-2 & $5 / 6 / 2011$ & 9:40 AM & 23 & 31 & 21 & 30 & 214 & 245 & 31 \\
\hline M1-3 & $5 / 11 / 2011$ & $8: 24 \mathrm{AM}$ & 23 & 40 & 22 & 31 & 193 & 223 & 30 \\
\hline M2-1 & $2 / 15 / 2011$ & 1:24 PM & 22 & 21 & 21 & 32 & - & - & - \\
\hline M2-2 & $2 / 17 / 2011$ & 1:18 PM & 22 & 30 & 21 & 31 & 193 & 225 & 33 \\
\hline M2-3 & $2 / 22 / 2011$ & 8:41 AM & 23 & 20 & 21 & 31 & 189 & 213 & 24 \\
\hline M2-4 & $4 / 19 / 2011$ & 1:28 PM & 20 & 26 & 20 & 30 & 191 & 226 & 34 \\
\hline M2-5 & $4 / 19 / 2011$ & 2:30 PM & 21 & 22 & 20 & 28 & 191 & 226 & 34 \\
\hline M2-6 & $4 / 26 / 2011$ & 11:18 AM & 24 & 25 & 22 & 31 & 204 & 235 & 31 \\
\hline M2-7 & $5 / 2 / 2011$ & 9:20 AM & 23 & 27 & 21 & 30 & 198 & 227 & 29 \\
\hline M2-8 & $6 / 3 / 2011$ & $8: 20 \mathrm{AM}$ & 23 & 32 & 22 & 34 & 189 & 221 & 33 \\
\hline M2-9 & $6 / 3 / 2011$ & 9:31 AM & 23 & 33 & 21 & 30 & 191 & 226 & 35 \\
\hline M2-10 & $6 / 7 / 2011$ & 5:09 PM & 25 & 52 & 22 & 27 & 205 & 234 & 29 \\
\hline M2-11 & $7 / 12 / 2011$ & 11:19 AM & 23 & 42 & 25 & 33 & 199 & 236 & 38 \\
\hline M2-12 & $7 / 19 / 2011$ & 11:07 AM & 24 & 59 & 25 & 36 & 200 & 239 & 39 \\
\hline M3-1 & $5 / 16 / 2011$ & 8:09 AM & 24 & 25 & 22 & 32 & 186 & 220 & 34 \\
\hline M3-2 & $5 / 16 / 2011$ & 9:15 AM & 23 & 25 & 21 & 30 & 176 & 224 & 48 \\
\hline M3-3 & $5 / 21 / 2011$ & 11:18 AM & 24 & 42 & 22 & 34 & 198 & 230 & 33 \\
\hline M3-4 & $6 / 7 / 2011$ & 4:10 PM & 24 & 56 & 23 & 33 & 210 & 241 & 31 \\
\hline M3-5 & $7 / 12 / 2011$ & 10:15 AM & 24 & 42 & 24 & 35 & 198 & 255 & 58 \\
\hline M3-6 & $7 / 19 / 2011$ & 10:07 AM & 23 & 62 & 24 & 35 & 199 & 236 & 38 \\
\hline
\end{tabular}

Based on these results it can be concluded that the room temperature did not vary much during mixing dates, staying between 20 and $25^{\circ} \mathrm{C}\left(68\right.$ and $\left.75{ }^{\circ} \mathrm{F}\right)$. The humidity, on the other hand, started at about 20-30\% during the winter and spring months and increase to around 40-60\% during the summer months. The mixing temperatures started at room temperature and increased by about $10^{\circ} \mathrm{C}\left(15^{\circ} \mathrm{F}\right)$, where final mixing 
temperatures varied between 27 to $36^{\circ} \mathrm{C}\left(80-95{ }^{\circ} \mathrm{F}\right)$. Finally the flow, other than a few outliers, tended to stay within $30-40 \mathrm{~mm}(1.2-1.6$ in).

\subsubsection{Validation of Results}

To verify these results, compressive strengths $\left(f^{\prime}\right)$ for cylinders with $2 \%$ fibers undergoing 28 day ambient and 7 day thermally treated curing were compared to previous results. These results are reported in Table 6.3 and provide values in MPa and ksi. Based on the statistical results in Table A.2 (Appendix A), it can be concluded that the ambient compression results from this research are comparable to work done by Graybeal (2005) and Peuse (2008). However, with regards to thermal treatment the value from this research is below results from previous work, but is within 2 standard deviations from the values obtained by Graybeal (2005) and Kollmorgen (2004). In conclusion the results from compressive tests are in agreement with previous work.

Furthermore, to verify the above conclusions for the compression results a series of hypothesis tests were performed. Detailed results of hypothesis testing can be found in Table A.3 (Appendix A). For further information on hypothesis testing, please reference Devore (2011)

First, comparisons between population means of varying fiber contents were performed for similar curing treatments. The hypothesis assumed that in each case the population means (compressive strengths) were similar. As presented in Table 6.4 for ambient curing, this was done by comparing fiber contents of $0 \%$ to $1 \%, 0 \%$ to $2 \%, 0 \%$ to $3 \%$, $1 \%$ to $2 \%, 1 \%$ to $3 \%$, and $2 \%$ to $3 \%$. Similar comparisons were also conducted for thermally treated and delayed thermally treated.

Table 6.3

Comparison of compression results

\begin{tabular}{|l|c|c|c|c|}
\hline \multirow{2}{*}{\multicolumn{1}{c|}{ Research }} & \multicolumn{2}{c|}{ Ambient } & \multicolumn{2}{c|}{ Thermal Treatment } \\
\cline { 2 - 5 } & $f_{c}^{\prime}(\mathrm{MPa})$ & $f_{c}^{\prime}(\mathrm{ksi})$ & $f_{c}^{\prime}(\mathrm{MPa})$ & $f_{c}^{\prime}(\mathrm{ksi})$ \\
\hline Current Study & 142 & 21 & 180 & 26 \\
\hline Graybeal, 2005 & 149 & 22 & 202 & 29 \\
\hline Peuse, 2008 & 165 & 24 & 214 & 31 \\
\hline Kollmorgen, 2004 & 207 & 30 & 199 & 29 \\
\hline
\end{tabular}


Table 6.4

Comparison of compressive strength with fiber content

\begin{tabular}{|c|c|c|c|}
\hline Curing & $\begin{array}{l}\text { Comparison of } \\
\text { Fiber Content }\end{array}$ & $\begin{array}{c}\text { Results of } \\
\text { Hypothesis Test }\end{array}$ & $\begin{array}{c}\text { Population means } \\
\text { Similar? }\end{array}$ \\
\hline \multirow{6}{*}{ 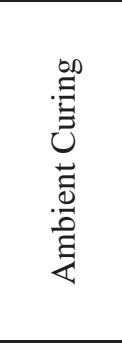 } & 0 to 1 & Reject & No \\
\hline & 0 to 2 & Reject & No \\
\hline & 0 to 3 & Reject & No \\
\hline & 1 to 2 & Reject & No \\
\hline & 1 to 3 & Reject & No \\
\hline & 2 to 3 & Reject & No \\
\hline \multirow{3}{*}{ 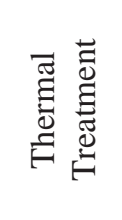 } & 0 to 1 & Reject & No \\
\hline & 0 to 2 & Reject & No \\
\hline & 1 to 2 & Failed to Reject & Yes \\
\hline \multirow{6}{*}{ 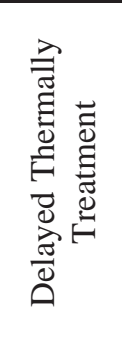 } & 0 to 1 & Reject & No \\
\hline & 0 to 2 & Reject & No \\
\hline & 0 to 3 & Reject & No \\
\hline & 1 to 2 & Failed to Reject & Yes \\
\hline & 1 to 3 & Reject & No \\
\hline & 2 to 3 & Failed to Reject & Yes \\
\hline
\end{tabular}

For ambient curing, the results the comparison of varying fiber contents confirms that the addition of fibers does increase the compressive strength. It also confirms that increasing the fiber content increases the compressive strength. With regards to thermal treatment, the increase in compressive strength is also observed. However, when increasing the fiber content by a single percent $(0 \%$ to $1 \%$ or $2 \%$ to $3 \%$ ) the fibers have little effect on the compressive strength. On the other hand, if the fiber content is increased by two percentages then the compressive strength does appear to increase with fiber content. From these results it can be concluded that the addition of fibers and increase in fiber content does increase the compressive strength of UHPFRC. Although, when cured under thermal conditions the increase in fiber content has less of an effect than under ambient conditions. 
Figure 6.1: Effect of fiber content on compressive strength

A graphical depiction of the effect of increasing fiber content on compressive strength is shown in Figure 6.1, which plots the compressive strength of each curing condition against the fiber volume percent. This phenomenon can best explained by the idea that the fibers must offer an internal confining effect due to good bonding between the steel fibers and the UHPC matrix.

In addition, hypothesis testing was also conducted to compare the population means for each curing condition at different fiber contents (Table 6.5). For example results for specimens with $0 \%$ fibers underwent ambient treatment were compared to those underwent thermal treatment and delayed thermal treatment. A comparison was also conducted for thermally treated and delayed thermally treated. Similar comparisons were then done for fiber contents of $1 \%, 2 \%$, and 3\%, as shown. These results showed that, regardless of fiber content, the compressive strength increases with thermal treatment, and that thermal treatment produces similar results, whether delayed just after demolding. 
Table 6.5

Comparison of compressive strength with type of curing

\begin{tabular}{|c|c|c|c|}
\hline $\begin{array}{c}\text { Fiber Content } \\
(\%)\end{array}$ & $\begin{array}{c}\text { Comparison } \\
\text { of Curing }\end{array}$ & $\begin{array}{c}\text { Results of } \\
\text { Hypothesis Test }\end{array}$ & $\begin{array}{c}\text { Are population } \\
\text { Means Similar? }\end{array}$ \\
\hline \multirow{4}{*}{0} & A to TT & Reject & No \\
\cline { 2 - 4 } & A to DTT & Reject & No \\
\cline { 2 - 4 } & TT to DTT & Failed to Reject & Yes \\
\hline \multirow{3}{*}{1} & A to TT & Reject & No \\
\cline { 2 - 4 } & A to DTT & Reject & No \\
\cline { 2 - 4 } & TT to DTT & Failed to Reject & Yes \\
\hline \multirow{3}{*}{2} & A to TT & Reject & No \\
\cline { 2 - 4 } & A to DTT & Reject & No \\
\cline { 2 - 4 } & TT to DTT & Failed to Reject & Yes \\
\hline 3 & A to DTT & Reject & No \\
\hline
\end{tabular}

\subsection{Fracture Testing}

In order to characterize the mode I fracture, a series of three-point bending fracture tests were performed, the details of which are discussed in chapter 5 (Section 5.5.2). As mentioned this test was performed on a variety of prisms with different design parameters: fiber content, specimen age, prism length (reported as span-to-depth ratio), prism cross-section, and type of curing regime. The number of parameters tested led to complexity in the results, therefore in order to report the results it is best to simplify their presentation. This discussion will begin by looking at the results of the reference specimen, NP-A-28d-f2-2580-4.5, which as stated in chapter 5 has a $51 \mathrm{~mm}$ x $51 \mathrm{~mm}$ ( 2 in $x 2$ in) cross section with a 4.5 span-to-depth (S/D) ratio, $2 \%$ fiber content and underwent a 28-day ambient cure. Successive sections will then discuss the addition of the different design parameters, and how they affect the fracture behavior of the material.

Before discussing the reference specimen, it may be best to look briefly at the variability associated between specimen data sets. This was done by performing a statistical analysis of the stress at first crack $\left(\sigma_{\mathrm{f}}\right)$ and ultimate strengths $\left(\sigma_{\mathrm{u}}\right)$ for all specimens, as reported in Appendix B. In accordance to ASTM C 1609 the material strengths at first crack and ultimate were calculated using the elastic stress calculation 
(Equation 6.1). This equation is for a three-point loading condition, which differs from that in ASTM C 1609 because that test is based on a four-point bend test.

$\sigma=\frac{3 P L}{2 b d^{2}}$

Equation 6.1

According to this equation the stress in the prism can be calculated knowing the load, $P$, prism support span, $L$, prism width, $b$, and prism depth, $d$.

The results of Appendix B, as mentioned, are quite lengthy, and therefore will not be discussed in its entirety. However, an excerpt from those results is included (Table 6.6). The prisms presented are those that underwent 28 days of ambient curing and contained $2 \%$ fibers by volume. The first of these prisms is the reference prism with a $4.5 \mathrm{~S} / \mathrm{D}$, followed by increases in the S/D ratio to $6.75,9$ and 13.75. Lastly, the table also includes the results for larger depth specimen with a depth of $76 \mathrm{~mm}$ (3 in) and an S/D of 4.5. This table reports the mean loads and stresses at cracking and ultimate, which for each data set were calculated using an arithmetic mean. It should be stated that verification for using the arithmetic mean is required, as results may follow another probability distribution. In addition to the mean loads and stresses, Table 6.6 includes the number of samples, the standard deviation for these stresses, and their associated coefficients of variation. As with the compression cylinders, the precision of test results was verified using ASTM C 670. Based on these results it can be concluded that there is little variability, with all but one data set having a COV less than $10 \%$. Furthermore, from the results in Appendix B it can be concluded that in general there is very little variability for most of the fracture results. Of the ambient cured specimens, those that were tested at early ages (3-day, and 7-day), and those with $0 \%$ fibers showed the most variability. In the case of thermal treatment, the specimen with $0 \%$ fibers showed the most variability.

From the results, as will be discussed in more depth in preceding sections, the loads decrease with increase in specimen length, and increase with specimen depth. The decrease in load with specimen length was expected, just as the stress in the beam was 
expected to be the same regardless of S/D ratio. This is an inherent result, which arose from the inclusion of the length in the above stress equation (Equation 6.1). Whereas, the increase in load with depth is associated with the specimens ability to carry more load due to its increased area moment of inertia. However, this does not lead to similar strength capacity, because deeper beams are subject to the size effect as discussed in chapter 2 (Section 2.3).

Table 6.6

Results for ambient 28-day flexural specimens with $2 \%$ fibers

\begin{tabular}{|c|c|c|c|c|c|c|}
\hline Specimen & $\begin{array}{c}\text { Samples } \\
(\#)\end{array}$ & \multicolumn{2}{|c|}{ Load Case } & Mean & Std. Dev. & $\begin{array}{c}\text { C.O.V. } \\
(\%)\end{array}$ \\
\hline \multirow{4}{*}{ NP-A-28d-f2-2580-4.5 } & \multirow{4}{*}{12} & \multirow{2}{*}{ Cracking } & Load $(\mathrm{kN})$ & 5.67 & 0.60 & 10.65 \\
\hline & & & Stress (Mpa) & 17.70 & 2.08 & 11.75 \\
\hline & & \multirow{2}{*}{ Ultimate } & Load $(\mathrm{kN})$ & 10.59 & 0.61 & 5.79 \\
\hline & & & Stress (Mpa) & 33.32 & 1.73 & 5.18 \\
\hline \multirow{4}{*}{ NP-A-28d-f2-2580-6.75 } & \multirow{4}{*}{2} & \multirow{2}{*}{ Cracking } & Load $(\mathrm{kN})$ & 2.79 & 0.13 & 4.81 \\
\hline & & & Stress (Mpa) & 17.28 & 0.56 & 3.25 \\
\hline & & \multirow{2}{*}{ Ultimate } & Load $(\mathrm{kN})$ & 5.04 & 0.27 & 5.30 \\
\hline & & & Stress (Mpa) & 31.29 & 1.96 & 6.25 \\
\hline \multirow{4}{*}{ NP-A-28d-f2-2580-9 } & \multirow{4}{*}{4} & \multirow{2}{*}{ Cracking } & Load $(\mathrm{kN})$ & 3.96 & 0.09 & 2.33 \\
\hline & & & Stress (Mpa) & 17.98 & 0.46 & 2.57 \\
\hline & & \multirow{2}{*}{ Ultimate } & Load $(\mathrm{kN})$ & 7.31 & 0.24 & 3.26 \\
\hline & & & Stress (Mpa) & 33.22 & 1.16 & 3.50 \\
\hline \multirow{4}{*}{ NP-A-28d-f2-2580-13.75 } & \multirow{4}{*}{1} & \multirow{2}{*}{ Cracking } & Load $(\mathrm{kN})$ & 1.82 & - & - \\
\hline & & & Stress (Mpa) & 17.21 & - & - \\
\hline & & \multirow{2}{*}{ Ultimate } & Load $(\mathrm{kN})$ & 3.39 & - & - \\
\hline & & & Stress (Mpa) & 32.11 & - & - \\
\hline \multirow{4}{*}{ NP-A-28d-f2-5180-4.5 } & \multirow{4}{*}{2} & \multirow{2}{*}{ Cracking } & Load $(\mathrm{kN})$ & 10.92 & 0.06 & 0.55 \\
\hline & & & Stress (Mpa) & 14.81 & 0.12 & 0.79 \\
\hline & & \multirow{2}{*}{ Ultimate } & Load $(\mathrm{kN})$ & 21.94 & 0.27 & 1.25 \\
\hline & & & Stress (Mpa) & 29.77 & 0.44 & 1.49 \\
\hline
\end{tabular}

Note: 1 kip=4.45 kN, 1 ksi=6.89 MPa 


\subsubsection{Reference Specimen}

Table 6.7 reports the results for all 12 specimens of the NP-A-28d-f2-51-4.5 reference specimen that underwent testing. The reported values include the crack openings $(\mathrm{w})$, loads $(P)$, and stresses $(\sigma)$ at first crack (f) and ultimate capacity $(u)$. The values of $w_{f}$ and $\mathrm{P}_{\mathrm{f}}$ were determined from the load-crack mouth opening $(\mathrm{P}-\mathrm{w})$ curve as the point where the P-w curve showed noticeable decrease in the slope of its original path. It should be noted that $\mathrm{w}_{\mathrm{f}}$ is not associated with the crack opening, but is instead a value tied more to straining of the material. Often times this point is accompanied by a sudden, but brief decline in load followed by a rebound in strength gain (Figure 6.2). As discussed in chapter 2, this occurs due to the release of energy from the formation of cracks followed by a strengthening mechanism (Section 2.3). The value of $\mathrm{P}_{\mathrm{u}}$ and $\mathrm{w}_{\mathrm{u}}$ were determined simply by finding the maximum of the load data and the associate $\mathrm{w}$ value (Figure 6.3). The value of $\mathrm{w}_{\mathrm{u}}$ was determined as the measured value subtracted by $\mathrm{w}_{\mathrm{f}}$, as $\mathrm{w}_{\mathrm{f}}$ is not associated with the crack mouth opening displacement (CMOD). As mentioned, for simplicity the values of $\sigma_{\mathrm{f}}$ and $\sigma_{\mathrm{u}}$ were determined based on the elastic stress equation for three-point bending (Equation 6.1). The bottom row of Table 6.7 includes averages for the reported values, which once again were calculated using an arithmetic mean. Due to the large number of data points associated with the testing of each prism this analysis, as described was performed using Matlab.

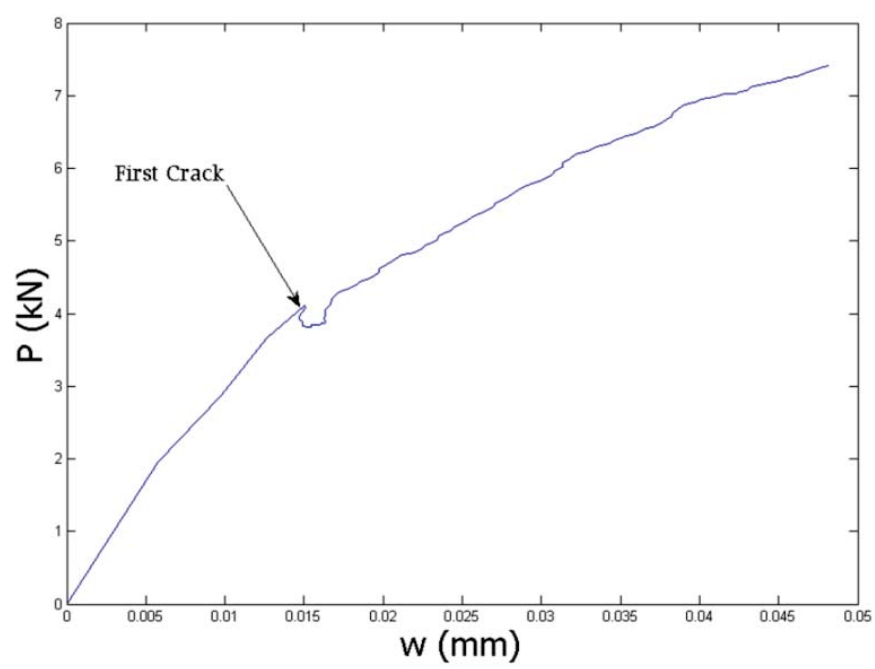

Figure 6.2: First crack load 


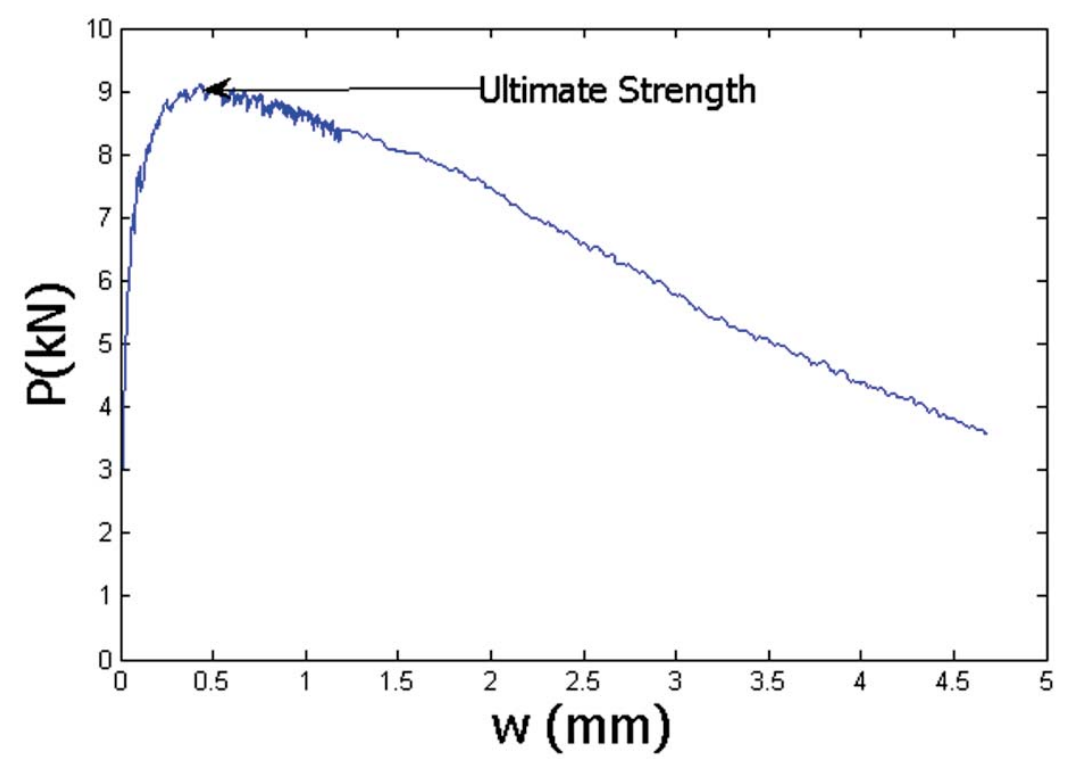

Figure 6.3: Ultimate load

Table 6.7

Results from fracture tests for reference specimens

\begin{tabular}{|l|c|c|c|c|c|c|}
\hline Specimen & $\begin{array}{c}\mathbf{W}_{\mathbf{f}} \\
(\mathbf{m m})\end{array}$ & $\mathbf{P}_{\mathbf{f}}(\mathbf{k N})$ & $\boldsymbol{\sigma}_{\mathbf{f}}(\mathbf{M p a})$ & $\mathbf{w}_{\mathbf{u}}(\mathbf{m m})$ & $\mathbf{P}_{\mathbf{u}}(\mathbf{k N})$ & $\begin{array}{c}\mathbf{\sigma}_{\mathbf{u}} \\
(\mathbf{M p a})\end{array}$ \\
\hline NP-A-28d-f2-2580-4.5-A & 0.037 & 6.41 & 20.49 & 0.342 & 10.54 & 33.70 \\
\hline NP-A-28d-f2-2580-4.5-B & 0.029 & 5.46 & 18.25 & 0.553 & 10.40 & 34.78 \\
\hline NP-A-28d-f2-2580-4.5-C & 0.030 & 5.58 & 17.51 & 0.347 & 10.91 & 34.22 \\
\hline NP-A-28d-f2-2580-4.5-D & 0.027 & 5.65 & 16.89 & 0.357 & 10.49 & 31.34 \\
\hline NP-A-28d-f2-2580-4.5-E & 0.033 & 5.43 & 17.87 & 0.348 & 9.89 & 32.52 \\
\hline NP-A-28d-f2-2580-4.5-F & 0.023 & 4.37 & 12.01 & 0.487 & 10.98 & 33.92 \\
\hline NP-A-28d-f2-2580-4.5-G & 0.030 & 5.11 & 16.05 & 0.605 & 10.25 & 32.20 \\
\hline NP-A-28d-f2-2580-4.5-H & 0.029 & .55 & 18.35 & 0.644 & 11.23 & 37.14 \\
\hline NP-A-28d-f2-2580-4.5-I & 0.038 & 6.39 & 19.96 & 0.726 & 10.89 & 34.00 \\
\hline NP-A-28d-f2-2580-4.5-J & 0.036 & 6.53 & 19.12 & 0.449 & 11.57 & 33.89 \\
\hline NP-A-28d-f2-2580-4.5-K & 0.028 & 5.29 & 17.57 & 0.518 & 9.14 & 30.39 \\
\hline NP-A-28d-f2-2580-4.5-L & 0.027 & 6.23 & 18.32 & 0.565 & 10.79 & 31.75 \\
\hline Average & 0.031 & 5.67 & 17.70 & 0.495 & 10.59 & 33.32 \\
\hline
\end{tabular}

Note: 1 kip=4.45 kN, 1 ksi=6.89 MPa, 1 in=25.4 mm 
Table 6.7 gives an overview for the change in loads and stresses at cracking and ultimate. A few things to note are that fracture occurs at a displacement value of 0.031 , which does not vary much from specimen to specimen. Additionally, the ultimate load occurs around $\mathrm{w}_{\mathrm{u}}=0.5 \mathrm{~mm}$, which again does not show much variation. It is important to state that the ultimate stress reached only after the occurrence of first crack. This is due to the combined effects of improved fiber-matrix bonding, and the ability of the fibers to bridge cracks and transfer loads from one crack face to the other.

In order to validate the results obtained during testing a comparison to previous flexure testing of similar sized prisms made of Ductal® brand UHPC was performed. Specifically, a comparison of the stress at first crack and the equivalent elastic stress at ultimate was performed (Table 6.8). From the results of this comparison it can be concluded that the first crack strength is higher than previous work, but is close to that of Graybeal (2005), after using Equation 4.1 to correct for the change in depth due to notching. On the other hand, the ultimate strength is comparable to several previous studies.

Table 6.8

Comparison of flexural strength results

\begin{tabular}{|l|c|c|c|}
\hline \multirow{2}{*}{ Research } & \multicolumn{3}{|c|}{ Stress Value } \\
\cline { 2 - 4 } & $\begin{array}{c}\text { First Crack } \\
(\mathrm{Mpa})\end{array}$ & $\begin{array}{c}\text { Corrected } \\
\text { First Crack } \\
(\mathrm{MPa})\end{array}$ & $\begin{array}{c}\text { Ultimate } \\
(\mathrm{Mpa})\end{array}$ \\
\hline Current study & 17.70 & 9.51 & 33.32 \\
\hline Graybeal (2005) & 15.92 & 8.81 & 30.32 \\
\hline Kollmorgen (2004) & 13.57 & - & 34.11 \\
\hline Peuse (2008) & 9.23 & 5.10 & 35.42 \\
\hline
\end{tabular}

Note: $1 \mathrm{ksi}=6.89 \mathrm{MPa}$

Although the strength of the material is important, as discussed in Chapter 2 the fracture energy is ultimately that which determines failure. The fracture energy is the area under the fracture curve, and has been calculated using a variety of methods (Section 2.5). The first is based on the fictitious crack model which relies on the stressCMOD $(\sigma-\mathrm{w})$ curve, the second is similar to the first but it uses the load-CMOD (P-w) curve instead, and the third is based on the concept of mechanical work and is 
determined using the load-deflection $(\mathrm{P}-\delta)$ curve (Bencardino et al. 2010). The calculation of the stress after fracture, as shown in chapters 3 and 4 can be performed by implementing the non-linear hinge model. This model is, however, not within the scope of this research, but should be considered for future work. The idea of using an equivalent elastic stress method was considered, but this method has no real physical meaning as the material is no longer elastic after fracture. Instead the strength relies primarily on the composite behavior between the fibers and the matrix to sustain the high strength capacity. The $\mathrm{P}-\delta$ method was considered, but it was decided that the $\mathrm{P}-\mathrm{w}$ method was the best choice based on the testing procedure and desired results.

For the 12 specimens in the reference prism data set the fracture energy was calculated and tabulated in Table 6.9. This table shows an incremental evolution of the fracture energy using both methods. The values were calculated up to the peak load $(\mathrm{Gf}, 100)$, followed by values of $90 \%$ (Gf,90), 80\% (Gf,80), 70\% (Gf,70), 60\% (Gf,60), $50 \%(\mathrm{Gf}, 50), 40 \%(\mathrm{Gf}, 40), 30 \%(\mathrm{Gf}, 30)$, and $20 \%$ (Gf,20) of the peak load after the occurrence of the peak load. The last row reports the average fracture energies using an arithmetic mean.

Table 6.9

Incremental fracture energies of the reference data set

\begin{tabular}{|l|c|c|c|c|c|c|c|c|c|}
\hline Specimen & $\mathbf{G}_{\mathbf{f , 1 0 0}}$ & $\mathbf{G}_{\mathbf{f}, \mathbf{9 0}}$ & $\mathbf{G}_{\mathbf{f , 8 0}}$ & $\mathbf{G}_{\mathbf{f}, \mathbf{7 0}}$ & $\mathbf{G}_{\mathbf{f , 6 0}}$ & $\mathbf{G}_{\mathbf{f}, \mathbf{5 0}}$ & $\mathbf{G}_{\mathbf{f , 4 0}}$ & $\mathbf{G}_{\mathbf{f , 3 0}}$ & $\mathbf{G}_{\mathbf{f}, \mathbf{2 0}}$ \\
\hline NP-A-28d-f2-2580-4.5-A & 1.38 & 4.12 & 6.98 & 9.38 & 11.33 & 12.96 & 15.10 & 17.51 & 19.61 \\
\hline NP-A-28d-f2-2580-4.5-B & 2.28 & 4.12 & 7.46 & 9.49 & 11.64 & 13.61 & 15.66 & 17.74 & 19.65 \\
\hline NP-A-28d-f2-2580-4.5-C & 1.42 & 6.27 & 9.21 & 11.16 & 13.78 & 15.77 & 17.81 & 19.47 & 21.49 \\
\hline NP-A-28d-f2-2580-4.5-D & 1.40 & 4.00 & 6.60 & 8.32 & 9.86 & 11.78 & 13.48 & 15.04 & 16.52 \\
\hline NP-A-28d-f2-2580-4.5-E & 1.32 & 5.82 & 7.89 & 10.00 & 11.74 & 13.93 & 15.59 & 17.54 & 19.88 \\
\hline NP-A-28d-f2-2580-4.5-F & 1.95 & 4.66 & 8.24 & 10.44 & 12.55 & 15.06 & 17.58 & 19.97 & - \\
\hline NP-A-28d-f2-2580-4.5-G & 2.29 & 4.81 & 7.58 & 9.43 & 11.23 & 13.14 & 14.89 & 16.52 & 18.02 \\
\hline NP-A-28d-f2-2580-4.5-H & 2.56 & 7.15 & 9.38 & 11.27 & 13.71 & 15.97 & 18.58 & 20.61 & 23.04 \\
\hline NP-A-28d-f2-2580-4.5-I & 3.08 & 7.62 & 9.47 & 11.81 & 13.58 & 15.61 & 17.48 & 19.12 & 20.95 \\
\hline NP-A-28d-f2-2580-4.5-J & 1.89 & 8.29 & 10.29 & 12.19 & 14.44 & 16.13 & 18.23 & 20.38 & 22.74 \\
\hline NP-A-28d-f2-2580-4.5-K & 1.92 & 5.18 & 7.47 & 9.21 & 10.49 & 11.99 & 13.41 & 14.89 & 16.83 \\
\hline NP-A-28d-f2-2580-4.5-L & 2.48 & 6.32 & 9.11 & 11.08 & 12.98 & 14.88 & 16.65 & 18.26 & 19.99 \\
\hline Average & 2.00 & 5.70 & 8.31 & 10.32 & 12.28 & 14.24 & 16.21 & 18.09 & 19.88 \\
\hline
\end{tabular}

Note: All values in this table are reported in $\mathrm{kJ} / \mathrm{m} 2,1 \mathrm{ft}-\mathrm{lb}=1.36 \mathrm{~J}, 1 \mathrm{~m}=3.28 \mathrm{ft}$ 
To better understand the fracture behavior, as discussed in chapter 2 (Section 2.4.2), it is necessary to know the shape of the fracture curve. Figure 6.4 shows the average P-w curve and the associated fracture energy curve. It is important to note the softening of the fracture curve and the associated exponential gain of the fracture energy, as they will be important later in this chapter. Similar plots for all other specimens can be found in Appendix C.
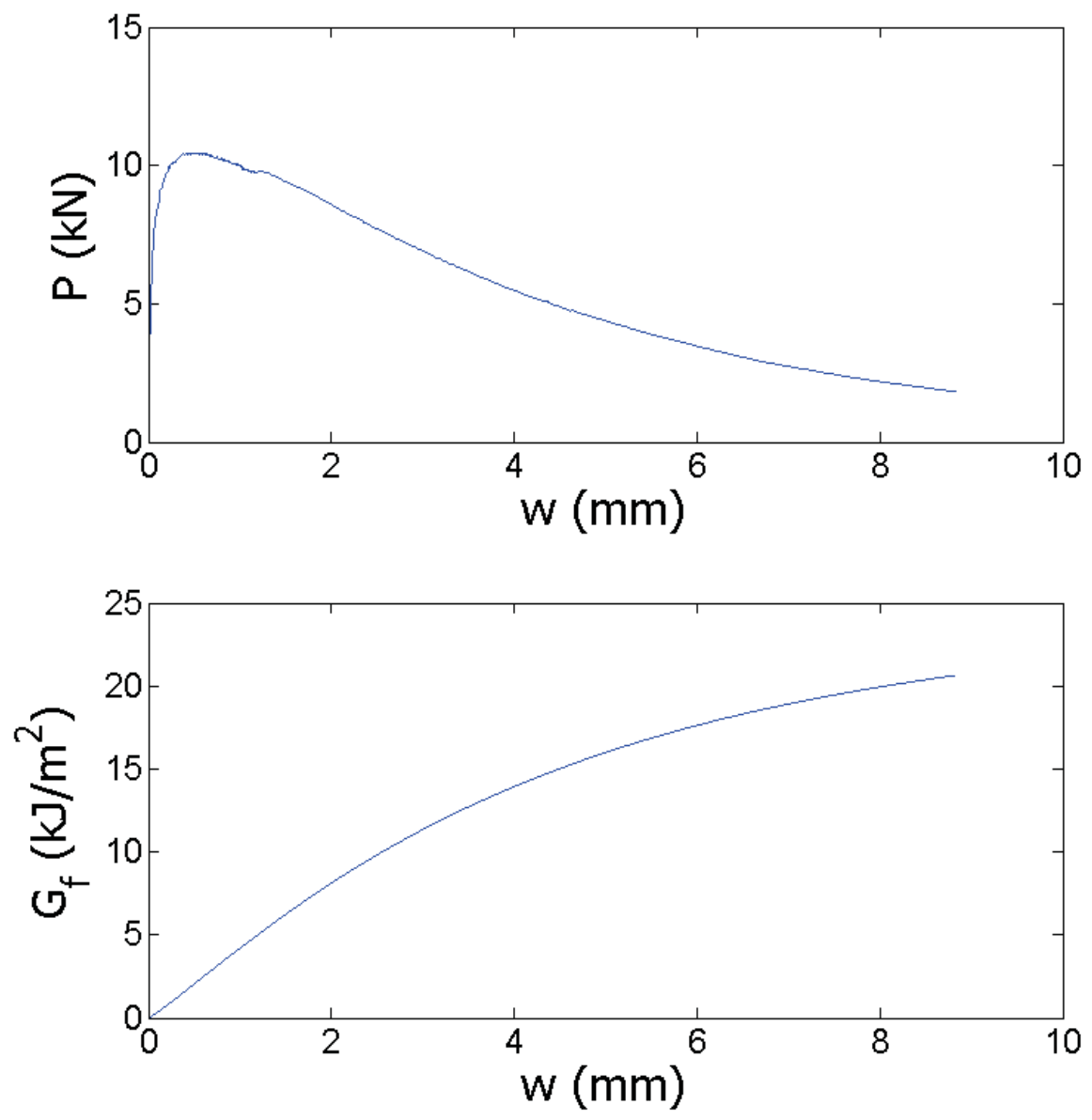

Figure 6.4: P-w curve and fracture energy curve for reference specimen Note: $1 \mathrm{kip}=4.45 \mathrm{kN}, 1 \mathrm{in}=25.4 \mathrm{~mm}, 1 \mathrm{ft}-\mathrm{lb}=1.36 \mathrm{~J}, 1 \mathrm{~m}=3.28 \mathrm{ft}$ 


\subsubsection{Fiber content}

As previously mentioned in Chapter 4, the addition of fibers increases the ductility and fracture resistance of UHPFRC (Section 4.7.1 and Section 4.9). In reference to the results of NP-28d-f2-2580-4.5 specimens, a comparison was performed between the first crack strengths, equivalent elastic peak load strengths, the $\mathrm{G}_{\mathrm{f}, 40}$ fracture energy, and $\mathrm{B}_{40}$ brittleness number for SENPs of the following type NP-28d-f0-2580-4.5, NP28d-f1-2580-4.5, and NP-28d-f3-2580-4.5. Essentially this is a comparison between specimens of varying fiber contents with the same span-to-depth ratio and depth at 28 days of ambient curing. The comparison of the mean first crack strengths, ultimate strengths and the associated statistics of these prisms are presented in Table 6.10. According to the statistics in Table 6.11, there appears to be low amounts of variability within data sets. Also, based on the results presented, there appears to be a linear increase in the first crack stress and ultimate stress as the fiber content increases from 1 $\%$ to $3 \%$. Furthermore, the increase in strength is shown graphically in Figure 6.5.

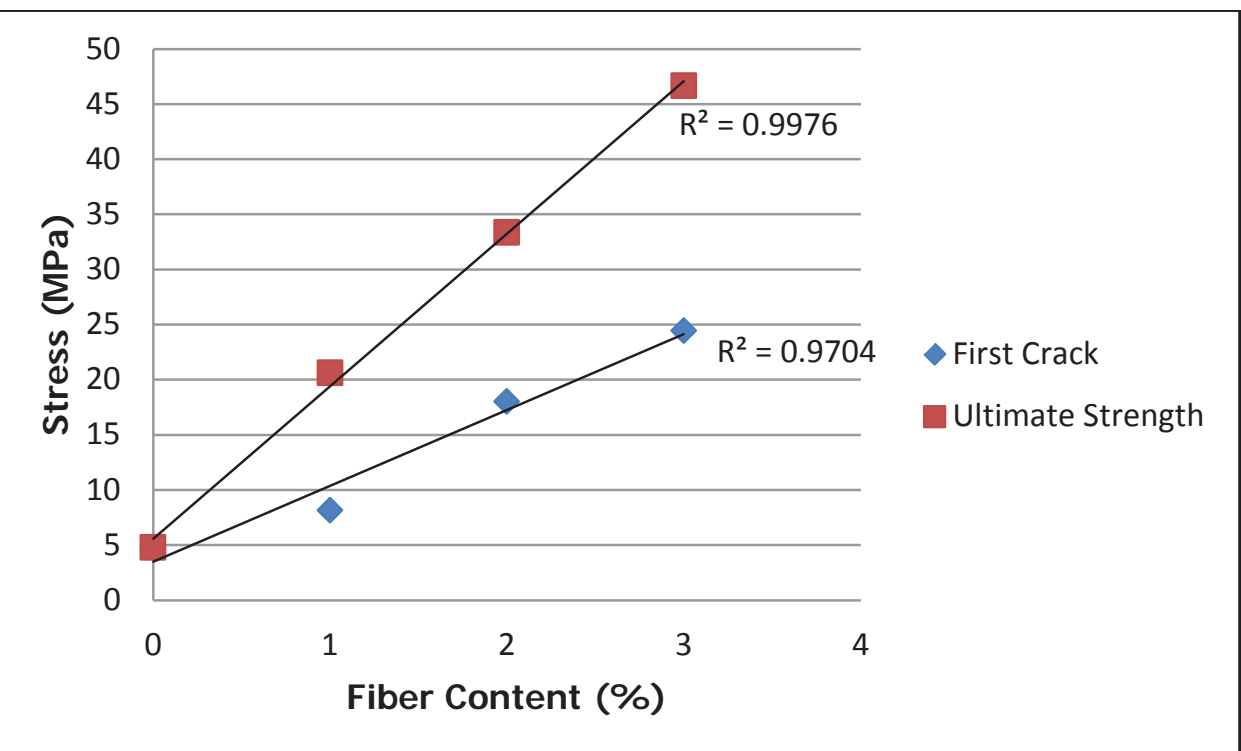

Figure 6.5: First crack and ultimate strengths at various fiber contents Note: $1 \mathrm{ksi}=6.89 \mathrm{MPa}$ 
Table 6.10

First crack and ultimate strengths at various fiber contents

\begin{tabular}{|r|r|r|r|r|r|r|}
\hline $\mathbf{V}_{\mathbf{f}}(\boldsymbol{\%})$ & $\boldsymbol{\sigma}_{\mathbf{f}}(\mathbf{M P a})$ & \multicolumn{1}{|c|}{ Std. Dev. } & C.O.V. & $\boldsymbol{\sigma}_{\mathbf{u}}(\mathbf{M P a})$ & Std. Dev. & C.O.V. \\
\hline 0 & 4.75 & 0.39 & 8.19 & 4.75 & 0.39 & 8.19 \\
\hline 1 & 8.13 & 0.92 & 11.33 & 20.61 & 2.14 & 10.38 \\
\hline 2 & 17.70 & 2.17 & 12.27 & 33.32 & 1.80 & 5.41 \\
\hline 3 & 24.41 & 1.00 & 4.11 & 46.64 & 2.66 & 5.71 \\
\hline
\end{tabular}

Note: $1 \mathrm{ksi}=6.89 \mathrm{MPa}$

From this plot it can be concluded that the first crack strength and ultimate strength for $0 \%$ fiber content are equal. Second in either case the increase in strength with fiber content appears to follow a linear relationship, with R-squared values of 0.9976 for ultimate strength and 0.9704 for first crack. This is in agreement with previous work discussed in chapter 4 (Section 4.9). In addition there may be an increased difference between ultimate strength and first crack strength as fiber content increases. From the previous statements this would be a fair conclusion if the strengths increase linearly from the same origin associated with the ultimate strength at $0 \%$ fiber content.

Turning now the shapes of P-w curves for a specimen with 0\% fibers (Figure 6.6), it can be concluded that the behavior up until the peak load is nearly linear. After the peak load the material exhibits a softening behavior until failure at a Crack opening around $0.3 \mathrm{~mm}$. If $2 \%$ fibers are added (Figure 6.7), the fibers allow for strengthening of the material. The loads achieved, with the addition of $2 \%$ fibers, is just over 6 times greater than that of the unreinforced material. Similar to unreinforced UHPC, the material with fibers exhibits a softening behavior after the peak, but the crack opening has reached almost $9 \mathrm{~mm}$ and still retains $20 \%$ of its ultimate capacity. By comparing these to plot it becomes apparent that the addition of fibers to a UHPC matrix leads to a considerable increase in strength and fracture toughness. 


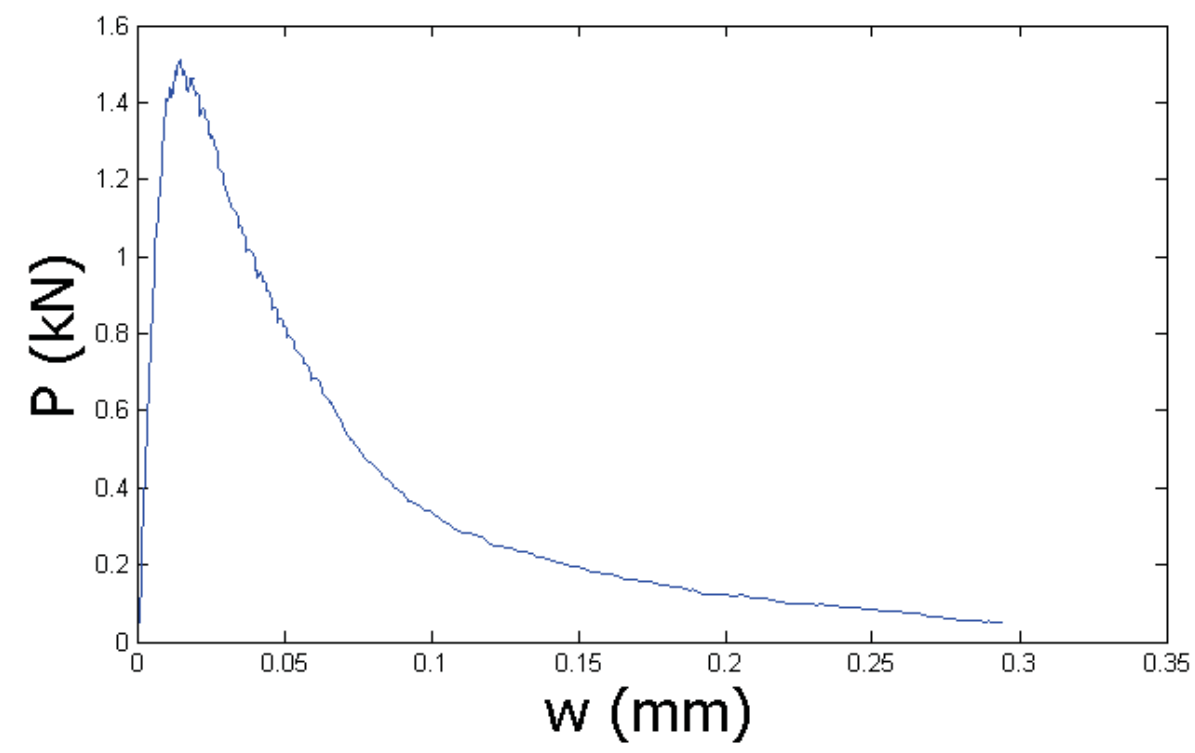

Figure 6.6: Average P-w curve for NP-A-28d-f0-2580-4.5

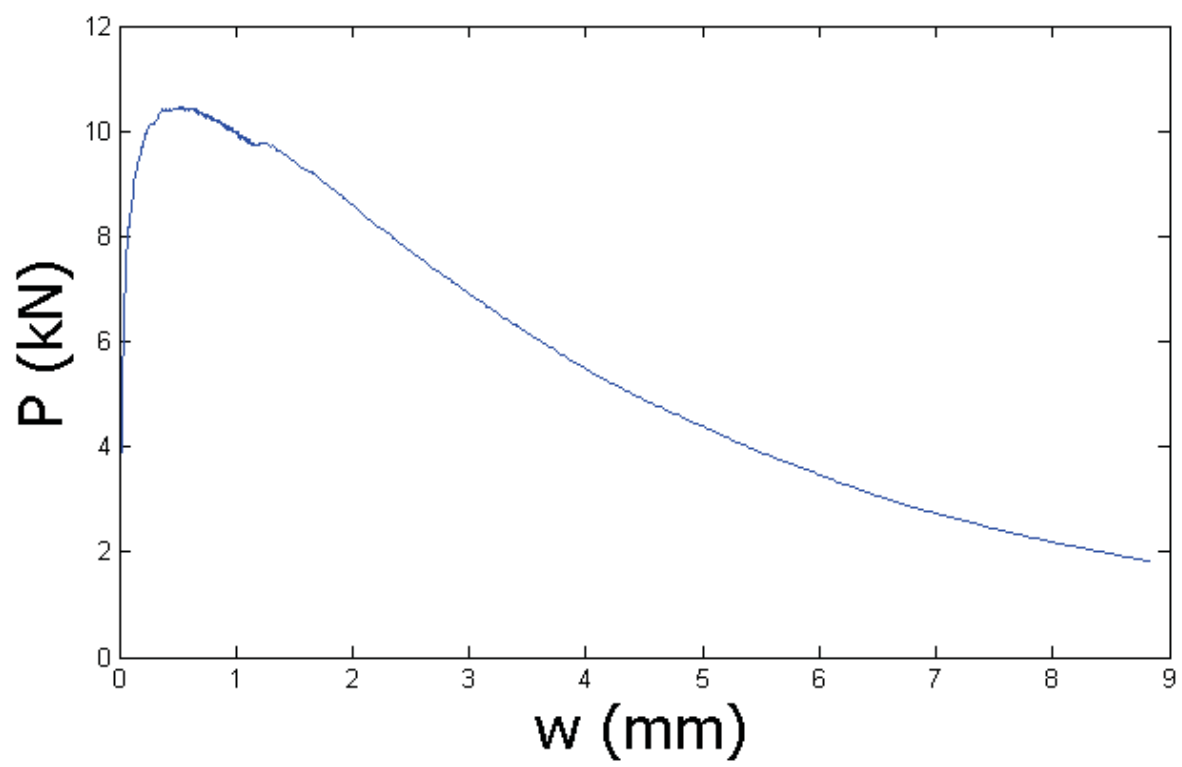

Figure 6.7: Average P-w curve for NP-A-28d-f2-2580-4.5 
The fracture energies for varying fiber contents of the above described specimens appear in Table 6.11. Based on these results it can be said that the fracture energy increases with increasing fiber contents. A plot of the fracture energies for each specimen in the data sets with fiber content is presented in Figure 6.8. This plot shows that similar to the strengths, the fracture energy increases with increasing fiber content, which agrees with previous work discussed in chapter 4 (Section 4.9). Additionally, Figure 6.8 also shows the spread of data points, which appear to show little variation, which agrees with Table 6.11 .

Table 6.11

First crack and ultimate strength with fiber content

\begin{tabular}{|r|r|r|r|}
\hline $\mathbf{V}_{\mathbf{f}}(\boldsymbol{\%})$ & $\begin{array}{c}\mathbf{G}_{\mathbf{f}, \mathbf{4 0}} \\
\left(\mathbf{k J} / \mathbf{m}^{\mathbf{2}}\right)\end{array}$ & \multicolumn{1}{c|}{$\begin{array}{c}\text { Std. } \\
\text { Dev. }\end{array}$} & C.O.V. \\
\hline 0 & 0.02 & 0.01 & 23.55 \\
\hline 1 & 9.53 & 0.61 & 6.39 \\
\hline 2 & 16.21 & 1.78 & 11.00 \\
\hline 3 & 23.79 & 1.89 & 7.95 \\
\hline
\end{tabular}

Note: $1 \mathrm{ft}-\mathrm{lb}=1.36 \mathrm{~J}, 1 \mathrm{~m}=3.28 \mathrm{ft}$

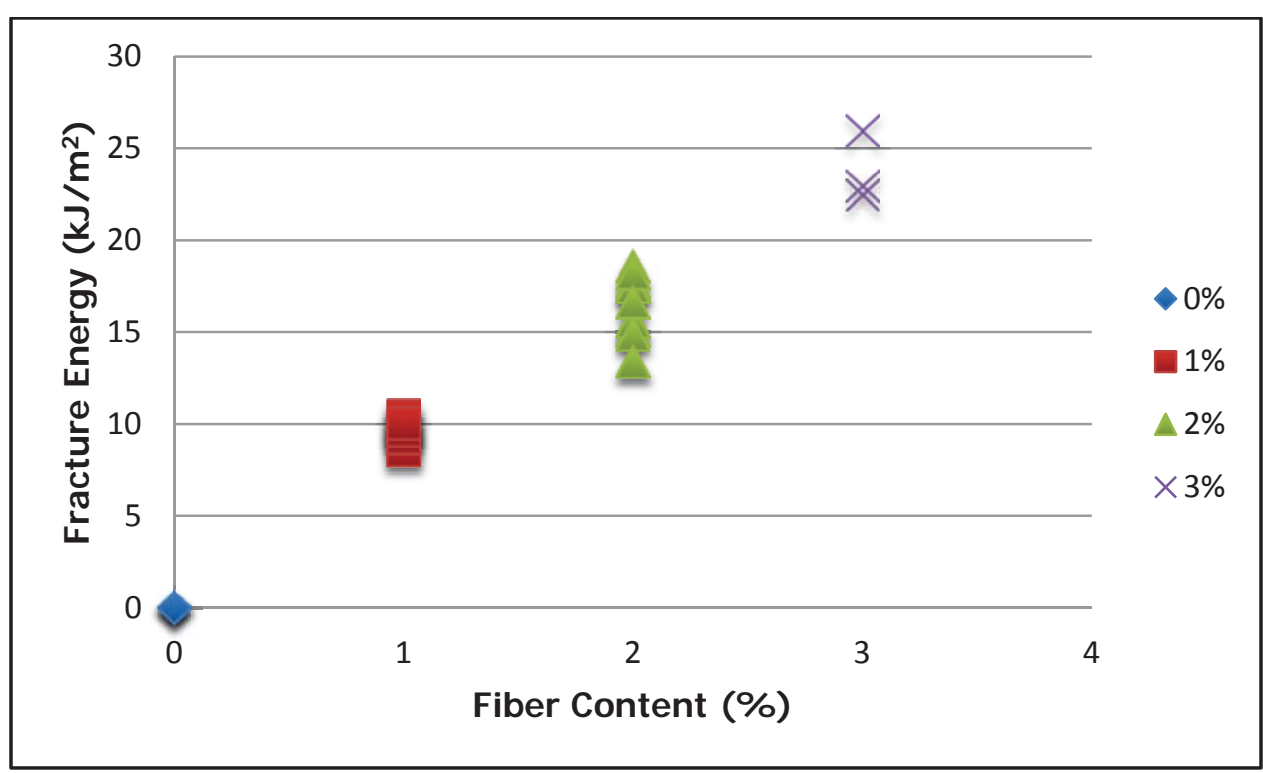

Figure 6.8: Fracture energy for various fiber contents Note: $1 \mathrm{ft}-\mathrm{lb}=1.36 \mathrm{~J}, 1 \mathrm{~m}=3.28 \mathrm{ft}$ 


\subsubsection{Age}

The results of age on the first crack and ultimate strength for mixes of various fiber contents are shown in figures 6.9. It can be said based on this plot that as age increases the strength of the material increases. Looking specifically at the first crack (Figure 6.10) and ultimate (Figure 6.11) strengths it can be said that there is an increase in strength development as the age of the mix increases. This can be attributed to the strengthening of the material as the concrete cures over time. At three days, however, there is an in discrepancy with $0 \%$ fibers where the strength is higher than older specimens. This is most likely associated with the lack of a significant number of specimens tested, as there was only one. Both plots show an increase in the strength of the material with increasing fiber content, which is in agreement with the above conclusions.

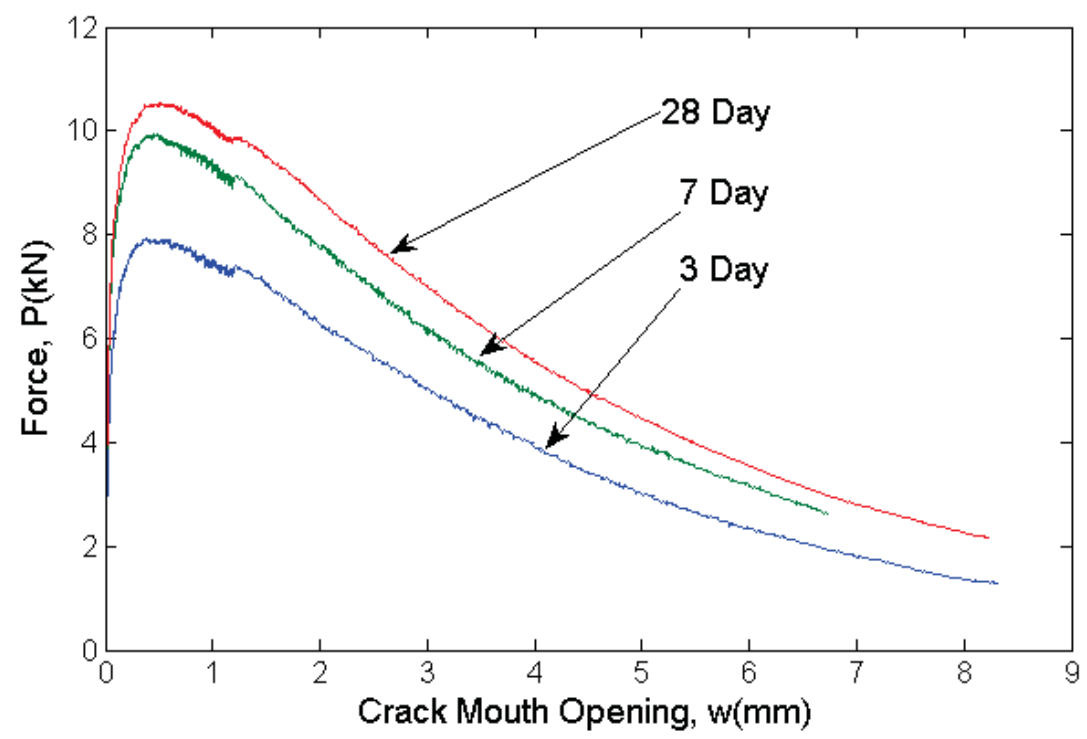

Figure 6.9: Change in $P-w$ curves with age 


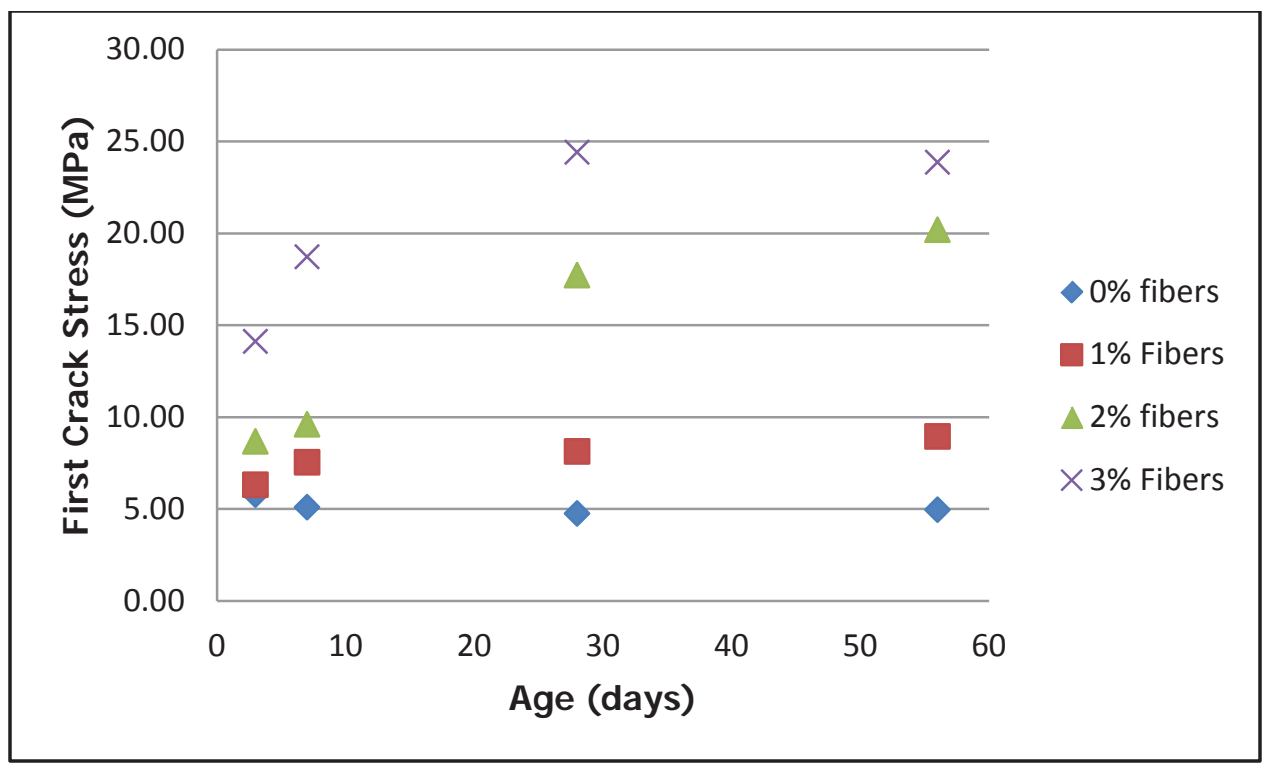

Figure 6.10: Time development of first crack strength for various fiber contents Note: $1 \mathrm{ksi}=6.89 \mathrm{MPa}$

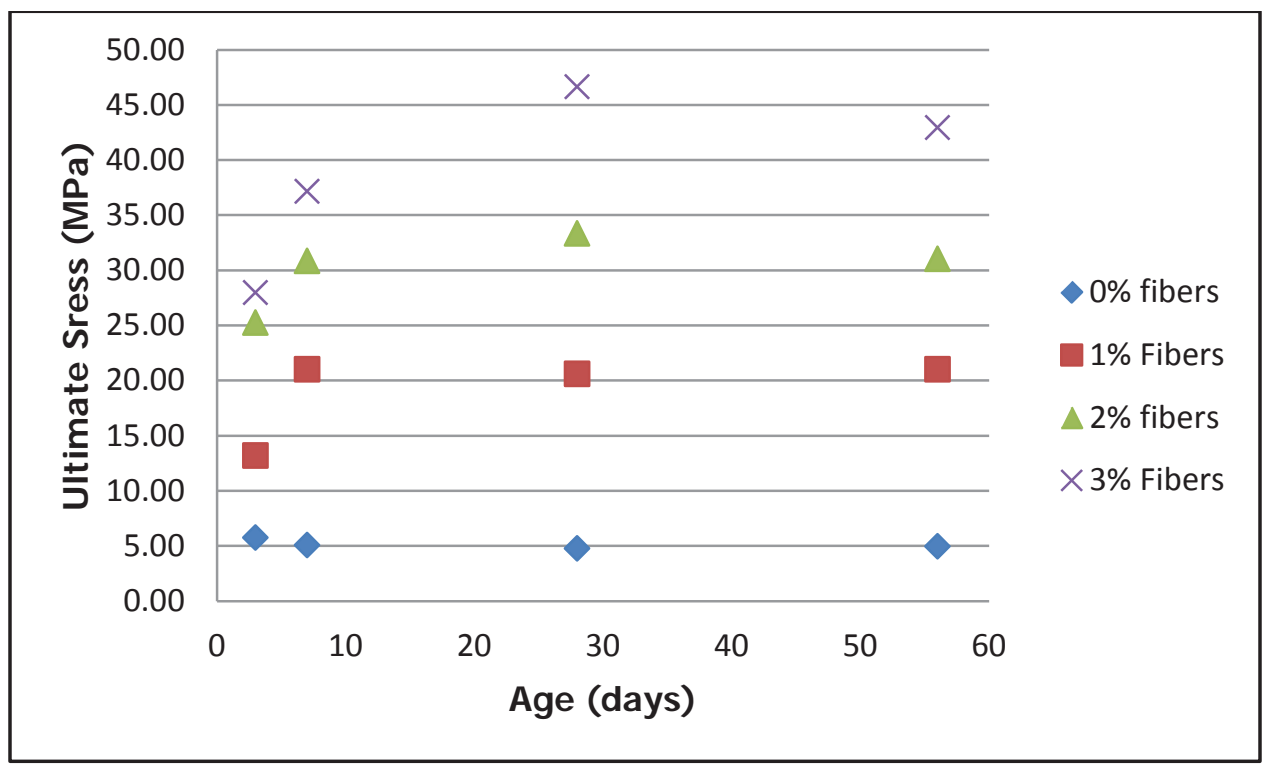

Figure 6.11: Time development of ultimate strength for various fiber contents Note: $1 \mathrm{ksi}=6.89 \mathrm{MPa}$

The age evolution of fracture energy is shown in Figure 6.12. As the prisms cure there is an initial increase in fracture energy, which is most likely associated with improvement to the fiber-matrix interface over time (chapter 4). In the case of specimens with $2 \%$ and $3 \%$ fibers there is a noticeable decrease in fracture energy. As 
mentioned previously (Section 4.7.1) it has been stated that the fiber efficiency for UHPC is optimized at a fiber volume of around $1.5 \%$ by volume. This would explain the increase in fracture as the material stiffens with age.

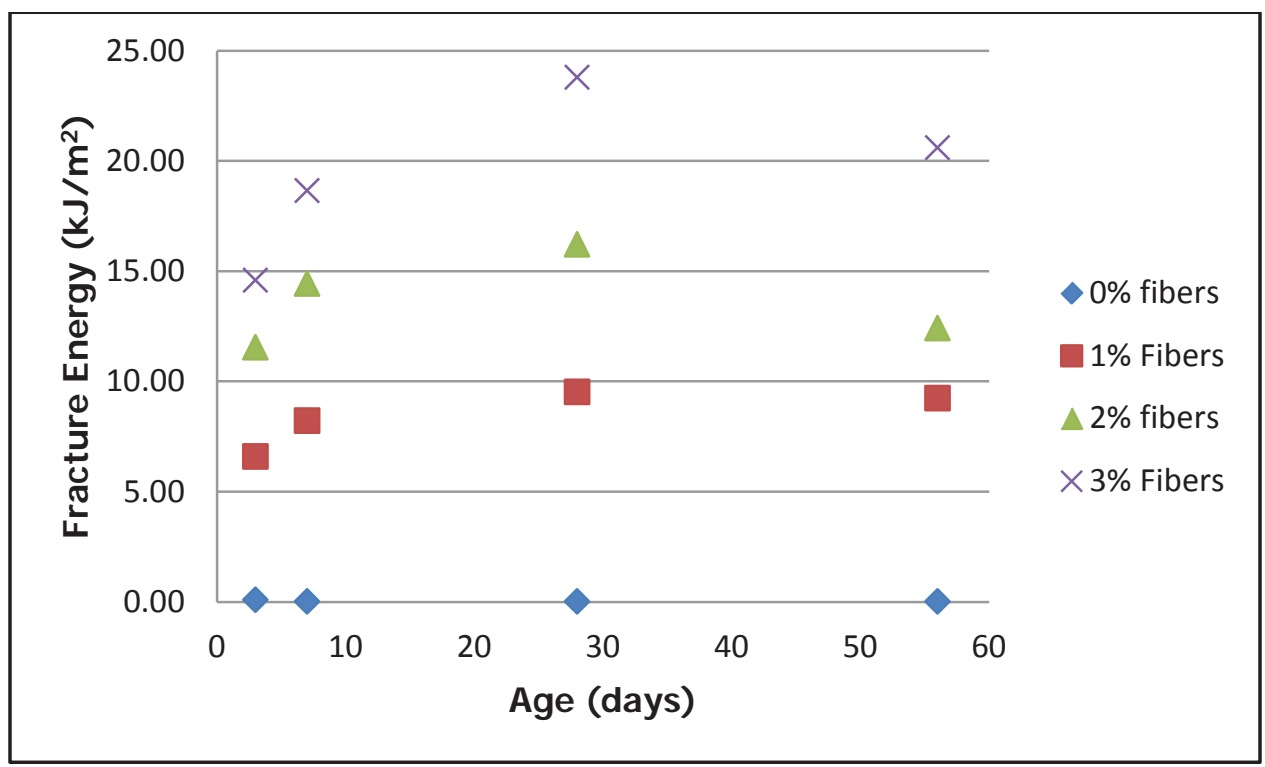

Figure 6.12: Time development of fracture energy for various fiber contents Note: $1 \mathrm{ft}-\mathrm{lb}=1.36 \mathrm{~J}, 1 \mathrm{~m}=3.28 \mathrm{ft}$

\subsubsection{Span-to-Depth}

As previously mentioned this research, in addition to looking at variations in material propertes, this research looked at variations in geometric properties. The first to be discussed is the change in length, which was reported as span-to-depth ratios. Figure 6.13 shows a comparison plot of $\mathrm{P}-\mathrm{w}$ curves for various S/D ratios. It is apparent that as the S/D increases the load carriying capacity decreases. The strength of the material at first crack and ultimate are plotted in Figure 6.14 and Figure 6.15, respectively. These figures report the strengths for changing S/D ratios, for specimens of different fiber contents at various ages. Begining with three days Figure 6.14 shows the three distinct groups; the first with two bars are specimens with $1 \%$ fibers, the second with four bars are specimens $2 \%$ fibers, and the third are specimens $3 \%$ fibers. In each group the S/D ratio increases from left to right. Similar groupings were used for later ages in Figure 6.14, and for Figure 6.15. 


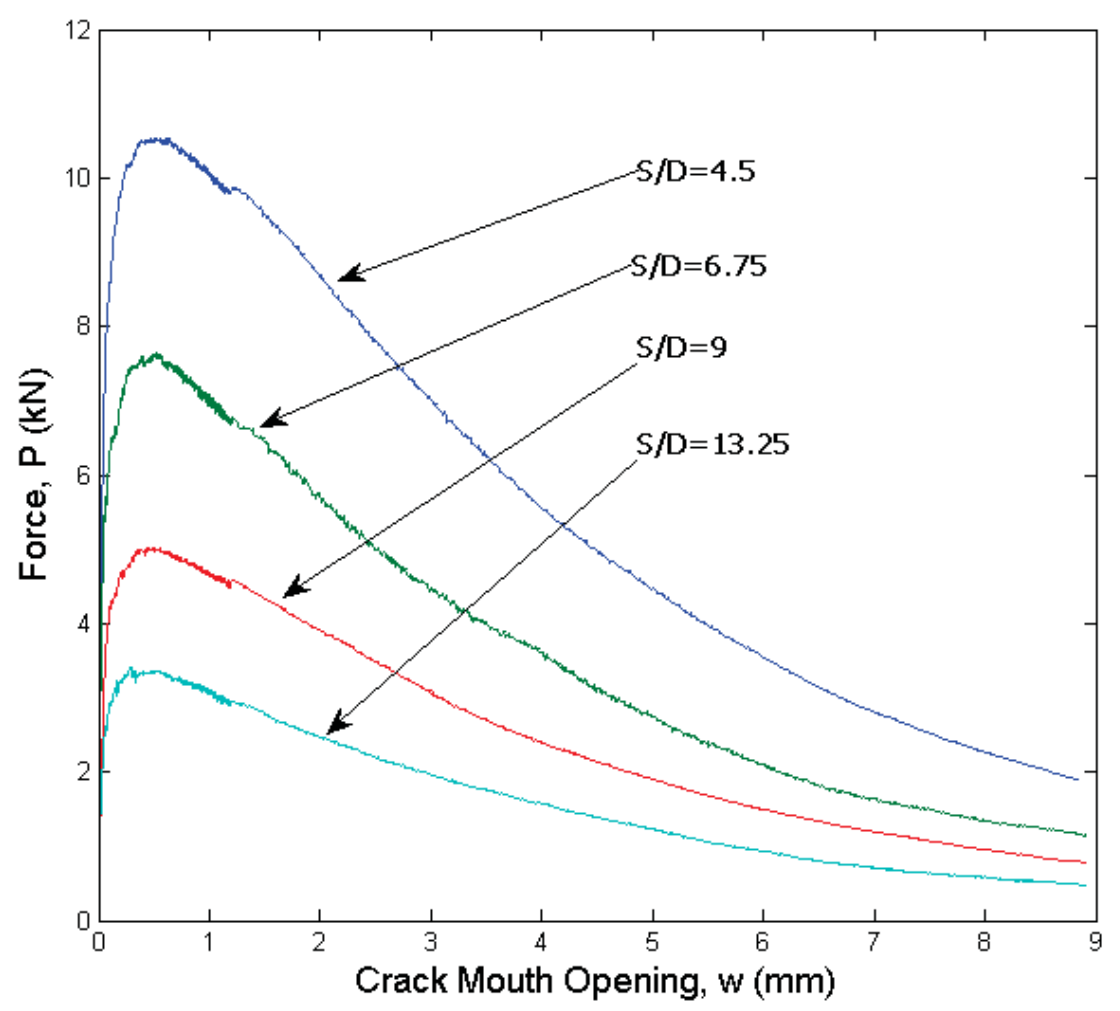

Figure 6.13: Change in P-w curve with length

It was thought that the change in length may exhibit a noticeable size effect. As mentioned (Chapter 2) this would most likely be associated with the statistical size effect. However, from these results there appears to be very little variation in the strength of the material as the S/D ratio changes. These plots also confirm previous conclusions that the strengths of the material increase with increased age and fiber content.

Figure 6.16 depicts the change in fracture energy for specimens of different S/D ratios with changes in age and fiber content. Figure 6.16 shows that the there is a decrease in fracture energy with increased S/D ratio, which means the length of the material decreases its ability to resist fracture. This is due to the decrease in load that occurs from the increase in length of the material. These figures agree with the conclusions 
made previously about fracture energy with variations in age and fiber content. It is believed that if the stress in the prism was calculated than the fracture energy may be more constant and not show a significant decrease.

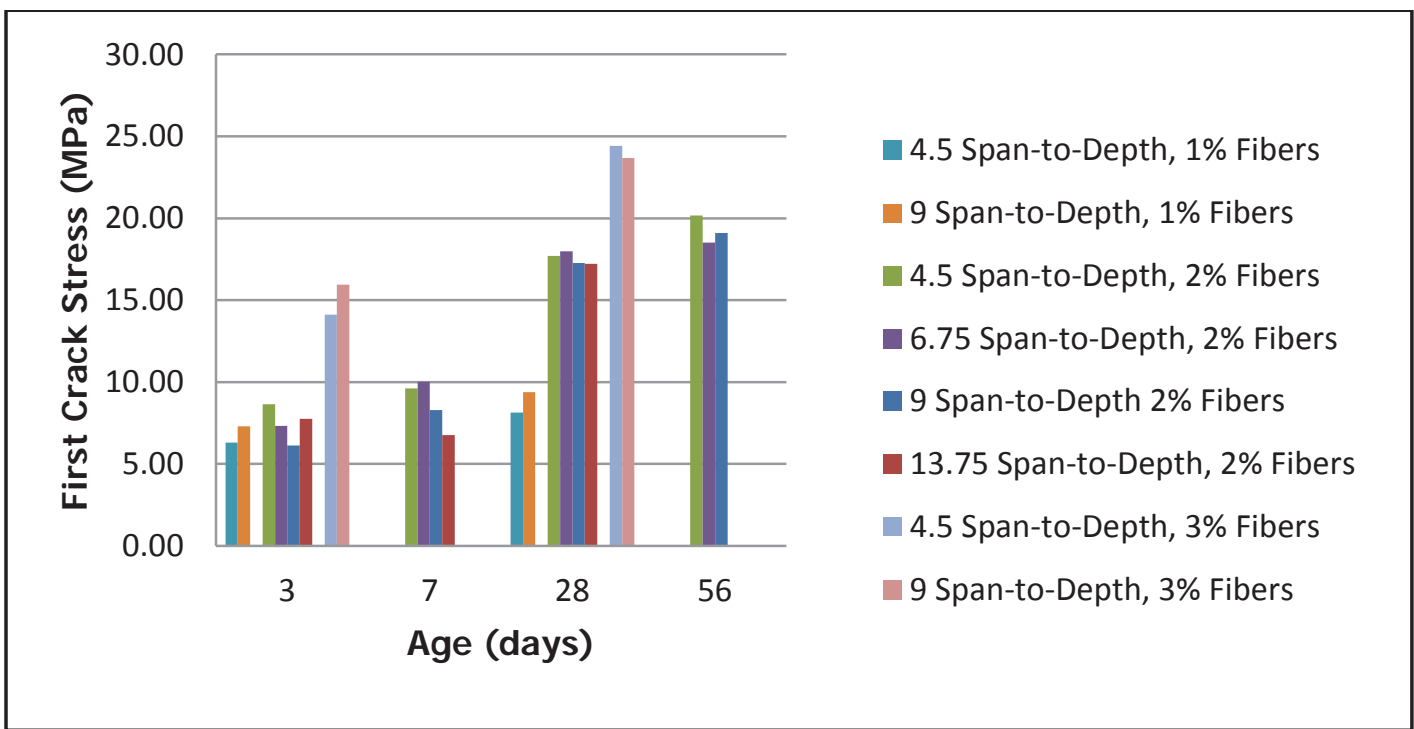

Figure 6.14: Time development of first crack strength for various S/D ratios and fiber contents Note: $1 \mathrm{ksi}=6.89 \mathrm{MPa}$

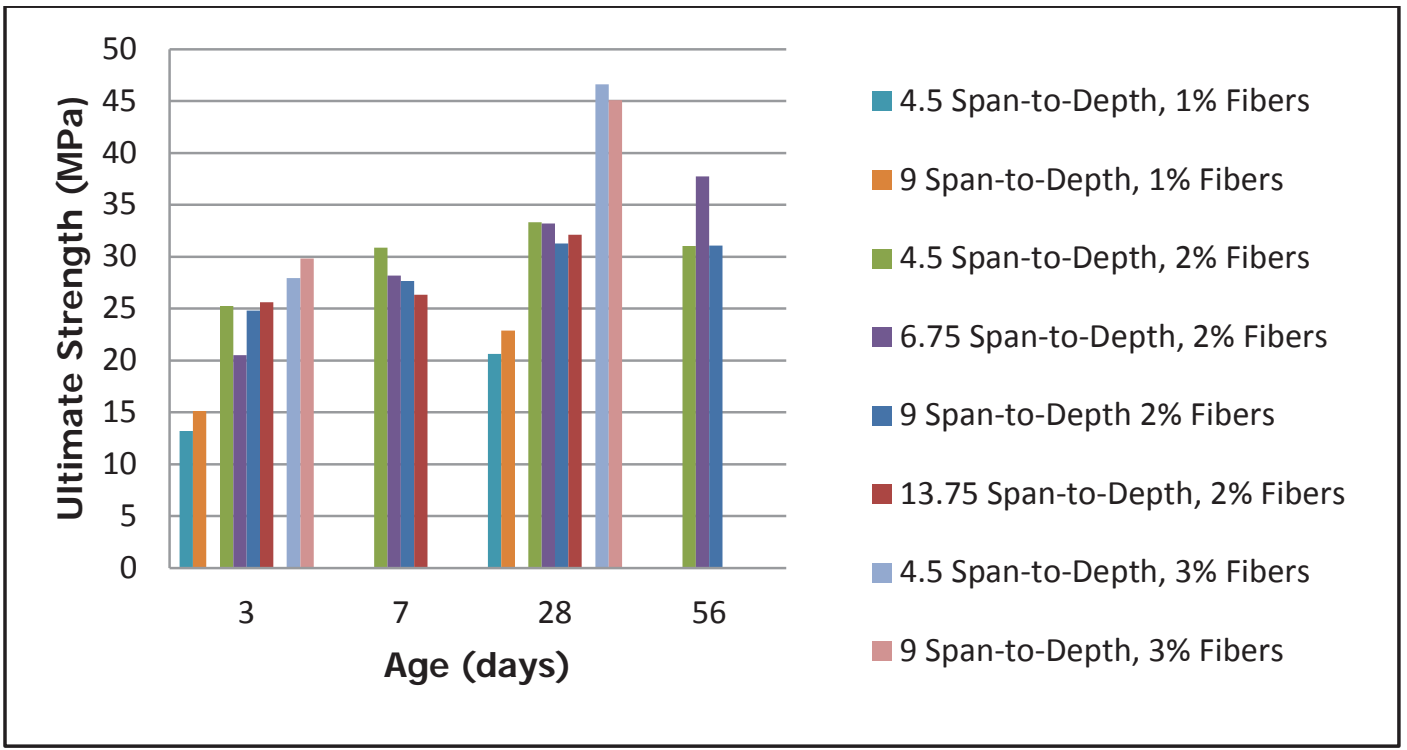

Figure 6.15: Time development of ultimate strength for various S/D ratios and fiber contents Note: $1 \mathrm{ksi}=6.89 \mathrm{MPa}$ 


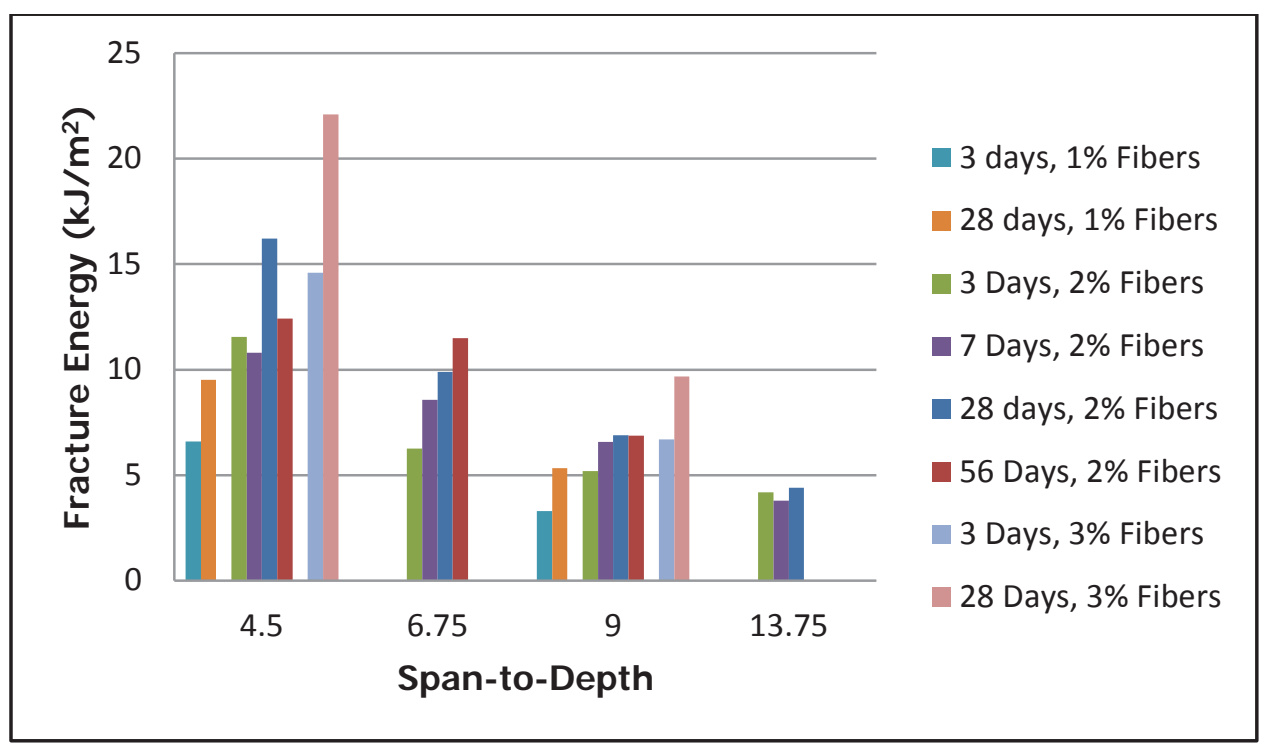

Figure 6.16: Fracture energy with change in S/D ratio for various fiber contents and ages Note: $1 \mathrm{ft}-1 \mathrm{~b}=1.36 \mathrm{~J}, 1 \mathrm{~m}=3.28 \mathrm{ft}$

\subsubsection{Cross-Section}

It was mentioned in Chapter 2 that the change in cross-section of concrete flexural beams leads to a decrease in material strength attributed to the size effect. It is for this reason that this research looked at the variations in fracture behavior with a change in cross-section. As previously mentioned Equation 4.1 incorporates the height of the specimen to account for the size effect. It is for this reason that Figure 6.17 shows the change in the first crack strength for beams of different fiber contents and ages with beam depth. The results of Figure 6.17 confirms that as previously stated (Chapter 4) that UHPFRC specimens do fall victim to the size effect with increased cross-section. Begining with $51 \mathrm{~mm}\left(2580 \mathrm{~mm}^{2}\right)$ specimen Figure 6.17 shows the three distinct groups; the first with two bars are specimens with $1 \%$ fibers, the second with four bars are specimens $2 \%$ fibers, and the third are specimens $3 \%$ fibers. In each group the age increases from left to right. Similar groupings were used for the $76 \mathrm{~mm}\left(5180 \mathrm{~mm}^{2}\right)$ prism in figure 6.14 , and for the following plots in this section. 
Figure 6.18 is similar to Figure 6.17, but it reports the corrected values using Equation 4.1. Based on Figure 6.18, other than 28 day specimens with $3 \%$ fiber content it can be said that these use of this equation does normalize the first crack strength.

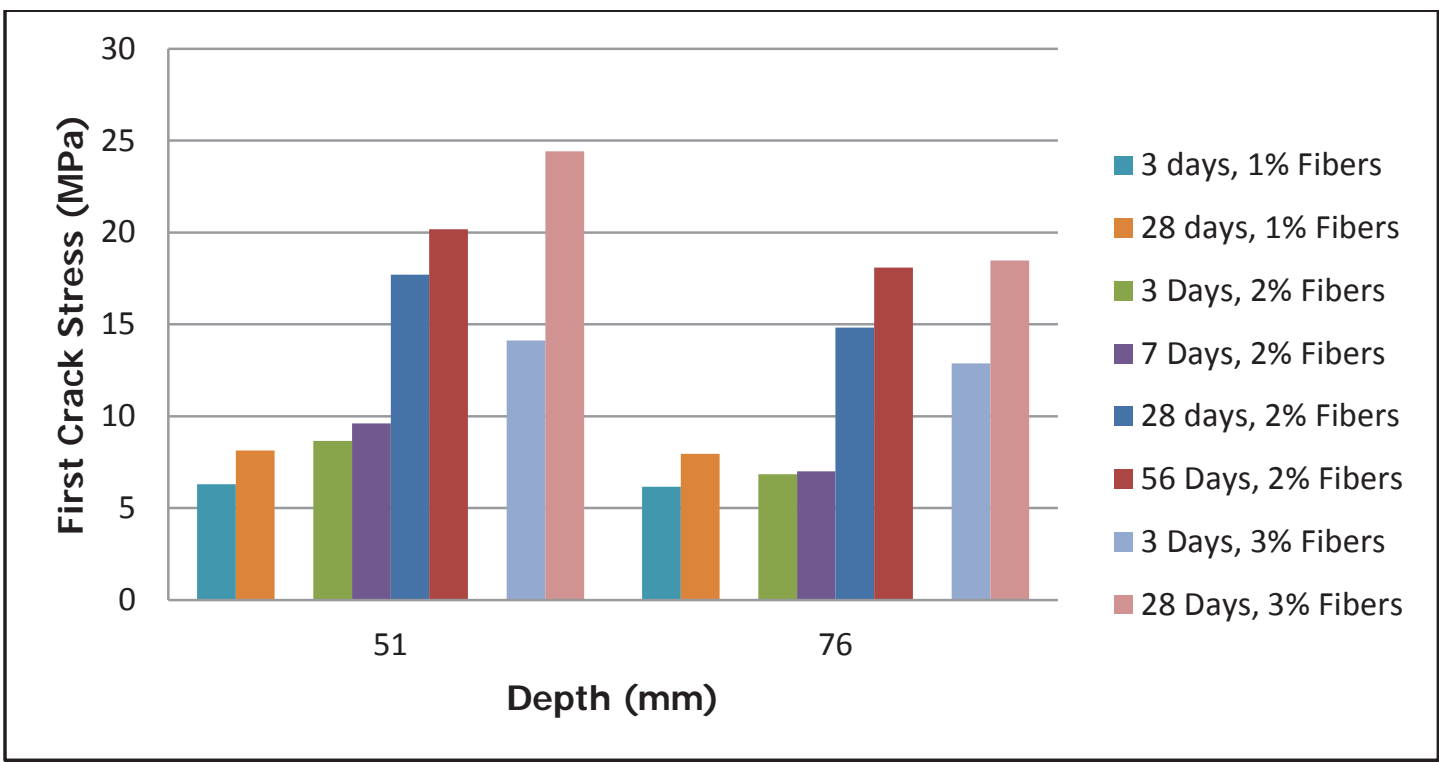

Figure 6.17: First crack strength with change in depth for various fiber content and ages Note: $1 \mathrm{ksi}=6.89 \mathrm{MPa}$

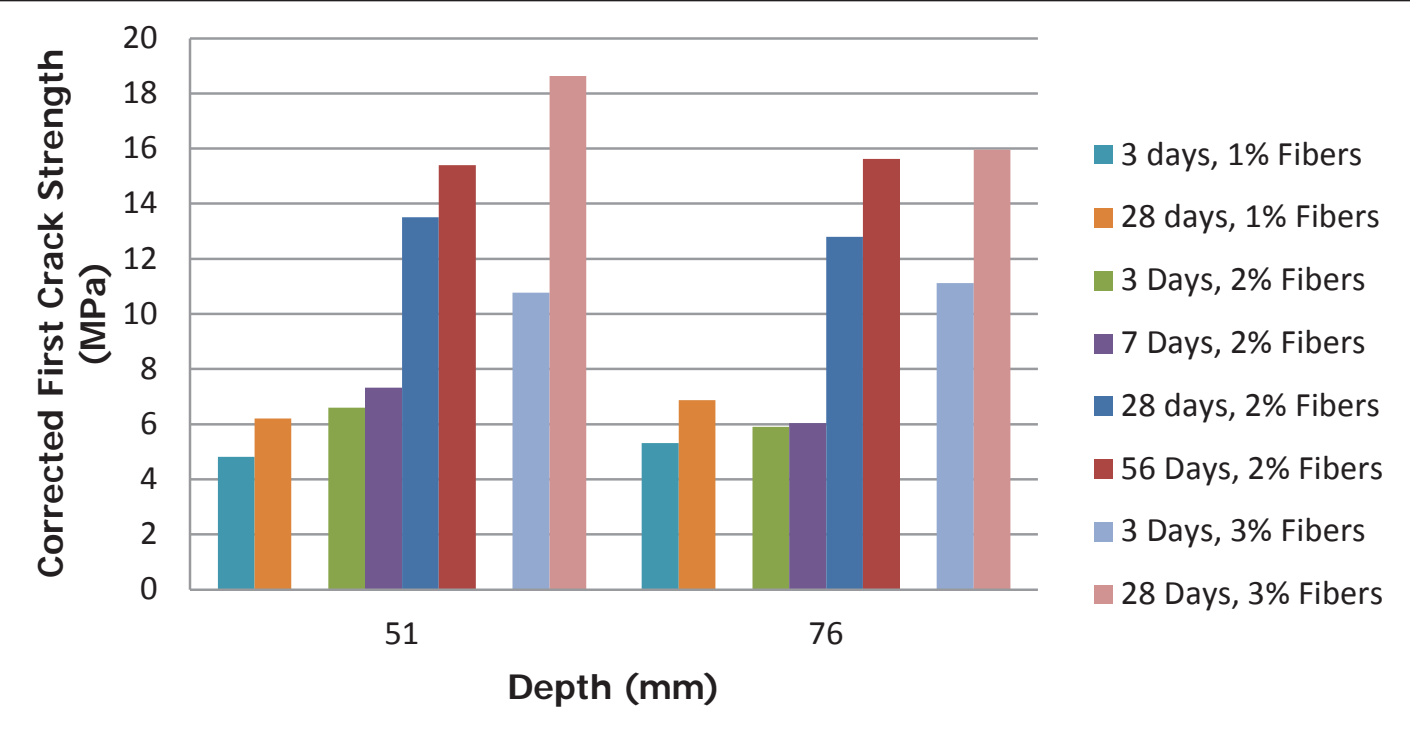

Figure 6.18: Corrected first crack strength

Note: $1 \mathrm{ksi}=6.89 \mathrm{MPa}$ 
The ultimate strength also appeared to exhibit strength reduction due to the size effect, as shown in Figure 6.19. Just as with the first crack strength the modifying equation was applied to the ultimate strength (Figure 6.20), which showed similar results to Figure 6.18.

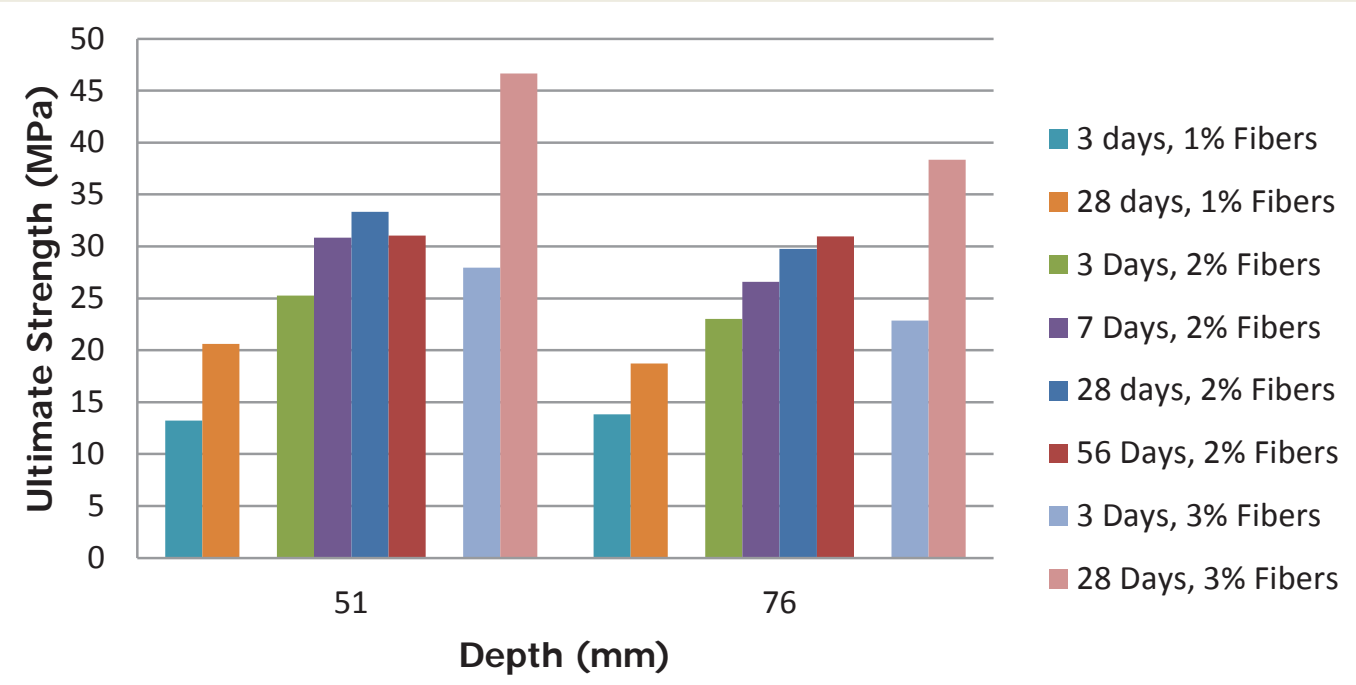

Figure 6.19: Ultimate strength with change in depth for various fiber content and ages Note: $1 \mathrm{ksi}=6.89 \mathrm{MPa}$

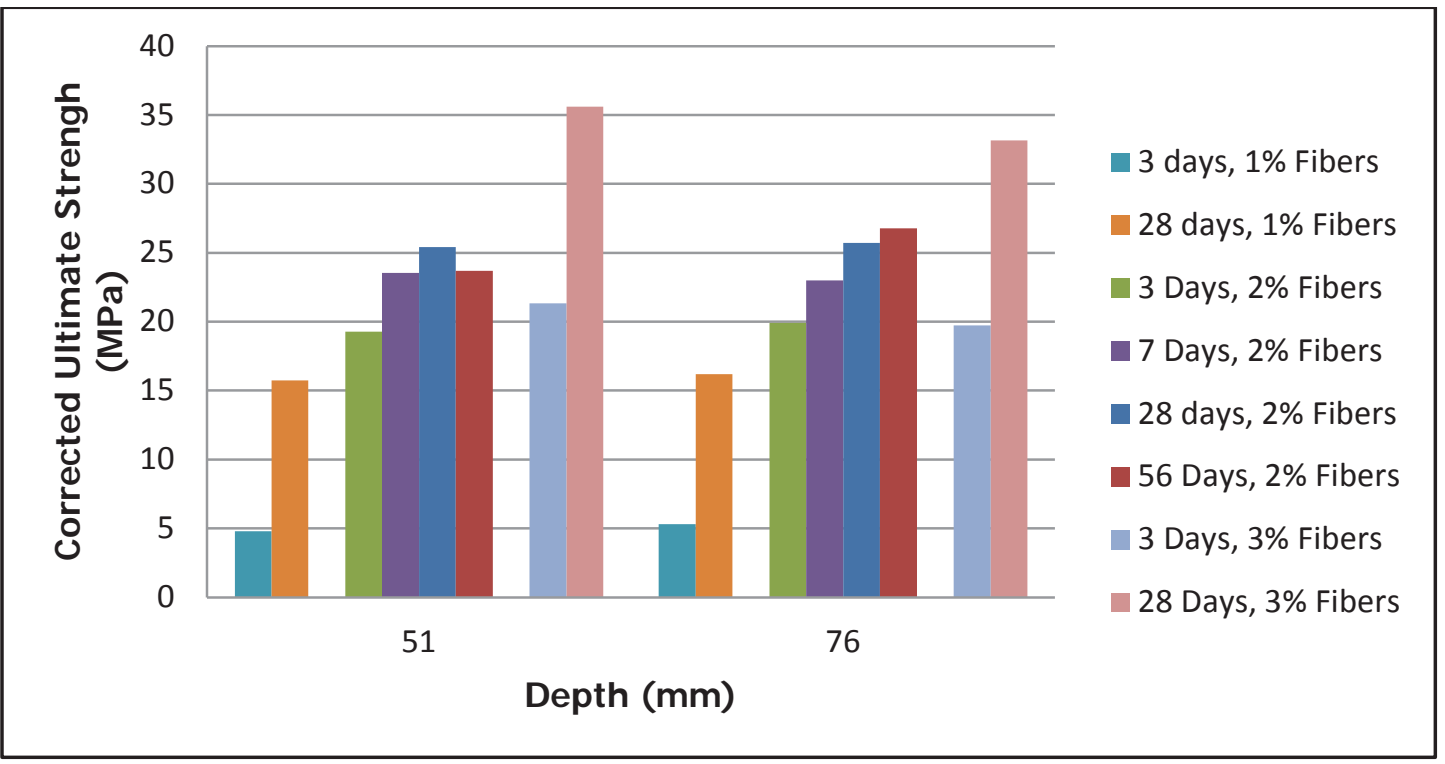

Figure 6.20: Corrected ultimate strength Note: $1 \mathrm{ksi}=6.89 \mathrm{MPa}$ 


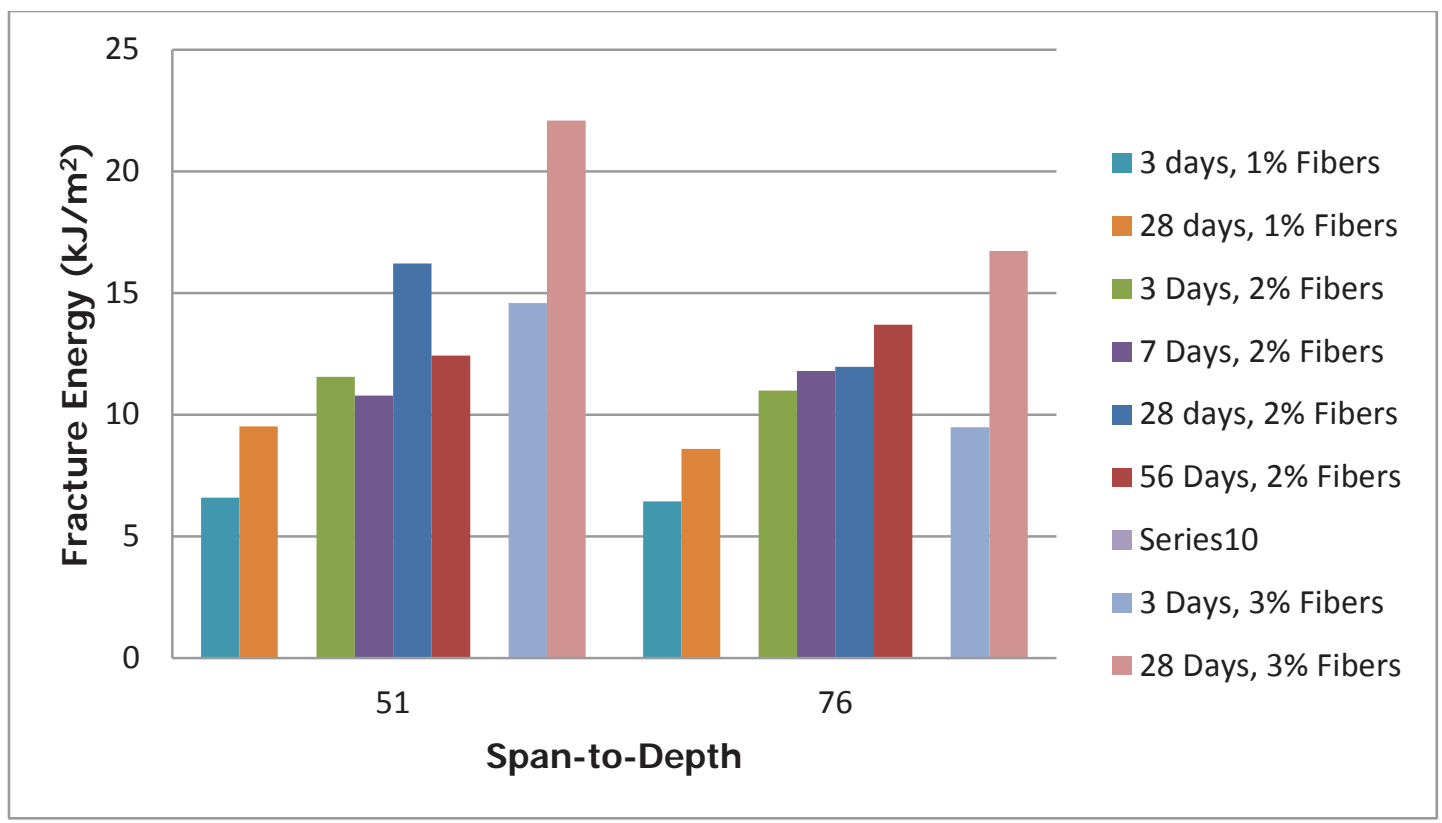

Figure 6.21: Fracture energy with change in depth for various fiber content and ages Note: $1 \mathrm{ft}-\mathrm{lb}=1.36 \mathrm{~J}, 1 \mathrm{~m}=3.28 \mathrm{ft}$

Figure 6.21 reports the change in fracture energy for beams of various ages and fiber contents with prism depth. Aside from the results of the 7 day prisms with $2 \%$ fibers and the 56 day prisms with $2 \%$ fibers there is a decrease in fracture energy with increased beam depth. This means that as the beam cross-section increases the material has less resistance to fracture.

\subsubsection{Curing}

As was discussed in Chapter 4 it has been concluded that the use of thermal treatment can increase the strength of the material or reach equivalent strengths at early ages. Figure 6.22 shows the first crack strength and Figure 6.23 reports the ultimate strengths of specimens with varying fiber contents, depths, and lengths with respect to type of curing regime. The fracture energy for prisms of varying fiber contents, depths, and S/D ratios plotted against the type of curing can be found in Figure 6.24. From this it can be concluded that for the most part there is actually very little change in the fracture energy. 


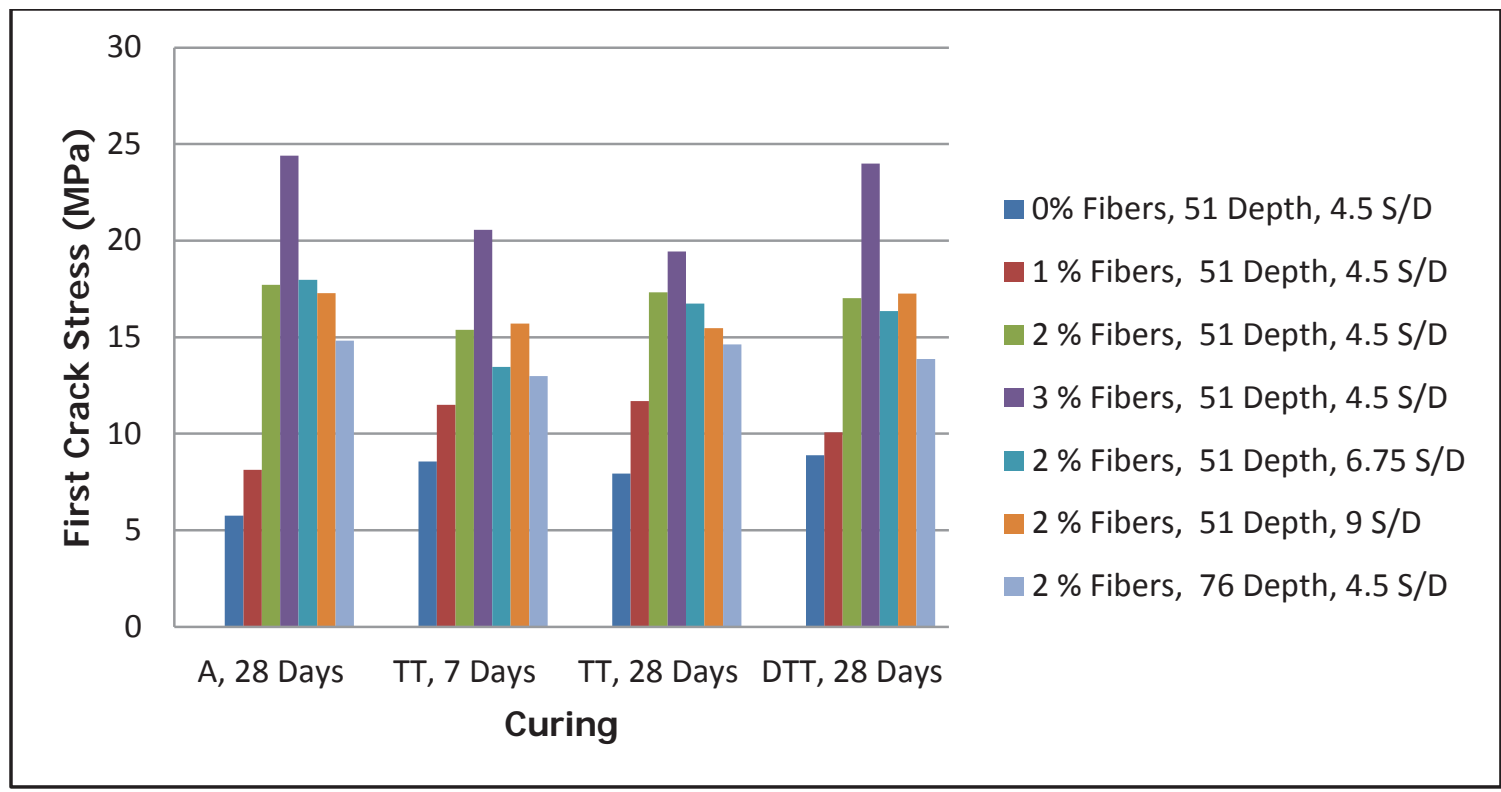

Figure 6.22: First crack strength with different curing Note: $1 \mathrm{ksi}=6.89 \mathrm{MPa}$

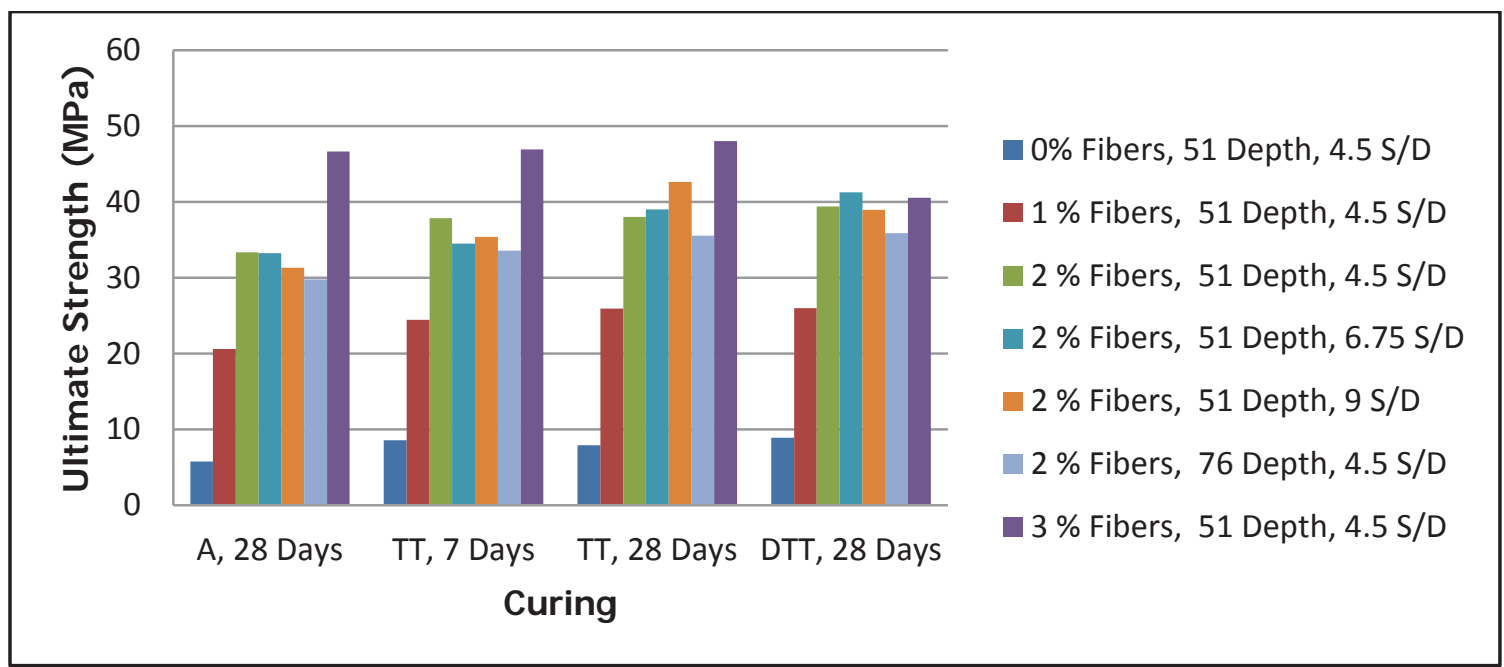

Figure 6.23: Ultimate strength with different curing Note: $1 \mathrm{ksi}=6.89 \mathrm{MPa}$ 


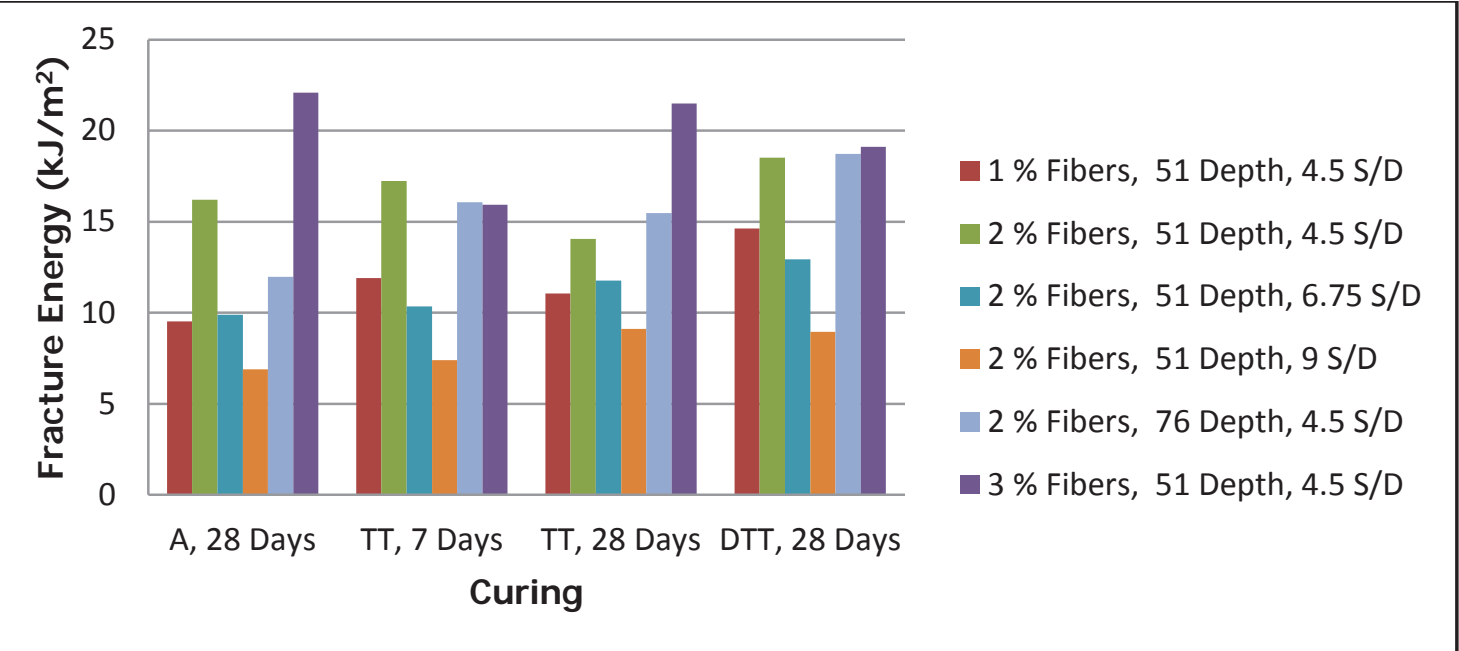

Figure 6.24: Fracture energies with different curing Note: $1 \mathrm{ft}-\mathrm{lb}=1.36 \mathrm{~J}, 1 \mathrm{~m}=3.28 \mathrm{ft}$

\subsection{Modeling}

During testing it was noticed that the shape of the post first-crack P-w curve had a similar shape to that of already established non-linear models that exist in mathematics and science. Some examples are the atomic attraction-repulsion energy function, Weibull probability distribution function (PDF), and the log-normal PDF. Of these the first may be most meaningful, because it consists of attractive and resistive terms. However, this model was not attempted as it was considered after the determination of a viable model. The latter two were attempted, which will be the discussion of the following section.

\subsubsection{Fitting the Data}

The lognormal function is frequently used in reliability analysis (Steinberg 2010).Whereas, the Weibull function (Weibull 1951), as covered in chapter 2 (Section 2.3.3), has been well established to describe the strength of brittle materials (Chawla 1993) and in some research has been used to describe the fracture process of concrete materials using acoustic emissions (Chen and Liu 2004; Dai et al. 2012). Equations 6.2 and 6.3 are modified versions of these distributions and are used to describe the applied load as a function of $\mathrm{w}$ during the fracture process. 
$P(w)=\left(\frac{A}{\sqrt{2 \pi(\gamma w)}}\right) e^{-\left(\frac{1}{2}\left(\frac{\ln (w)-\lambda}{\gamma}\right)^{2}\right)}$

Equation 6.2

The modified lognormal PDF consists of an equation modifier, A, the associated lognormal mean, $\lambda$, and variance, $\varsigma$, and an input CMOD, w.

$P(w)=W_{F} \frac{m}{w_{i}}\left(\frac{w}{w_{i}}\right)^{m-1} e^{-\left(\left(\frac{w}{w_{i}}\right)^{m}\right)}$

Equation 6.3

Similar to the modified lognormal the modified Weibull PDF relies on a distribution modifier, $G$, and an input CMOD, $w$. This equation also incorporates a shape parameter, $m$, and a skewness parameter, $w_{i}$.

An initial fit of the data was performed by inputting values of the equation parameters in such a way that limits the curve so that it underestimate or is equal to the strength and CMOD values, while minimizing the value of the $\chi^{2}$ goodness of fit test. The $\chi^{2}$ test is one of several possible methods that could be used to estimate these parameters (Ang and Tang 2007; Leon and Kittl 1985), which can be performed using equation 6.4.

$\sum_{i=1}^{n}\left[\frac{\left(n_{i}-e_{i}\right)^{2}}{e_{i}}\right]<c_{1-\alpha, f}$ Equation 6.4

where $n_{i}$ is the observed frequency of $n$ number of values within a certain range of values, $e_{i}$ is the theoretical frequency estimated for that same range, $c_{1-\alpha, f}$ is the critical $\chi^{2}$ value at cumulative probability of $1-\alpha$, and $f$ degrees of freedom. The value of $c_{1-\alpha, f}$ can be found using a $\chi^{2}$ table, which is commonly provided in any standard statistics text. The values $\alpha$, and $f$ can further be explained, respectively, as the significance level and the number of samples subtracted by the number of unknown parameters. 
This procedure is demonstrated for a 28 -day $51 \mathrm{~mm}$ depth, $4.5 \mathrm{~S} / \mathrm{D}$ specimens. The best fit of the modified lognormal PDF and the modified Weibull PDF, as shown in Figure 6.19 , were graphically compared to the fracture curve for tested prism. From visual inspection, the modified Weibull achieved a better fit than the Modified Lognormal, suggesting that the P-w curve for UHPC follows a modified Weibull distribution.

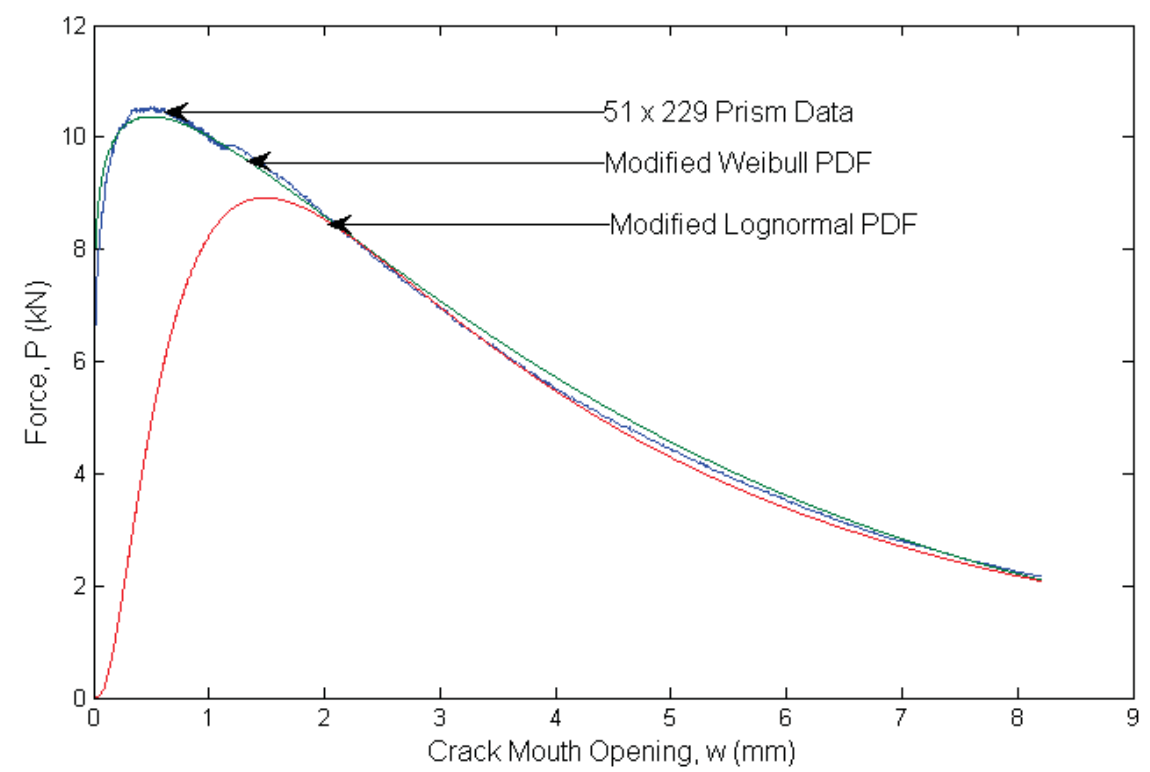

Figure 6.25: P-w curve fit

The best fit was tested only for values of force above $2 \mathrm{kN}$, because the data collected during the fracture process never dropped below this value. The force ranges were in increments of $0.5 \mathrm{kN}$ until values above $10 \mathrm{kN}$ (see Table 3), which lead to an $\mathrm{n}$ of 18 . For both models the f value would be 13 , because there are four unknown parameters. If a confidence level $(\alpha)$ of 0.05 was chosen the corresponding $\chi^{2}$ reference value $\left(c_{1-\alpha, f}\right)$ would be 23.7. Based on this analysis it can be concluded that the modified Weibull distribution passes and the modified lognormal fails the $\chi^{2}$ test. 
Table 6.12

Chi-squared goodness of fit test

\begin{tabular}{|c|c|c|c|c|c|}
\hline $\begin{array}{c}\text { Force } \\
(\mathbf{k N})\end{array}$ & $\mathbf{n}_{\mathbf{i}}$ & $\begin{array}{c}\mathbf{e}_{\mathbf{i}} \\
\text { Weibull }\end{array}$ & $\mathbf{e}_{\mathbf{i}}$ Lognormal & $\begin{array}{l}\left(n_{i}-e_{i}\right)^{2} / e_{i} \\
\text { Weibull }\end{array}$ & $\begin{array}{c}\left(\mathrm{n}_{\mathrm{i}}-\mathrm{e}_{\mathrm{i}}\right)^{2} / \mathrm{e}_{\mathrm{i}} \\
\text { Lognormal }\end{array}$ \\
\hline$<2.0$ & 59 & 0 & 596 & NA & NA \\
\hline $2-2.5$ & 227 & 232 & 363 & 0.11 & 50.95 \\
\hline $2.5-3.0$ & 288 & 250 & 357 & 5.78 & 13.34 \\
\hline $3.0-3.5$ & 218 & 215 & 303 & 0.04 & 23.84 \\
\hline $3.5-4.0$ & 196 & 189 & 273 & 0.26 & 21.72 \\
\hline $4.0-4.5$ & 170 & 170 & 250 & 0.00 & 25.60 \\
\hline $4.5-5.0$ & 164 & 214 & 238 & 11.68 & 23.01 \\
\hline $5.0-5.5$ & 149 & 143 & 230 & 0.25 & 28.53 \\
\hline $5.5-6.0$ & 136 & 135 & 228 & 0.01 & 37.12 \\
\hline $6.0-6.5$ & 129 & 128 & 235 & 0.01 & 47.81 \\
\hline $6.5-7.0$ & 132 & 124 & 247 & 0.52 & 53.54 \\
\hline $7.0-7.5$ & 123 & 123 & 272 & 0.00 & 81.62 \\
\hline $7.5-8.0$ & 129 & 127 & 322 & 0.03 & 115.68 \\
\hline $8.0-8.5$ & 149 & 140 & 432 & 0.58 & 185.39 \\
\hline $8.5-9.0$ & 157 & 166 & 456 & 0.49 & 196.05 \\
\hline $9.0-9.5$ & 199 & 214 & 0 & 1.05 & $\mathrm{NA}$ \\
\hline $9.5-10.0$ & 560 & 565 & 0 & 0.04 & $\mathrm{NA}$ \\
\hline$>10.0$ & 1617 & 1667 & 0 & 1.50 & $\mathrm{NA}$ \\
\hline Sum & 4802 & 4802 & 4802 & 22.34 & NA \\
\hline
\end{tabular}

Based upon this analysis the parameters A, $\lambda, \varsigma$ for the modified lognormal and those of $\mathrm{W}_{\mathrm{F}}, \mathrm{m}$, and $\mathrm{w}_{0}$ for the modified Weibull were determined to be 21.95, 1.4, 1 and 50 , $4.45,1.1$, respectively. 
From the above plot and the passing of the $\chi^{2}$ test, it can be concluded that the modified Weibull distribution is better for describing the fracture process of UHPFRC. It is for these reasons that the modified Weibull distribution will be used to describe and model the variations in fracture data from the previously mentioned test parameters.

\subsubsection{Fracture Model}

In the previous section it was demonstrated that the P-w curve could be modeled using a modified Weibull distribution. At first glance the model may appear complicated and may be unfamiliar to some readers, which is why it will be discussed in this section. The previous section demonstrated the use of the modified Weibull PDF to describe the shape of the P-w curve. Now that the shape of the curve is known all one needs to do in order to determine the fracture energy is to determine the area under the curve. This is typically done by integrating equation 6.3, however the integral of a PDF in probability is termed the cumulative distribution function (CDF). It just so happens that the use of calculus is not required, as the Weibull CDF is a well-established equation in mathematics. By implementing this equation the modified Weibull CDF (Equation 6.5) can be written in the following way.

$$
G_{f}(w)=\frac{W_{F}}{A_{f}}\left(1-e^{\left(-\left(\frac{w}{w_{i}}\right)^{m}\right)}\right)
$$

This equitation describes the shape of the fracture energy curve, which will increase as one minus the inverse exponential with increasing values of $w$. Again $\mathrm{m}$ and $w_{i}$ simply describe the shape of the fracture energy curve. The power of this model is in the ratio of the modifier, $W_{F}$, and the area of fracture, $A_{f}$, which is related to the fracture energy to cause complete failure. This value based on the fictitious crack model is said to be obtained once the CMOD has reached some critical value, $w_{c}$. From the above results it was concluded that the fracture energy was increased with increasing fiber content, 
$\mathrm{V}_{\mathrm{f}}$, and with first-crack strength, $\sigma_{\mathrm{f}}$. As these values are typical design parameters they were incorporated into the calculation of the G modifier as shown in Equation 6.6.

$W_{F}=\beta V_{f} \sigma_{f}$

Equation 6.6

Based on Equation 2.9 the total fracture energy can be calculated using the following equation.

$G_{f}=\frac{W_{F}}{b(h-a)}$

Equation 6.7

This model was fitted to the data using an internal Matlab function called fit, which allows for the fitting of a user-defined equation. This function is new to the 2011 version of Matlab. The load (p) and CMOD (w) were set as the inputs, and the modified Weibull PDF, as described in Equation 6.3 was the fitting function. An example of this is shown below (Equation 6.8), were $\mathrm{a}, \mathrm{b}$, and $\mathrm{c}$ are $\mathrm{W}_{\mathrm{F}}, \mathrm{m}$, and $\mathrm{w}_{\mathrm{i}}$, respectively. Initial estimates for the modified Weibull parameters were made to assist the function in determining these parameters. In the fit function these were input as estimated start points for a, b, and c, as shown.

Parameters $=f i t\left(w, p,{ }^{*} a^{*}(b / c)^{\star}(x / c)^{\wedge}(b-1)^{\star} \exp \left(-(x / c)^{\wedge} b\right)^{\prime}\right.$, 'startpoint', [a, b, c]) Equation 6.8

Appendix D includes the determined model constants $\mathrm{W}_{\mathrm{F}}$, beta, $\mathrm{m}$, and wi for the P-W fit with $95 \%$ confidence intervals for all prisms tested, which resulted from this fitting process. The variation for the values of $\mathrm{m}$, and wi appear to range from 1.08 to 1.18 and 3.5 to 4.8 , respectively. As these ranges are quite narrow it difficult to make definitive conclusions other that the ranges given. This means that the shape of the curve does not change vary much for changes in age, curing, fiber content, or geometry for the P-w curve. Figure 6.21, shows the values of $\beta$ decreasing with increasing fiber content. From Appendix D, It is difficult to make similar conclusions about the $\beta$ modifier for other parameters. 
The following shows the fit for a P-w curve and its associated fracture energy development curve. Appendix E shows the rest of these plots for all other tested specimens. What can be concluded based on these plots is that the modified Weibull function can be used to describe the $\mathrm{P}-\mathrm{w}$ curves regardless of the variation in the parameters.
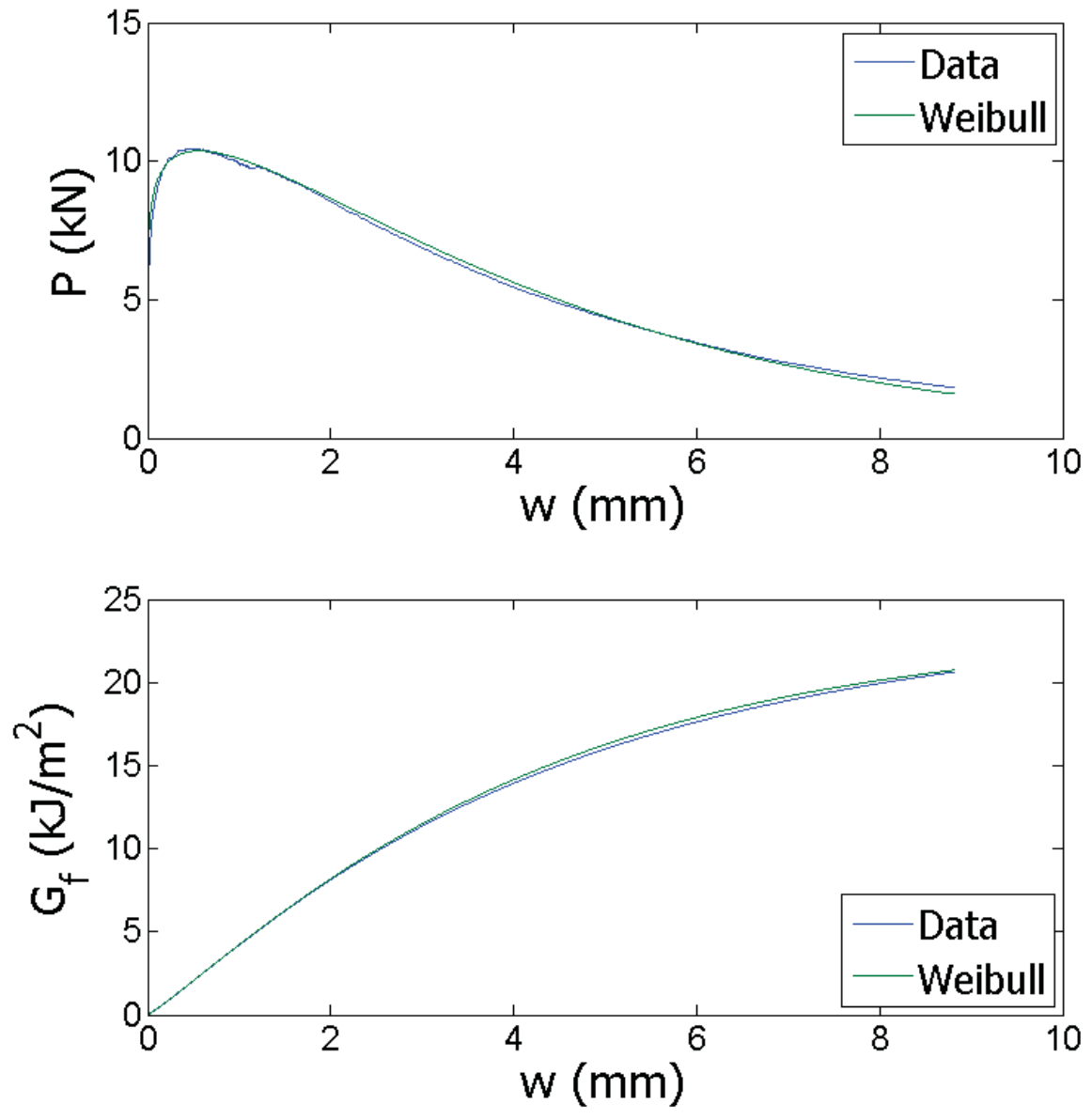

Figure 6.26: Modified Weibull best fit for NP-A-28d-f2-2580-4.5 specimen 


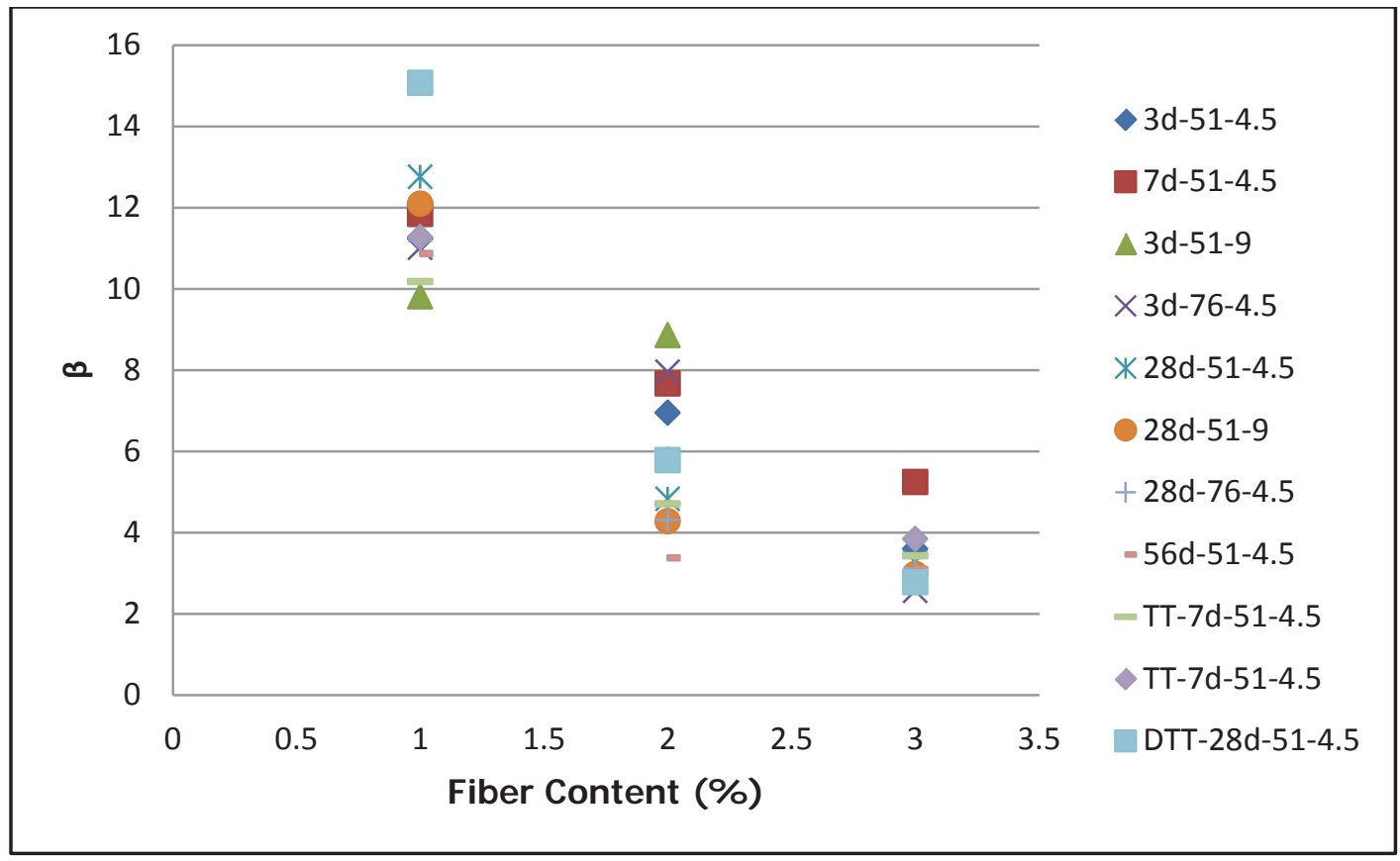

Figure 6.27: Plot of the Beta parameter with fiber content for several specimens

\subsubsection{Model Comparison}

One of the goals of this research was to look at current models used to describe FRCCs and UHPFRC. The ACI 544 model as discussed in chapter 3, has been said to apply to laboratory sized Specimens, and as discussed this model is based on the rule of mixtures. One of the foremost models for UHPFRCs is the AFGC/SETRA model discussed in chapter 4 . The section will provide a brief discussion on their applicability to the tested specimens.

The ACI 544 analysis was done for the N-A-NP-TT-28d-f2-2580-4.5 specimen, which means that $\mathrm{V}_{\mathrm{f}}$ was taken to be 0.02 . Based on testing, the ultimate strength of the UHPC material of similar geometry without fibers was determined to be around $5 \mathrm{MPa}$. The value for $1 / \mathrm{d}$ was taken to be 69 based on fiber manufacturing info provided by LaFarge North America. Using this information the stresses a cracking and ultimate were then calculated and are provided in table 6.5. 
The AFGC/SETRA is a model that requires the accumulation of data and geometric properties on the tested specimens. It should be noted that this model defines the occurrence of the peak load to occur at a $\mathrm{w}=0.3 \mathrm{~mm}$. Testing showed (Appendix B) that this value was only obtained for specimens undergoing thermal treatment and is therefore not applicable for UHPFC that is not thermally treated..

A comparison between these models and the data for the NP-A-28d-f2-2580-4.5 (Table 6.13), and NP-TT-28d-f2-2580-4.5 (Table 6.14) specimens. In these tables the values of $\mathrm{w}_{\mathrm{f}}, \mathrm{w}_{\mathrm{u}}, \mathrm{w}_{0.1}, \sigma_{\mathrm{f}}, \sigma_{\mathrm{u}}$, and $\sigma_{0.1}$ are the crack mouth openings and stresses at the occurrence of first crack, ultimate, $10 \%$ of the prism height. The term $\mathrm{G}_{\mathrm{f}}$ is the ultimate fracture energy at the time the fracture test was ended.

Table 6.13

Model comparison for NP-A-28d-f2-2580-4.5

\begin{tabular}{|l|c|c|c|c|c|c|c|}
\hline Model & $\mathbf{w}_{\mathbf{f}}$ & $\boldsymbol{\sigma}_{\mathbf{f}}$ & $\mathbf{w}_{\mathbf{u}}$ & $\boldsymbol{\sigma}_{\mathbf{u}}$ & $\mathbf{w}_{\mathbf{0 . 1}}$ & $\boldsymbol{\sigma}_{\mathbf{0 . 1}}$ & $\mathbf{G}_{\mathbf{f}}$ \\
\hline Data & 0.03 & 17.22 & 0.50 & 33.32 & 0.50 & 33.32 & 20.62 \\
\hline Model & 0.03 & 22.40 & 0.50 & 17.69 & - & - & 20.74 \\
\hline ACI 544 & - & 8.18 & - & 9.46 & - & - & - \\
\hline AFGC/SETRA & 0.03 & 17.22 & 0.30 & 32.92 & 0.50 & 33.32 & - \\
\hline
\end{tabular}

Table 6.14

Model Comparison for NP-TT-28d-f2-2580-4.5

\begin{tabular}{|l|c|c|c|c|c|c|c|}
\hline Model & $\mathbf{w}_{\mathbf{f}}$ & $\boldsymbol{\sigma f}$ & $\mathbf{w}_{\mathbf{u}}$ & $\boldsymbol{\sigma u}$ & $\mathbf{w}_{\mathbf{0 . 1}}$ & $\boldsymbol{\sigma}_{\mathbf{0 . 1}}$ & $\mathbf{G}_{\mathbf{f}}$ \\
\hline Data & 0.01 & 17.33 & 0.30 & 38.02 & 0.50 & 35.88 & 21.05 \\
\hline Model & 0.01 & 29.35 & 0.30 & 34.44 & - & - & 20.88 \\
\hline ACI 544 & - & 9.83 & - & 11.36 & - & - & - \\
\hline AFGC/SETRA & 0.01 & 17.33 & 0.30 & 35.574 & 0.50 & 35.88 & - \\
\hline
\end{tabular}

Based on the results of these tables it can be concluded that the ACI 544 model is not applicable in its current form and should be modified. The AFGC/SETRA model works well for determining first crack and ultimate strengths but should be modified for prism sizes of this type $\left(2580 \mathrm{~mm}^{2}, 51 \mathrm{~mm}\right.$ deep), as $10 \%$ of the height is not long enough to notice a decrease in the load. The modified Weibull model does not accurately calculate the first crack strength, but can determine the ultimate strength and the fracture energy. 



\section{Conclusions and Future Work}

\subsection{Overview}

The material behavior of steel fiber reinforced UHPC as discussed in Chapter 4 is highly dependent on material selection, mix design, curing process. This is especially true if the material is loaded under direct or indirect tension. Of particular importance to the material behavior under tension is the fracture behavior (Chapter 2), which depends on microstructure of the material (Chapter 4), the interaction between the fibers and the UHPC (Chapters 3 and 4), and the specimen geometry (Chapter 2). As of yet, there has only been a handful of studies, which have looked at the material behavior under post-cracking conditions. It is for these reasons that the topic of this thesis addressed variations in material and geometrical properties and there effect on UHPFRC's fracture behavior.

Specifically, this research looked at the effect of variations in fiber content, specimen age, specimen length (span-to-depth), specimen cross-section, and type of curing on the mode I fracture of a Ductal ${ }^{\circledR}$ brand steel fiber reinforced UHPC. Fracture testing was performed on single-edge notched prisms loaded under a crack mouth opening displacement (CMOD) controlled three point bending test. The analysis of the postcracking behavior was analyzed using a fracture mechanics based approach. This led to the calculation of the fracture energy, which was calculated using the load-CMOD (Pw) curve divided by the fracture area. For comparison purposes the elastic stress at first crack and equivalent elastic stress were also calculated. From this data a model to describe the shape of the fracture process was developed based on a non-linear curve fit using a modified Weibull function. In addition compression tests were also performed to look at the variability from mix to mix.

\subsection{Conclusions}

Based on the results of testing several conclusions can be made with regards to compression testing, fracture testing, and fracture modeling. 


\subsubsection{Compression Testing}

- Based on statistical analysis it was determined that there is little variability between mixes

- Results were comparable to previous research with a compressive strength of $142 \mathrm{MPa}$ for ambient cured specimens with $2 \%$ fibers.

- Thermally treated specimens with $2 \%$ fibers were, however, low compared to previous work, at an average strength of $180 \mathrm{MPa}$.

- Compressive strength increases with the addition of fibers, as well as with increased fiber content. Fibers are more of effective for ambient cured specimens than for thermally treated specimens.

- The compressive strength increases with thermal treatment, where the strengths are comparable regardless of time of thermal treatment.

\subsubsection{Fracture Testing}

- There is very little variability for most of the fracture data sets. Of the ambient cured specimens, those that were tested at early ages (3-day, and 7-day), and those with $0 \%$ fibers showed the most variability. In the case of thermal treatment, the specimen with $0 \%$ fibers showed high variability.

- The first crack strength and ultimate strength for the reference prism showed comparable results to that of previous work on Ductal brand UHPFRC with similar size and fiber content.

- The addition of fibers leads to improvements in first-crack and ultimate strengths, and significantly improves the fracture resistance.

- As the concrete cures the strengthening of the material and improvement to the fiber-matrix bond leads to improvements in strength, and fracture resistance. 
- Increasing the span-to-depth of prisms has little to no effect on the strength of the prisms. However, there is an associated decrease in fracture energy. This is most likely associated with the decrease in load for longer specimens. It has been mentioned that this may not be the case if instead of load, the stress was calculated and used in place of the measured load.

- The result from testing the prism cross-section verified that UHPFRC is subject to the size-effect. Results also showed that the equation proposed by AFGC/SETRA to relate the increase in flexural strength with small beam sizes to the direct tensile strength does close the gap between prisms of different cross-sections.

- Thermal treatment leads to similar or improved strengths due to improvements in the UHPC microstructure and fiber-matrix bond. The fracture energy appears to show little variation with type of curing. It should be noted that with the use of thermal treatment comparable strengths and fracture behavior can be achieved at earlier ages ( 7 days) than with ambient curing.

\subsubsection{Fracture modeling}

Based on the data it was determined that the shape of the P-w curve, and associate fracture energy curves could be accurately modeled using a modified Weibull distribution (equation 6.4 and 6.5). This equation was shown to be applicable for all tested specimens of varying fiber contents, changes in age, different specimen geometry, and type of curing. It is proposed that this model could be implemented in design to estimate, and research to predict the behavior of the material after the occurrence of cracks. In addition, comparisons of the data and modified Weibull model to the AFGC/SETRA model and the ACI 544 model were conducted. Based on the results the ACI 544 model is not applicable in its current form and should be modified. The AFGC/SETRA model works well for determining first crack and ultimate strengths but should be modified for prism sizes of this type $\left(2580 \mathrm{~mm}^{2}, 51 \mathrm{~mm}\right.$ deep $)$, as $10 \%$ of the height is not long enough to notice a decrease in the load. The modified Weibull 
model does not accurately calculate the first crack strength, but can determine the ultimate strength and the fracture energy.

\subsection{Future Work}

As this research was conducted as a preliminary study on the fracture behavior of UHPFRC it is essential that all results be verified. This includes confirmation of the conclusions as well as verification of the applicability of the modified Weibull function to describe the fracture behavior. In addition further development of a fracture mechanics based test method and analysis for UHPC materials should be established, as its improved post cracking behavior sets it apart from other FRCCS and should be regarded as a characteristic of the material. Furthermore, a design procedure should be developed, which focuses not only on the use of strength criteria, but also fracture criteria $\left(G_{f}\right)$, which are associated with the fracture resistance and ductility of the material. This method could also incorporate the brittleness number discussed in Chapter 2.

In addition, further testing should be performed to examine the results of fracture and the post-cracking strength of the material. This includes performing fiber pull-out tests to estimate the fiber-matrix bond strength and work of pull-out, which could be used in a composite material based approach. Also, further testing of material properties (Young's modulus, direct tensile strength, compressive strengths, flexural strengths, and fracture properties) with various fiber contents should be performed. As mentioned in chapter 6 it would be beneficial to determine the probabilistic distribution that will describe the variability is first crack and ultimate strengths. Lastly, it would be beneficial to perform image based approaches to describe the nature of fracture in UHPFRC materials. This could include imaging of fracture surfaces, through the use of microscopy. The following is an image (Figure 7.1) taken using a stereo microscope of the crack surface of a UHPFRC beam that was tested as part of this research. 


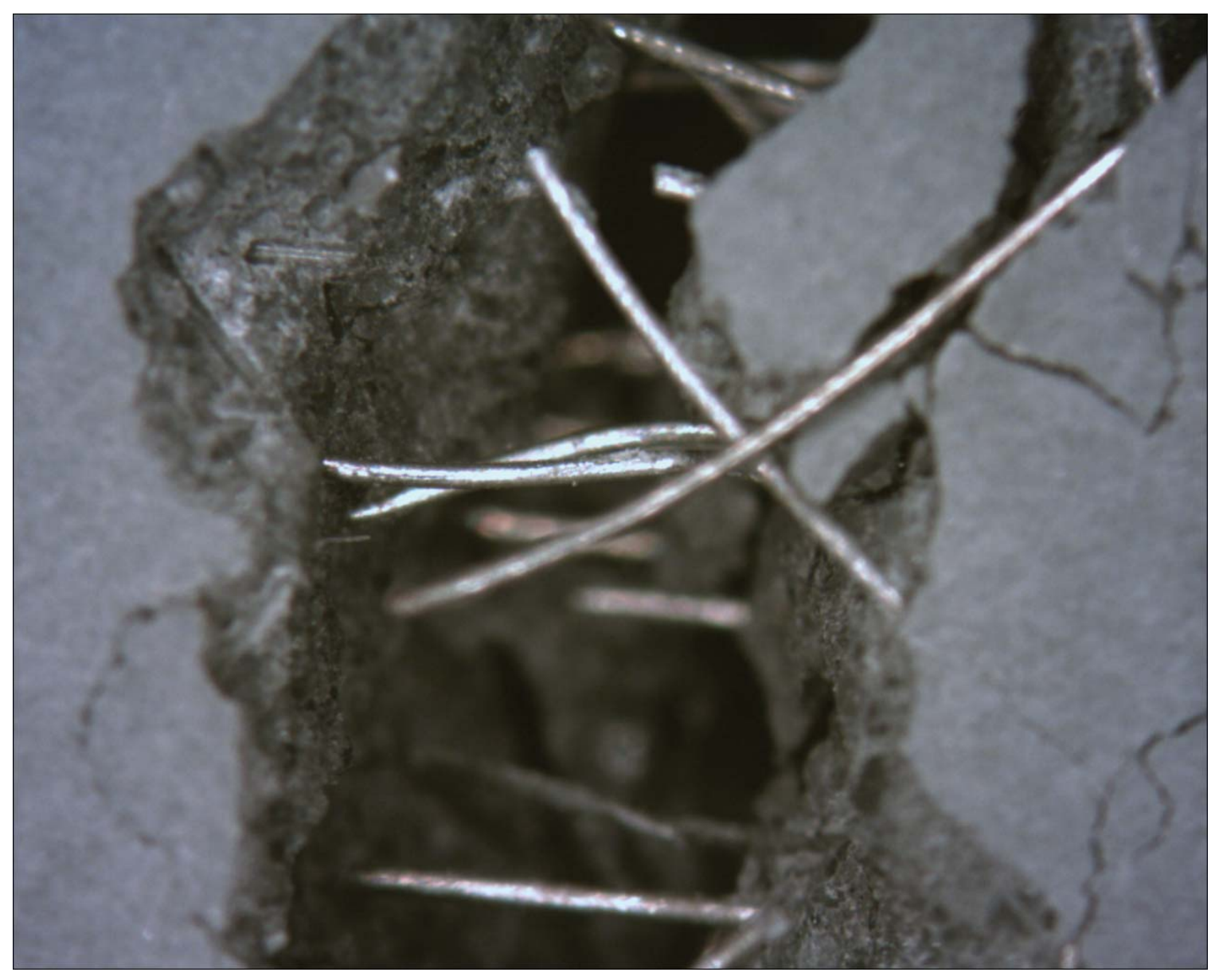

Figure 7.1: Crack Face (Zoomed)

Some of what can be initially noticed is that these bending in the fibers due to the pullout process. Also, if one looks at the surface of the fibers and one of the pull-out locations (top left) there appears to be a clean pull-out with little breaking of the concrete. This could be associated with the lack of interfacial transition zone in the material. However, further imaging of various specimens would be required to verify this result. It may be beneficial to look at the fracture surface microstructure using a scanning electron microscope (SEM). Finally, fracture mechanics is based on knowing the crack depth and analysis would benefit from being able to experimentally determine the crack length, which as reported by (Shah and Kishen 2011) can be done through the use of digital image correlation (DIC). This is especially critical in a material, such as UHPFRC, that exhibits a non-linear crack propagation. 


\section{References}

A. Aveston, G. A. C., and A. Kelly "Single and Multiple Fracture." Proc., Properties of Fiber Reinforced Composites, National Physical Labratories, IPC, Science and Technology Press, 15-24.

ACI 446 (1991). "ACI 446.1R Fracture Mechanics of Concrete: Concepts, Models and Determination of Material Properties." ACI Manual of Concrete Practice, ACI International, Farmington Hills, MI.

ACI 544 (2001). "ACI 544.1R State-of-the-Art Report on Fiber Reinforced Concrete." ACI Manual of Concrete Practice, ACI International, Farmington Hills, MI.

ACI 544 (2001). "ACI 544.4R Design Considerations for Steel Fiber Reinforced Concrete." ACI Manual of Concrete Practice, ACI International, Farmington Hills, MI.

ACI 544 (2010). "ACI 544.5R Report on the Physical Properties and Durability of Fiber-Reinforced Concrete." ACI Manual of Concrete Practice, ACI International, Farmington Hills, MI.

ACI (2011). "ACI Commitee 239 Home."

<http://www.concrete.org/committees/committeehome.asp? committee code $=0000239$ $\underline{00>}$. (2012).

AFGC, and SETRA (2002). "Ultra High Performance Fiber Reincorced ConcreteInterim Recomendations."France, 153.

Al-Azzawi, A. A., Sultan, A., and Risan, H. K. (2011). "Behaviore of Ultra High Performance Concrete Structures." ARPN Journal of Engineering and Applied Sciences, 6(5), 95-109.

Anderson, T. L. (2005). Fracture Mechanics Fundamentals and Applications, CRC Press, Boca Raton, FL.

Ang, A. H.-S., and Tang, W. H. (2007). Probability Concepts in Engineering Emphasis on Applications to Civil and Environmental Engineering, John Wiley \& Sons, Hoboken, NJ.

ASTM C1609 (2007). "Flexural Performance of Fiber Reinforced Concrete (Using Beam with Third-Point Bending Test)." Section 4: Construction, ASTM International, West Conshohocken, PA.

ASTM C 39 (2005). "Test Method for Compressive Strength of Cylindrical Concrete Specimens " Section 4: Construction, ASTM International, West Conshohocken, PA. 
ASTM C 192 (2007). "Standard Practice for Making and Curing Concrete Specimens in thye Labratory." Section 4: Construction, ASTM International, West Conshohocken, PA.

ASTM C 470 (2008). "Standard Specifications for Molds for Forming Concrete test Cylinders Vertically." Section 4: Construction, ASTM International, West Conshohocken, PA.

ASTM C 670 (2003). "Standard Practice for Preparing Precision and Bias Statements for Test Methods for Construction Materials." Section 4: Construction, ASTM International, West Conshohocken, PA.

Bache, H. H. (1981). "Densified Cement Ultra-fine Particle-Based Materials." CBL Report No. 40, Aalborg Portland, Aalborg, Denmark.

Bache, H. H. (1987). "Compact Reinforced Composite, Basic Principles." CBL Report No. 41, Aalborg Portland, Aalborg, Denmark.

Ballani, F., Daley, D. J., and Stoyan, D. (2006). "Modelling the microstructure of concrete with spherical grains." Computational Materials Science, 35(4), 399-407.

Barnett, S. J., Lataste, J.-F., Parry, T., Millard, S. G., and Soutsos, M. N. (2009). "Assessment of fibre orientation in ultra high performance fibre reinforced concrete and its effect on flexural strength." Materials and Structures, 43(7), 1009-1023.

Bažant, Z. P. (1985). "Fracture Mechanics of Concrete: Structural Application and Numerical Calculation." Fracture Mechanics of Concrete: Structural Application and Numerical Calculation, A. D. George C. Sih, ed.

Bažant, Z. P., and Kazemi, M. T. (1991). "Size Dependence of Concrete Fracture Energy Determined by RILEM Work-of-Fracture Method." International Journal for Fracture, 51, 121-138.

Bažant, Z. P., and Planas, J. (1998). Fracture and Size Effect in Concrete and Other Quisibrittle Materials, CRC Press, Boca Raton, FL.

Bencardino, F., Rizzuti, L., Spadea, G., and Swamy, R. N. (2010). "Experimental evaluation of fiber reinforced concrete fracture properties." Composites Part B: Engineering, 41(1), 17-24.

Bentur, A., Diamond, S., and Mindess, S. (1985). "The Microstructure of Steel FibreCement Interface." Journal of Materials Science, 20, 3610-3620.

Bentur, A., and Mindess, S. (2007). Fibre Reinforced Cementitious Composites, Taylor and Francis, New York, NY. 
Broek, D. (1986). Elementary Engineering Fracture Mechanics, Martinus Nijhoff, Dordrecht, The Netherlands.

Callister, W. D. (2005). Materials Science and Engineering An Integrated Approach, John Wiley \& Sons, Hoboken, NJ.

Chan, Y.-W., and Chu, S.-H. (2004). "Effect of Silica Fume on Steel Fiber Bond Characteristics in Reactive Powder Concrete." Cement and Concrete Research, 34(7), 1167-1172.

Chan, Y.-W., and Li, V. C. (1997). "Age Effect on the CharacterIstics of Fiber/Cement Interfacial Properties." Journal of Materials Science, 32, 5287-5292.

Chawla, K. K. (1987). Composite Materials Science and Engineering, Springer-Verlag, New York, NY.

Chawla, K. K. (1993). Ceramic Matrix Composites, Chapman \& Hall, London, England.

Chen, B., and Liu, J. (2004). "Experimental Study on AE Characteristics of Three-Point Bending Concrete Beams." Cement and Concrete Research, 34(3), 391-397.

Chen, Y., and Qiao, P. (2011). "Crack Growth Resistance of Hybrid Fiber-Reinforced Cement Matrix Composites." Journal of Aerospace Engineering, 24(2), 154-161.

Cheyrezy, M., Maret, V., and Frouin, L. (1995). "Microstructural Analysis of RPC (Reactive Powder Concrete)." Cement and Concrete Research, 25(7), 1491-1500.

Collepardi, S., Coppola, L., Troli, R., and Collepardi, M. (1997). "Mechanical Properties of Modified Reactive Powder Concrete." Superplasticizers and other Chemical Admixtures in Concrete Procedings, Fifth CANMET/ACI International Conferance, 1-22.

Dai, Q., Ng, K., Zhou, J., Kreiger, E. L., and Ahlborn, T. M. (2012). "Damage investigation of single-edge notched beam tests with normal strength concrete and ultra high performance concrete specimens using acoustic emission techniques." Construction and Building Materials, 31, 231-242.

de Larrard, F. (1999). Concrete Mixture Proportioning A Scientific Approach, E \& FN Spon, New York, NY.

de Larrard, F., and Sedran, T. (1994). "Optimization of Ultra-High Performance Concrete by the use of a Particle Packing Model." Cement and Concrete Research, 24(6), 997-1009.

Devore, J. L. (2011). Probability and Statistics for Engineering and the Sciences, Duxbury Press, Pacific Grove, CA. 
Ductal ${ }^{\circledR}$ reference T 001 "Operating Procedure Compressive Test." Lafarge North America, Calgary, Canada.

Ductal ${ }^{\circledR}$ reference T 006 "Operating Procedure Flow Test." Lafarge North America, Calgary, Canada.

Einsfeld, R. A., and Velasco, M. S. L. (2006). "Fracture parameters for HighPerformance Concrete." Cement and Concrete Research, 36(3), 576-583.

Fu, G., and Dekelbab, W. (2003). "3-D random packing of polydisperse particles and concrete aggregate grading." Powder Technology, 133(1-3), 147-155.

Gagné, R., Boisvert, A., and Pigeon, M. (1996). "Effect of Superplasticizer dosage on mechanical properties, permeability and freeze-thaw of high strength concrete with and without silica fume." ACI Materials Journal, 93(2), 111-120.

Goldman, A., and Bentur, A. (1986). "Bond Effects in High-Strength Silica-Fume Concretes." ACI Materials Journal, 86(5), 8.

Gopalaratnam, V. S., and Shah, S. P. (1985). "Softening Response of Plain Concrete in Direct Tension." ACI Journal, 82(3), 310-332.

Graybeal, B. A. (2005). "Characterization of the Behavior of Ultra-High Perfomance Concrete." Doctor of Philosophy, University of Maryland, College Park, MD.

Graybeal, B. A. (2006). "Structural Behavior of Ultra-High Performance Concrete Prestressed I-Girders." FHWA-HRT-06-115 Report, FHWA, McLean, VA, 104.

Graybeal, B. A. (2008). "Flexural Behavior of an Ultrahigh-Performance Concrete IGirder." Journal of Bridge Engineering, 13(6), 602-610.

Graybeal, B. A., and Hartmann, J. L. (2003). "Ultra-High Performance Concrete Material Properties." Transportation Rsearch Board Conference.

Guinea, G. V., El-Sayedb, K., Roccoc, C. G., Elicesa, M., and Planasa, J. (2002). "The effect of the bond between the matrix and the aggregates on the cracking mechanism and fracture parameters of concrete." Cement and Concrete Research, 32, 1961-1970.

Gustafsson, P. J., and Hillerborg, A. (1985). "Improvements in Concrete Design Achieved Through The Application of Fracture Mechanics " Applications of Fracture Mechanics to Cementitious Materials, S. P. Shah, ed., Martinus Nijhoff Publishers, Dordrecht, The Netherlands, 667-680.

Ha, L. T., Siewert, K., and Ludwig, H.-M. (2012). "Synergistic Effect of Rice Husk Ash and Fly Ash on Properties of Self-Compacting High Performance Concrete." Proceedings of Hipermat 2012 - 3rd International Symposium on UHPC and Nanotechnology for Construction Materials, Kassel University Press, Kassel, Germany. 
Habel, K., Denarié, E., and Brühwiler, E. (2006). "Time Dependent Behavior of Elements Combining Ultra-High Performance Fiber Reinforced Concretes (UHPFRC) and Reinforced Concrete." Materials and Structures, 39, 557-569.

Habel, K., Viviani, M., Denarié, E., and Brühwiler, E. (2006). "Development of the Mechanical Properties of an Ultra-High Performance Fiber Reinforced Concrete (UHPFRC)." Cement and Concrete Research, 36(7), 1362-1370.

Hackman, L. E., Farrel, M. B., and Dunham, O. O. (1992). "Slurry Infiltrated Mat Concrete." Concrete International, 14, 53-56.

Hamoush, S., Abu-Lebdeh, T., Cummins, T., and Zornig, B. (2010). "Pullout Characterizations of Various Steel Fibers Embedded in Very High-Strength Concrete." American J. of Engineering and Applied Sciences, 3(2), 418-426.

Hannant, D. J. (1978). Fibre Cements and Fibre Concretes, John Wiley \& Sons, Chichester, England.

Hassan, K. E., Cabrera, J. G., and Maliehe, R. S. (2000). "The Effect of Mineral Admixtures on the Properties of High-Performance Concrete." Cement \& Concrete Composites, 22, 267-271.

Hawkins, N. M. (1985). "Role of Fracture Mechanics in Conventional Reinforced Concrete Design." Applications of Fracture Mechanics to Cementitious Materials, S. P. Shah, ed., Martinus Nijhoff Publishers, Dordrecht, The Netherlands, 639-666.

Hillerborg, A. (1985). "The Theoretical Basis of a Method to Determine the Fracture energy Gf of Concrete." Materials and Structures, 18(106), 291-296.

Hillerborg, A., Modeer, M., and Petersson, P. E. (1976). "Analysis of Crack Formation and Crack Growth in Concrete by Means of Fracture Mechanics and Finite Elements." Cement and Concrete Research, 6(6), 773-782.

Hirschi, T., and Wombacher, F. "Influence of Different Superplasticizers on UHPC." Proc., Second international Symposium on Ultra High Performance Concrete, Kassel University Press.

İpek, M., Yilmaz, K., and Uysal, M. (2012). "The Effect of Pre-Setting Pressure Applied Flexural Strength and Fracture Toughness of Reactive Powder Concrete During the Setting Phase." Construction and Building Materials, 26(1), 459-465.

JCI (2003). "Method of test for fracture energy of concrete by use of notched beam." Japan Concrete Institute.

Ju, Y., Liu, H., Chen, J., Jia, Y., and Peng, P. (2009). "Toughness and Characterization of reactive Powder Concrete with Ultra-High Strength." Science in China Series E: Technological Sciences, 52(4), 1000-1018. 
Jueshi, Q., and Hui, L. (1997). "Size Effect on Fracture Energy of Concrete Determined by Three-Point Bending." Cement and Concrete Research, 27(7), 1031-1036.

Kang, S.-T., Lee, Y., Park, Y.-D., and Kim, J.-K. (2010). "Tensile Fracture Properties of an Ultra High Performance Fiber Reinforced Concrete (UHPFRC) with Steel Fiber." Composite Structures, 92(1), 61-71.

Kollmorgen, G. A. A. (2004). "Impact of Age and Size on the Mechanical Behavior of Ultra High Performance Concrete." Master's of Science, Michigan Technological University, Houghton, MI.

Kosmatka, S. H., Kerkhoff, B., and Panarese, W. C. (2008). Design and Control of Concrete Mixtures, Portland Cement Association, Skokie, Il.

Kumar V, S., and Santhanam, M. (2003). "Particle Packing Theories and their Application in Concrete Mixture Proportioning: A Review." The Indian Concrete Journal, 77(9), 1324-1331.

Lankard, D. R. "Slurry Infiltrated Concrete (SIFCON) : Properties and Applications." Proc., Very High Strength Cement Based Materials, Material Research Society, 277286.

Laskar, A. I., and Talukdar, S. (2008). "Rheological behavior of high performance concrete with mineral admixtures and their blending." Construction and Building Materials, 22(12), 2345-2354.

Laws, V. (1983). "On the Mixture Rule for Strength of Fiber Reinforced Cements " Journal of Materials Science Letters, 2, 527-531.

Leon, M., and Kittl, P. (1985). "On the Estimation of Weibull's Parameters in Brittle Materials." Journal of Materials Science, 20, 3778-3782.

Li, V. C. (2003). "On Engineered Cementitious Composites (ECC) A Review of the Materials and Applications." Journal of Advanced Concrete Technology, 1(3), 215-130.

Longa, G., Wanga, X., and Xieb, Y. (2002). "Very-high-performance concrete with ultrafine powders." Cement and Concrete Research, 32, 601-605.

Mansour, S. M., Abadlia, M. T., Bekkour, K., and Messaoudene, I. (2010). "Improvement of Rheological Behaviour of Cement Pastes by Incorporating Metakaolin." European Journal of Scientific Research, 42(3), 442-452.

Márquez, S., Hanson, S., and Tikalsky, P. J. "Environmental Advantages of Ternary Cement Combinations." Proc., Second international Symposium on Ultra High Performance Concrete, Kassel University Press. 
Mindess, S., Young, J. F., and Darwin, D. (2003). Concrete, Pearson Education, Upper Saddle River, NJ.

Mobasher, B., and Li, C. Y. (1996). "Mechanical Properties of Hybrid Cement-Based Composites." ACI Materials Journal, 93(3), 284-292.

Möser, B., Pfeifer, C., Heinz, D., Gerlicher, T., Mechtcherine, V., and Dudziak, L. (2010). "Investigations on the Workability and Microstructure Development of UHPC; part 2: Influence of Admixtures and Curing on the Microstructure of Ultra-High Strength Concretes." Cement International, 8, 74-85.

Muralidhara, S., Raghu Prasad, B. K., Karihaloo, B. L., and Singh, R. K. (2011). "Sizeindependent fracture energy in plain concrete beams using tri-linear model." Construction and Building Materials, 25(7), 3051-3058.

Naaman, A. E. (2003). "Strain Hardening and Deflection Hardening Fiber Reinfoced Cement Composites." Fourth International Work-shop on High Performance Fiber Reinforced Cement Composites (HPFRCC 4) Bagneux, France, 95-113.

Naaman, A. E. (2003). "Strain Hardening and Deflection Hardening of Fiber Reinforced Cement Composites." 4th International Workshop High Performance Fiber Reinforced Cement Composites, 95-113.

Orange, G., Dugat, J., and Acker, P. (2000). "Ductal (R) : New Ultra High Performance Concretes. Damage Resistance and Micromechanical Analysis." Fifth RILEM Symposium on Fibre-Reinforced Concretes (FRC)Lyon, France, 781-790.

Pedersen, C. (1996). "New Production Processes, Materials and Calculation Techniques for Fiber Reinfoced Concrete Pipes." Technical University of Denmark.

Peng, Y. Z., Chen, K., and Hu, S. G. (2011). "Durability and Microstructure of UltraHigh Performance Concrete Having High Volume of Steel Slag Powder and Ultra-Fine Fly Ash." Advanced Materials Research, 255-260, 452-456.

Peuse, E. J. (2008). "Impact of Age at Thermal Treatment on the Mechanical Properties of an Ultra-High Performance Concrete." Master's of Science, Michigan Technological University, Houghton, MI.

Quiroga, P. N., and Fowler, D. W. (2004). "The effect of Aggregates Characteristics on the Performance of Portland Cement." Research Report ICAR-104F, International Center for Aggregates Research, Austin, TX, 382.

Reda, M. M., Shrive, N. G., and Gillott, J. E. (1999). "Microstructural Investigation of Innovative UHPC." Cement and Concrete Research, 29, 323-329.

Respiendino, J. (2012). "State of the Art Design and Construction of UHPFRC Structures in France." Proceedings of Hipermat 2012 - 3rd International Symposium on 
UHPC and Nanotechnology for Construction Materials, Kassel University Press, Kassel, Germany.

Richard, P., and Cheyrezy, M. (1995). "Composition of Reactive Powder Concretes." Cement and Concrete Research, 25(7), 1501-1511.

RILEM TC 162-TDF (2002). "Bending test Final Recommendation." Materials and Structures, 35(November 2002), 579-582.

Roelfstra, R. E., and Wittman, F. H. (1986). "A Numerical Model to Link Strain Softening to Concrete." Fracture Toughness and Fracture Energy in Concrete, F. H. Wittman, ed., Elsevier Science, Amsterdam, 163-175.

Rossi, P. (1997). "High Performance Multimodal Fiber Reinforced Cement Composite (HPMFRCC): The LCPC Experience." ACI Materials Journal, 94(6), 478-483.

Rossi, P. (2001). "Ultra-High-Performance Fiber-Reinforced Concretes " Concrete International, 23(12), 46-52.

Roux, B. N., Andrade, C., and Sanjuan, M. A. (1996). "Experimental Study of Durability of Reactive Powder Concretes." Journal of Materials in Civil Engineering,, 8(1), 1-6.

Ryu, G.-S., Kang, S.-T., Park, J.-J., and Koh, K.-T. (2010). "Evaluation of Flexural Performance in UHPC (Ultra High Performance Concrete) According to Placement Methods." Key Engineering Materials, 417-418, 581-584.

Schieß1, P., Mazanec, O., Lowka, D., Plank, J., Schöfl, C., Gruber, M., Schmidt, M., Stephan, D., and Glotzbach, C. (2010). "Investigations on the Workability and Microstructure Development of UHPC; part 1: Effect of Superplasticizer and Silica Fume on Mixing and Workability of UHPC " Cement International, 8, 60-71.

Schmidt, M., and Fehling, E. (2005). "Ultra-High-Performance Concrete: Research, Development and Application in Europe." Seventh International Symposium on the Utilization of High-Strength/High-Performance Concrete, ACI SP-288, American Concrete Institute, Detroit, MI.

Shah, S. G., and Kishen, J. M. C. (2011). "Fracture Properties of Concrete-Concrete Interfaces Using Digital Image Correlation." Experimental Mechanics, 51, 303-313.

Shah, S. P. (2012). "Applications of Nanoparticles." Proceedings of Hipermat 2012 $3 r d$ International Symposium on UHPC and Nanotechnology for Construction Materials, E. F. E. Schmidt, C. Glotzbach, S. Fröhlich, S. Piotrowski, ed., Kassel University Press, Kassel, Germany, 59-67.

Shah, S. P., Swartz, S. E., and Ouyang, C. (1995). Fracture Mechanics of Concrete, John Wiley \& Sons, New York, NY. 
Siiriä, S., and Yliruusi, J. (2007). "Particle packing simulations based on Newtonian mechanics." Powder Technology, 174(3), 82-92.

Sobolev, K. (2004). "The development of a new method for the proportioning of highperformance concrete mixtures." Cement and Concrete Composites, 26(7), 901-907.

Sobolev, K., and Amirjanov, A. (2007). "The Simulation of Particulate Materials Packing using a Particle Suspension Model." Advanced Powder Technology, 18(3), 261-271.

Steinberg, E. (2010). "Structural Reliability of Prestressed UHPC Flexure Models for Bridge Girders." Journal of Bridge Engineering, 15(1), 65-72.

Steinberg, E., and Lubbers, A. (2003). "Bond of Prestressing Strands." Proceedings of the 2003 PCI/FHWA 3rd International Symposium on High Performance ConcreteOrlando, Florida.

Stengel, T. "Effect of Surface Roughness on the Steel Fibre Bonding in Ultra High Performance Concrete (UHPC)." Proc., Nanotechnology in Construction 3: Proceedings of the NICOM3, Springer, 371-376.

Swamy, R. N., Mangat, P. S., and Rao, C. V. S. K. (1974). "The Mechanics of Fiber Reinforcement of Cement Matricies." Fiber Reinforced Concrete ACI SP-44, American Concrete Institute, Detroit, MI, 1-28.

Tafraoui, A., Escadeillas, G., Lebaili, S., and Vidal, T. (2009). "Metakaolin in the formulation of UHPC." Construction and Building Materials, 23(2), 669-674.

Tamrakar, R. (1999). "Fracture Mechanics of Fiber Reinforced Concrete." Journal of Structural Engineering, 26(2), 135-142.

Tassions, T. P. (1985). "Design Codes and Fracture Mechanics." Applications of Fracture Mechanics to Cementitious Materials, S. P. Shah, ed., Martinus Nijhoff Publishers, Dordrecht, The Netherlands, 681-694.

Taylor, H. F. W. (1997). Cement Chemistry, Thyomas Telford Publishing, London, England.

Weibull, W. (1951). "A Statistical Distribution Function of Wide Applicability." Journal of Applied Mechanics, 293-297.

Wight, J. K., and MacGregor, J. G. (2009). Reinforced Concrete Mechanics and Design, Pearson Prentice Hall, Upper Saddle River, NJ.

Wittman, F. H. (2002). "Crack formation and fracture energy of normal and high strength concrete." Sādhanā, 27, 413-423. 
Xiao, J., Schneider, H., Dönnecke, C., and König, G. (2004). "Wedge Splitting Test on Fracture Behaviour of Ultra High Strength Concrete." Construction and Building Materials, 18(6), 359-365.

Yang, I. H., Joh, C., and Kim, B.-S. (2010). "Structural Behavior of Ultra High Performance Concrete Beams Subjected to Bending." Engineering Structures, 32(11), 3478-3487.

Yang, S. L., Millard, S. G., Soutsos, M. N., Barnett, S. J., and Le, T. T. (2009). "Influence of Aggregate and Curing Regime on the Mechanical Properties of UltraHigh Performance Fibre Reinforced Concrete (UHPFRC)." Construction and Building Materials, 23(6), 2291-2298.

Yazıc1, H., Yardımcı, M. Y., Aydın, S., and Karabulut, A. Ş. (2009). "Mechanical properties of reactive powder concrete containing mineral admixtures under different curing regimes." Construction and Building Materials, 23(3), 1223-1231.

Yazıcı, H., Yiğiter, H., Karabulut, A. Ş., and Baradan, B. (2008). "Utilization of fly ash and ground granulated blast furnace slag as an alternative silica source in reactive powder concrete." Fuel, 87(12), 2401-2407.

Zhang, B. (2011). "Effects of moisture evaporation (weight loss) on fracture properties of high performance concrete subjected to high temperatures." Fire Safety Journal, 46(8), 543-549. 


\section{Appendix A: Compression Results}

Table A.1

Results from compression testing (ambient cured specimens)

\begin{tabular}{|l|c|c|}
\hline Specimen & $\mathbf{f}_{\mathbf{c}}(\mathbf{k s i})$ & $\mathbf{f}_{\mathbf{c}}(\mathbf{M P a})$ \\
\hline CA-28d-f0-C & 7.95 & 54.80 \\
\hline CA-28d-f0-A & 12.45 & 85.83 \\
\hline CA-28d-f0-B & 12.67 & 87.36 \\
\hline CA-28d-f1-C & 15.18 & 104.63 \\
\hline CA-28d-f1-D & 17.55 & 121.00 \\
\hline CA-28d-f1-A & 18.27 & 125.92 \\
\hline CA-28d-f1-A & 19.08 & 131.55 \\
\hline CA-28d-f1-B & 19.16 & 132.10 \\
\hline CA-28d-f1-B & 21.52 & 148.39 \\
\hline CA-f2-28d-B & 18.05 & 124.46 \\
\hline CA-28d-f2-B-1 & 19.33 & 133.26 \\
\hline CA-28d-f2-D & 19.37 & 133.57 \\
\hline CA-28d-f2-A & 19.40 & 133.72 \\
\hline CA-28d-f2-A-2 & 19.46 & 134.16 \\
\hline CA-f2-28d-A & 20.75 & 143.02 \\
\hline CA-28d-f2-B & 21.05 & 145.11 \\
\hline CA-28d-f2-B-2 & 22.69 & 156.45 \\
\hline CA-28d-f2-A-1 & 23.17 & 159.74 \\
\hline CA-28d-f2-C & 23.19 & 159.85 \\
\hline CA-28d-f3-D-1 & 21.17 & 145.94 \\
\hline CA-28d-f3-A-2 & 21.25 & 146.49 \\
\hline CA-28d-f3-A-1 & 22.23 & 153.22 \\
\hline CA-28d-f3-C-1 & 23.38 & 161.15 \\
\hline CA-28d-f3-B-1 & 23.45 & 161.63 \\
\hline CA-28d-f3-B-1 & 23.75 & 163.73 \\
\hline
\end{tabular}


Table A.2

Results from compression testing (thermally treated specimens)

\begin{tabular}{|l|c|c|}
\hline Specimen & $\mathbf{f}_{\mathbf{c}}(\mathbf{k s i})$ & $\mathbf{f}_{\mathbf{c}}(\mathbf{M P a})$ \\
\hline CTT-7d-f0-A & 13.90 & 95.85 \\
\hline CTT-7d-f0-A & 16.98 & 117.03 \\
\hline CTT-7d-f0-B & 18.15 & 125.11 \\
\hline CTT-7d-f0-B & 24.11 & 166.24 \\
\hline CTT-7d_f1-B & 23.24 & 160.25 \\
\hline CTT-7d-f1-A & 26.43 & 182.22 \\
\hline CTT-7d-f2-C & 18.73 & 129.15 \\
\hline CTT-7d-f2-D & 24.77 & 170.74 \\
\hline CTT-7d-f2-A & 25.96 & 178.97 \\
\hline CTT-7d-f2-B & 27.73 & 191.17 \\
\hline CDTT-28d-f0-A & 17.24 & 118.86 \\
\hline CDTT-28d-f0-A & 17.98 & 123.96 \\
\hline CDTT-28d-f1-A & 21.08 & 145.35 \\
\hline CDTT-28d-f1-B & 27.33 & 188.38 \\
\hline CDTT-28d-f1-A & 27.86 & 192.05 \\
\hline CDTT-28d-f1-B & 28.25 & 194.74 \\
\hline CDTT-28d-f2-A & 26.85 & 185.09 \\
\hline CDTT-28d-f2-A & 28.31 & 195.15 \\
\hline CDTT-28d-f3-A & 28.69 & 197.77 \\
\hline CDTT-28d-f3-B & 30.14 & 207.81 \\
\hline
\end{tabular}

Table A.3

Table of means an standard deviations for compression results

\begin{tabular}{|l|r|r|r|r|r|}
\hline Specimen & \multicolumn{1}{|c|}{$\mathbf{2 s}$} & \multicolumn{1}{c|}{ 1s } & \multicolumn{1}{c|}{ mean } & \multicolumn{1}{c|}{$\mathbf{1 s}$} & \multicolumn{1}{c|}{ 2s } \\
\hline CA-28d-f0 & 67.30 & 71.63 & 76.00 & 80.28 & 81.88 \\
\hline CA-28d-f1 & 102.01 & 114.60 & 127.26 & 139.78 & 152.37 \\
\hline CA-28d-f2 & 102.14 & 122.19 & 142.33 & 162.31 & 182.37 \\
\hline CA-28d-f3 & 124.53 & 139.90 & 155.36 & 170.64 & 186.01 \\
\hline CTT-7d-f0 & 107.59 & 116.79 & 126.06 & 135.18 & 144.38 \\
\hline CTT-7d-f1 & 157.79 & 164.46 & 171.23 & 177.81 & 177.81 \\
\hline CTT-7d-f2 & 154.35 & 160.88 & 167.51 & 173.94 & 180.47 \\
\hline CDTT-28d-f0 & 111.87 & 116.61 & 121.41 & 126.07 & 126.07 \\
\hline CDTT-28d-f1 & 153.74 & 166.88 & 180.13 & 193.17 & 206.31 \\
\hline CDTT-28d-f2 & 175.19 & 182.60 & 190.12 & 197.42 & 197.42 \\
\hline CDTT-28d-f3 & 186.86 & 194.77 & 202.79 & 210.58 & 210.57 \\
\hline
\end{tabular}


Table A.4

Hypothesis testing of fiber content for ambient cured specimens

\begin{tabular}{|c|c|c|c|c|c|c|}
\hline Test Values & $\mathbf{0}$ to $\mathbf{1}$ & $\mathbf{0}$ to $\mathbf{2}$ & $\mathbf{0}$ to $\mathbf{3}$ & $\mathbf{1}$ to $\mathbf{2}$ & $\mathbf{1}$ to 3 & $\mathbf{2}$ to 3 \\
\hline dof & 5 & 10 & 6 & 13 & 9 & 14 \\
\hline $\mathrm{S}_{\mathrm{p}}$ & 9.25 & 11.99 & 7.26 & 11.97 & 9.08 & 11.19 \\
\hline Significance( $\alpha)$ & 0.05 & 0.05 & 0.05 & 0.05 & 0.05 & 0.05 \\
\hline Confidence & 0.95 & 0.95 & 0.95 & 0.95 & 0.95 & 0.95 \\
\hline $\mathrm{t}_{\text {crit }}$ & 2.57 & 2.23 & 2.45 & 2.16 & 2.26 & 2.14 \\
\hline std error & 0.77 & 0.77 & 0.77 & 4.62 & 4.62 & 4.00 \\
\hline lower limit & 84.63 & 84.89 & 84.72 & 121.81 & 121.34 & 133.76 \\
\hline Upper limit & 88.57 & 88.31 & 88.47 & 141.77 & 142.24 & 150.90 \\
\hline Hypothesis & 131.79 & 142.33 & 155.36 & 142.33 & 155.36 & 155.36 \\
\hline $\mathrm{t}$ & 5.84 & 6.00 & 11.60 & 1.61 & 4.29 & 2.26 \\
\hline $\mathrm{p}$-value & 0.00208 & 0.00013 & 0.00002 & 0.13185 & 0.00202 & 0.04066 \\
\hline reject null & 0.998 & 1.000 & 1.000 & 0.868 & 0.998 & 0.959 \\
\hline Answer & Yes & Yes & Yes & Yes & Yes & Yes \\
\hline
\end{tabular}

Table A.5

Hypothesis testing of fiber content for thermally treated specimens

\begin{tabular}{|c|c|c|c|}
\hline Test Values & 0 to 1 & 0 to 2 & 1 to 2 \\
\hline dof & 4 & 6 & 4 \\
\hline Sp & 9.21 & 8.31 & 11.81 \\
\hline Significance $(\alpha)$ & 0.05 & 0.05 & 0.05 \\
\hline Confidence & 0.95 & 0.95 & 0.95 \\
\hline $\mathrm{t}_{\text {crit }}$ & 2.78 & 2.45 & 2.78 \\
\hline std error & 2.86 & 2.86 & 10.98 \\
\hline lower limit & 113.14 & 114.08 & 140.74 \\
\hline Upper limit & 129.00 & 128.06 & 201.73 \\
\hline Hypothesis & 171.23 & 180.29 & 180.29 \\
\hline $\mathrm{t}$ & 6.29 & 10.07 & 0.89 \\
\hline p-value & 0.00326 & 0.00006 & 0.42597 \\
\hline reject null & 0.997 & 1.000 & 0.574 \\
\hline Answer & Yes & Yes & No \\
\hline
\end{tabular}


Table A.6

Hypothesis testing of fiber content for delayed thermally treated specimens

\begin{tabular}{|c|c|c|c|c|c|c|}
\hline Test Values & $\mathbf{0}$ to $\mathbf{1}$ & $\mathbf{0}$ to 2 & $\mathbf{0}$ to 3 & $\mathbf{1}$ to 2 & $\mathbf{1}$ to 3 & $\mathbf{2}$ to 3 \\
\hline dof & 4 & 2 & 2 & 4 & 4 & 2 \\
\hline Sp & 3.30 & 5.64 & 5.63 & 4.50 & 3.99 & 7.11 \\
\hline Significance $(\alpha)$ & 0.05 & 0.05 & 0.05 & 0.05 & 0.05 & 0.05 \\
\hline Confidence & 0.95 & 0.95 & 0.95 & 0.95 & 0.95 & 0.95 \\
\hline tcrit & 2.78 & 4.30 & 4.30 & 2.78 & 2.78 & 4.30 \\
\hline std error & 2.55 & 2.55 & 2.55 & 1.60 & 1.60 & 5.03 \\
\hline lower limit & 114.34 & 110.45 & 110.45 & 187.30 & 187.30 & 168.47 \\
\hline Upper limit & 128.48 & 132.37 & 132.37 & 196.15 & 196.15 & 211.77 \\
\hline Hypothesis & 191.72 & 190.12 & 202.79 & 190.12 & 202.79 & 202.79 \\
\hline $\mathrm{t}$ & 24.61 & 12.18 & 14.46 & 0.41 & 3.20 & 1.78 \\
\hline p-value & 0.00002 & 0.00667 & 0.00475 & 0.70171 & 0.03278 & 0.21647 \\
\hline reject null & 1.000 & 0.993 & 0.995 & 0.298 & 0.967 & 0.784 \\
\hline Answer & Yes & Yes & Yes & No & Yes & No \\
\hline
\end{tabular}

Table A.7

Hypothesis testing of curing for $0 \%$ fiber specimens

\begin{tabular}{|c|c|c|c|}
\hline Test Values & A to TT & A to DTT & TT to DTT \\
\hline dof & 4 & 2 & 4 \\
\hline Sp & 4.98 & 2.66 & 5.26 \\
\hline Significance $(\alpha)$ & 0.05 & 0.05 & 0.05 \\
\hline Confidence & 0.95 & 0.95 & 0.95 \\
\hline $\mathrm{t}_{\text {crit }}$ & 2.78 & 4.30 & 2.78 \\
\hline std error & 0.77 & 0.77 & 2.86 \\
\hline lower limit & 84.47 & 83.30 & 113.14 \\
\hline Upper limit & 88.73 & 89.90 & 129.00 \\
\hline Hypothesis & 121.07 & 121.41 & 121.41 \\
\hline $\mathrm{t}$ & 8.00 & 13.08 & 0.07 \\
\hline p-value & 0.00132 & 0.00579 & 0.94427 \\
\hline reject null & 0.999 & 0.994 & 0.056 \\
\hline Answer & Yes & Yes & No \\
\hline
\end{tabular}


Table A.8

Hypothesis testing of curing for $1 \%$ fiber specimens

\begin{tabular}{|c|c|c|c|}
\hline Test Values & A to TT & A to DTT & TT to DTT \\
\hline dof & 5 & 7 & 4 \\
\hline $\mathrm{Sp}$ & 11.56 & 8.08 & 8.24 \\
\hline Significance $(\alpha)$ & 0.05 & 0.05 & 0.05 \\
\hline Confidence & 0.95 & 0.95 & 0.95 \\
\hline $\mathrm{t}_{\text {crit }}$ & 2.57 & 2.36 & 2.78 \\
\hline std error & 4.62 & 4.62 & 10.98 \\
\hline lower limit & 119.92 & 120.87 & 140.74 \\
\hline Upper limit & 143.66 & 142.71 & 201.73 \\
\hline Hypothesis & 171.23 & 191.72 & 191.72 \\
\hline $\mathrm{t}$ & 4.08 & 11.06 & 2.87 \\
\hline $\mathrm{p}$-value & 0.00955 & 0.00001 & 0.04547 \\
\hline reject null & 0.990 & 1.000 & 0.955 \\
\hline Answer & Yes & Yes & No \\
\hline
\end{tabular}

Table A.9

Hypothesis testing of curing for $2 \%$ fiber specimens

\begin{tabular}{|c|c|c|c|}
\hline Test Values & A to TT & A to DTT & TT to DTT \\
\hline dof & 12 & 10 & 4 \\
\hline Sp & 12.09 & 12.20 & 13.92 \\
\hline Significance( $\alpha)$ & 0.05 & 0.05 & 0.05 \\
\hline Confidence & 0.95 & 0.95 & 0.95 \\
\hline tcrit & 2.18 & 2.23 & 2.78 \\
\hline std error & 4.00 & 4.00 & 10.98 \\
\hline lower limit & 133.63 & 133.43 & 149.79 \\
\hline Upper limit & 151.04 & 151.24 & 210.79 \\
\hline Hypothesis & 190.12 & 180.29 & 190.12 \\
\hline $\mathrm{t}$ & 1.74 & 5.06 & 0.82 \\
\hline p-value & 0.10758 & 0.00049 & 0.46059 \\
\hline reject null & 0.892 & 1.000 & 0.539 \\
\hline Answer & Yes & Yes & No \\
\hline
\end{tabular}


Table A.10

Hypothesis testing of curing for $3 \%$ fiber specimens

\begin{tabular}{|c|c|}
\hline Test Values & A vs. DTT \\
\hline dof & 6 \\
\hline Sp & 7.80 \\
\hline Significance $(\alpha)$ & 0.05 \\
\hline Confidence & 0.95 \\
\hline tcrit & 2.45 \\
\hline std error & 3.24 \\
\hline lower limit & 147.43 \\
\hline Upper limit & 163.29 \\
\hline Hypothesis & 202.79 \\
\hline $\mathrm{t}$ & 7.45 \\
\hline p-value & 0.00030 \\
\hline reject null & 1.000 \\
\hline Answer & Yes \\
\hline
\end{tabular}




\section{Appendix B: Fracture Testing Results}

Table B.1

Fracture test results for $0 \%$ fibers under ambient conditions

\begin{tabular}{|l|r|r|r|r|r|r|r|}
\hline Specimen & $\begin{array}{c}\mathbf{w}_{\mathbf{f}} \\
\mathbf{m m}\end{array}$ & $\begin{array}{c}\mathbf{P}_{\mathbf{f}} \\
\mathbf{k N}\end{array}$ & $\begin{array}{c}\boldsymbol{\sigma}_{\mathbf{f}} \\
\mathbf{M p a}\end{array}$ & $\begin{array}{c}\mathbf{w}_{\mathbf{u}} \\
\mathbf{m m}\end{array}$ & $\begin{array}{c}\mathbf{P}_{\mathbf{u}} \\
\mathbf{k N}\end{array}$ & $\begin{array}{c}\boldsymbol{\sigma}_{\mathbf{u}} \\
\mathbf{M p a}\end{array}$ & $\begin{array}{c}\mathbf{G}_{\mathbf{f}, \mathbf{4 0}} \\
\mathbf{k J} \mathbf{J} / \mathbf{m}^{2}\end{array}$ \\
\hline NP-A-3d-f0-2580-4.5 & 0.006 & 1.99 & 5.76 & 0.006 & 1.99 & 5.76 & 0.01 \\
\hline NP-A-7d-f0-2580-4.5 & 0.008 & 1.73 & 5.07 & 0.008 & 1.73 & 5.07 & 0.02 \\
\hline NP-A-28d-f0-2580-4.5 & 0.015 & 1.56 & 4.75 & 0.015 & 1.56 & 4.75 & 0.02 \\
\hline NP-A-56d-f0-2580-4.5 & 0.016 & 1.51 & 4.94 & 0.016 & 1.51 & 4.94 & 0.03 \\
\hline
\end{tabular}

Table B.2

Fracture test results for $1 \%$ fibers under ambient conditions

\begin{tabular}{|l|r|r|r|r|r|r|r|}
\hline Specimen & $\begin{array}{c}\mathbf{w}_{\mathbf{f}} \\
\mathbf{m m}\end{array}$ & $\begin{array}{c}\mathbf{P}_{\mathbf{f}} \\
\mathbf{k N}\end{array}$ & $\begin{array}{c}\boldsymbol{\sigma}_{\mathbf{f}} \\
\mathbf{M p a}\end{array}$ & $\begin{array}{c}\mathbf{w}_{\mathbf{u}} \\
\mathbf{m m}\end{array}$ & $\begin{array}{c}\mathbf{P}_{\mathbf{u}} \\
\mathbf{k N}\end{array}$ & $\begin{array}{c}\boldsymbol{\sigma}_{\mathbf{u}} \\
\mathbf{M p a}\end{array}$ & $\begin{array}{c}\mathbf{G}_{\mathbf{f}}, \mathbf{4 0} \\
\mathbf{k J} \mathbf{J} / \mathbf{m}^{\mathbf{2}}\end{array}$ \\
\hline NP-A-3d-f1-2580-4.5 & 0.011 & 1.97 & 6.30 & 0.408 & 4.12 & 13.21 & 6.60 \\
\hline NP-A-3d-f1-2580-9 & 0.013 & 1.15 & 7.28 & 0.314 & 2.39 & 15.13 & 3.29 \\
\hline NP-A-3d-f1-5180-4.5 & 0.011 & 4.51 & 6.15 & 0.318 & 10.14 & 13.81 & 6.44 \\
\hline NP-A-7d-f1-2580-4.5 & 0.011 & 2.53 & 7.54 & 0.135 & 7.05 & 21.02 & 8.23 \\
\hline NP-A-28d-f1-2580-4.5 & 0.012 & 2.55 & 8.13 & 0.292 & 6.47 & 20.61 & 9.53 \\
\hline NP-A-28d-f1-2580-9 & 0.018 & 1.52 & 9.39 & 0.254 & 3.69 & 22.86 & 5.34 \\
\hline NP-A-28d-f1-5180-4.5 & 0.013 & 5.75 & 7.96 & 0.379 & 13.55 & 18.74 & 8.59 \\
\hline NP-A-56d-f1-2580-4.5 & 0.015 & 3.09 & 8.94 & 0.216 & 7.25 & 21.02 & 9.23 \\
\hline
\end{tabular}

Table B.3

Fracture test results for $3 \%$ fibers under ambient conditions

\begin{tabular}{|l|r|r|r|r|r|r|r|}
\hline Specimen & $\begin{array}{c}\mathbf{w}_{\mathbf{f}} \\
\mathbf{m m}\end{array}$ & $\begin{array}{c}\mathbf{P}_{\mathbf{f}} \\
\mathbf{k N}\end{array}$ & $\begin{array}{c}\boldsymbol{\sigma}_{\mathbf{f}} \\
\mathbf{M p a}\end{array}$ & $\begin{array}{c}\mathbf{w}_{\mathbf{u}} \\
\mathbf{m m}\end{array}$ & $\begin{array}{c}\mathbf{P}_{\mathbf{u}} \\
\mathbf{k N}\end{array}$ & $\begin{array}{c}\boldsymbol{\sigma}_{\mathbf{u}} \\
\mathbf{M p a}\end{array}$ & $\begin{array}{c}\mathbf{G}_{\mathbf{f}}, \mathbf{4 0} \\
\mathbf{k J} \mathbf{J} \mathbf{m}^{\mathbf{2}}\end{array}$ \\
\hline NP-A-3d-f3-2580-4.5 & 0.029 & 4.57 & 14.11 & 0.518 & 9.09 & 27.95 & 14.58 \\
\hline NP-A-3d-f3-2580-9 & 0.034 & 2.67 & 15.94 & 0.530 & 5.00 & 29.82 & 6.70 \\
\hline NP-A-3d-f3-5180-4.5 & 0.035 & 9.66 & 12.86 & 0.528 & 17.16 & 22.85 & 9.48 \\
\hline NP-A-7d-f1-2580-4.5 & 0.030 & 6.13 & 18.71 & 0.558 & 12.17 & 37.14 & 18.65 \\
\hline NP-A-28d-f3-2580-4.5 & 0.033 & 7.58 & 24.41 & 0.649 & 14.46 & 46.64 & 22.09 \\
\hline NP-A-28d-f3-2580-9 & 0.039 & 3.76 & 23.67 & 0.497 & 7.16 & 45.10 & 9.68 \\
\hline NP-A-28d-f3-5180-4.5 & 0.030 & 14.12 & 18.47 & 0.535 & 29.31 & 38.35 & 16.72 \\
\hline NP-A-56d-f3-2580-4.5 & 0.044 & 7.60 & 23.85 & 0.692 & 13.68 & 42.93 & 20.59 \\
\hline
\end{tabular}


Table B.4

Fracture test results for $2 \%$ fibers under ambient conditions

\begin{tabular}{|l|c|c|c|c|c|c|c|}
\hline Specimen & $\begin{array}{c}\mathbf{w}_{\mathbf{f}} \\
\mathbf{m m}\end{array}$ & $\begin{array}{c}\mathbf{P}_{\mathbf{f}} \\
\mathbf{k N}\end{array}$ & $\begin{array}{c}\mathbf{\sigma}_{\mathbf{f}} \\
\mathbf{M p a}\end{array}$ & $\begin{array}{c}\mathbf{w}_{\mathbf{u}} \\
\mathbf{m m}\end{array}$ & $\begin{array}{c}\mathbf{P}_{\mathbf{u}} \\
\mathbf{k N}\end{array}$ & $\begin{array}{c}\mathbf{\sigma}_{\mathbf{u}} \\
\mathbf{M p a}\end{array}$ & $\begin{array}{c}\mathbf{G}_{\mathbf{f}, \mathbf{4 0}} \\
\mathbf{k J} / \mathbf{m}^{\mathbf{2}}\end{array}$ \\
\hline NP-A-3d-f2-2580-4.5 & 0.010 & 2.72 & 8.65 & 0.427 & 7.93 & 25.25 & 11.56 \\
\hline NP-A-3d-f2-2580-6.75 & 0.013 & 1.57 & 7.32 & 0.339 & 4.39 & 20.52 & 6.26 \\
\hline NP-A-3d-f2-2580-9 & 0.012 & 0.96 & 6.14 & 0.436 & 3.82 & 24.80 & 5.20 \\
\hline NP-A-3d-f2-2580-13.75 & 0.011 & 0.85 & 7.75 & 0.483 & 2.81 & 25.61 & 4.18 \\
\hline NP-A-3d-f2-5180-4.5 & 0.010 & 5.08 & 6.84 & 0.471 & 17.12 & 23.03 & 10.99 \\
\hline NP-A-7d-f2-2580-4.5 & 0.011 & 3.11 & 9.60 & 0.534 & 9.99 & 30.86 & 10.79 \\
\hline NP-A-7d-f2-2580-6.75 & 0.014 & 2.14 & 10.01 & 0.425 & 6.03 & 28.20 & 8.57 \\
\hline NP-A-7d-f2-2580-9 & 0.012 & 1.30 & 8.30 & 0.613 & 4.34 & 27.66 & 6.58 \\
\hline NP-A-7d-f2-2580-13.75 & 0.008 & 0.74 & 6.76 & 0.327 & 2.88 & 26.33 & 3.79 \\
\hline NP-A-7d-f2-5180-4.5 & 0.009 & 5.30 & 6.99 & 0.466 & 20.19 & 26.60 & 11.80 \\
\hline NP-A-28d-f2-2580-4.5 & 0.031 & 5.67 & 17.70 & 0.526 & 10.59 & 33.32 & 16.21 \\
\hline NP-A-28d-f2-2580-6.75 & 0.028 & 3.96 & 17.98 & 0.457 & 7.31 & 33.22 & 9.89 \\
\hline NP-A-28d-f2-2580-9 & 0.039 & 2.79 & 17.28 & 0.456 & 5.04 & 31.29 & 6.90 \\
\hline NP-A-28d-f2-2580-13.75 & 0.027 & 1.82 & 17.21 & 0.288 & 3.39 & 32.11 & 4.40 \\
\hline NP-A-28d-f2-5180-4.5 & 0.024 & 10.92 & 14.81 & 0.445 & 21.94 & 29.77 & 11.97 \\
\hline NP-A-56d-f2-2580-4.5 & 0.058 & 6.55 & 20.17 & 0.403 & 10.07 & 31.03 & 12.42 \\
\hline NP-A-56d-f2-2580-6.75 & 0.027 & 3.95 & 18.51 & 0.536 & 8.07 & 37.74 & 11.49 \\
\hline NP-A-56d-f2-2580-9 & 0.039 & 3.32 & 19.09 & 0.476 & 5.40 & 31.07 & 6.88 \\
\hline NP-A-56d-f2-5180-4.5 & 0.035 & 13.07 & 18.08 & 0.397 & 22.39 & 30.98 & 13.69 \\
\hline
\end{tabular}

Table B.5

Fracture test results for delayed thermally treated specimens

\begin{tabular}{|l|r|r|r|r|r|r|r|}
\hline Specimen & $\begin{array}{c}\mathbf{w}_{\mathbf{f}} \\
\mathbf{m m}\end{array}$ & $\begin{array}{c}\mathbf{P}_{\mathbf{f}} \\
\mathbf{k N}\end{array}$ & $\begin{array}{c}\mathbf{\sigma}_{\mathbf{f}} \\
\mathbf{M p a}\end{array}$ & $\begin{array}{c}\mathbf{w}_{\mathbf{u}} \\
\mathbf{m m}\end{array}$ & $\begin{array}{c}\mathbf{P}_{\mathbf{u}} \\
\mathbf{k N}\end{array}$ & $\begin{array}{c}\mathbf{\sigma}_{\mathbf{u}} \\
\mathbf{M p a}\end{array}$ & $\begin{array}{c}\mathbf{G}_{\mathbf{f}, \mathbf{4 0}} \\
\mathbf{k J} / \mathbf{m}^{2}\end{array}$ \\
\hline NP-DTT-28d-f0-2580-4.5 & 0.011 & 2.98 & 8.86 & 0.011 & 2.98 & 8.88 & - \\
\hline NP-DTT-28d-f1-2580-4.5 & 0.011 & 3.10 & 10.06 & 0.785 & 8.00 & 25.99 & 14.64 \\
\hline NP-DTT-28d-f2-2580-4.5 & 0.018 & 5.42 & 17.01 & 0.324 & 12.49 & 39.37 & 18.52 \\
\hline NP-DTT-28d-f2-2580-6.75 & 0.036 & 3.43 & 16.36 & 0.364 & 8.65 & 41.25 & 12.94 \\
\hline NP-DTT-28d-f2-2580-9 & 0.019 & 2.78 & 17.27 & 0.359 & 6.28 & 38.93 & 8.96 \\
\hline NP-DTT-28d-f2-5180-4.5 & 0.017 & 10.32 & 13.88 & 0.324 & 26.64 & 35.86 & 18.71 \\
\hline NP-DTT-28d-f3-2580-4.5 & 0.053 & 8.99 & 23.99 & 0.538 & 14.91 & 40.51 & 19.11 \\
\hline
\end{tabular}


Table B.6

Fracture test results for thermally treated specimens

\begin{tabular}{|l|r|r|r|r|r|r|r|}
\hline Specimen & $\begin{array}{c}\mathbf{w}_{\mathbf{f}} \\
\mathbf{m m}\end{array}$ & $\begin{array}{c}\mathbf{P}_{\mathbf{f}} \\
\mathbf{k N}\end{array}$ & $\begin{array}{c}\mathbf{\sigma}_{\mathbf{f}} \\
\mathbf{M p a}\end{array}$ & $\begin{array}{c}\mathbf{w}_{\mathbf{u}} \\
\mathbf{m m}\end{array}$ & $\begin{array}{c}\mathbf{P}_{\mathbf{u}} \\
\mathbf{k N}\end{array}$ & $\begin{array}{c}\boldsymbol{\sigma}_{\mathbf{u}} \\
\mathbf{M p a}\end{array}$ & $\begin{array}{c}\mathbf{G}_{\mathbf{f}}, \mathbf{4 0} \\
\mathbf{k J} \mathbf{m}\end{array}$ \\
\hline NP-TT-7d-f0-2580-4.5 & 0.007 & 2.92 & 8.55 & 0.007 & 2.92 & 8.55 & - \\
\hline NP-TT-28d-f0-2580-4.5 & 0.006 & 2.63 & 7.71 & 0.006 & 2.63 & 7.93 & - \\
\hline NP-TT-7d-f1-2580-4.5 & 0.021 & 3.68 & 11.50 & 0.500 & 7.81 & 24.43 & 11.91 \\
\hline NP-TT-7d-f1-2580-9 & 0.015 & 1.91 & 12.09 & 0.606 & 4.32 & 27.44 & 7.63 \\
\hline NP-TT-7d-f1-5180-4.5 & 0.010 & 7.96 & 10.80 & 0.410 & 14.55 & 19.82 & 10.24 \\
\hline NP-TT-28d-f1-2580-4.5 & 0.011 & 3.91 & 11.68 & 0.494 & 8.69 & 25.95 & 11.07 \\
\hline NP-TT-7d-f2-2580-4.5 & 0.017 & 5.04 & 15.38 & 0.329 & 12.41 & 37.86 & 17.24 \\
\hline NP-TT-7d-f2-2580-6.75 & 0.014 & 2.85 & 13.46 & 0.361 & 7.31 & 34.51 & 10.36 \\
\hline NP-TT-7d-f2-2580-9 & 0.016 & 2.58 & 15.71 & 0.368 & 5.80 & 35.37 & 7.39 \\
\hline NP-TT-7d-f2-5180-4.5 & 0.017 & 9.43 & 12.99 & 0.331 & 24.47 & 33.57 & 16.07 \\
\hline NP-TT-28d-f2-2580-4.5 & 0.014 & 5.61 & 17.33 & 0.252 & 12.29 & 38.02 & 14.04 \\
\hline NP-TT-28d-f2-2580-6.75 & 0.023 & 3.75 & 16.74 & 0.365 & 8.75 & 39.01 & 11.77 \\
\hline NP-TT-28d-f2-2580-9 & 0.016 & 2.51 & 15.46 & 0.341 & 6.90 & 42.63 & 9.10 \\
\hline NP-TT-28d-f2-5180-4.5 & 0.021 & 10.77 & 14.62 & 0.367 & 26.20 & 35.56 & 15.46 \\
\hline NP-TT-7d-f3-2580-4.5 & 0.039 & 7.02 & 20.57 & 0.627 & 15.92 & 46.89 & 22.85 \\
\hline NP-TT-7d-f3-2580-9 & 0.023 & 3.19 & 19.44 & 0.572 & 7.81 & 47.60 & 11.27 \\
\hline NP-TT-7d-f3-5180-4.5 & 0.059 & 12.51 & 16.35 & 0.674 & 28.10 & 36.72 & 15.93 \\
\hline NP-TT-28d-f3-2580-4.5 & 0.037 & 7.27 & 22.49 & 0.642 & 15.50 & 48.01 & 21.48 \\
\hline
\end{tabular}

Table B.7

Statistics for first crack strength with $0 \%$ and $1 \%$ fiber contents (ambient conditions)

\begin{tabular}{|l|c|c|c|c|}
\hline \multicolumn{1}{|c|}{ Specimen } & $\begin{array}{c}\text { Samples } \\
\#\end{array}$ & $\begin{array}{c}\boldsymbol{\sigma}_{\mathrm{f}} \\
(\mathbf{M P a})\end{array}$ & $\begin{array}{c}\text { Std. Dev. } \\
(\mathbf{M P a})\end{array}$ & C. O. V. \\
\hline NP-A-3d-f0-2580-4.5 & 1 & - & - & - \\
\hline NP-A-7d-f0-2580-4.5 & 2 & - & - & - \\
\hline NP-A-28d-f0-2580-4.5 & 4 & - & - & - \\
\hline NP-A-56d-f0-2580-4.5 & 4 & - & - & - \\
\hline NP-A-3d-f1-2580-4.5 & 4 & 6.30 & 0.51 & 8.09 \\
\hline NP-A-3d-f1-2580-9 & 3 & 7.28 & 0.60 & 8.27 \\
\hline NP-A-3d-f1-5180-4.5 & 2 & 6.15 & 0.54 & 8.79 \\
\hline NP-A-7d-f1-2580-4.5 & 2 & 7.54 & 1.19 & 15.80 \\
\hline NP-A-28d-f1-2580-4.5 & 8 & 8.13 & 0.92 & 11.33 \\
\hline NP-A-28d-f1-2580-9 & 3 & 9.39 & 1.84 & 19.65 \\
\hline NP-A-28d-f1-5180-4.5 & 4 & 7.96 & 1.06 & 13.29 \\
\hline NP-A-56d-f1-2580-4.5 & 3 & 8.94 & 0.43 & 4.82 \\
\hline
\end{tabular}


Table B.8

Statistics for first crack strength with $2 \%$ fiber content (ambient conditions)

\begin{tabular}{|l|c|c|c|c|}
\hline \multicolumn{1}{|c|}{ Specimen } & $\begin{array}{c}\text { Samples } \\
\#\end{array}$ & $\begin{array}{c}\boldsymbol{\sigma}_{\mathbf{f}} \\
(\mathbf{M P a})\end{array}$ & $\begin{array}{c}\text { Std. Dev. } \\
(\mathbf{M P a})\end{array}$ & C. O. V. \\
\hline NP-A-3d-f2-2580-4.5 & 3 & 8.65 & 3.40 & 39.32 \\
\hline NP-A-3d-f2-2580-6.75 & 3 & 7.32 & 0.72 & 9.90 \\
\hline NP-A-3d-f2-2580-9 & 3 & 6.14 & 2.45 & 39.97 \\
\hline NP-A-3d-f2-2580-13.75 & 1 & 7.75 & - & - \\
\hline NP-A-3d-f2-5180-4.5 & 3 & 6.84 & 1.45 & 21.25 \\
\hline NP-A-7d-f2-2580-4.5 & 3 & 9.60 & 1.82 & 18.91 \\
\hline NP-A-7d-f2-2580-6.75 & 3 & 10.01 & 2.58 & 25.81 \\
\hline NP-A-7d-f2-2580-9 & 3 & 8.30 & 1.11 & 13.42 \\
\hline NP-A-7d-f2-2580-13.75 & 2 & 6.76 & 4.39 & 64.92 \\
\hline NP-A-7d-f2-5180-4.5 & 2 & 6.99 & 3.62 & 51.77 \\
\hline NP-A-28d-f2-2580-4.5 & 12 & 17.70 & 2.17 & 12.27 \\
\hline NP-A-28d-f2-2580-6.75 & 2 & 17.98 & 0.65 & 3.63 \\
\hline NP-A-28d-f2-2580-9 & 4 & 17.28 & 0.65 & 3.76 \\
\hline NP-A-28d-f2-2580-13.75 & 1 & 17.21 & - & - \\
\hline NP-A-28d-f2-5180-4.5 & 2 & 14.81 & 0.17 & 1.12 \\
\hline NP-A-56d-f2-2580-4.5 & 3 & 20.17 & 1.96 & 9.73 \\
\hline NP-A-56d-f2-2580-6.75 & 4 & 19.22 & 2.77 & 14.44 \\
\hline NP-A-56d-f2-2580-9 & 2 & 19.09 & 4.16 & 21.79 \\
\hline NP-A-56d-f2-5180-4.5 & 2 & 18.08 & 0.93 & 5.12 \\
\hline
\end{tabular}

Table B.9

Statistics for first crack strength with $3 \%$ fiber content (ambient conditions)

\begin{tabular}{|l|c|c|c|c|}
\hline \multicolumn{1}{|c|}{ Specimen } & $\begin{array}{c}\text { Samples } \\
\#\end{array}$ & $\begin{array}{c}\boldsymbol{\sigma}_{\mathbf{f}} \\
(\mathbf{M P a})\end{array}$ & $\begin{array}{c}\text { Std. Dev. } \\
(\mathbf{M P a})\end{array}$ & $\mathbf{C .} \mathbf{\text { O. V. }}$ \\
\hline NP-A-3d-f3-2580-4.5 & 3 & 14.11 & 0.44 & 3.12 \\
\hline NP-A-3d-f3-2580-9 & 3 & 15.94 & 2.08 & 13.06 \\
\hline NP-A-3d-f3-5180-4.5 & 2 & 12.86 & 1.61 & 12.52 \\
\hline NP-A-7d-f3-2580-4.5 & 3 & 18.71 & 0.48 & 2.59 \\
\hline NP-A-28d-f3-2580-4.5 & 3 & 24.41 & 1.00 & 4.11 \\
\hline NP-A-28d-f3-2580-9 & 3 & 23.67 & 1.58 & 6.66 \\
\hline NP-A-28d-f3-5180-4.5 & 3 & 18.47 & 0.83 & 4.48 \\
\hline NP-A-56d-f3-2580-4.5 & 3 & 23.85 & 1.92 & 8.04 \\
\hline
\end{tabular}


Table B.10

Statistics for first crack strength (thermal treatment)

\begin{tabular}{|l|c|c|c|c|}
\hline \multicolumn{1}{|c|}{ Specimen } & $\begin{array}{c}\text { Samples } \\
\#\end{array}$ & $\begin{array}{c}\boldsymbol{\sigma}_{\mathbf{f}} \\
(\mathbf{M P a})\end{array}$ & $\begin{array}{c}\text { Std. Dev. } \\
(\mathbf{M P a})\end{array}$ & C. O. V. \\
\hline NP-TT-7d-f0-2580-4.5 & 2 & - & - & - \\
\hline NP-TT-28d-f0-2580-4.5 & 5 & - & - & - \\
\hline NP-TT-7d-f1-2580-4.5 & 6 & 11.50 & 0.49 & 4.24 \\
\hline NP-TT-7d-f1-2580-9 & 3 & 12.09 & 0.99 & 8.18 \\
\hline NP-TT-7d-f1-5180-4.5 & 5 & 10.80 & 1.15 & 10.62 \\
\hline NP-TT-28d-f1-2580-4.5 & 4 & 11.68 & 1.46 & 12.54 \\
\hline NP-TT-7d-f2-2580-4.5 & 7 & 15.38 & 1.85 & 12.05 \\
\hline NP-TT-7d-f2-2580-6.75 & 3 & 13.46 & 1.21 & 8.96 \\
\hline NP-TT-7d-f2-2580-9 & 3 & 15.71 & 1.51 & 9.63 \\
\hline NP-TT-7d-f2-5180-4.5 & 4 & 12.99 & 2.54 & 19.56 \\
\hline NP-TT-28d-f2-2580-4.5 & 2 & 17.33 & 0.84 & 4.85 \\
\hline NP-TT-28d-f2-2580-6.75 & 3 & 16.74 & 1.58 & 9.43 \\
\hline NP-TT-28d-f2-2580-9 & 3 & 15.46 & 0.46 & 2.95 \\
\hline NP-TT-28d-f2-5180-4.5 & 3 & 14.62 & 1.45 & 9.93 \\
\hline NP-TT-7d-f3-2580-4.5 & 3 & 20.57 & 1.55 & 7.53 \\
\hline NP-TT-7d-f3-2580-9 & 3 & 19.44 & 3.24 & 16.66 \\
\hline NP-TT-7d-f3-5180-4.5 & 1 & 16.35 & - & - \\
\hline NP-TT-28d-f3-2580-4.5 & 3 & 22.49 & 1.50 & 6.69 \\
\hline
\end{tabular}

Table B.11

Statistics for first crack strength (delayed thermal treatment)

\begin{tabular}{|l|c|c|c|c|}
\hline \multicolumn{1}{|c|}{ Specimen } & $\begin{array}{c}\text { Samples } \\
\#\end{array}$ & $\begin{array}{c}\boldsymbol{\sigma}_{\mathbf{f}} \\
(\mathbf{M P a})\end{array}$ & $\begin{array}{c}\text { Std. Dev. } \\
(\mathbf{M P a})\end{array}$ & $\mathbf{C .} \mathbf{\text { O. V. }}$ \\
\hline NP-DTT-28d-f0-2580-4.5 & 4 & - & - & - \\
\hline NP-DTT-28d-f1-2580-4.5 & 4 & 10.06 & 3.42 & 33.98 \\
\hline NP-DTT-28d-f2-2580-4.5 & 3 & 17.01 & 2.84 & 16.67 \\
\hline NP-DTT-28d-f2-2580-6.75 & 2 & 16.36 & 0.65 & 4.00 \\
\hline NP-DTT-28d-f2-2580-9 & 2 & 17.27 & 0.38 & 2.21 \\
\hline NP-DTT-28d-f2-5180-4.5 & 3 & 13.88 & 0.77 & 5.52 \\
\hline NP-DTT-28d-f3-2580-4.5 & 3 & 23.99 & 5.04 & 21.00 \\
\hline
\end{tabular}


Table B.12

Statistics for ultimate strength with $0 \%$ and $1 \%$ fiber contents (ambient conditions)

\begin{tabular}{|l|c|c|c|c|}
\hline \multicolumn{1}{|c|}{ Specimen } & $\begin{array}{c}\text { Samples } \\
\#\end{array}$ & $\begin{array}{c}\boldsymbol{\sigma}_{\mathbf{u}} \\
(\mathbf{M P a})\end{array}$ & $\begin{array}{c}\text { Std. Dev. } \\
(\mathbf{M P a})\end{array}$ & C. O. V. \\
\hline NP-A-3d-f0-2580-4.5 & 1 & 5.76 & & \\
\hline NP-A-7d-f0-2580-4.5 & 2 & 5.07 & 0.17 & 3.40 \\
\hline NP-A-28d-f0-2580-4.5 & 4 & 4.75 & 0.39 & 8.19 \\
\hline NP-A-56d-f0-2580-4.5 & 4 & 4.94 & 0.43 & 8.70 \\
\hline NP-A-3d-f1-2580-4.5 & 4 & 13.21 & 1.06 & 7.99 \\
\hline NP-A-3d-f1-2580-9 & 3 & 15.13 & 1.38 & 9.15 \\
\hline NP-A-3d-f1-5180-4.5 & 2 & 13.81 & 0.02 & 0.11 \\
\hline NP-A-7d-f1-2580-4.5 & 2 & 21.02 & 0.18 & 0.87 \\
\hline NP-A-28d-f1-2580-4.5 & 8 & 20.61 & 2.14 & 10.38 \\
\hline NP-A-28d-f1-2580-9 & 3 & 22.86 & 3.28 & 14.34 \\
\hline NP-A-28d-f1-5180-4.5 & 4 & 18.74 & 2.08 & 11.11 \\
\hline NP-A-56d-f1-2580-4.5 & 3 & 21.02 & 1.12 & 5.34 \\
\hline
\end{tabular}

Table B.13

Statistics for ultimate strength with $2 \%$ fiber contents (ambient conditions)

\begin{tabular}{|l|c|c|c|c|}
\hline \multicolumn{1}{|c|}{ Specimen } & $\begin{array}{c}\text { Samples } \\
\#\end{array}$ & $\begin{array}{c}\boldsymbol{\sigma}_{\mathbf{u}} \\
(\mathbf{M P a})\end{array}$ & $\begin{array}{c}\text { Std. Dev. } \\
(\mathbf{M P a})\end{array}$ & C. O. V. \\
\hline NP-A-3d-f2-2580-4.5 & 3 & 25.25 & 6.60 & 26.12 \\
\hline NP-A-3d-f2-2580-6.75 & 3 & 20.52 & 1.13 & 5.51 \\
\hline NP-A-3d-f2-2580-9 & 3 & 24.80 & 0.88 & 3.56 \\
\hline NP-A-3d-f2-2580-13.75 & 1 & 25.61 & - & - \\
\hline NP-A-3d-f2-5180-4.5 & 3 & 23.03 & 2.63 & 11.42 \\
\hline NP-A-7d-f2-2580-4.5 & 3 & 30.86 & 4.03 & 13.07 \\
\hline NP-A-7d-f2-2580-6.75 & 3 & 28.20 & 4.64 & 16.45 \\
\hline NP-A-7d-f2-2580-9 & 3 & 27.66 & 4.96 & 17.94 \\
\hline NP-A-7d-f2-2580-13.75 & 2 & 26.33 & 1.90 & 7.23 \\
\hline NP-A-7d-f2-5180-4.5 & 2 & 26.60 & 0.77 & 2.89 \\
\hline NP-A-28d-f2-2580-4.5 & 12 & 33.32 & 1.80 & 5.41 \\
\hline NP-A-28d-f2-2580-6.75 & 2 & 33.22 & 1.65 & 4.95 \\
\hline NP-A-28d-f2-2580-9 & 4 & 31.29 & 2.26 & 7.22 \\
\hline NP-A-28d-f2-2580-13.75 & 1 & 32.11 & - & - \\
\hline NP-A-28d-f2-5180-4.5 & 2 & 29.77 & 0.63 & 2.10 \\
\hline NP-A-56d-f2-2580-4.5 & 3 & 31.03 & 3.22 & 10.36 \\
\hline NP-A-56d-f2-2580-6.75 & 4 & 36.69 & 3.92 & 10.68 \\
\hline NP-A-56d-f2-2580-9 & 2 & 31.07 & 1.99 & 6.41 \\
\hline NP-A-56d-f2-5180-4.5 & 2 & 30.98 & 4.94 & 15.93 \\
\hline
\end{tabular}


Table B.14

Statistics for ultimate strength with $3 \%$ fiber contents (ambient conditions)

\begin{tabular}{|l|c|c|c|c|}
\hline \multicolumn{1}{|c|}{ Specimen } & $\begin{array}{c}\text { Samples } \\
\#\end{array}$ & $\begin{array}{c}\boldsymbol{\sigma}_{\mathbf{u}} \\
(\mathbf{M P a})\end{array}$ & $\begin{array}{c}\text { Std. Dev. } \\
(\mathbf{M P a})\end{array}$ & C. O. V. \\
\hline NP-A-3d-f3-2580-4.5 & 3 & 27.95 & 4.75 & 16.98 \\
\hline NP-A-3d-f3-2580-9 & 3 & 29.82 & 0.75 & 2.52 \\
\hline NP-A-3d-f3-5180-4.5 & 2 & 22.85 & 1.70 & 7.44 \\
\hline NP-A-7d-f3-2580-4.5 & 3 & 37.14 & 1.70 & 4.58 \\
\hline NP-A-28d-f3-2580-4.5 & 3 & 46.64 & 2.66 & 5.71 \\
\hline NP-A-28d-f3-2580-9 & 3 & 45.10 & 2.37 & 5.25 \\
\hline NP-A-28d-f3-5180-4.5 & 3 & 38.35 & 3.15 & 8.23 \\
\hline NP-A-56d-f3-2580-4.5 & 3 & 42.93 & 3.79 & 8.84 \\
\hline
\end{tabular}

Table B.15

Statistics for ultimate strength (thermal treatment)

\begin{tabular}{|l|c|c|c|c|}
\hline \multicolumn{1}{|c|}{ Specimen } & $\begin{array}{c}\text { Samples } \\
\#\end{array}$ & $\begin{array}{c}\sigma_{\mathrm{u}} \\
(\mathrm{MPa})\end{array}$ & $\begin{array}{c}\text { Std. Dev. } \\
(\mathrm{MPa})\end{array}$ & C. O. V. \\
\hline NP-TT-7d-f0-2580-4.5 & 2 & 8.55 & 5.96 & 69.69 \\
\hline NP-TT-28d-f0-2580-4.5 & 5 & 7.71 & 3.78 & 49.07 \\
\hline NP-TT-7d-f1-2580-4.5 & 6 & 24.43 & 4.09 & 16.76 \\
\hline NP-TT-7d-f1-2580-9 & 3 & 27.44 & 3.97 & 14.48 \\
\hline NP-TT-7d-f1-5180-4.5 & 5 & 19.82 & 2.32 & 11.71 \\
\hline NP-TT-28d-f1-2580-4.5 & 4 & 25.95 & 4.60 & 17.71 \\
\hline NP-TT-7d-f2-2580-4.5 & 7 & 37.86 & 5.19 & 13.71 \\
\hline NP-TT-7d-f2-2580-6.75 & 3 & 34.51 & 3.63 & 10.52 \\
\hline NP-TT-7d-f2-2580-9 & 3 & 35.37 & 3.57 & 10.10 \\
\hline NP-TT-7d-f2-5180-4.5 & 4 & 33.57 & 1.91 & 5.69 \\
\hline NP-TT-28d-f2-2580-4.5 & 2 & 38.02 & 4.01 & 10.56 \\
\hline NP-TT-28d-f2-2580-6.75 & 3 & 39.01 & 1.62 & 4.16 \\
\hline NP-TT-28d-f2-2580-9 & 3 & 42.63 & 5.35 & 12.55 \\
\hline NP-TT-28d-f2-5180-4.5 & 3 & 35.56 & 1.72 & 4.83 \\
\hline NP-TT-7d-f3-2580-4.5 & 3 & 46.89 & 5.34 & 11.38 \\
\hline NP-TT-7d-f3-2580-9 & 3 & 47.60 & 3.55 & 7.46 \\
\hline NP-TT-7d-f3-5180-4.5 & 1 & 36.72 & - & - \\
\hline NP-TT-28d-f3-2580-4.5 & 3 & 48.01 & 5.34 & 11.12 \\
\hline
\end{tabular}


Table B.16

Statistics for ultimate strength (delayed thermal treatment)

\begin{tabular}{|l|c|c|c|c|}
\hline \multicolumn{1}{|c|}{ Specimen } & $\begin{array}{c}\text { Samples } \\
\#\end{array}$ & $\begin{array}{c}\boldsymbol{\sigma}_{\mathbf{u}} \\
(\mathbf{M P a})\end{array}$ & $\begin{array}{c}\text { Std. Dev. } \\
(\mathbf{M P a})\end{array}$ & $\mathbf{C .} \mathbf{\text { O. V. }}$ \\
\hline NP-DTT-28d-f0-2580-4.5 & 4 & 8.88 & 3.40 & 38.27 \\
\hline NP-DTT-28d-f1-2580-4.5 & 4 & 25.99 & 3.04 & 11.70 \\
\hline NP-DTT-28d-f2-2580-4.5 & 3 & 39.37 & 2.81 & 7.14 \\
\hline NP-DTT-28d-f2-2580-6.75 & 2 & 41.25 & 1.07 & 2.58 \\
\hline NP-DTT-28d-f2-2580-9 & 2 & 38.93 & 2.30 & 5.91 \\
\hline NP-DTT-28d-f2-5180-4.5 & 3 & 35.86 & 3.39 & 9.45 \\
\hline NP-DTT-28d-f3-2580-4.5 & 3 & 40.51 & 11.55 & 28.50 \\
\hline
\end{tabular}




\section{Appendix C: Plots of Fracture Data}
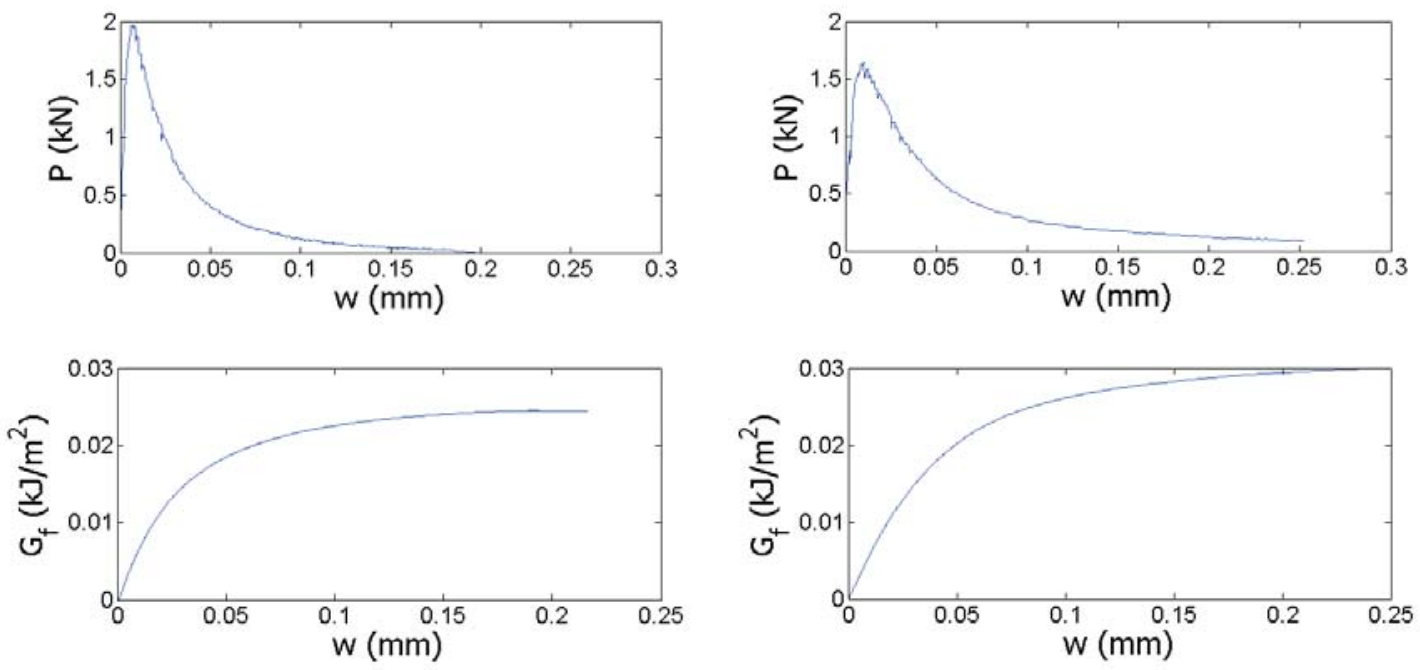

Figure C.1: NP-A-3d-f0-2580-4.5 data (Left) and NP-A-7d-f0-2580-4.5 data (Right)
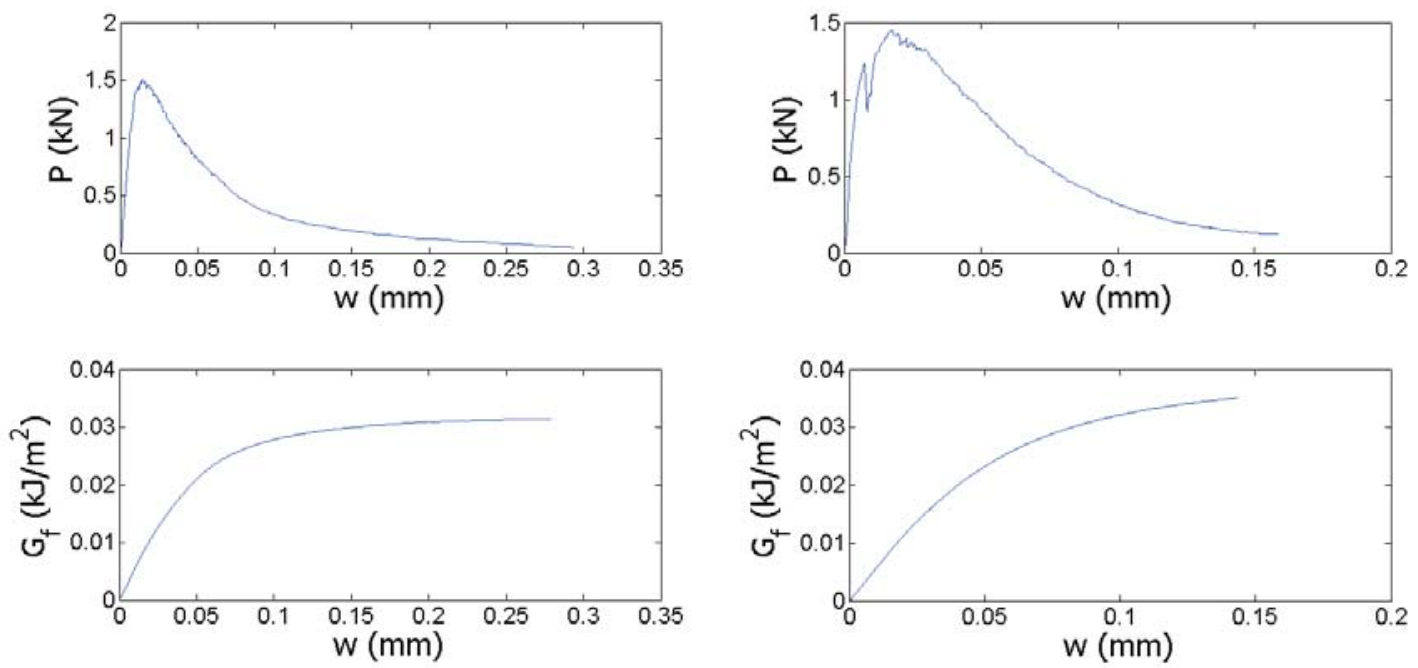

Figure C.2: NP-A-28d-f0-2580-4.5 data (Left) and NP-A-56d-f0-2580-4.5 data (Right) 

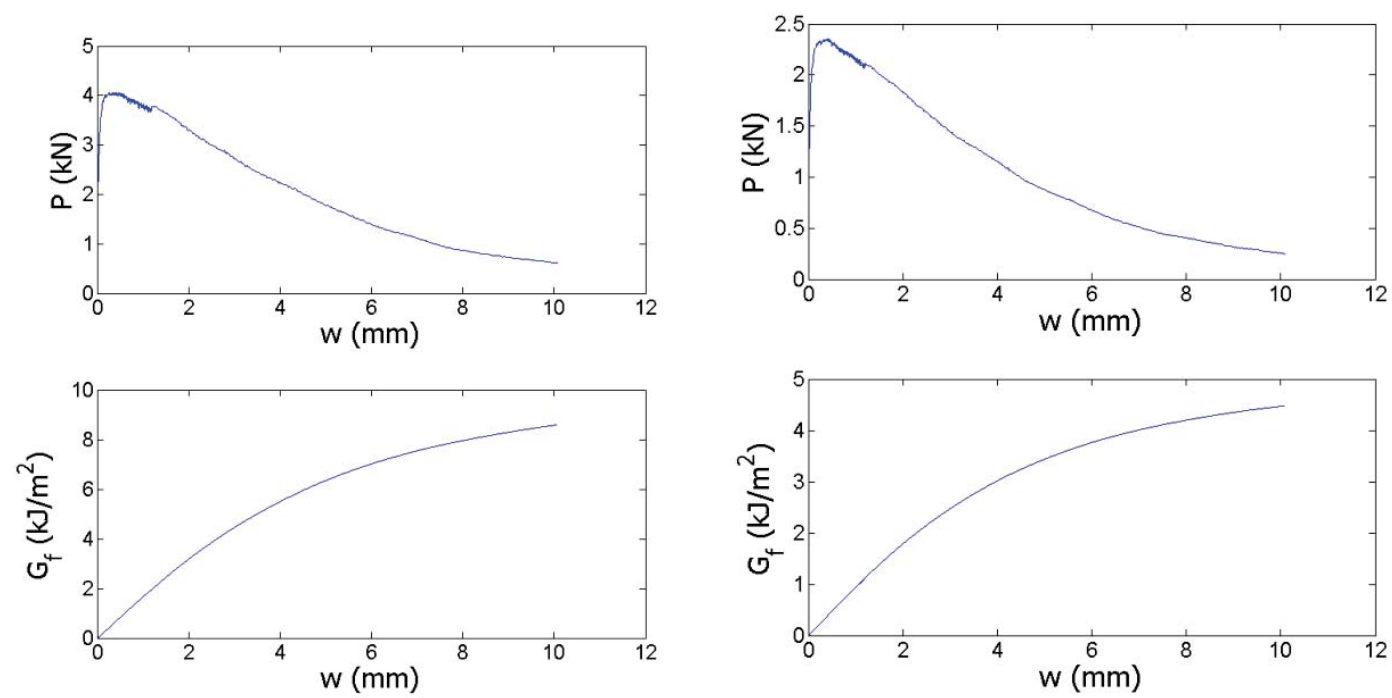

Figure C.3: NP-A-3d-f1-2580-4.5 data (Left) and NP-A-3d-f1-2580-9 data (Right)
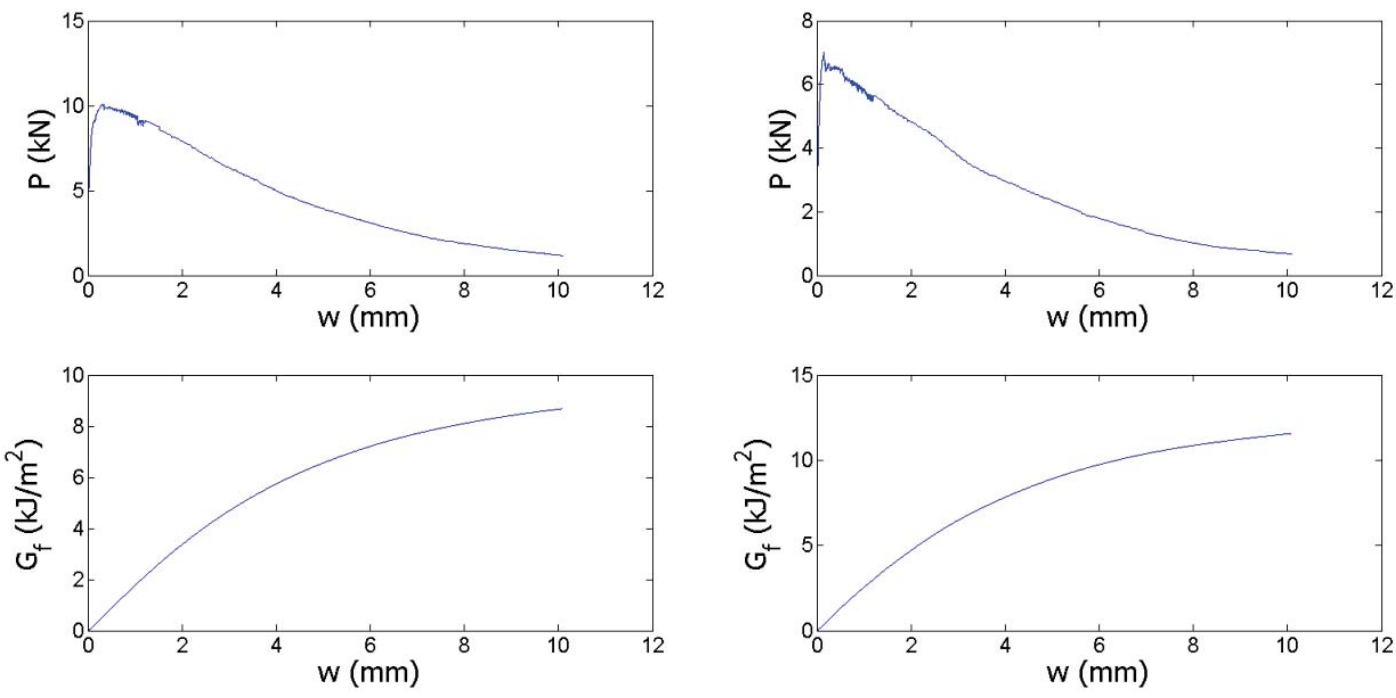

Figure C.4: NP-A-3d-f1-5180-4.5 data (Left) and NP-A-7d-f1-2580-4.5 data (Right) 

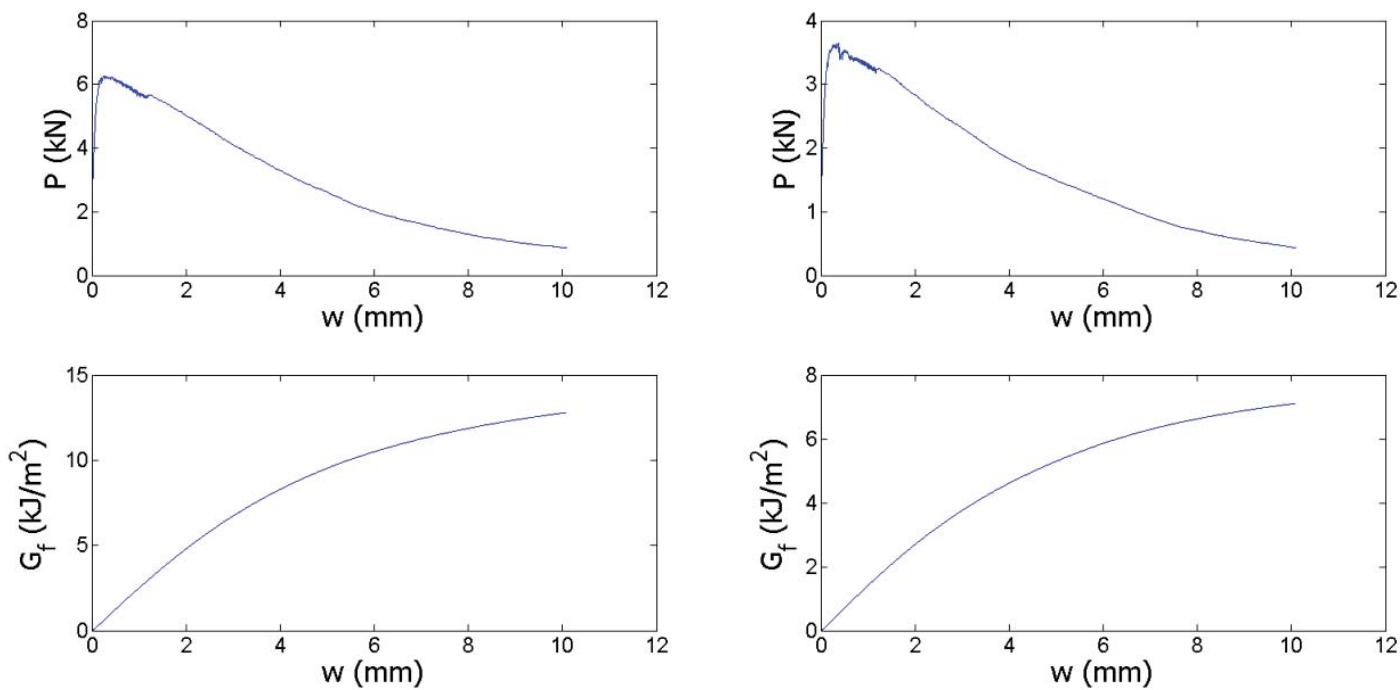

Figure C.5: NP-A-28d-f1-2580-4.5 data (Left) and NP-A-28d-f1-2580-9 data (Right)
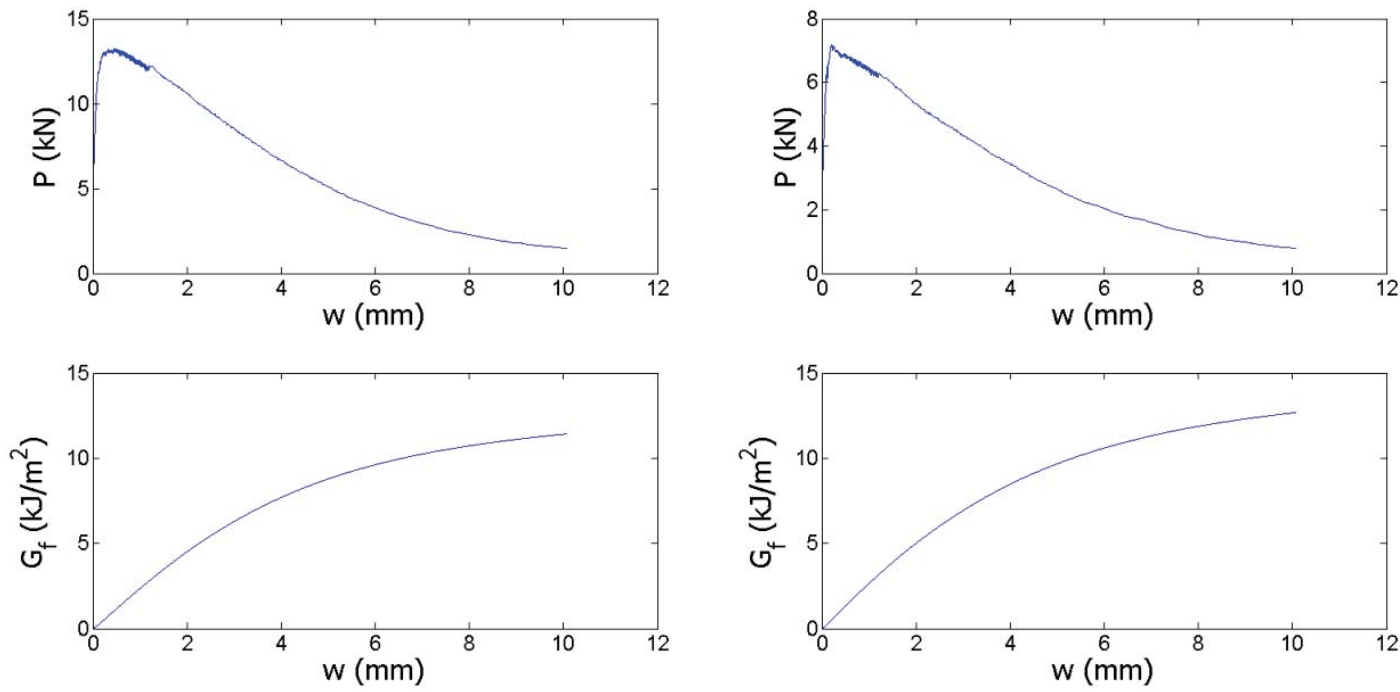

Figure C.6: NP-A-28d-f1-5180-4.5 data (Left) and NP-A-56d-f1-2580-4.5 data (Right) 

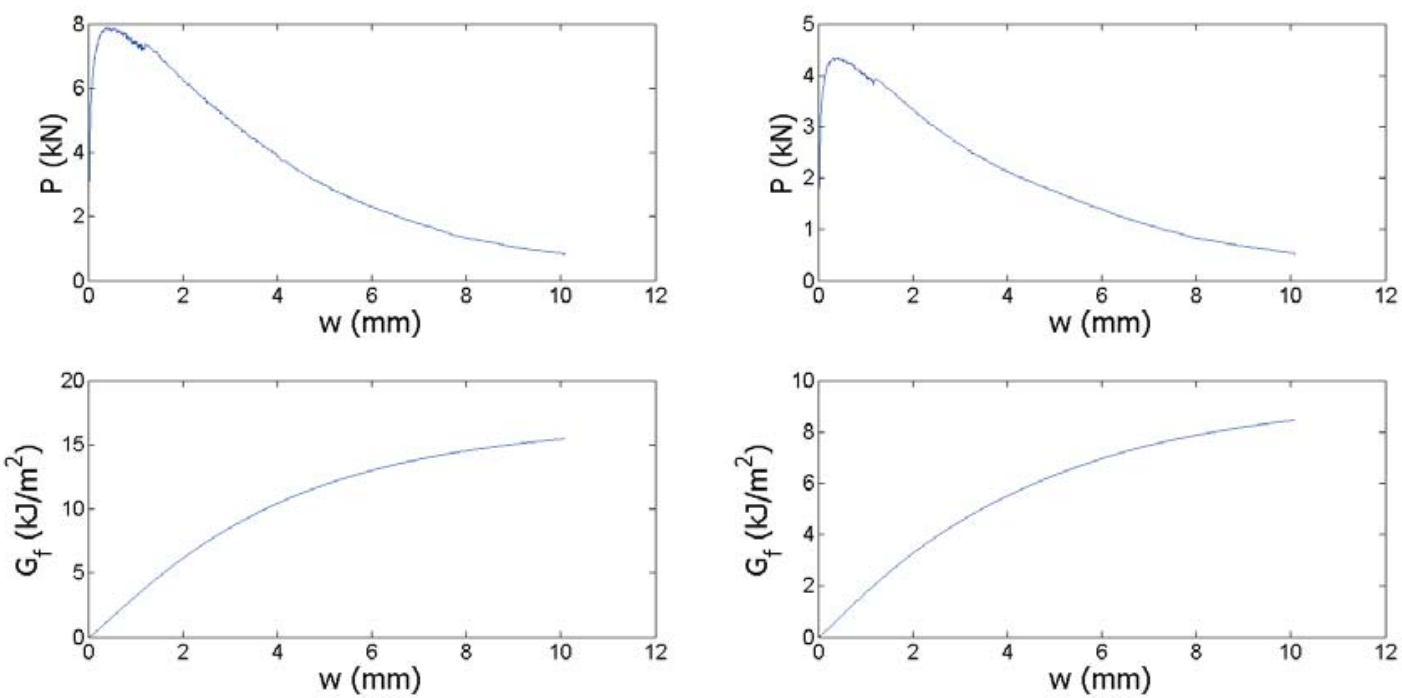

Figure C.7: NP-A-3d-f2-2580-4.5 data (Left) and NP-A-3d-f2-2580-6.75 data (Right)
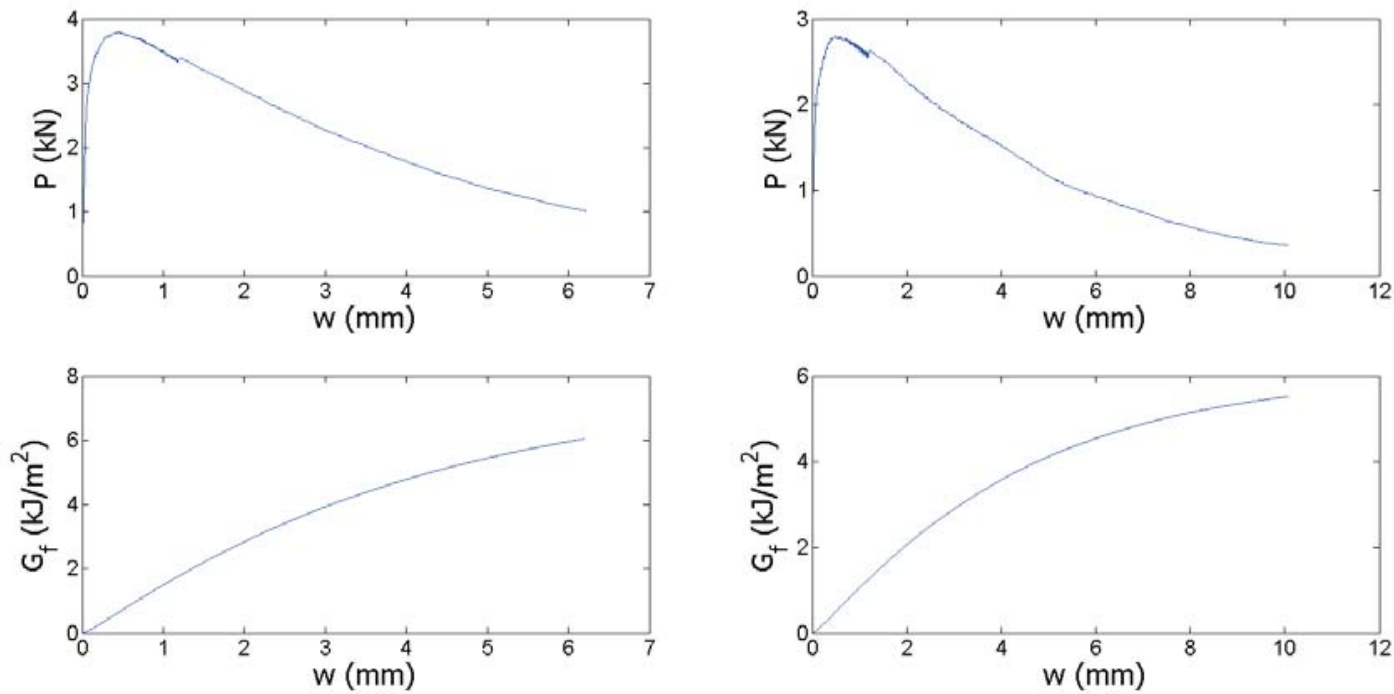

Figure C.8: NP-A-3d-f1-2580-9 data (Left) and NP-A-3d-f1-2580-13.75 data (Right) 

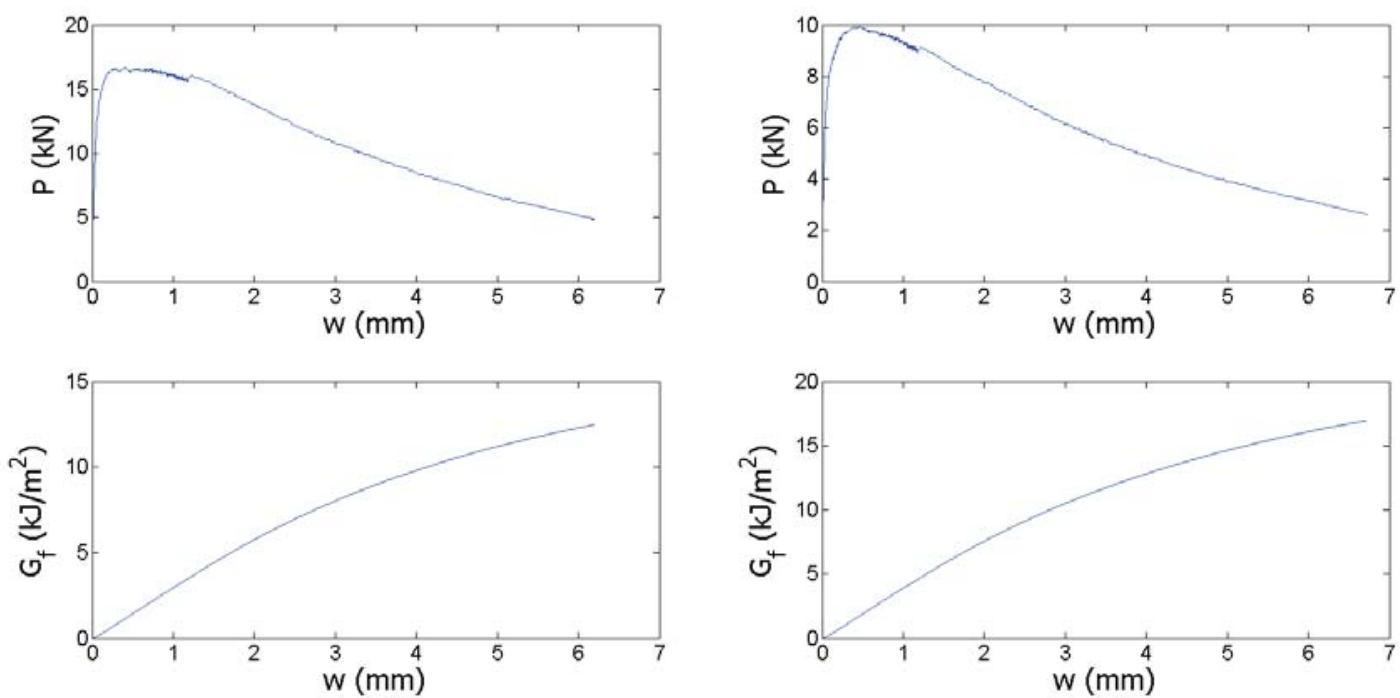

Figure C.9: NP-A-3d-f2-5180-4.5 data (Left) and NP-A-7d-f2-2580-4.5 data (Right)
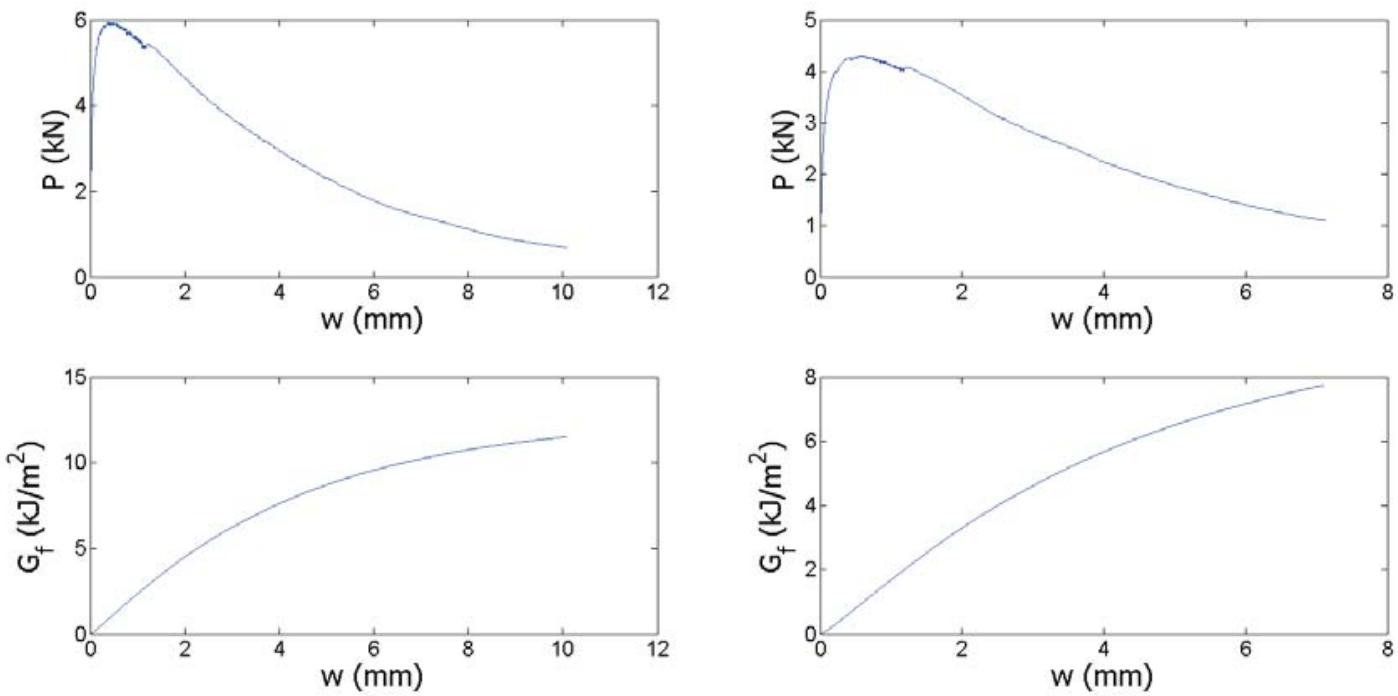

Figure C.10: NP-A-7d-f2-5180-6.75 data (Left) and NP-A-7d-f2-2580-9 data (Right) 

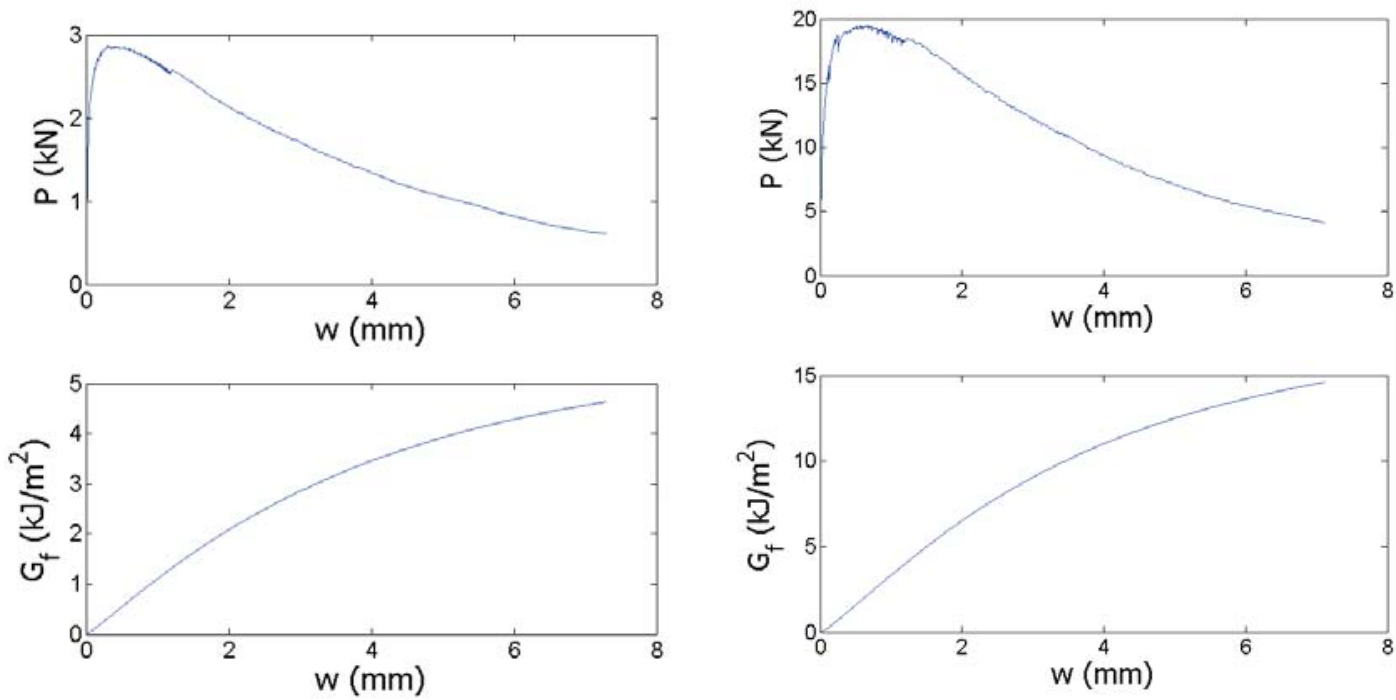

Figure C.11: NP-A-7d-f2-2580-13.75 data (Left) and NP-A-7d-f2-5180-4.5 data (Right)
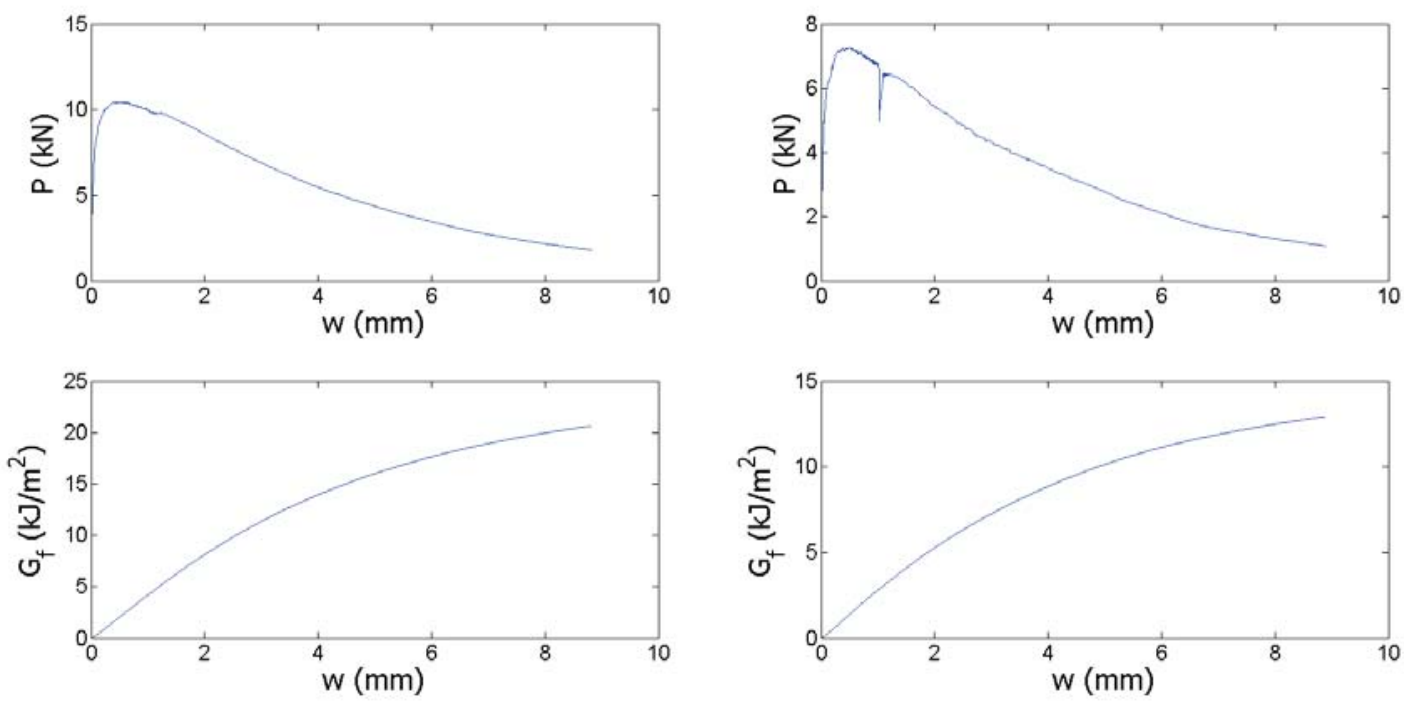

Figure C.12: NP-A-28d-f2-2580-4.5 data (Left) and NP-A-28d-f2-2580-6.75 data (Right) 

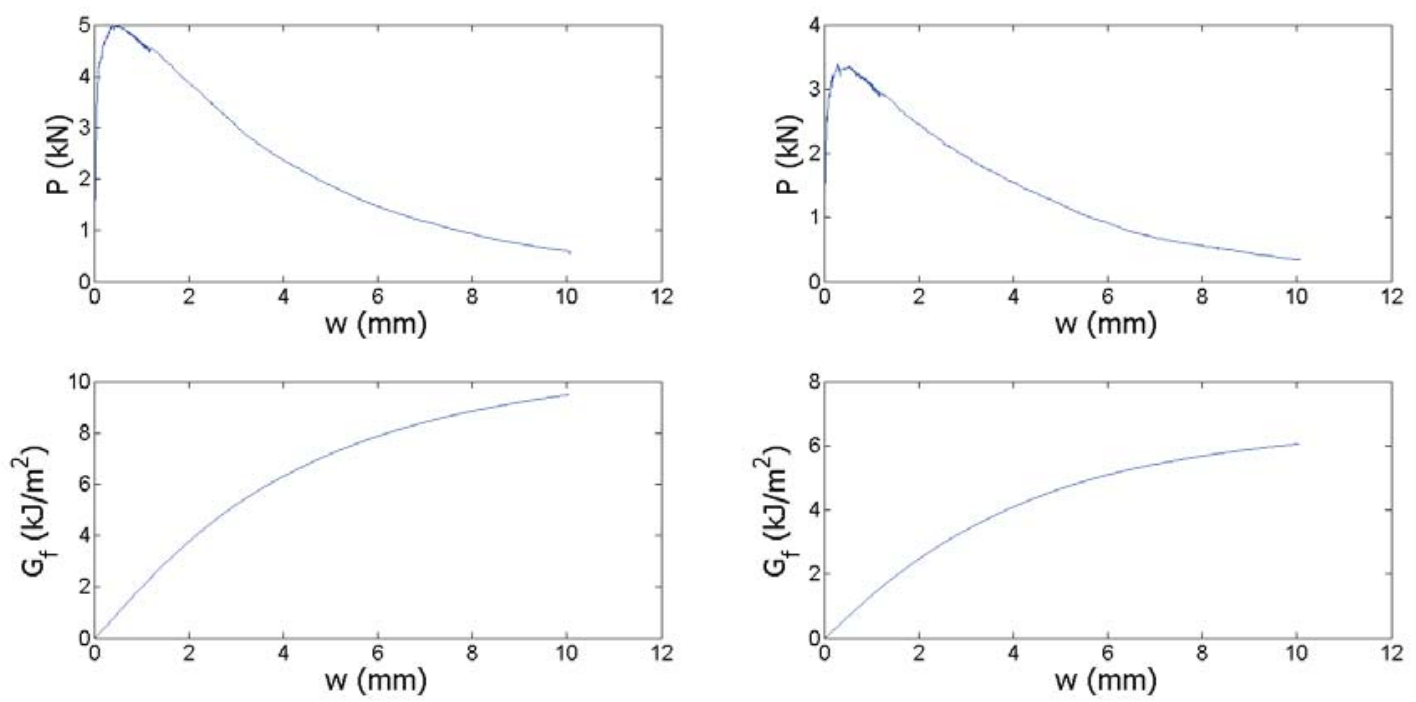

Figure C.13: NP-A-28d-f1-2580-9 data (Left) and NP-A-28d-f1-2580-13.75 data (Right)
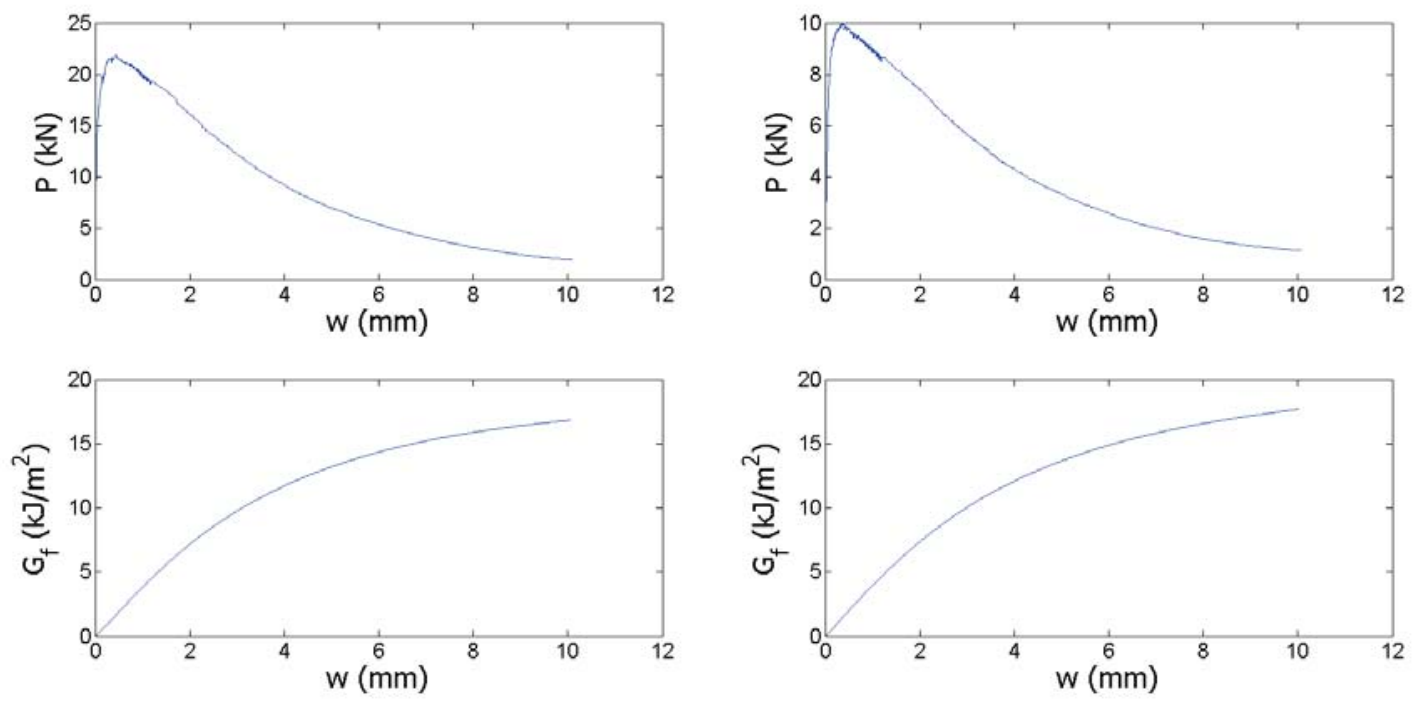

Figure C.14: NP-A-28d-f2-25180-4.5 data (Left) and NP-A-56d-f2-2580-4.5 data (Right) 

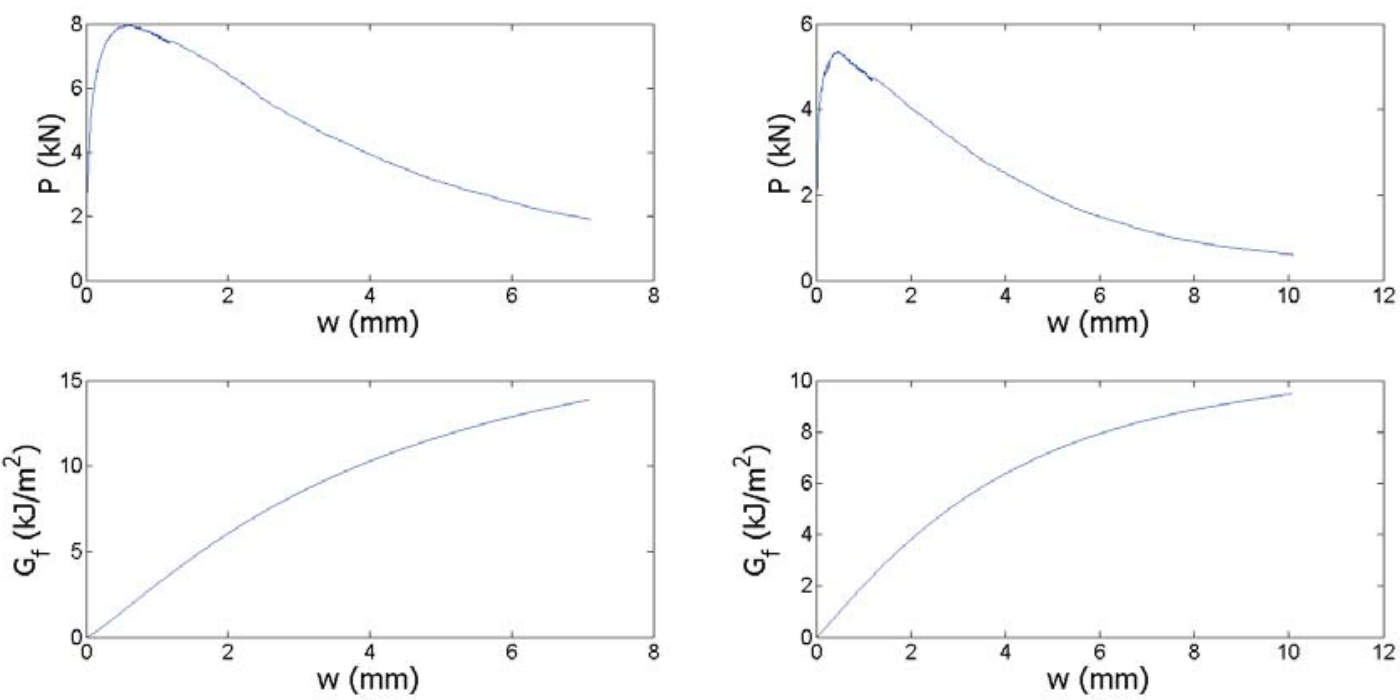

Figure C.15: NP-A-56d-f2-2580-6.75 data (Left) and NP-A-56d-f2-5180-9 data (Right)
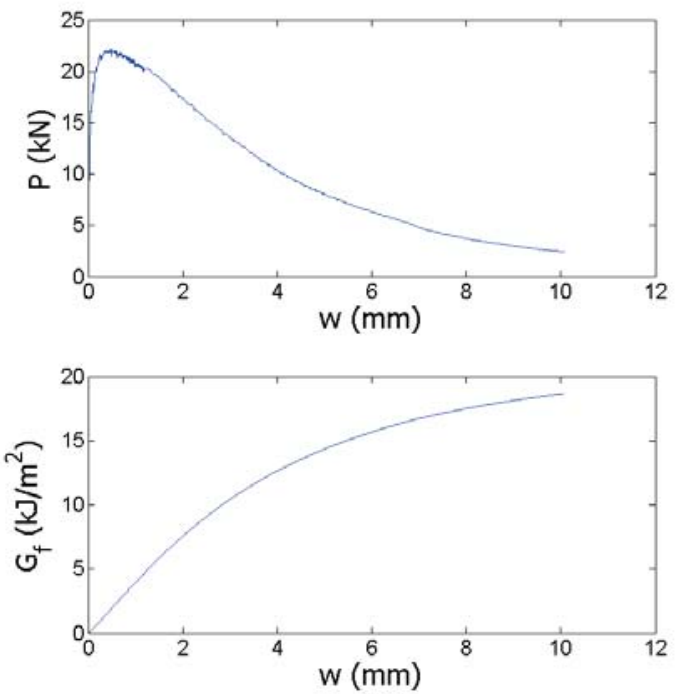

Figure C.16: NP-A-56d-f2-5180-4.5 data 

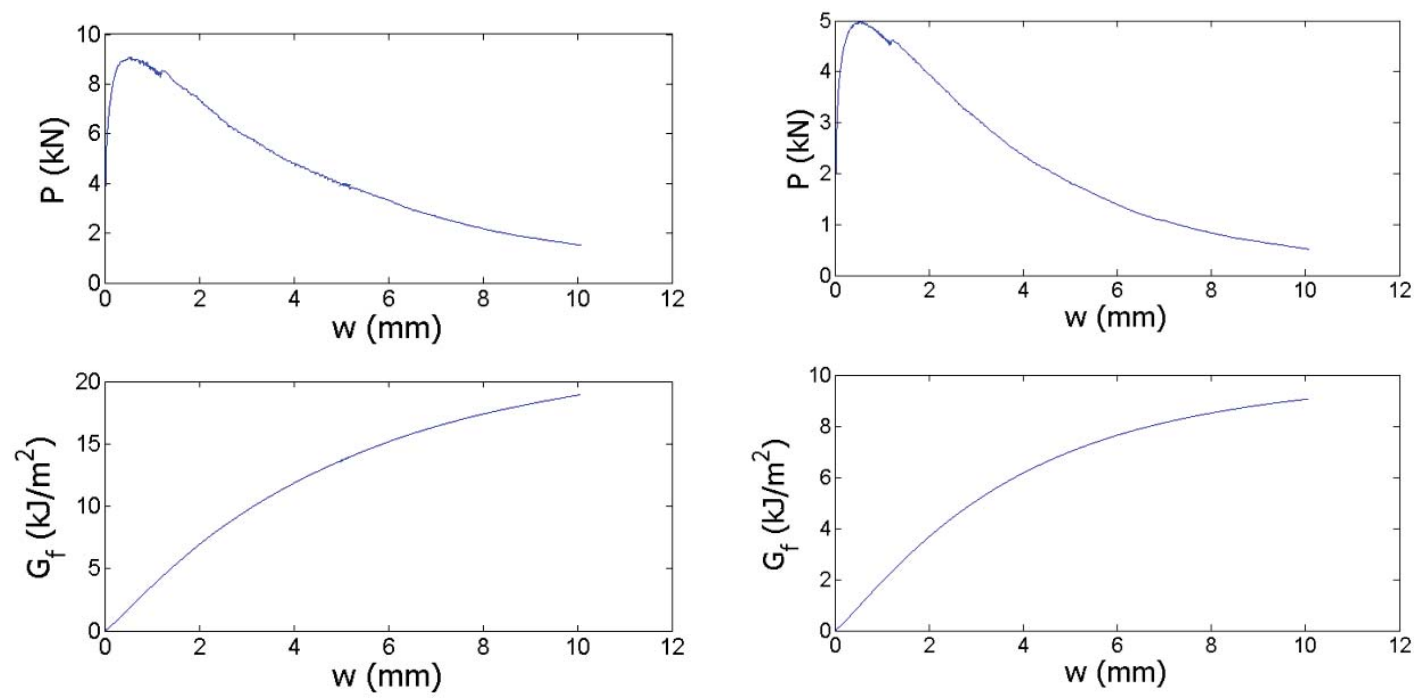

Figure C.17: NP-A-3d-f3-2580-4.5 data (Left) and NP-A-3d-f3-2580-9 data (Right)
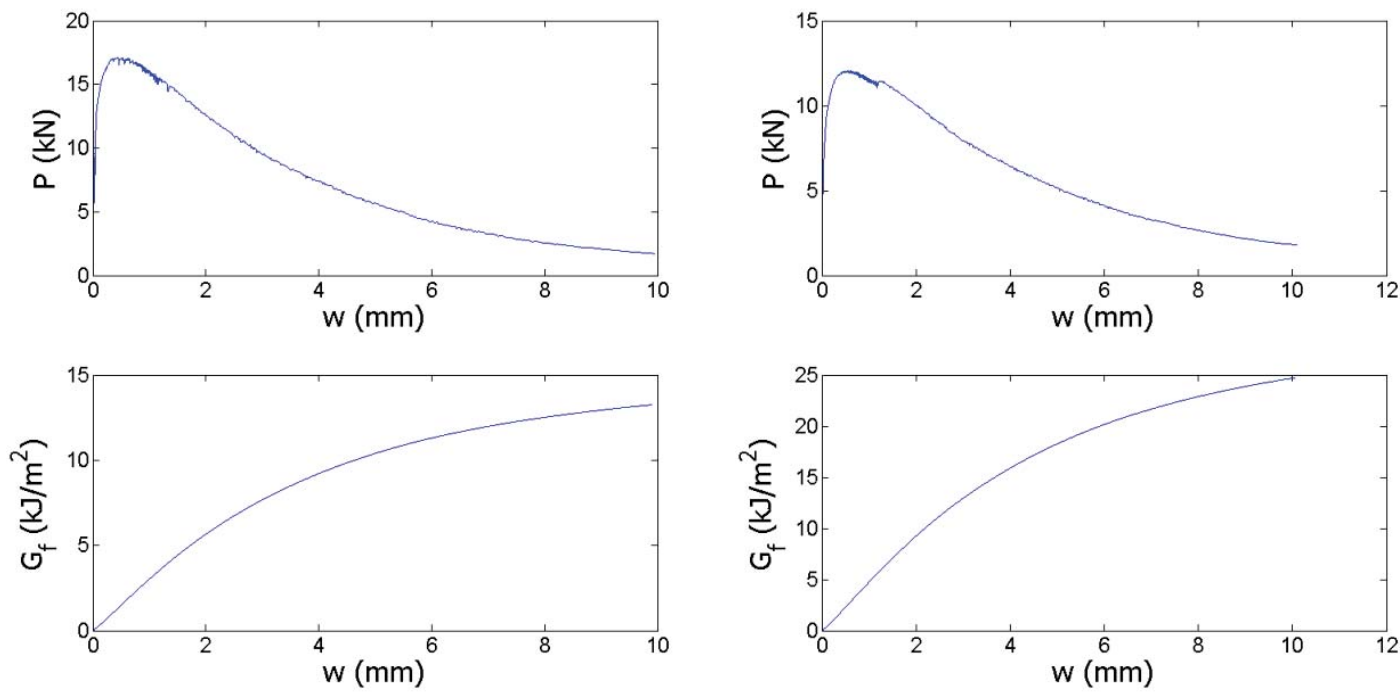

Figure C.18: NP-A-3d-f3-5180-4.5 data (Left) and NP-A-7d-f3-2580-4.5 data (Right) 

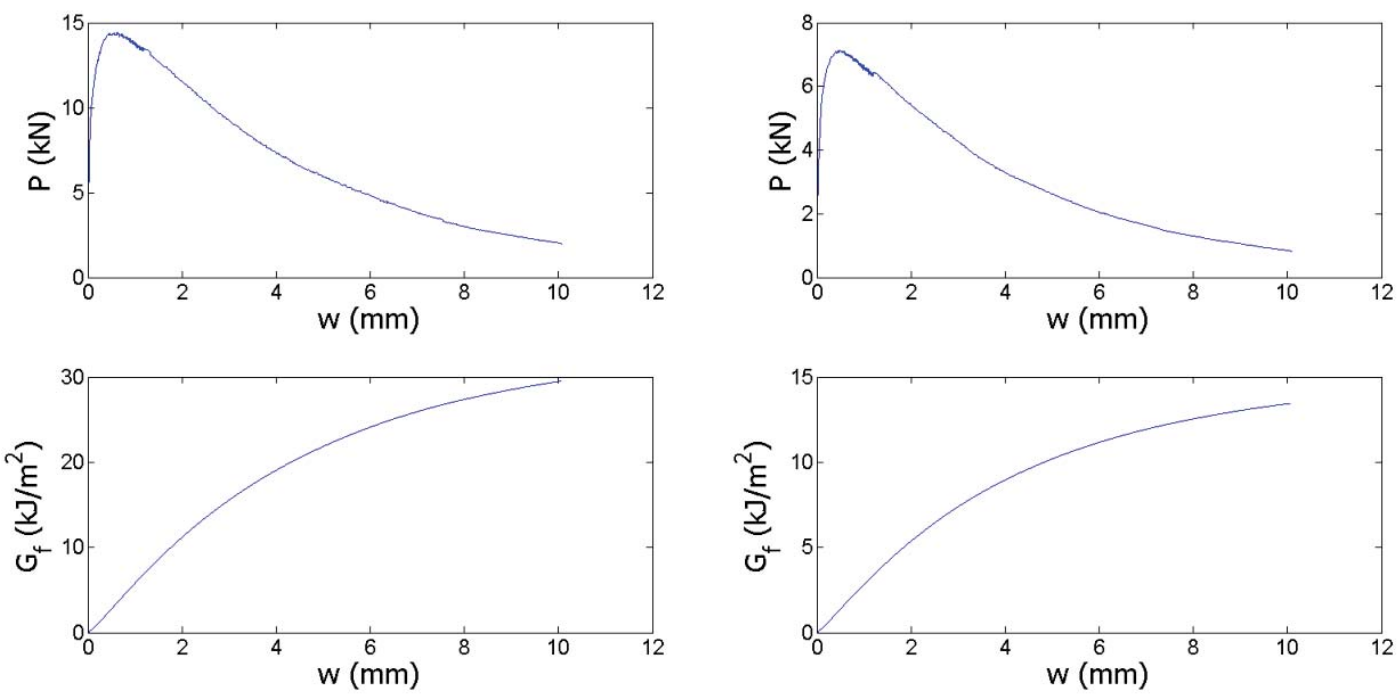

Figure C.19: NP-A-28d-f3-2580-4.5 data (Left) and NP-A-28d-f3-2580-9 data (Right)
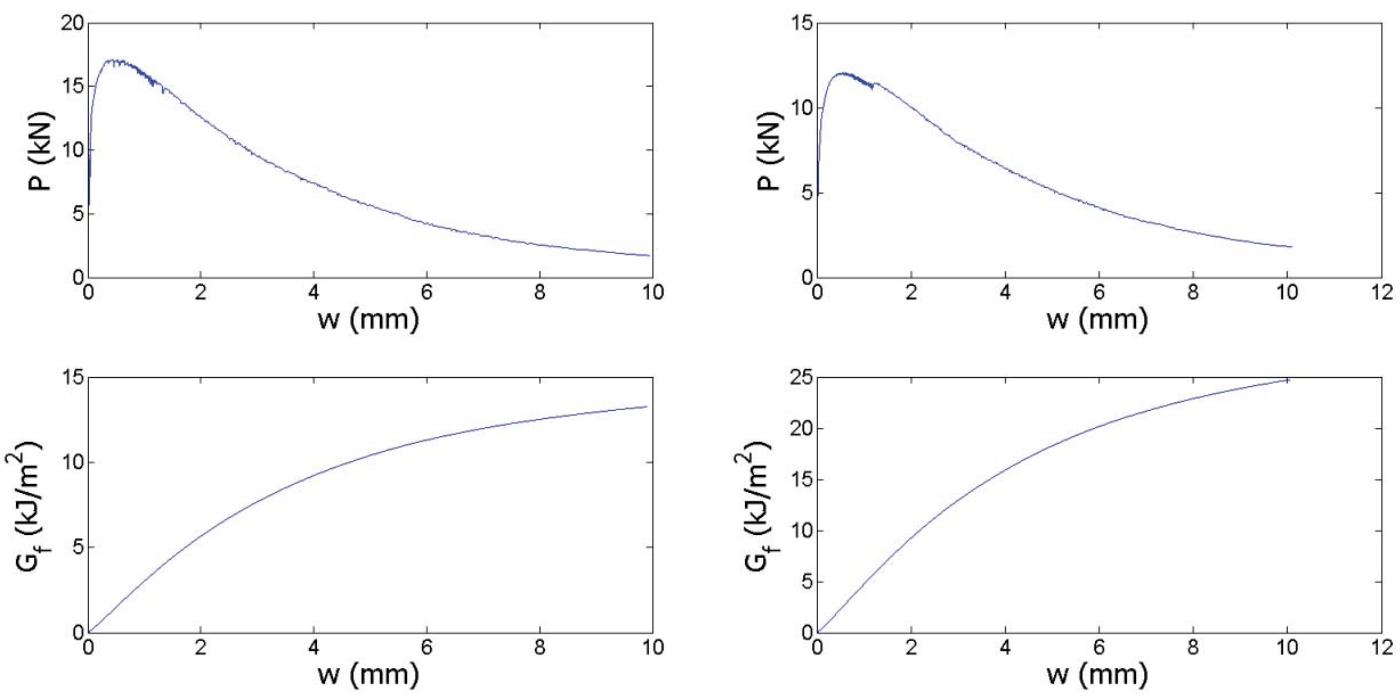

Figure C.20: NP-A-28d-f3-5180-4.5 data (Left) and NP-A-56d-f3-2580-4.5 data (Right) 

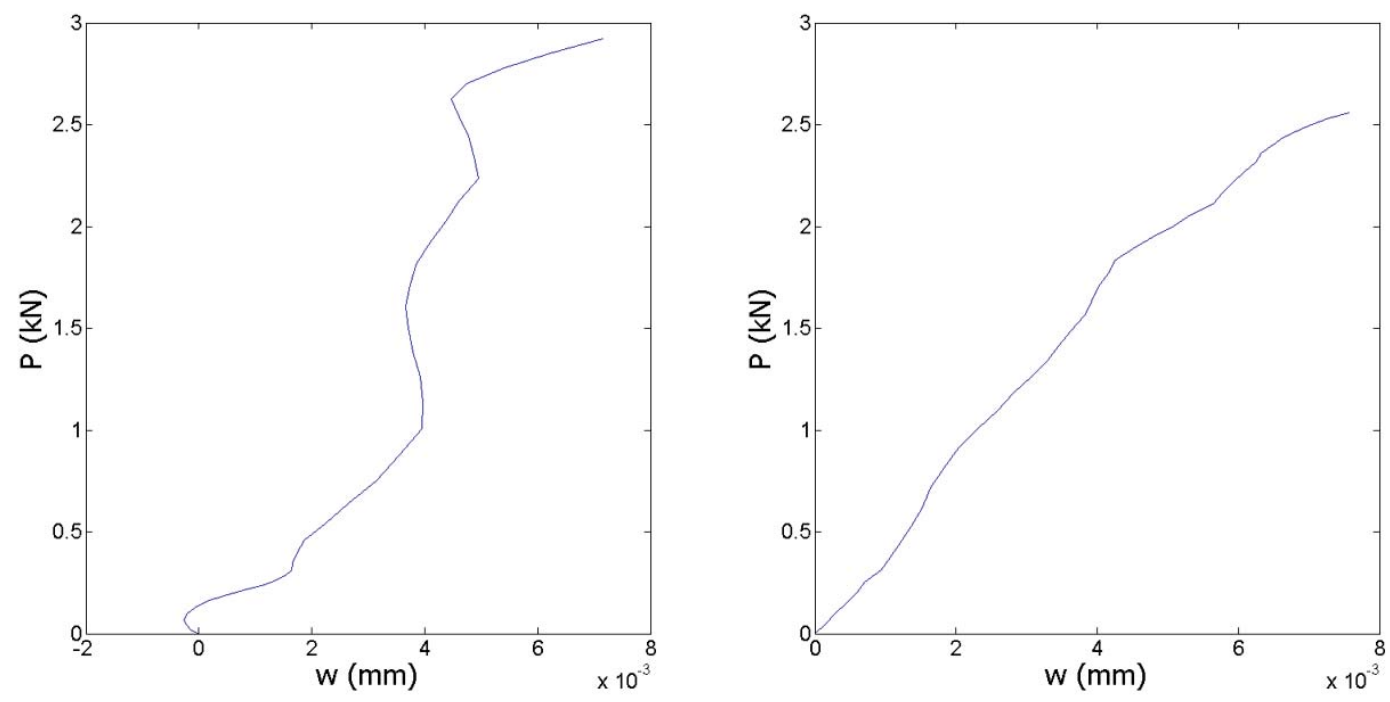

Figure C.21: NP-TT-7d-f0-2580-4.5 data (Left) and NP-TT-28d-f0-2580-4.5 data (Right)
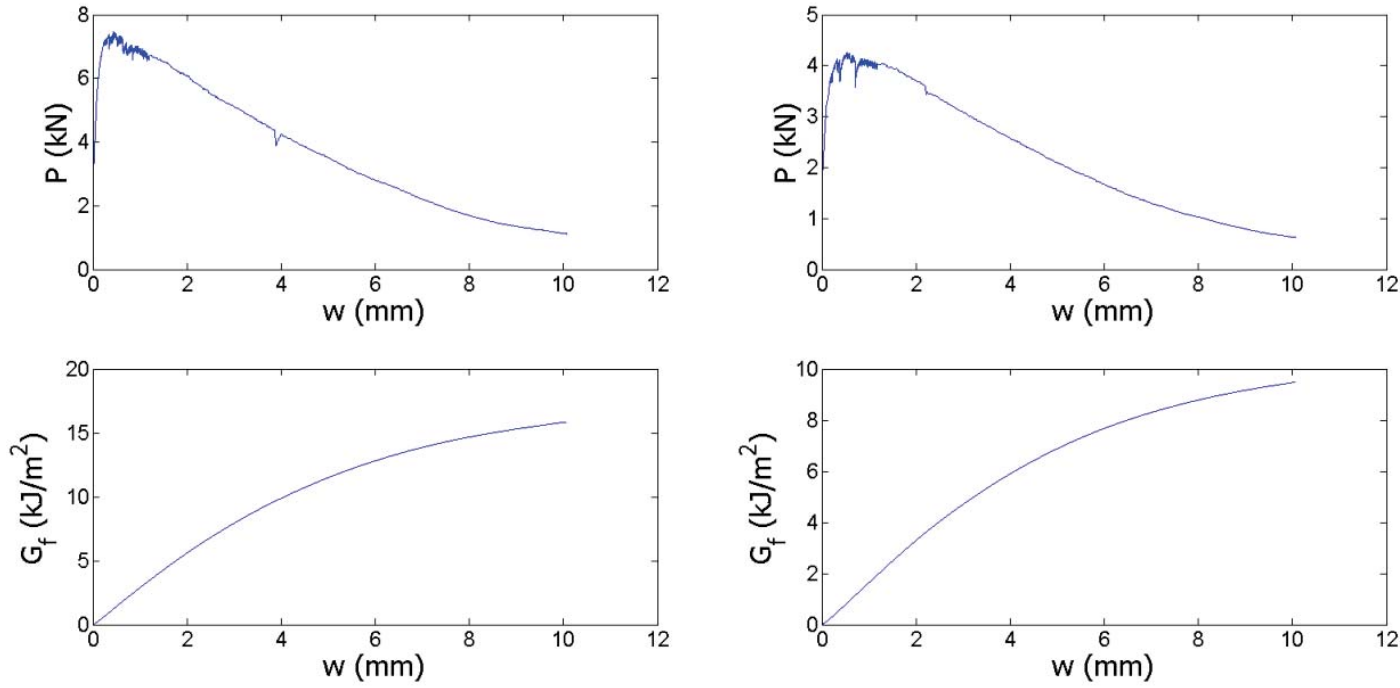

Figure C.22: NP-TT-7d-f1-2580-4.5 data (Left) and NP-TT-7d-f1-2580-9 data (Right) 

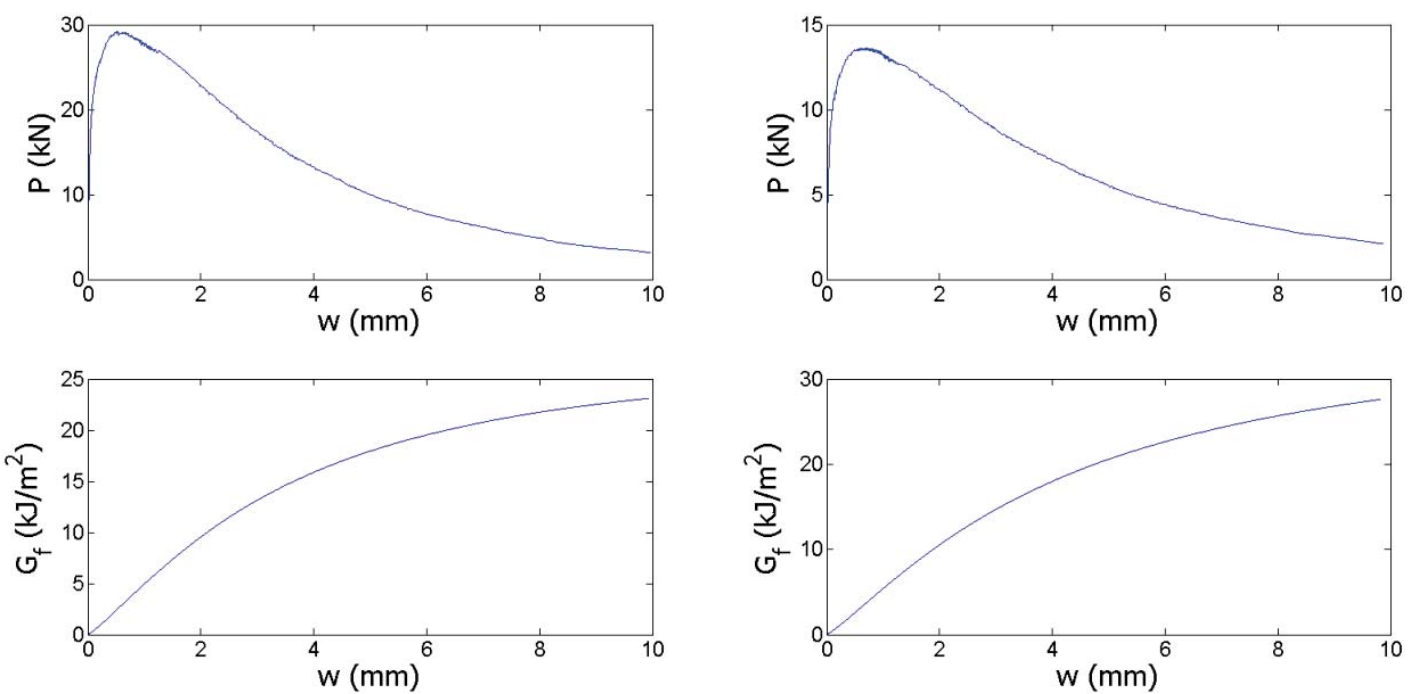

Figure C.23: NP-TT-7d-f1-5180-4.5 data (Left) and NP-TT-28d-f1-2580-4.5 data (Right)
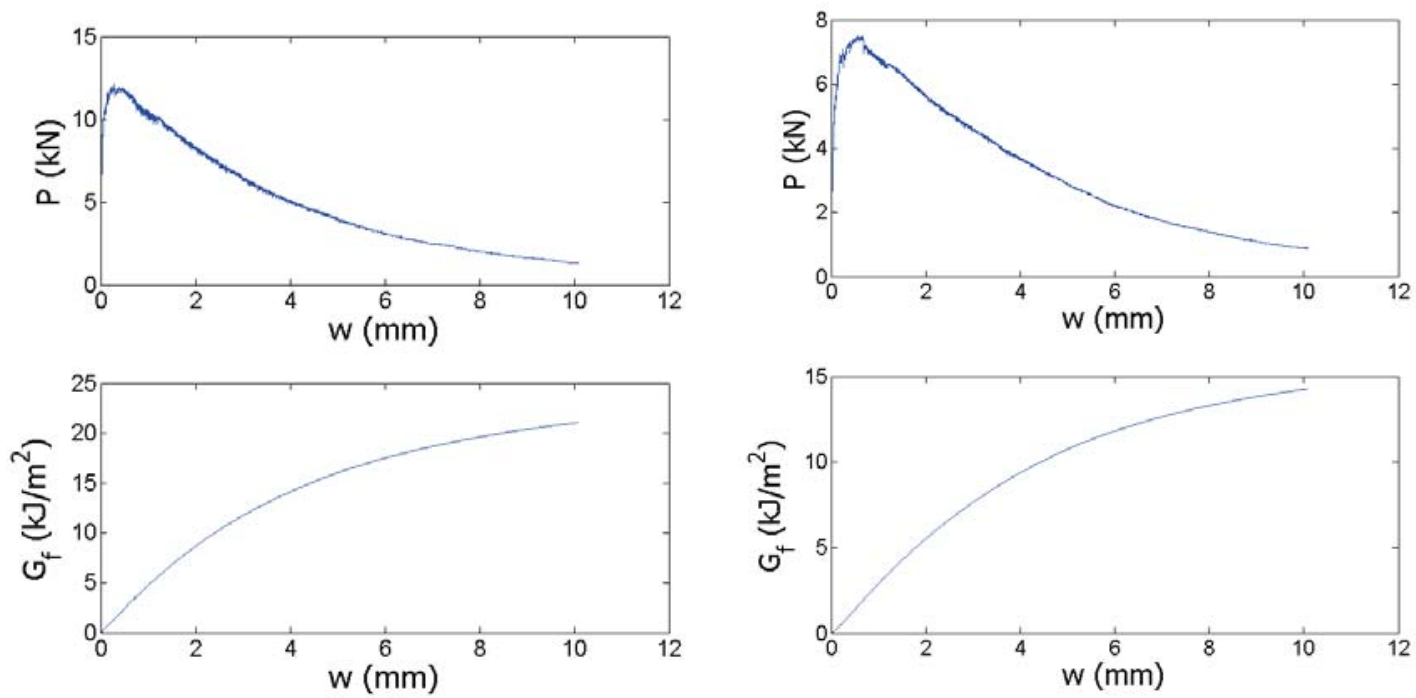

Figure C.24: NP-TT-7d-f2-2580-4.5 data (Left) and NP-TT-7d-f2-2580-6.75 data (Right) 

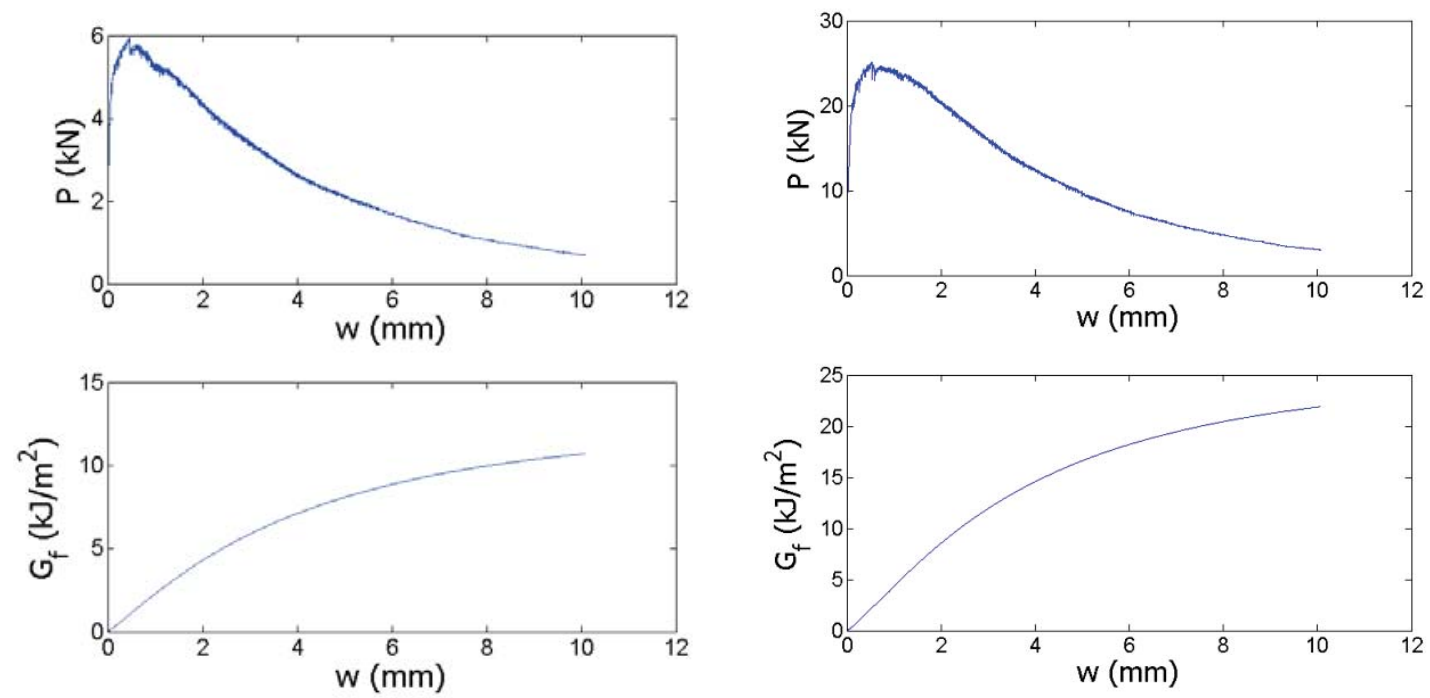

Figure C.25: NP-TT-7d-f2-2580-9 data (Left) and NP-TT-7d-f2-5180-4.5 data (Right)
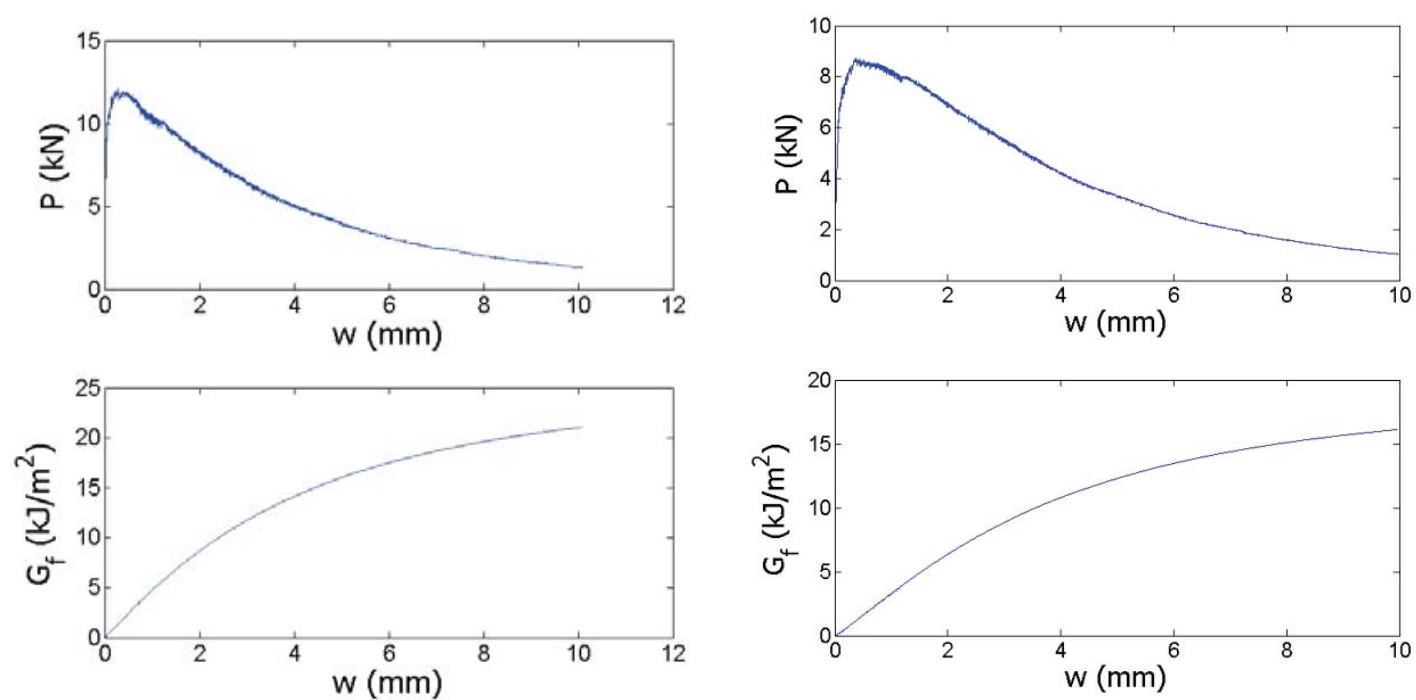

Figure C.26: NP-TT-28d-f2-2580-4.5 data (Left) and NP-TT-28d-f2-2580-6.75 data (Right) 

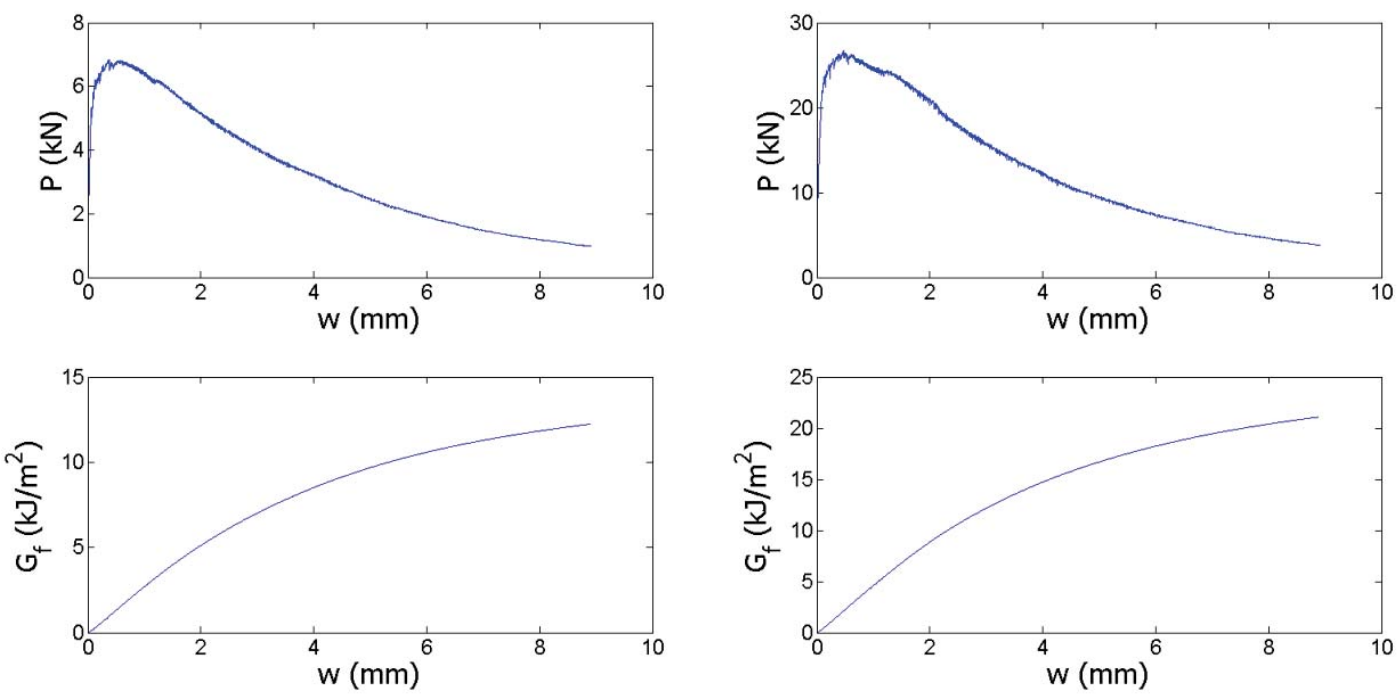

Figure C.27: NP-TT-28d-f2-2580-9 data (Left) and NP-TT-28d-f2-5180-4.5 data (Right)
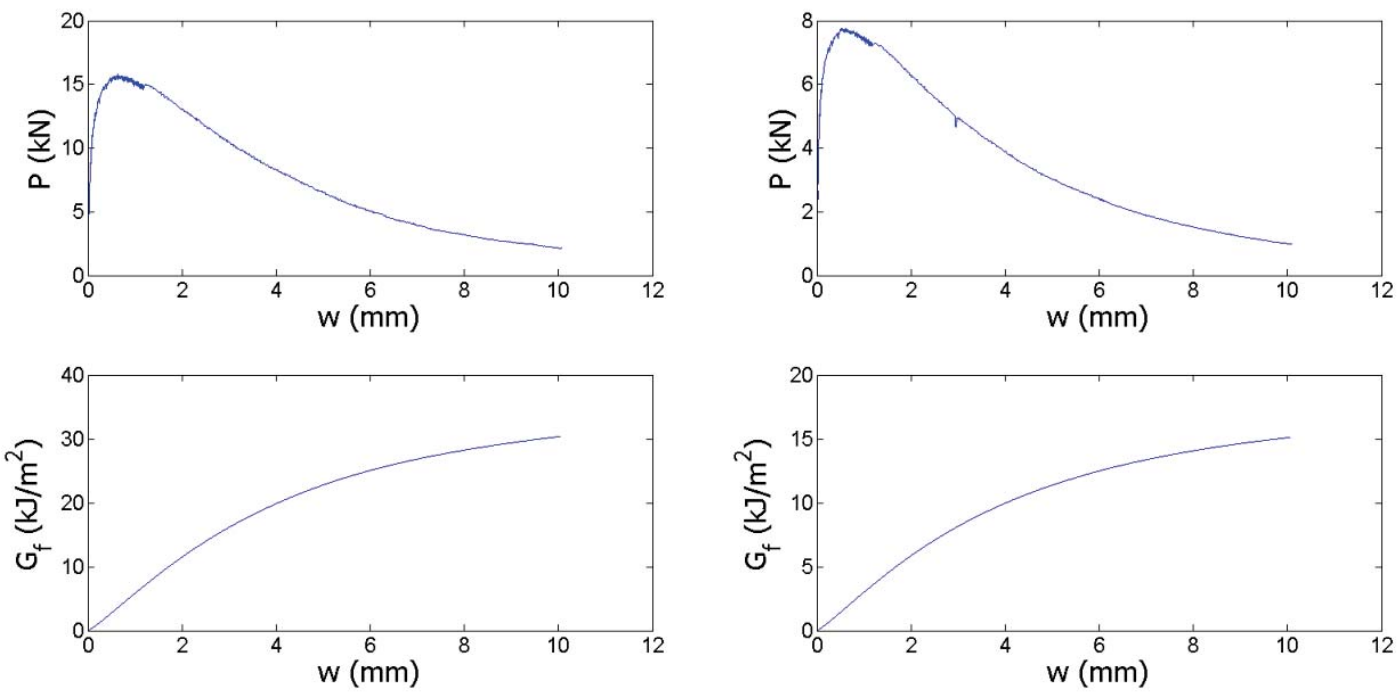

Figure C.28: NP-TT-7d-f3-2580-4.5 data (Left) and NP-TT-7d-f3-2580-9 data (Right) 

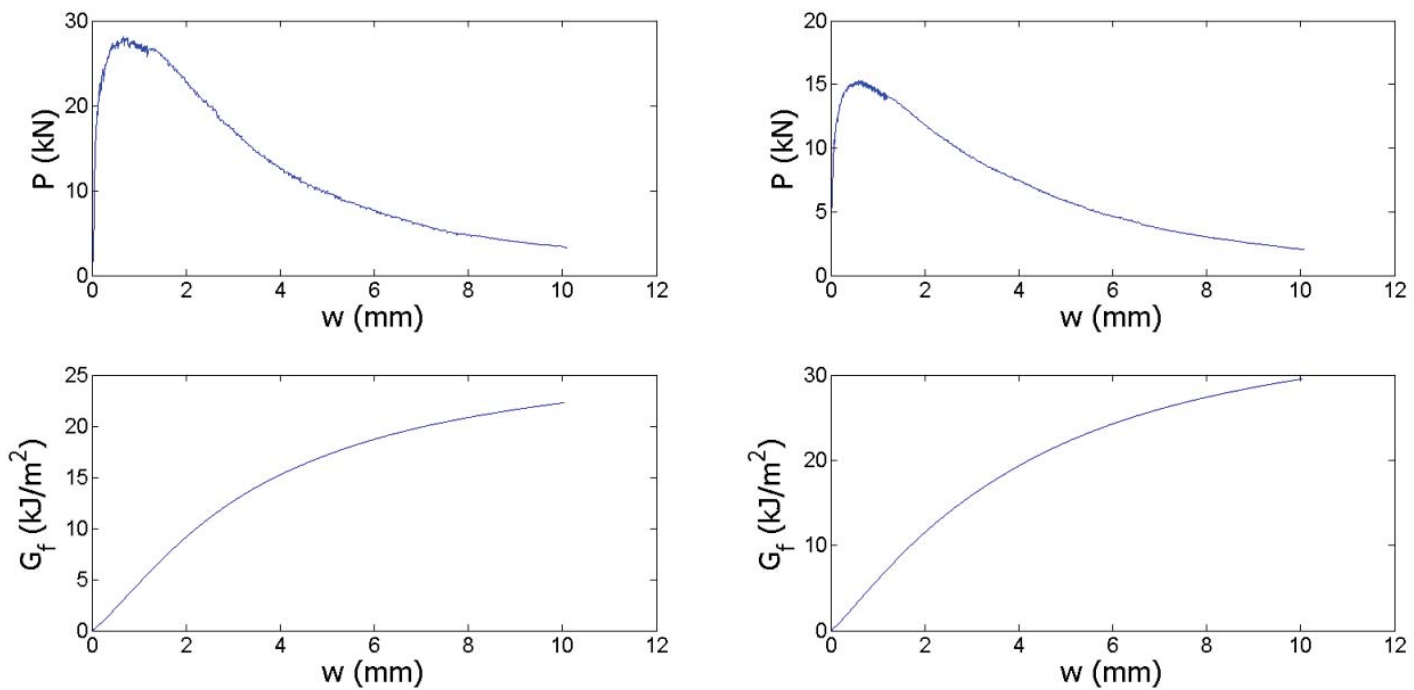

Figure C.30: NP-TT-7d-f3-5180-4.5 data (Left) and NP-TT-28d-f3-2580-4.5 data (Right)

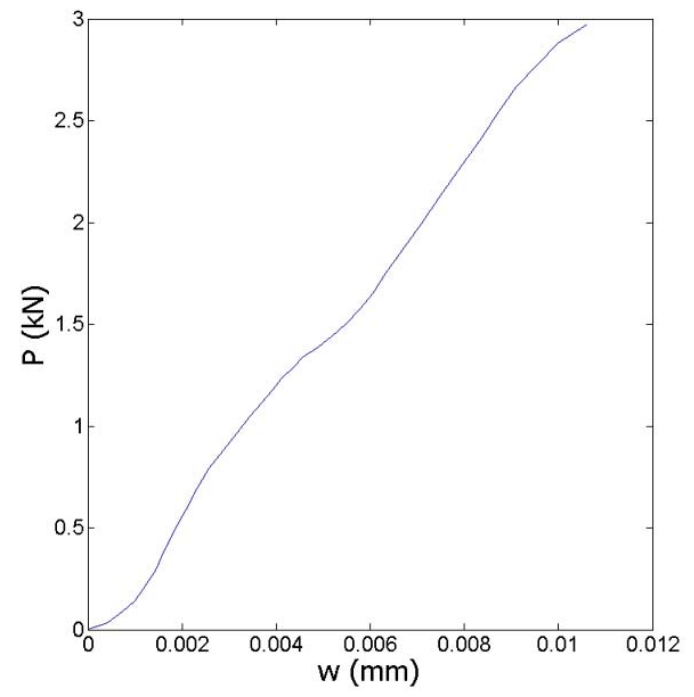

Figure C.29 NP-DTT-28d-f0-2580-4.5 data 

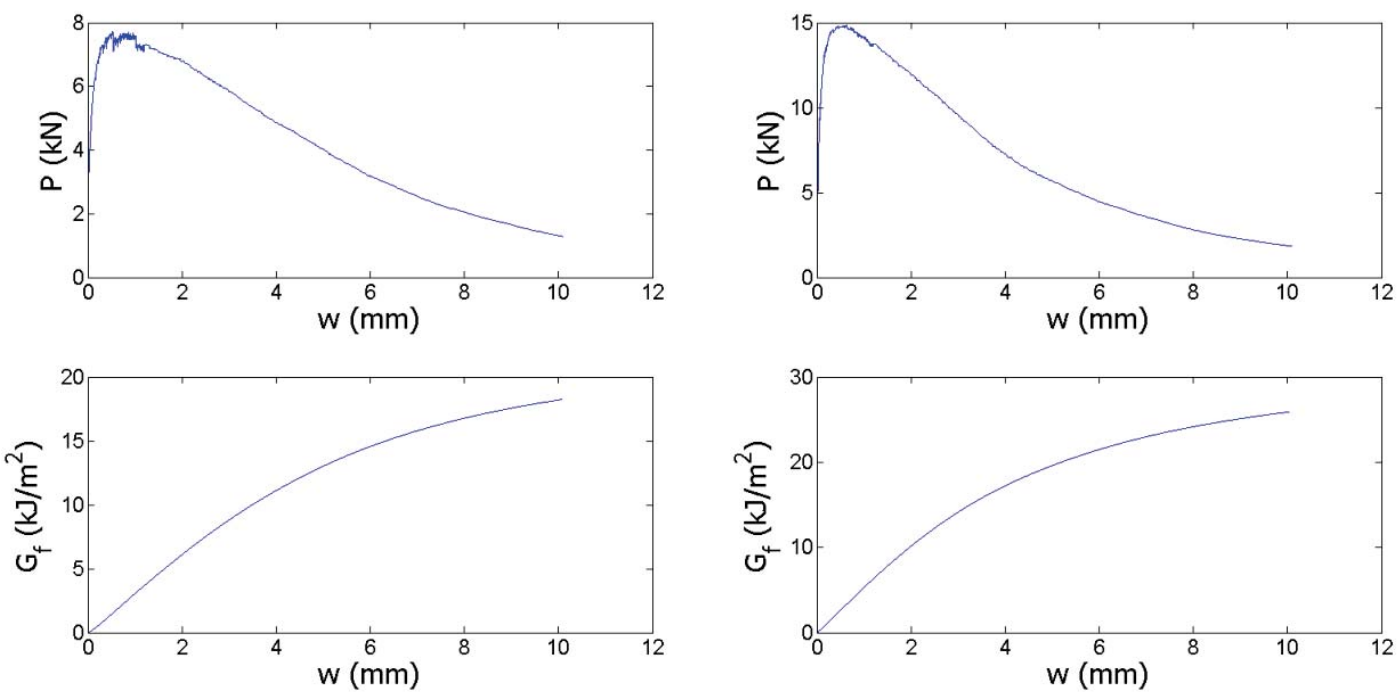

Figure C.31: NP-DTT-28d-f1-2580-4.5 data (Left) and NP-DTT-28d-f3-2580-4.5 data (Left)
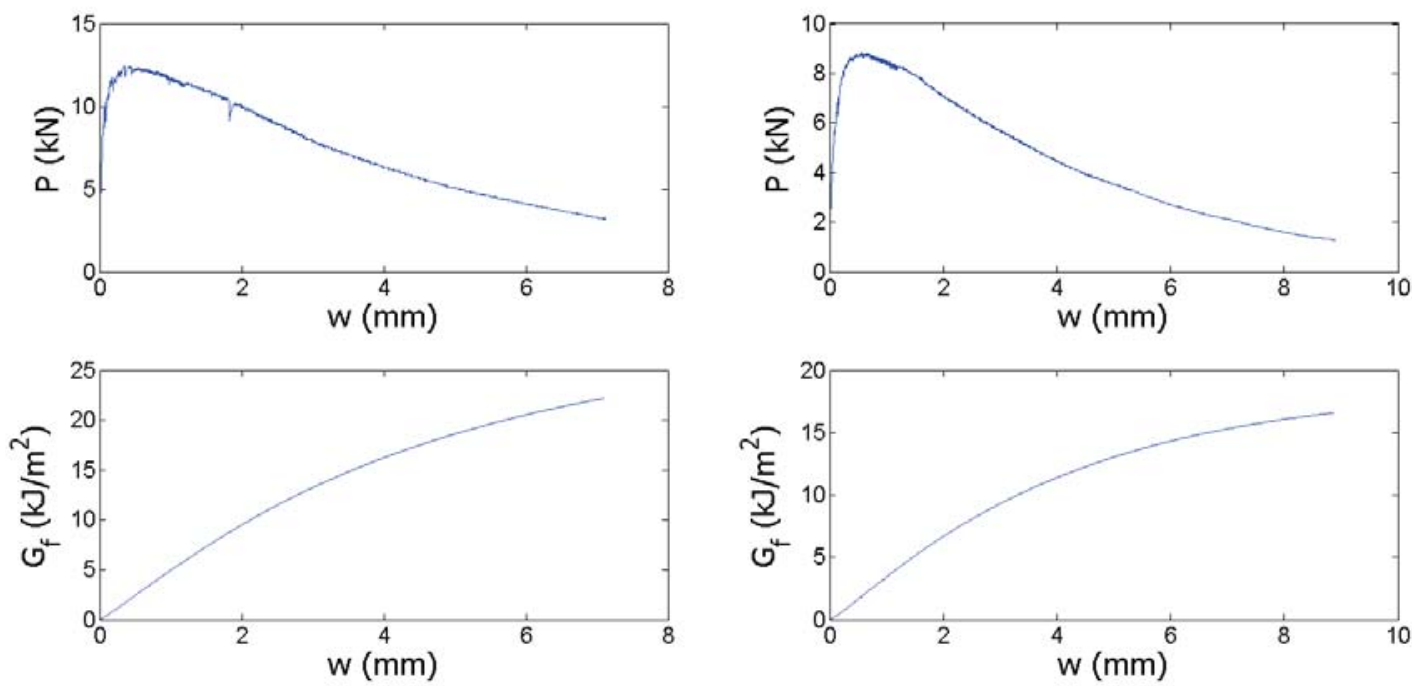

Figure C.32: NP-DTT-28d-f2-2580-4.5 data (Left) and NP-DTT-28d-f2-2580-6.75 data (Right) 

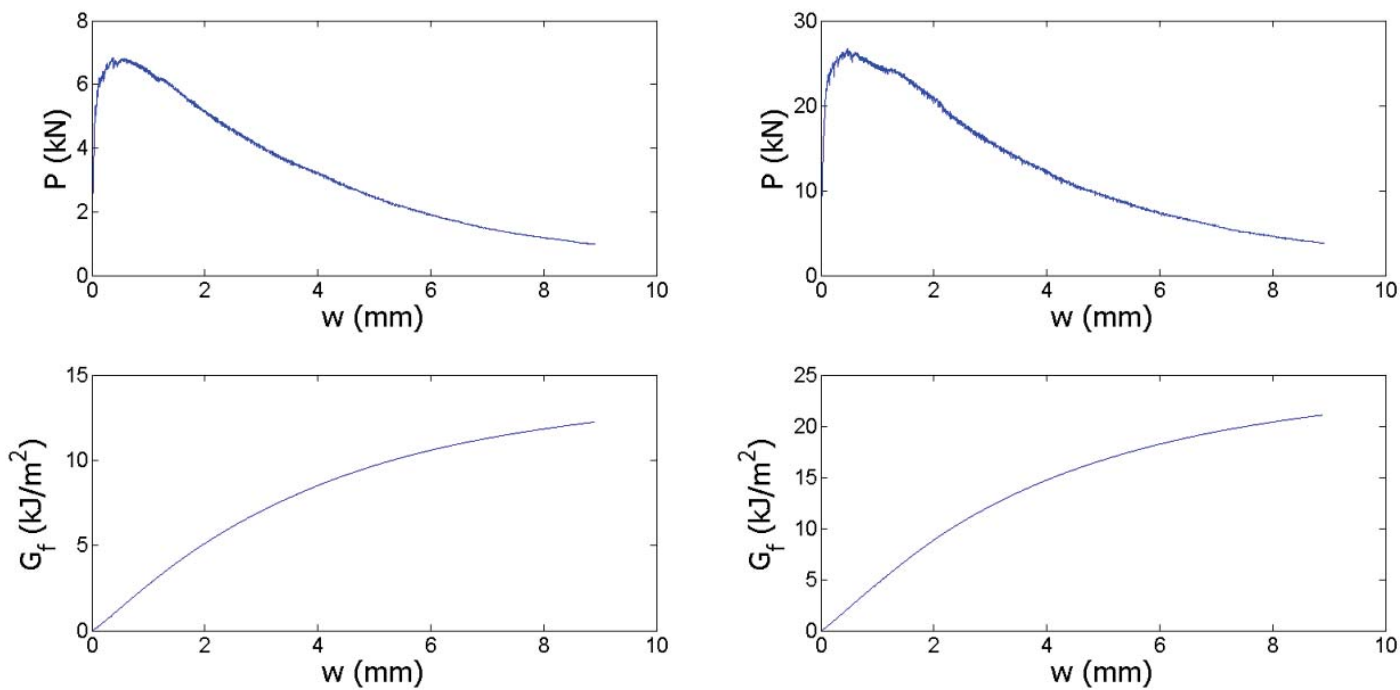

Figure C.33: NP-DTT-28d-f2-2580-9 data (Left) and NP-DTT-28d-f2-5180-4.5 data (Right) 


\section{Appendix D: Model Parameters}

Table D.1

Model parameters $\left(\mathrm{W}_{\mathrm{F}}, \beta\right)$ for $1 \%$ fiber content and ambient curing (with $95 \%$ confidence intervals)

\begin{tabular}{|l|c|c|c|c|c|c|}
\hline Specimen & $\mathbf{W}_{\mathbf{F}}$ & $\begin{array}{c}\text { Lower } \\
\text { Bound }\end{array}$ & $\begin{array}{c}\text { Upper } \\
\text { Bound }\end{array}$ & $\boldsymbol{\beta}$ & $\begin{array}{c}\text { Lower } \\
\text { Bound }\end{array}$ & $\begin{array}{c}\text { Upper } \\
\text { Bound }\end{array}$ \\
\hline NP-A-3d-f1-2580-4.5 & 70.8 & 70.74 & 70.87 & 11.23 & 11.22 & 11.24 \\
\hline NP-A-3d-f1-2580-9 & 71.45 & 71.3 & 71.6 & 9.81 & 9.79 & 9.83 \\
\hline NP-A-3d-f1-5180-4.5 & 67.69 & 67.55 & 67.83 & 11.00 & 10.98 & 11.02 \\
\hline NP-A-7d-f1-2580-4.5 & 89.27 & 88.97 & 89.57 & 11.84 & 11.80 & 11.88 \\
\hline NP-A-28d-f1-2580-4.5 & 103.7 & 103.4 & 104 & 12.75 & 12.72 & 12.79 \\
\hline NP-A-28d-f1-2580-9 & 113.5 & 113.2 & 113.9 & 12.09 & 12.06 & 12.13 \\
\hline NP-A-28d-f1-5180-4.5 & 88.95 & 88.77 & 89.13 & 11.17 & 11.15 & 11.20 \\
\hline NP-A-56d-f1-2580-4.5 & 97.11 & 96.82 & 97.4 & 10.86 & 10.83 & 10.90 \\
\hline
\end{tabular}

Table D.2

Model parameters $\left(W_{\mathrm{F}}, \beta\right)$ for $2 \%$ fiber content and ambient curing (with $95 \%$ confidence intervals)

\begin{tabular}{|l|c|c|c|c|c|c|}
\hline Specimen & $\mathbf{W}_{\mathbf{F}}$ & $\begin{array}{c}\text { Lower } \\
\text { Bound }\end{array}$ & $\begin{array}{c}\text { Upper } \\
\text { Bound }\end{array}$ & $\boldsymbol{\beta}$ & $\begin{array}{c}\text { Lower } \\
\text { Bound }\end{array}$ & $\begin{array}{c}\text { Upper } \\
\text { Bound }\end{array}$ \\
\hline NP-A-3d-f2-2580-4.5 & 120.2 & 119.9 & 120.5 & 6.94 & 6.92 & 6.96 \\
\hline NP-A-3d-f2-2580-6.75 & 100.4 & 100.1 & 100.7 & 6.85 & 6.83 & 6.87 \\
\hline NP-A-3d-f2-2580-9 & 108.6 & 108.2 & 109.1 & 8.84 & 8.82 & 8.89 \\
\hline NP-A-3d-f2-2580-13.75 & 131.4 & 131.4 & 131.8 & 8.48 & 8.48 & 8.50 \\
\hline NP-A-3d-f2-5180-4.5 & 108.8 & 108.4 & 109.2 & 7.95 & 7.92 & 7.98 \\
\hline NP-A-7d-f2-2580-4.5 & 147.2 & 146.8 & 147.6 & 7.66 & 7.64 & 7.68 \\
\hline NP-A-7d-f2-2580-6.75 & 136 & 135.7 & 136.3 & 6.80 & 6.78 & 6.81 \\
\hline NP-A-7d-f2-2580-9 & 136.3 & 136.0 & 136.7 & 8.21 & 8.19 & 8.23 \\
\hline NP-A-7d-f2-2580-13.75 & 119.9 & 119.5 & 120.2 & 8.87 & 8.84 & 8.89 \\
\hline NP-A-7d-f2-5180-4.5 & 117 & 116.7 & 117.3 & 8.36 & 8.34 & 8.39 \\
\hline NP-A-28d-f2-2580-4.5 & 170.9 & 170.6 & 171.2 & 4.83 & 4.82 & 4.84 \\
\hline NP-A-28d-f2-2580-6.75 & 156.3 & 155.6 & 157.0 & 4.35 & 4.33 & 4.37 \\
\hline NP-A-28d-f2-2580-9 & 147.7 & 147.3 & 148.1 & 4.27 & 4.26 & 4.29 \\
\hline NP-A-28d-f2-2580-13.75 & 145.8 & 145.3 & 146.4 & 4.24 & 4.22 & 4.25 \\
\hline NP-A-28d-f2-5180-4.5 & 127.5 & 127.1 & 127.8 & 4.30 & 4.29 & 4.31 \\
\hline NP-A-56d-f2-2580-4.5 & 136.2 & 135.7 & 136.7 & 3.38 & 3.36 & 3.39 \\
\hline NP-A-56d-f2-2580-6.75 & 176.3 & 175.9 & 176.7 & 4.76 & 4.75 & 4.77 \\
\hline NP-A-56d-f2-2580-9 & 145.1 & 144.4 & 145.7 & 3.80 & 3.78 & 3.81 \\
\hline NP-A-56d-f2-5180-4.5 & 145.1 & 144.5 & 144.6 & 4.01 & 3.99 & 3.99 \\
\hline
\end{tabular}


Table D.3

Model parameters $\left(W_{\mathrm{F}}, \beta\right)$ for $3 \%$ fiber content and ambient curing (with $95 \%$ confidence intervals)

\begin{tabular}{|l|c|c|c|c|c|c|}
\hline Specimen & $\mathbf{W}_{\mathbf{F}}$ & $\begin{array}{c}\text { Lower } \\
\text { Bound }\end{array}$ & $\begin{array}{c}\text { Upper } \\
\text { Bound }\end{array}$ & $\boldsymbol{\beta}$ & $\begin{array}{c}\text { Lower } \\
\text { Bound }\end{array}$ & $\begin{array}{c}\text { Upper } \\
\text { Bound }\end{array}$ \\
\hline NP-A-3d-f3-2580-4.5 & 152.3 & 151.9 & 152.8 & 3.60 & 3.59 & 3.61 \\
\hline NP-A-3d-f3-2580-9 & 139.8 & 139.3 & 140.3 & 2.92 & 2.91 & 2.93 \\
\hline NP-A-3d-f3-5180-4.5 & 98.72 & 98.27 & 99.17 & 2.56 & 2.55 & 2.57 \\
\hline NP-A-7d-f1-2580-4.5 & 294 & 195.4 & 196.5 & 5.24 & 3.48 & 3.50 \\
\hline NP-A-28d-f3-2580-4.5 & 239.2 & 238.3 & 240.1 & 3.27 & 3.25 & 3.28 \\
\hline NP-A-28d-f3-2580-9 & 211.3 & 210.6 & 212 & 2.98 & 2.97 & 2.99 \\
\hline NP-A-28d-f3-5180-4.5 & 172.8 & 172.3 & 173.3 & 3.12 & 3.11 & 3.13 \\
\hline NP-A-56d-f3-2580-4.5 & 221.1 & 220.1 & 222.1 & 3.09 & 3.08 & 3.10 \\
\hline
\end{tabular}

Table D.4

Model parameters $\left(\mathrm{W}_{\mathrm{F}}, \boldsymbol{\beta}\right)$ for thermal treatment (with $95 \%$ confidence intervals)

\begin{tabular}{|l|c|c|c|c|c|c|}
\hline Specimen & $\mathbf{W}_{\mathbf{F}}$ & $\begin{array}{c}\text { Lower } \\
\text { Bound }\end{array}$ & $\begin{array}{c}\text { Upper } \\
\text { Bound }\end{array}$ & $\boldsymbol{\beta}$ & $\begin{array}{c}\text { Lower } \\
\text { Bound }\end{array}$ & $\begin{array}{c}\text { Upper } \\
\text { Bound }\end{array}$ \\
\hline NP-TT-7d-f1-2580-4.5 & 129.6 & 129.3 & 130 & 11.27 & 11.24 & 11.30 \\
\hline NP-TT-7d-f1-2580-9 & 156.8 & 156.4 & 157.1 & 12.97 & 12.94 & 13.00 \\
\hline NP-TT-7d-f1-5180-4.5 & 104.9 & 104.6 & 105.1 & 9.72 & 9.69 & 9.73 \\
\hline NP-TT-28d-f1-2580-4.5 & 118.8 & 118.4 & 119.2 & 10.17 & 10.14 & 10.20 \\
\hline NP-TT-7d-f2-2580-4.5 & 177.9 & 177.7 & 178.2 & 5.78 & 5.78 & 5.79 \\
\hline NP-TT-7d-f2-2580-6.75 & 168.4 & 168.2 & 168.6 & 6.26 & 6.25 & 6.26 \\
\hline NP-TT-7d-f2-2580-9 & 166 & 165.8 & 166.2 & 5.28 & 5.28 & 5.29 \\
\hline NP-TT-7d-f2-5180-4.5 & 167 & 166.8 & 167.2 & 6.43 & 6.42 & 6.44 \\
\hline NP-TT-28d-f2-2580-4.5 & 162.8 & 162.6 & 163.1 & 4.70 & 4.69 & 4.71 \\
\hline NP-TT-28d-f2-2580-6.75 & 186.8 & 186.6 & 187 & 5.58 & 5.57 & 5.59 \\
\hline NP-TT-28d-f2-2580-9 & 193.5 & 193.3 & 193.7 & 6.26 & 6.25 & 6.26 \\
\hline NP-TT-28d-f2-5180-4.5 & 164.3 & 164.1 & 164.5 & 5.62 & 5.61 & 5.62 \\
\hline NP-TT-7d-f3-2580-4.5 & 236.6 & 236 & 237.2 & 3.83 & 3.82 & 3.84 \\
\hline NP-TT-7d-f3-2580-9 & 234.7 & 234.1 & 235.3 & 4.03 & 4.02 & 4.04 \\
\hline NP-TT-7d-f3-5180-4.5 & 500.4 & 166.2 & 167.3 & 10.20 & 3.39 & 3.41 \\
\hline NP-TT-28d-f3-2580-4.5 & 230.8 & 230 & 231.5 & 3.42 & 3.41 & 3.43 \\
\hline
\end{tabular}


Table D.5

Model parameters $\left(W_{F}, \beta\right)$ for delayed thermal treatment (with $95 \%$ confidence intervals)

\begin{tabular}{|l|c|c|c|c|c|c|}
\hline Specimen & $\mathbf{W}_{\mathbf{F}}$ & $\begin{array}{c}\text { Lower } \\
\text { Bound }\end{array}$ & $\begin{array}{c}\text { Upper } \\
\text { Bound }\end{array}$ & $\boldsymbol{\beta}$ & $\begin{array}{c}\text { Lower } \\
\text { Bound }\end{array}$ & $\begin{array}{c}\text { Upper } \\
\text { Bound }\end{array}$ \\
\hline NP-DTT-28d-f1-2580-4.5 & 151.60 & 151.30 & 151.90 & 15.06 & 15.03 & 15.09 \\
\hline NP-DTT-28d-f2-2580-4.5 & 196.60 & 196.30 & 196.80 & 5.78 & 5.77 & 5.78 \\
\hline NP-DTT-28d-f2-2580-6.75 & 202.20 & 202.00 & 202.50 & 6.18 & 6.18 & 6.19 \\
\hline NP-DTT-28d-f2-2580-9 & 187.70 & 187.50 & 187.90 & 5.44 & 5.43 & 5.44 \\
\hline NP-DTT-28d-f2-5180-4.5 & 186.60 & 164.10 & 164.50 & 6.72 & 5.91 & 5.93 \\
\hline NP-DTT-28d-f3-2580-4.5 & 199.70 & 199.00 & 200.50 & 2.77 & 2.76 & 2.79 \\
\hline
\end{tabular}

Table D.6

Model parameters $\left(\mathrm{m}, \mathrm{w}_{\mathrm{i}}\right)$ for $1 \%$ fiber content and ambient curing (with $95 \%$ confidence intervals)

\begin{tabular}{|l|r|r|r|r|r|r|}
\hline Specimen & $\mathbf{m}$ & $\begin{array}{r}\text { Lower } \\
\text { Bound }\end{array}$ & $\begin{array}{r}\text { Upper } \\
\text { Bound }\end{array}$ & $\mathbf{w}_{\mathbf{i}}$ & $\begin{array}{r}\text { Lower } \\
\text { Bound }\end{array}$ & $\begin{array}{r}\text { Upper } \\
\text { Bound }\end{array}$ \\
\hline NP-A-3d-f1-2580-4.5 & 1.10 & 1.10 & 1.10 & 4.47 & 4.46 & 4.48 \\
\hline NP-A-3d-f1-2580-9 & 1.10 & 1.10 & 1.10 & 3.98 & 3.97 & 3.99 \\
\hline NP-A-3d-f1-5180-4.5 & 1.12 & 1.12 & 1.12 & 4.05 & 4.04 & 4.06 \\
\hline NP-A-7d-f1-2580-4.5 & 1.08 & 1.08 & 1.09 & 3.88 & 3.86 & 3.90 \\
\hline NP-A-28d-f1-2580-4.5 & 1.11 & 1.11 & 1.11 & 4.30 & 4.29 & 4.32 \\
\hline NP-A-28d-f1-2580-9 & 1.11 & 1.11 & 1.11 & 4.24 & 4.22 & 4.26 \\
\hline NP-A-28d-f1-5180-4.5 & 1.13 & 1.12 & 1.13 & 3.92 & 3.91 & 3.93 \\
\hline NP-A-56d-f1-2580-4.5 & 1.11 & 1.11 & 1.12 & 3.95 & 3.93 & 3.96 \\
\hline
\end{tabular}


Table D.7

Model parameters $\left(\mathrm{m}, \mathrm{w}_{\mathrm{i}}\right.$ ) for $\mathbf{2 \%}$ fiber content and ambient curing (with $95 \%$ confidence intervals)

\begin{tabular}{|l|r|r|r|r|r|r|}
\hline \multicolumn{1}{|c|}{ Specimen } & $\mathrm{m}$ & $\begin{array}{r}\text { Lower } \\
\text { Bound }\end{array}$ & $\begin{array}{r}\text { Upper } \\
\text { Bound }\end{array}$ & $\mathrm{w}_{\mathrm{i}}$ & $\begin{array}{r}\text { Lower } \\
\text { Bound }\end{array}$ & $\begin{array}{r}\text { Upper } \\
\text { Bound }\end{array}$ \\
\hline NP-A-3d-f2-2580-4.5 & 1.15 & 1.15 & 1.15 & 3.80 & 3.79 & 3.82 \\
\hline NP-A-3d-f2-2580-6.75 & 1.12 & 1.12 & 1.12 & 4.08 & 4.06 & 4.09 \\
\hline NP-A-3d-f2-2580-9 & 1.15 & 1.15 & 1.15 & 3.52 & 3.50 & 3.54 \\
\hline NP-A-3d-f2-2580-13.75 & 1.16 & 1.16 & 1.17 & 4.08 & 4.07 & 4.10 \\
\hline NP-A-3d-f2-5180-4.5 & 1.15 & 1.15 & 1.15 & 3.76 & 3.75 & 3.78 \\
\hline NP-A-7d-f2-2580-4.5 & 1.14 & 1.13 & 1.14 & 3.86 & 3.85 & 3.88 \\
\hline NP-A-7d-f2-2580-6.75 & 1.13 & 1.13 & 1.13 & 3.97 & 3.96 & 3.98 \\
\hline NP-A-7d-f2-2580-9 & 1.16 & 1.16 & 1.16 & 3.89 & 3.88 & 3.91 \\
\hline NP-A-7d-f2-2580-13.75 & 1.12 & 1.12 & 1.12 & 3.72 & 3.70 & 3.73 \\
\hline NP-A-7d-f2-5180-4.5 & 1.18 & 1.18 & 1.18 & 3.52 & 3.51 & 3.53 \\
\hline NP-A-28d-f2-2580-4.5 & 1.12 & 1.12 & 1.12 & 4.18 & 4.17 & 4.19 \\
\hline NP-A-28d-f2-2580-6.75 & 1.11 & 1.10 & 1.11 & 3.97 & 3.95 & 3.99 \\
\hline NP-A-28d-f2-2580-9 & 1.14 & 1.14 & 1.14 & 3.85 & 3.84 & 3.87 \\
\hline NP-A-28d-f2-2580-13.75 & 1.09 & 1.09 & 1.10 & 3.85 & 3.83 & 3.87 \\
\hline NP-A-28d-f2-5180-4.5 & 1.12 & 1.12 & 1.12 & 3.54 & 3.53 & 3.56 \\
\hline NP-A-56d-f2-2580-4.5 & 1.09 & 1.09 & 1.09 & 3.77 & 3.76 & 3.79 \\
\hline NP-A-56d-f2-2580-6.75 & 1.17 & 1.16 & 1.17 & 3.71 & 3.70 & 3.72 \\
\hline NP-A-56d-f2-2580-9 & 1.10 & 1.10 & 1.10 & 3.96 & 3.94 & 3.99 \\
\hline NP-A-56d-f2-5180-4.5 & 1.11 & 1.11 & 1.11 & 3.88 & 3.86 & 3.90 \\
\hline
\end{tabular}

Table D.8

Model parameters $\left(\mathrm{m}, \mathrm{w}_{\mathrm{i}}\right)$ for $3 \%$ fiber content and ambient curing (with $95 \%$ confidence intervals)

\begin{tabular}{|l|c|c|c|c|c|c|}
\hline Specimen & $\mathbf{m}$ & $\begin{array}{c}\text { Lower } \\
\text { Bound }\end{array}$ & $\begin{array}{c}\text { Upper } \\
\text { Bound }\end{array}$ & $\mathbf{w}_{\mathbf{i}}$ & $\begin{array}{c}\text { Lower } \\
\text { Bound }\end{array}$ & $\begin{array}{c}\text { Upper } \\
\text { Bound }\end{array}$ \\
\hline NP-A-3d-f3-2580-4.5 & 1.12 & 1.119 & 1.121 & 4.469 & 4.453 & 4.486 \\
\hline NP-A-3d-f3-2580-9 & 1.128 & 1.126 & 1.129 & 3.793 & 3.775 & 3.811 \\
\hline NP-A-3d-f3-5180-4.5 & 1.119 & 1.117 & 1.121 & 3.529 & 3.508 & 3.55 \\
\hline NP-A-7d-f1-2580-4.5 & 1.127 & 1.125 & 1.128 & 4.292 & 4.275 & 4.309 \\
\hline NP-A-28d-f3-2580-4.5 & 1.127 & 1.126 & 1.129 & 4.18 & 4.16 & 4.12 \\
\hline NP-A-28d-f3-2580-9 & 1.119 & 1.118 & 1.121 & 3.877 & 3.86 & 3.894 \\
\hline NP-A-28d-f3-5180-4.5 & 1.146 & 1.145 & 1.148 & 3.618 & 3.604 & 3.631 \\
\hline NP-A-56d-f3-2580-4.5 & 1.131 & 1.129 & 1.133 & 4.166 & 4.141 & 4.191 \\
\hline
\end{tabular}


Table D.9

Model parameters $\left(\mathrm{m}, \mathrm{w}_{\mathrm{i}}\right)$ for thermal treatment (with $95 \%$ confidence intervals)

\begin{tabular}{|l|c|c|c|c|c|c|}
\hline Specimen & $\mathbf{m}$ & $\begin{array}{c}\text { Lower } \\
\text { Bound }\end{array}$ & $\begin{array}{c}\text { Upper } \\
\text { Bound }\end{array}$ & $\mathbf{w}_{\mathbf{i}}$ & $\begin{array}{c}\text { Lower } \\
\text { Bound }\end{array}$ & $\begin{array}{c}\text { Upper } \\
\text { Bound }\end{array}$ \\
\hline NP-TT-7d-f1-2580-4.5 & 1.12 & 1.12 & 1.13 & 4.64 & 4.62 & 4.66 \\
\hline NP-TT-7d-f1-2580-9 & 1.15 & 1.15 & 1.15 & 4.65 & 4.64 & 4.67 \\
\hline NP-TT-7d-f1-5180-4.5 & 1.15 & 1.14 & 1.15 & 4.38 & 4.37 & 4.40 \\
\hline NP-TT-28d-f1-2580-4.5 & 1.11 & 1.11 & 1.11 & 4.06 & 4.04 & 4.07 \\
\hline NP-TT-7d-f2-2580-4.5 & 1.15 & 1.14 & 1.15 & 3.74 & 3.73 & 3.74 \\
\hline NP-TT-7d-f2-2580-6.75 & 1.14 & 1.14 & 1.14 & 3.94 & 3.93 & 3.95 \\
\hline NP-TT-7d-f2-2580-9 & 1.11 & 1.11 & 1.11 & 3.91 & 3.90 & 3.92 \\
\hline NP-TT-7d-f2-5180-4.5 & 1.16 & 1.16 & 1.16 & 3.88 & 3.87 & 3.88 \\
\hline NP-TT-28d-f2-2580-4.5 & 1.08 & 1.08 & 1.08 & 3.84 & 3.84 & 3.85 \\
\hline NP-TT-28d-f2-2580-6.75 & 1.14 & 1.14 & 1.14 & 3.89 & 3.89 & 3.90 \\
\hline NP-TT-28d-f2-2580-9 & 1.13 & 1.13 & 1.13 & 3.72 & 3.71 & 3.73 \\
\hline NP-TT-28d-f2-5180-4.5 & 1.14 & 1.14 & 1.14 & 3.69 & 3.69 & 3.70 \\
\hline NP-TT-7d-f3-2580-4.5 & 1.16 & 1.16 & 1.16 & 4.05 & 4.04 & 4.06 \\
\hline NP-TT-7d-f3-2580-9 & 1.15 & 1.14 & 1.15 & 3.97 & 3.96 & 3.98 \\
\hline NP-TT-7d-f3-5180-4.5 & 1.17 & 1.17 & 1.17 & 3.61 & 3.59 & 3.62 \\
\hline NP-TT-28d-f3-2580-4.5 & 1.13 & 1.13 & 1.14 & 3.98 & 3.96 & 3.99 \\
\hline
\end{tabular}

Table D.10

Model parameters (m, wi) for thermal treatment (with $95 \%$ confidence intervals)

\begin{tabular}{|l|c|c|c|c|c|c|}
\hline Specimen & $\mathbf{m}$ & $\begin{array}{l}\text { Lower } \\
\text { Bound }\end{array}$ & $\begin{array}{c}\text { Upper } \\
\text { Bound }\end{array}$ & $\mathbf{w}_{\mathbf{i}}$ & $\begin{array}{l}\text { Lower } \\
\text { Bound }\end{array}$ & $\begin{array}{c}\text { Upper } \\
\text { Bound }\end{array}$ \\
\hline NP-DTT-28d-f1-2580-4.5 & 1.17 & 1.16 & 1.17 & 4.76 & 4.75 & 4.77 \\
\hline NP-DTT-28d-f2-2580-4.5 & 1.13 & 1.13 & 1.13 & 4.07 & 4.07 & 4.08 \\
\hline NP-DTT-28d-f2-2580-6.75 & 1.18 & 1.18 & 1.18 & 3.77 & 3.77 & 3.78 \\
\hline NP-DTT-28d-f2-2580-9 & 1.14 & 1.14 & 1.14 & 3.74 & 3.74 & 3.75 \\
\hline NP-DTT-28d-f2-5180-4.5 & 1.17 & 1.14 & 1.14 & 3.92 & 3.69 & 3.70 \\
\hline NP-DTT-28d-f3-2580-4.5 & 1.12 & 1.12 & 1.12 & 4.00 & 3.98 & 4.02 \\
\hline
\end{tabular}




\section{Appendix E: Model Fit}
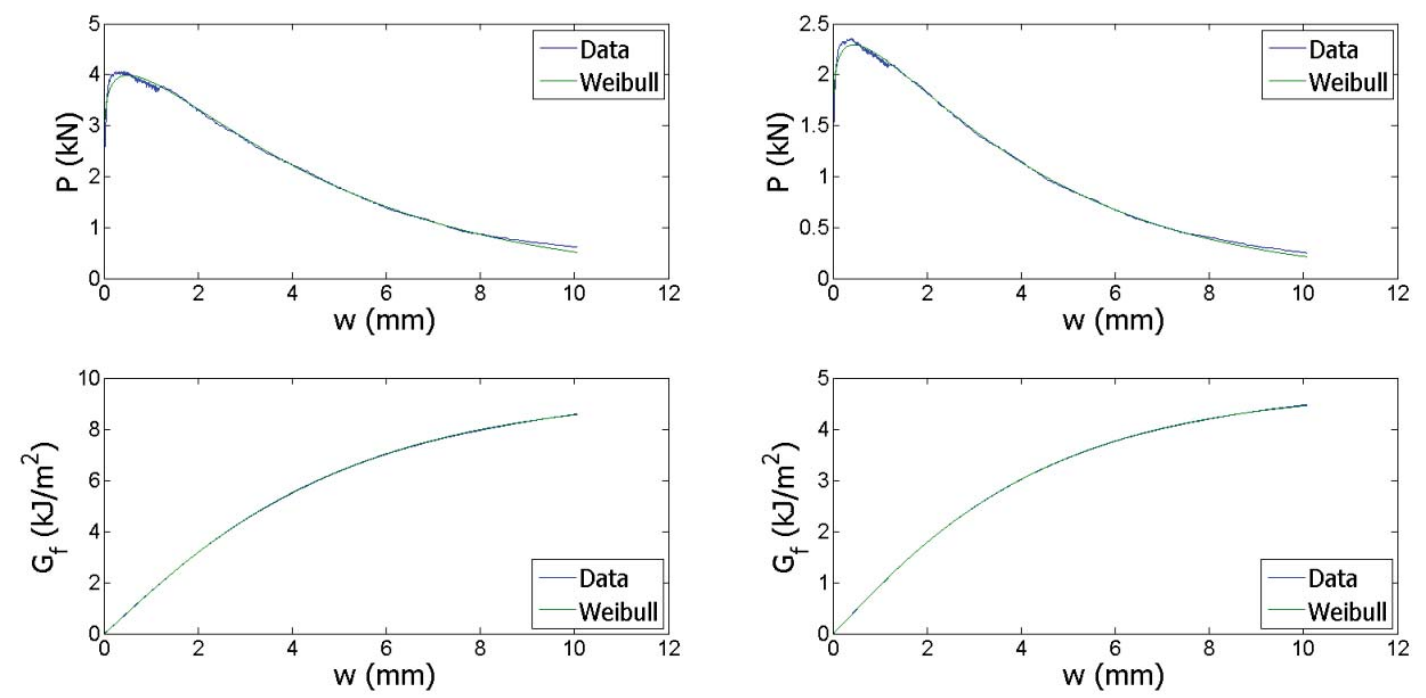

Figure E.1: NP-A-3d-f1-2580-4.5 best fit (Left) and NP-A-3d-f1-2580-9 best fit (Right)
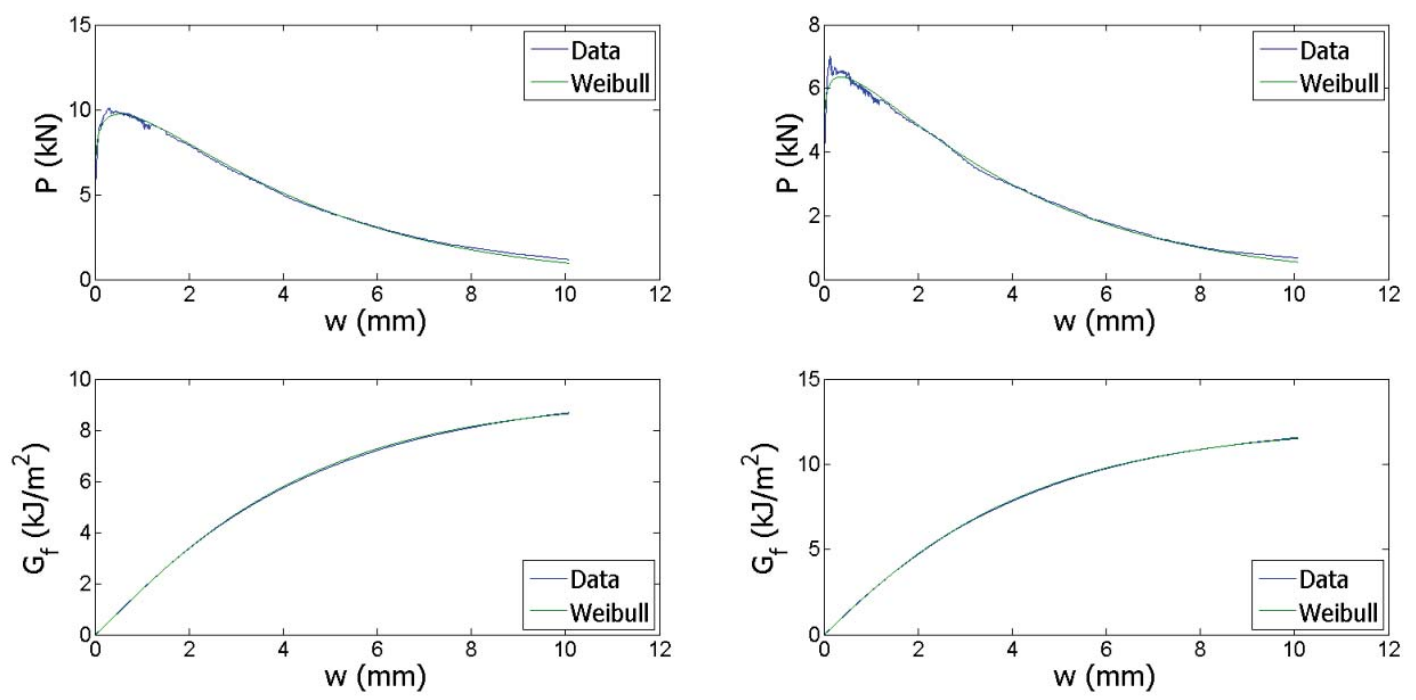

Figure E.2: NP-A-3d-f1-5180-4.5 best fit (Left) and NP-A-7d-f1-2580-4.5 best fit (Right) 

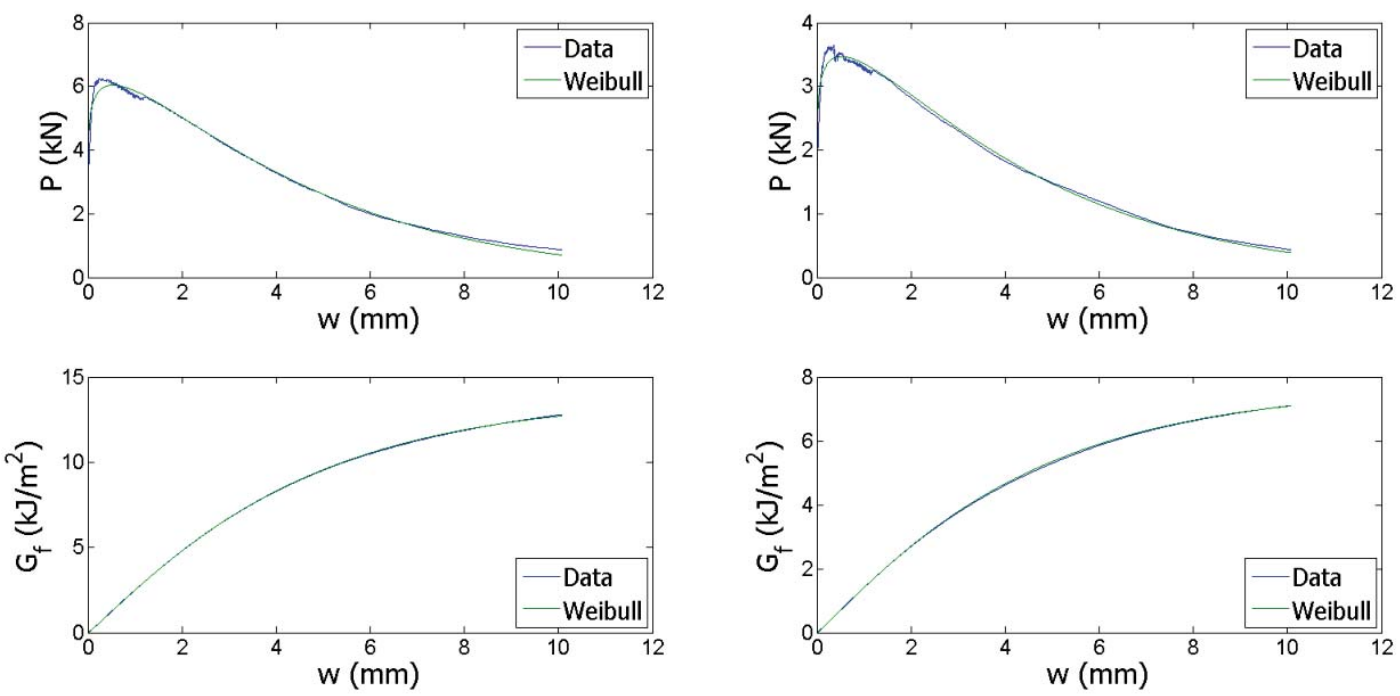

Figure E.3: NP-A-28d-f1-2580-4.5 best fit (Left) and NP-A-28d-f1-2580-9 best fit (Right)
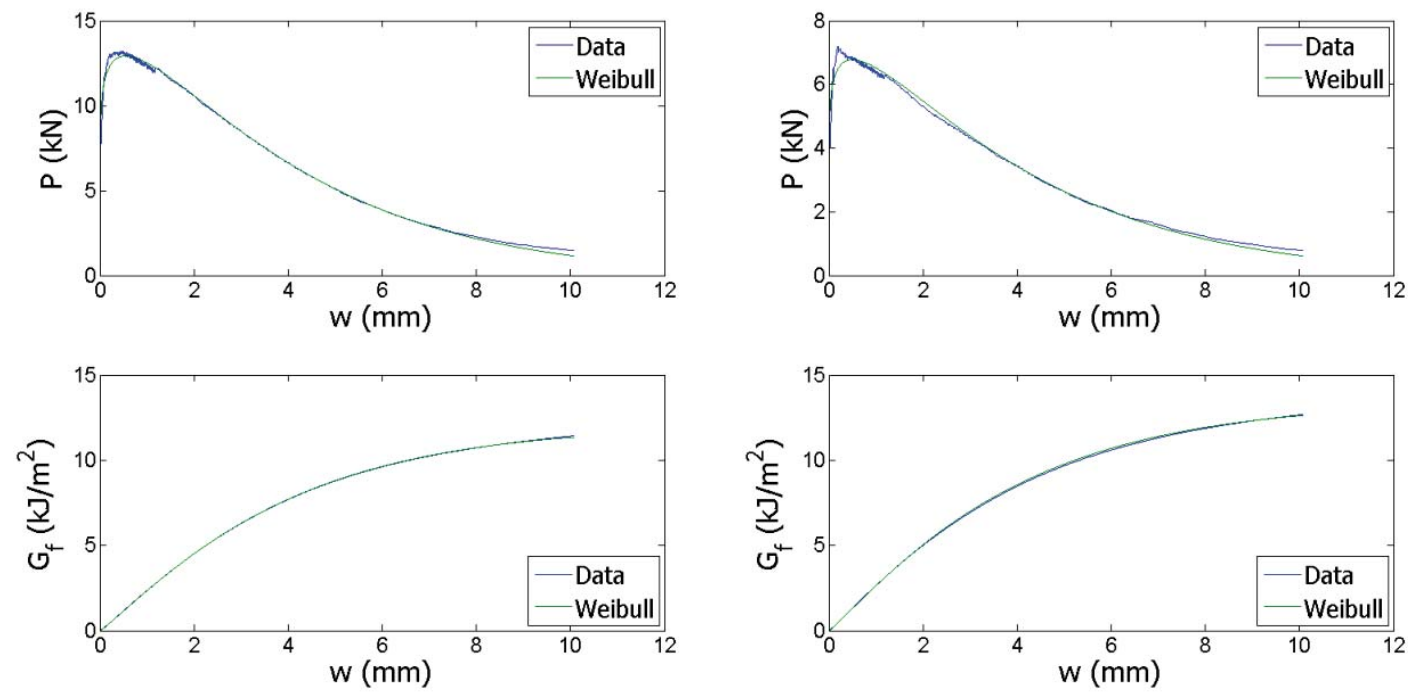

Figure E.4: NP-A-28d-f1-5180-4.5 best fit (Left) and NP-A-56d-f1-2580-4.5 best fit (Right) 

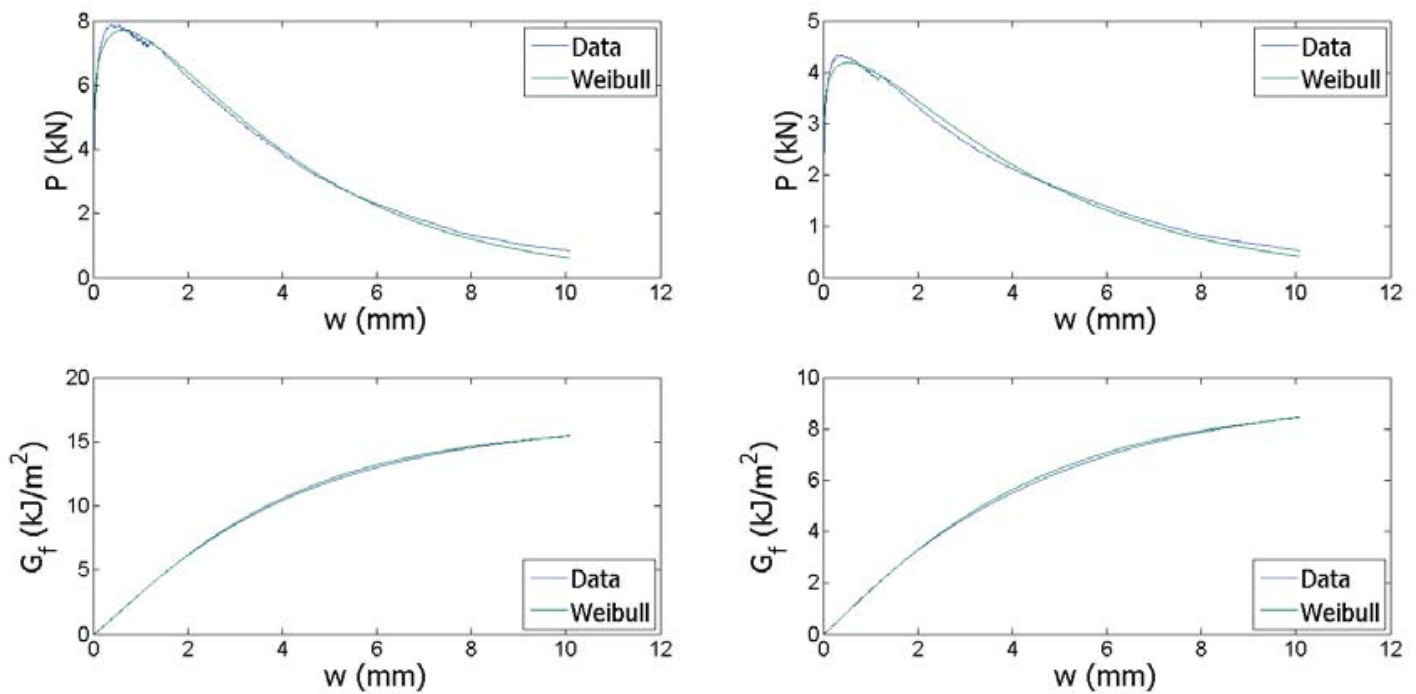

Figure E.5: NP-A-3d-f2-2580-4.5 best fit (Left) and NP-A-3d-f2-2580-6.75 best fit (Right)
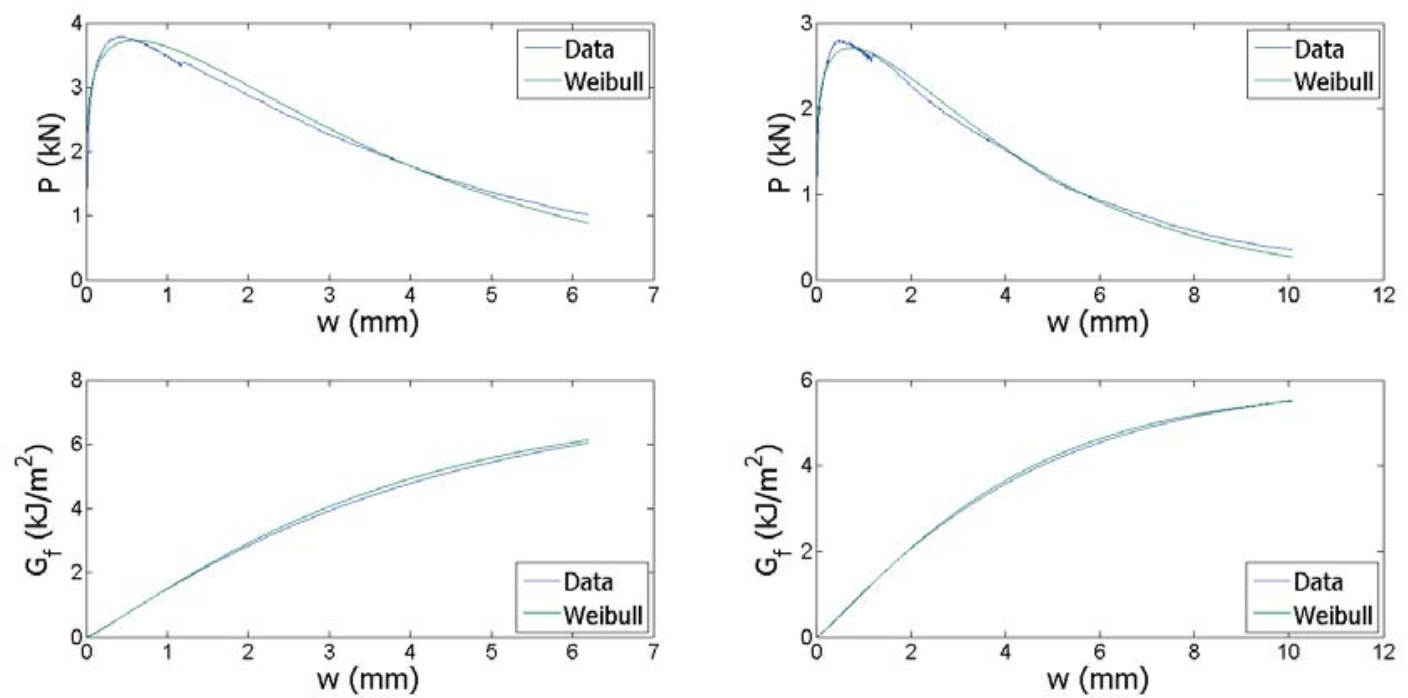

Figure E.6: NP-A-3d-f1-2580-9 best fit (Left) and NP-A-3d-f1-2580-13.75 best fit (Right) 

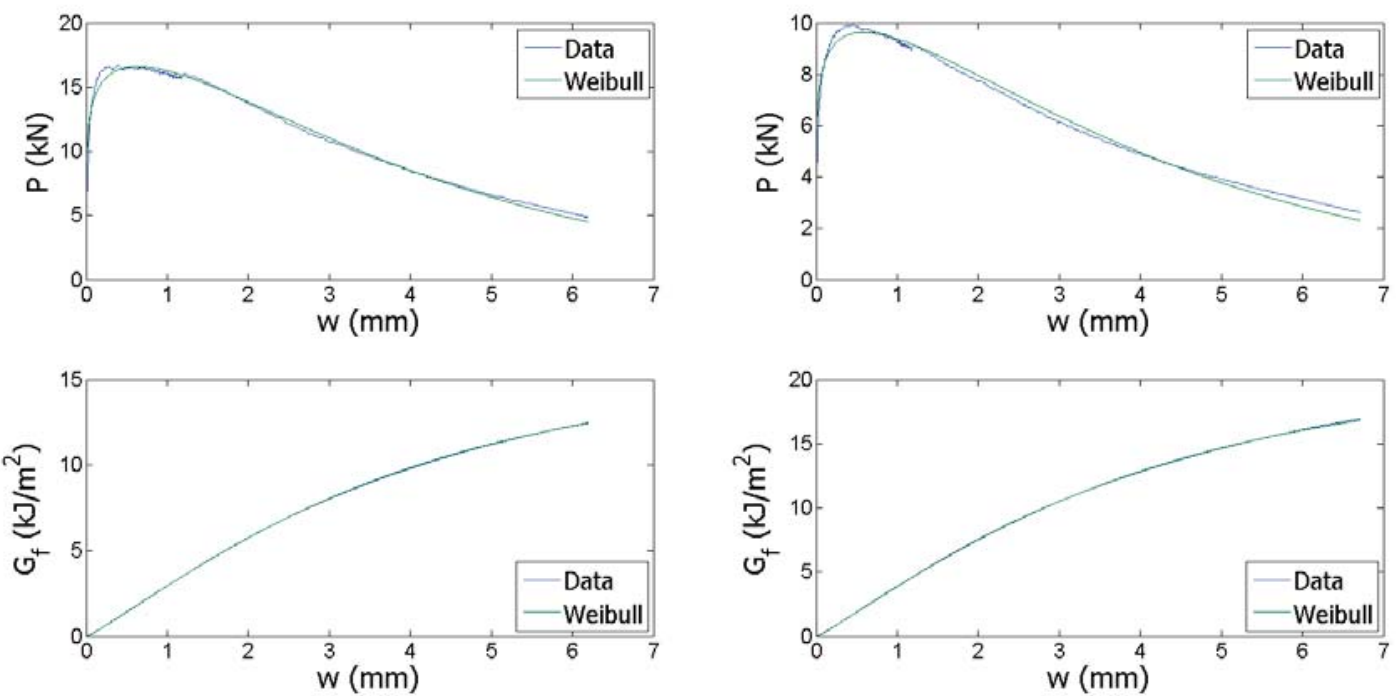

Figure E.7: NP-A-3d-f2-5180-4.5 best fit (Left) and NP-A-7d-f2-2580-4.5 best fit (Right)
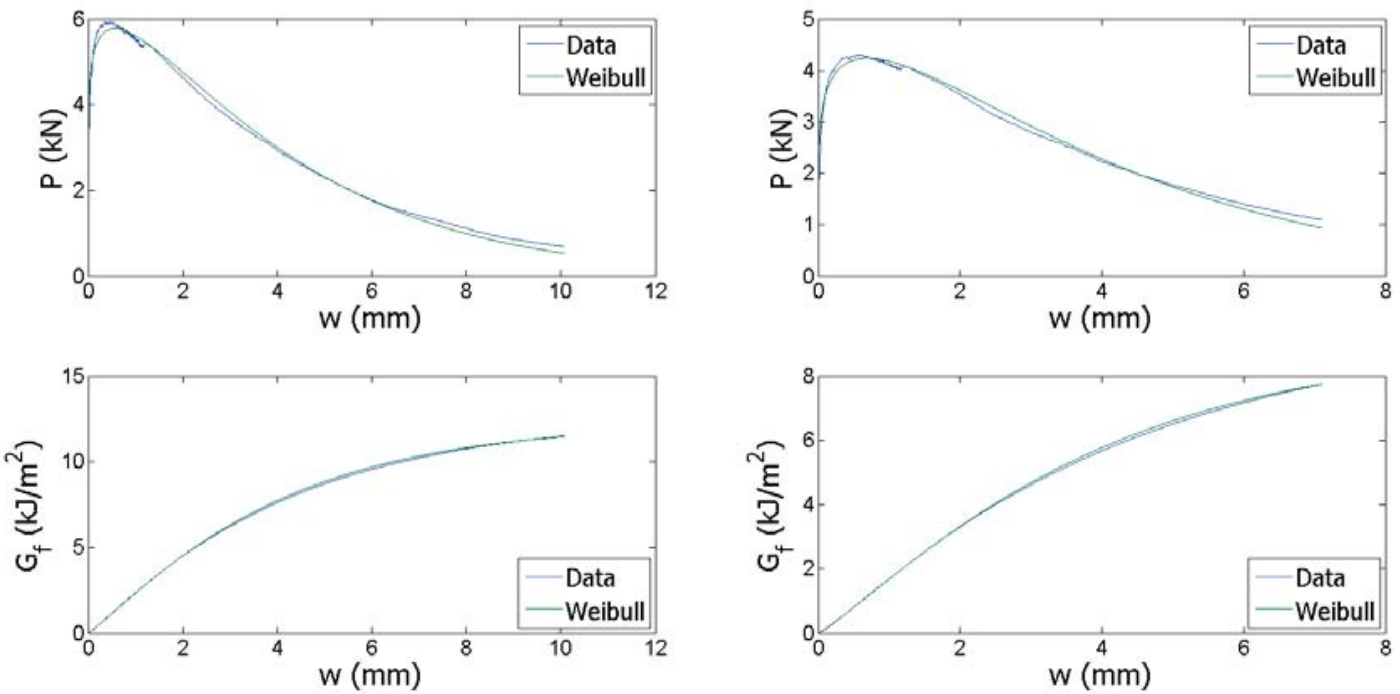

Figure E.8: NP-A-7d-f2-5180-6.75 best fit (Left) and NP-A-7d-f2-2580-9 best fit (Right) 

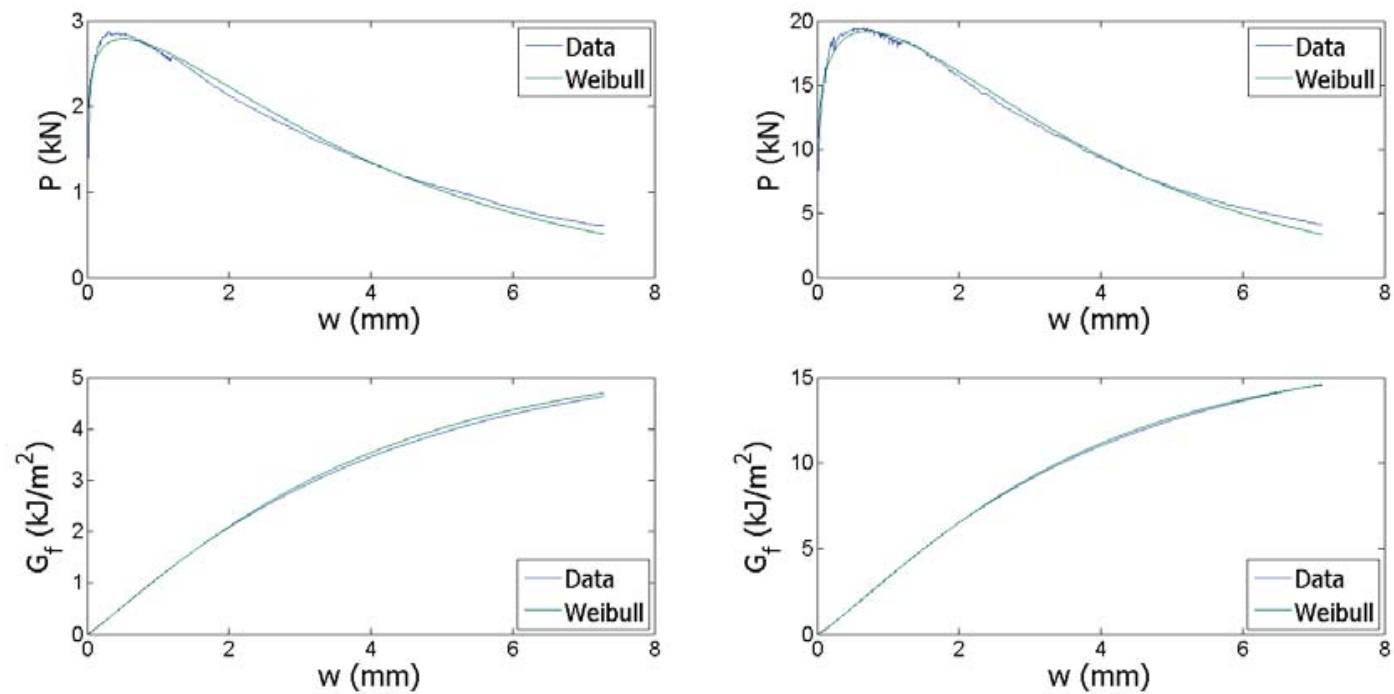

Figure E.9: NP-A-7d-f2-2580-13.75 best fit (Left) and NP-A-7d-f2-5180-4.5 best fit (Right)
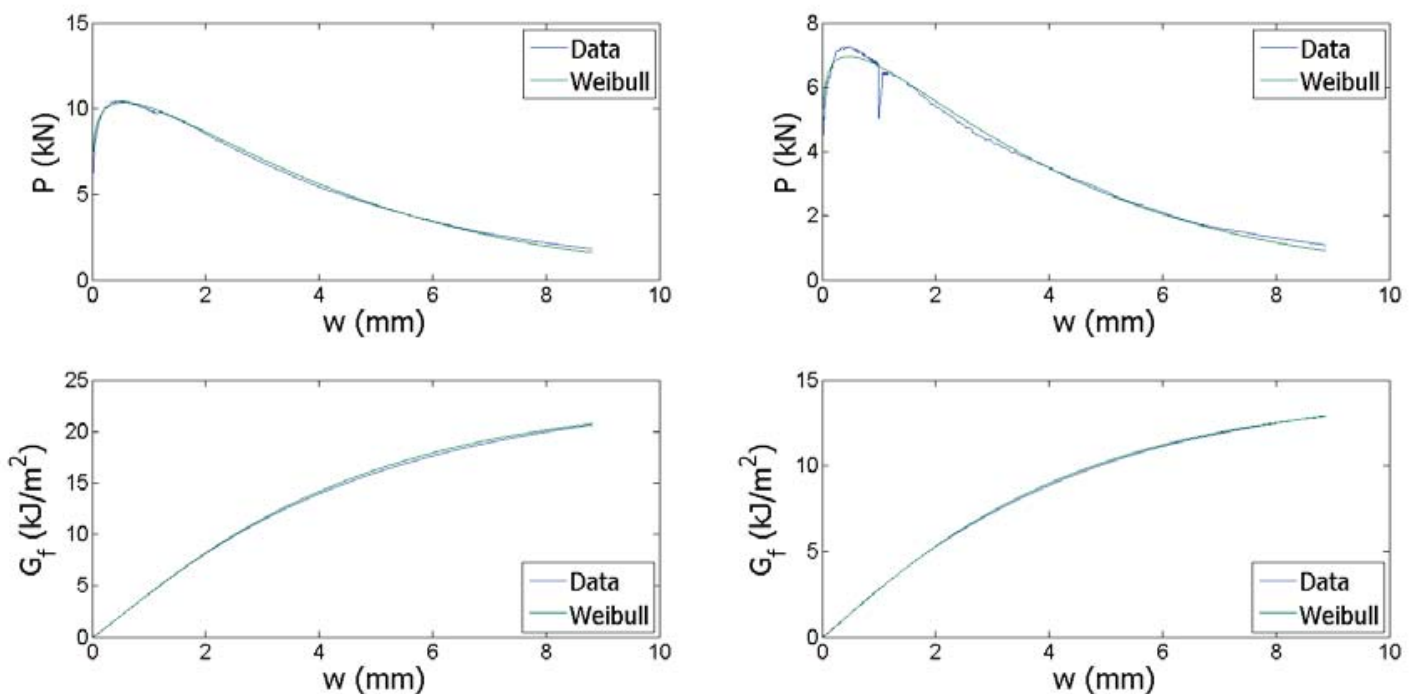

Figure E.10: NP-A-28d-f2-2580-4.5 best fit (Left) and NP-A-28d-f2-2580-6.75 best fit (Right) 

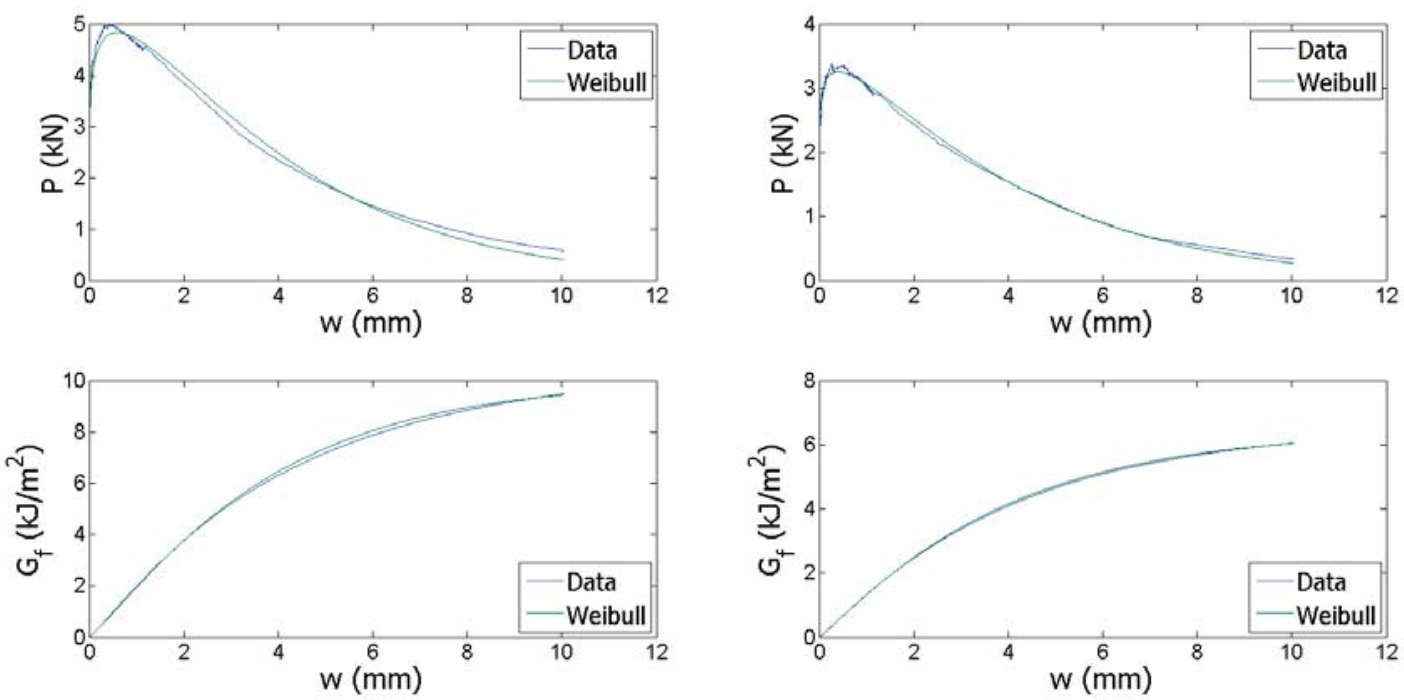

Figure E.11: NP-A-28d-f1-2580-9 best fit (Left) and NP-A-28d-f1-2580-13.75 best fit (Right)
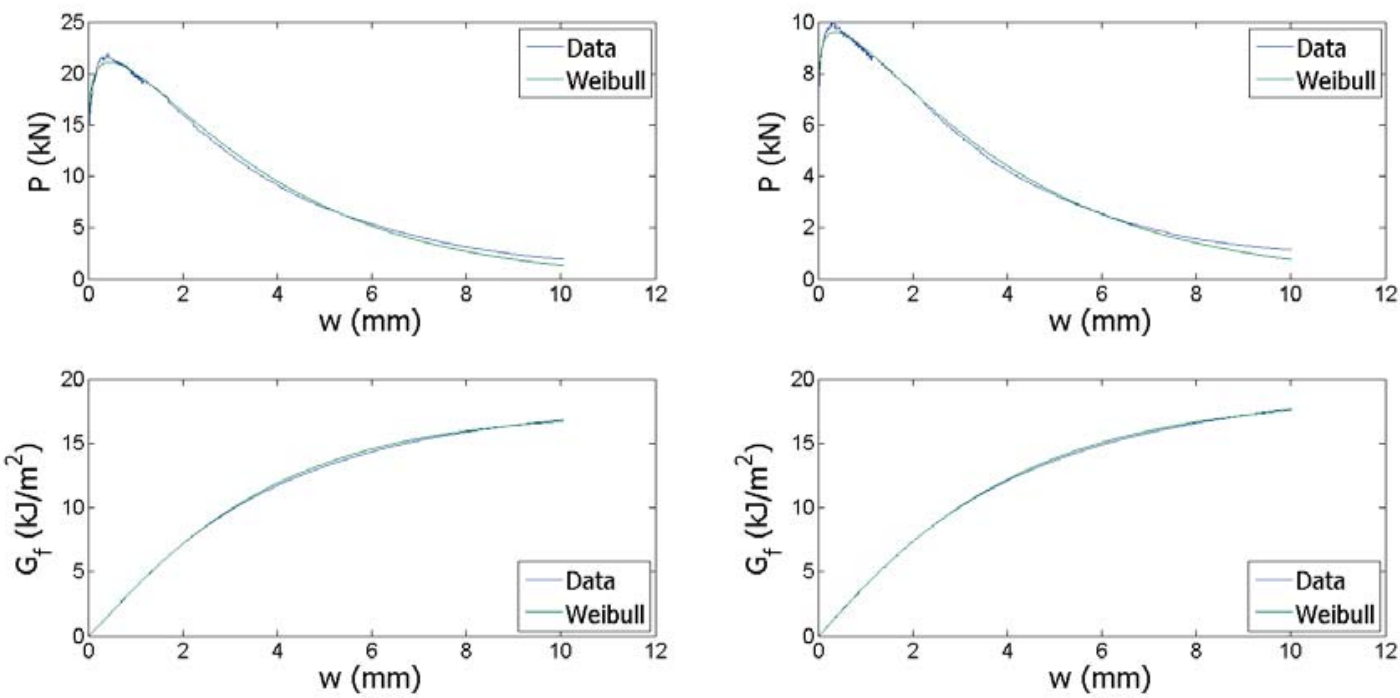

Figure E.12: NP-A-28d-f2-5180-4.5 best fit (Left) and NP-A-56d-f2-2580-4.5 best fit (Right) 

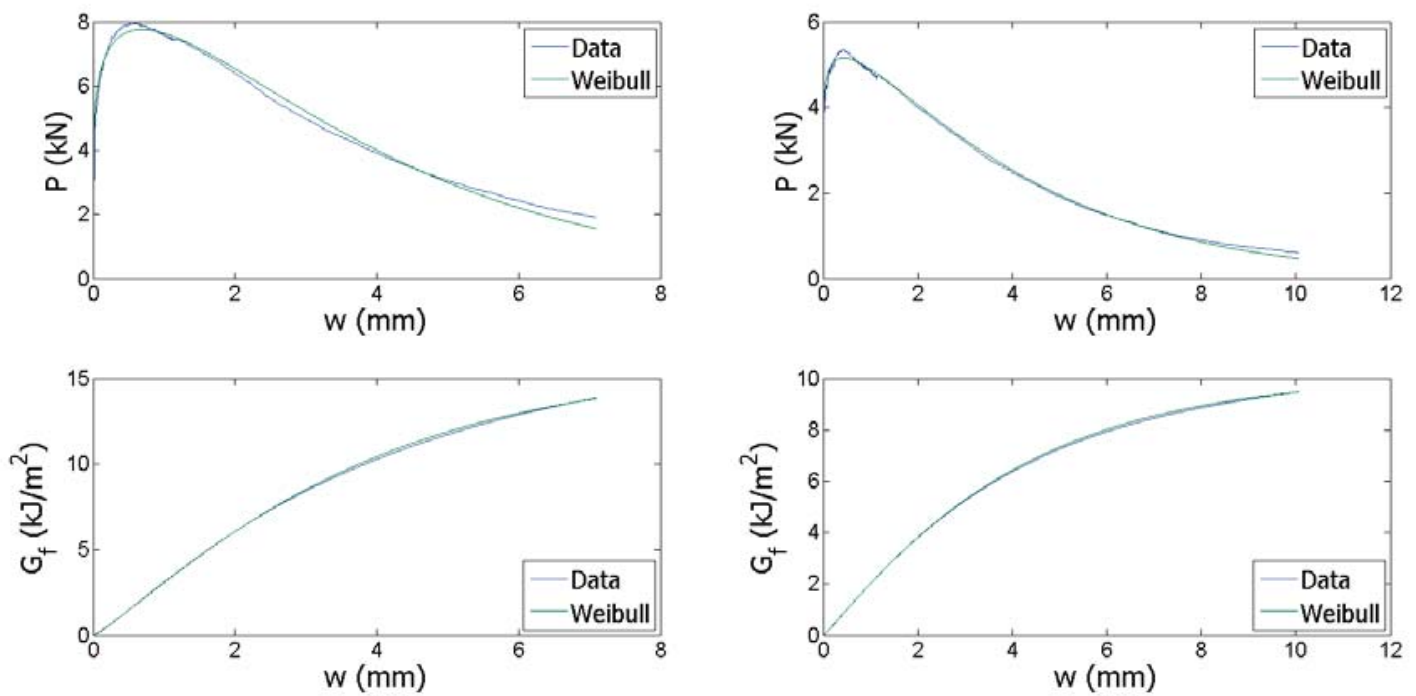

Figure E.13: NP-A-56d-f2-2580-6.75 best fit (Left) and NP-A-56d-f2-5180-9 best fit (Right)
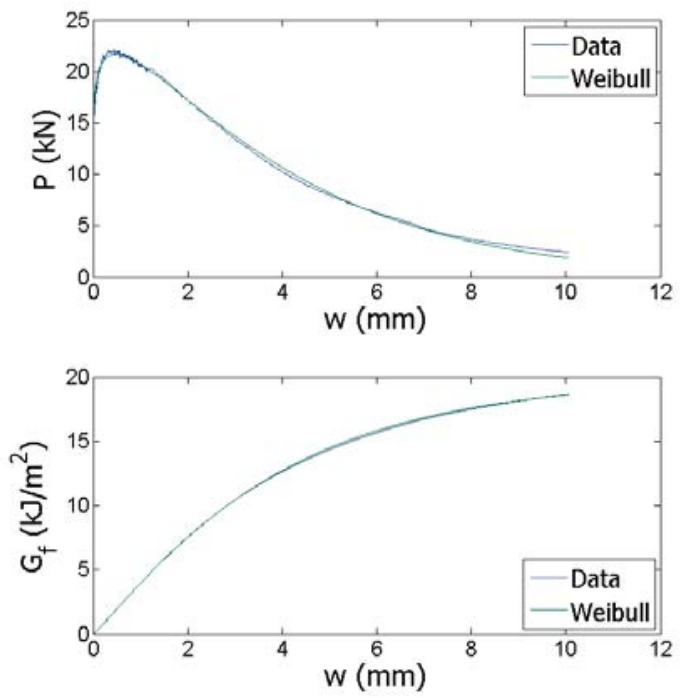

Figure E.14: NP-A-56d-f2-5180-4.5 best fit 

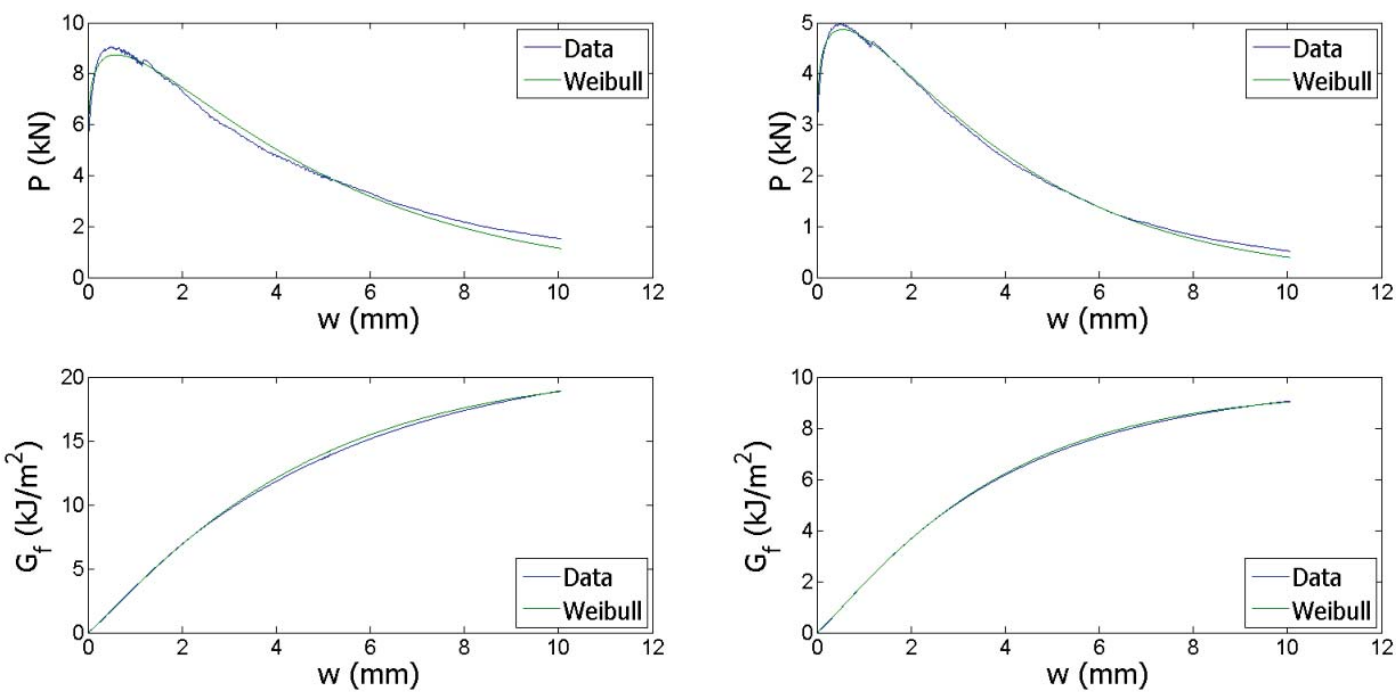

Figure E.15: NP-A-3d-f3-2580-4.5 best fit (Left) and NP-A-3d-f3-2580-9 best fit (Right)
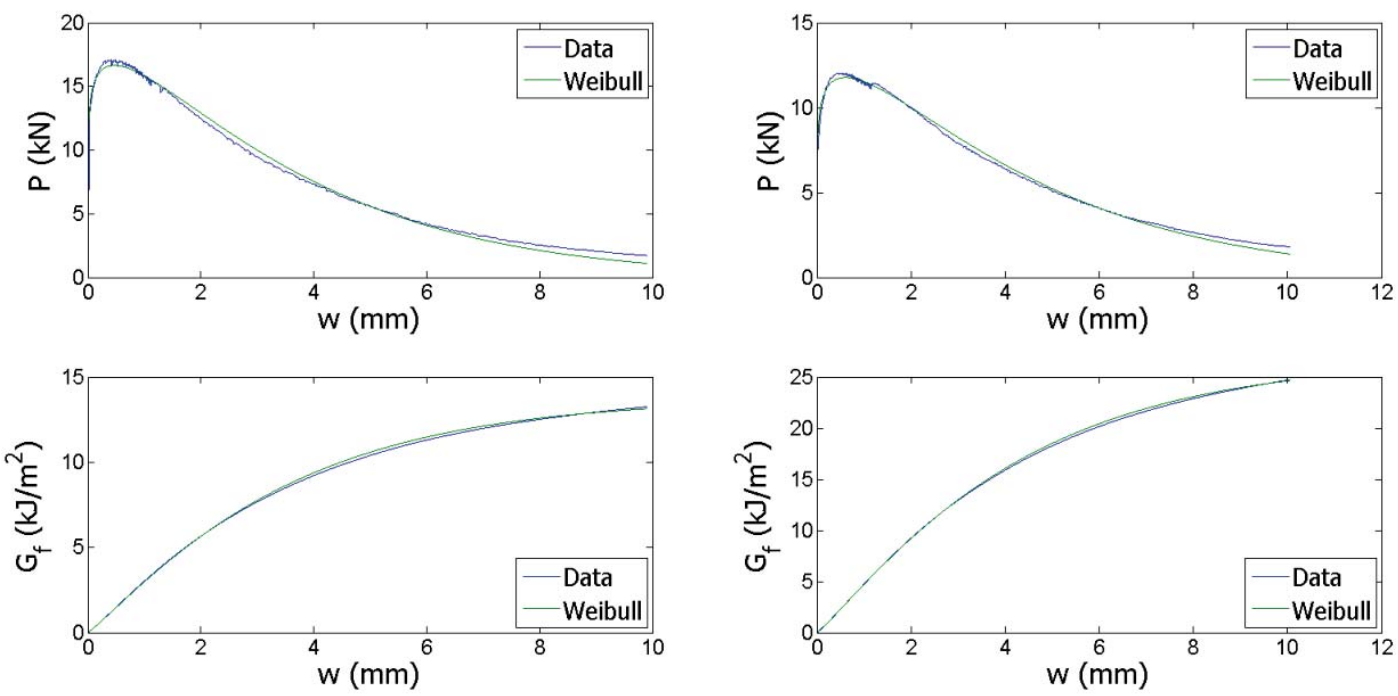

Figure E.16: NP-A-3d-f3-5180-4.5 best fit (Left) and NP-A-7d-f3-2580-4.5 best fit (Right) 

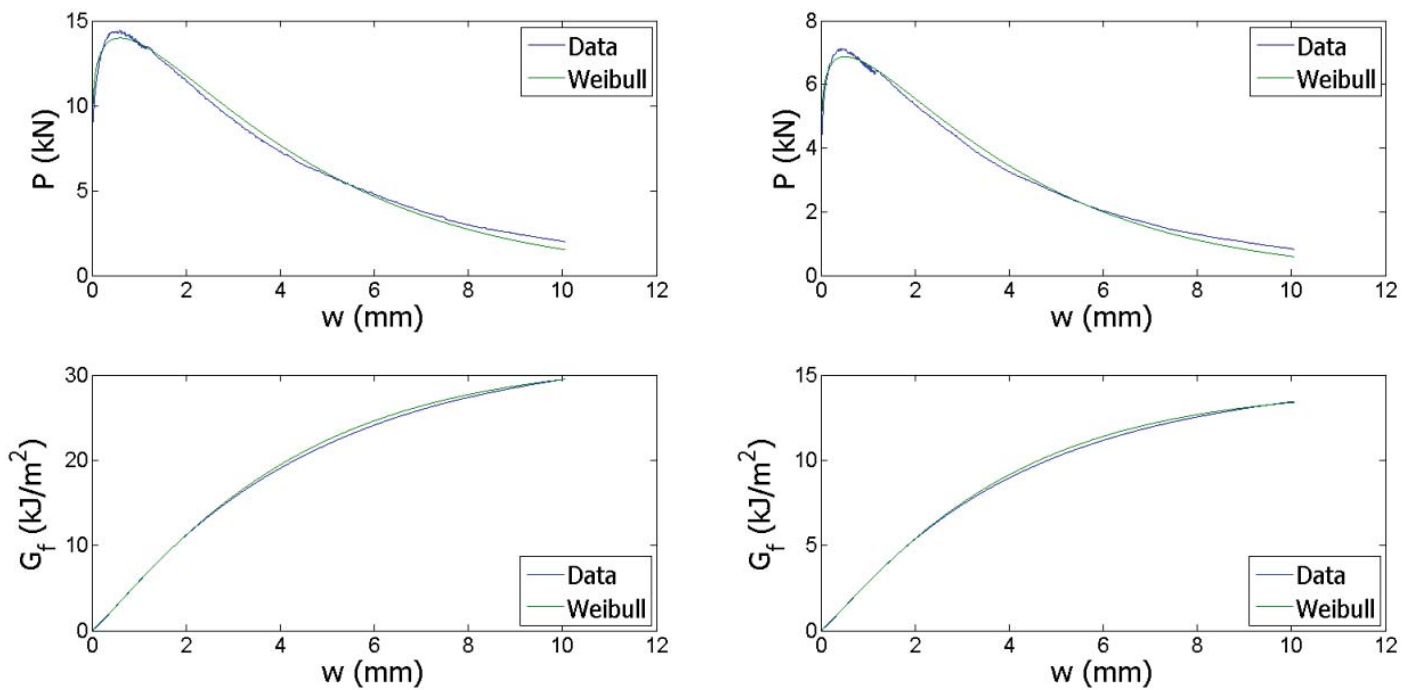

Figure E.17: NP-A-28d-f3-2580-4.5 best fit (Left) and NP-A-28d-f3-2580-9 best fit (Right)
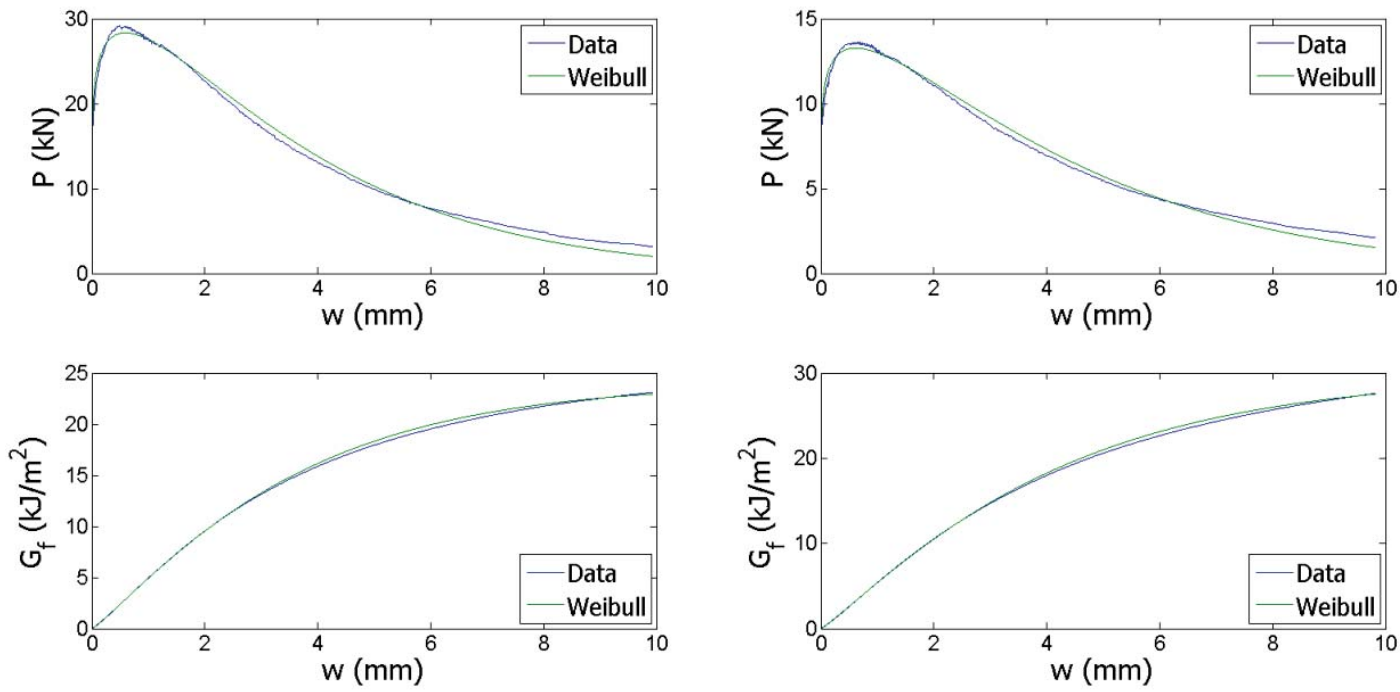

Figure E.18: NP-A-28d-f3-5180-4.5 best fit (Left) and NP-A-56d-f3-2580-4.5 best fit (Right) 

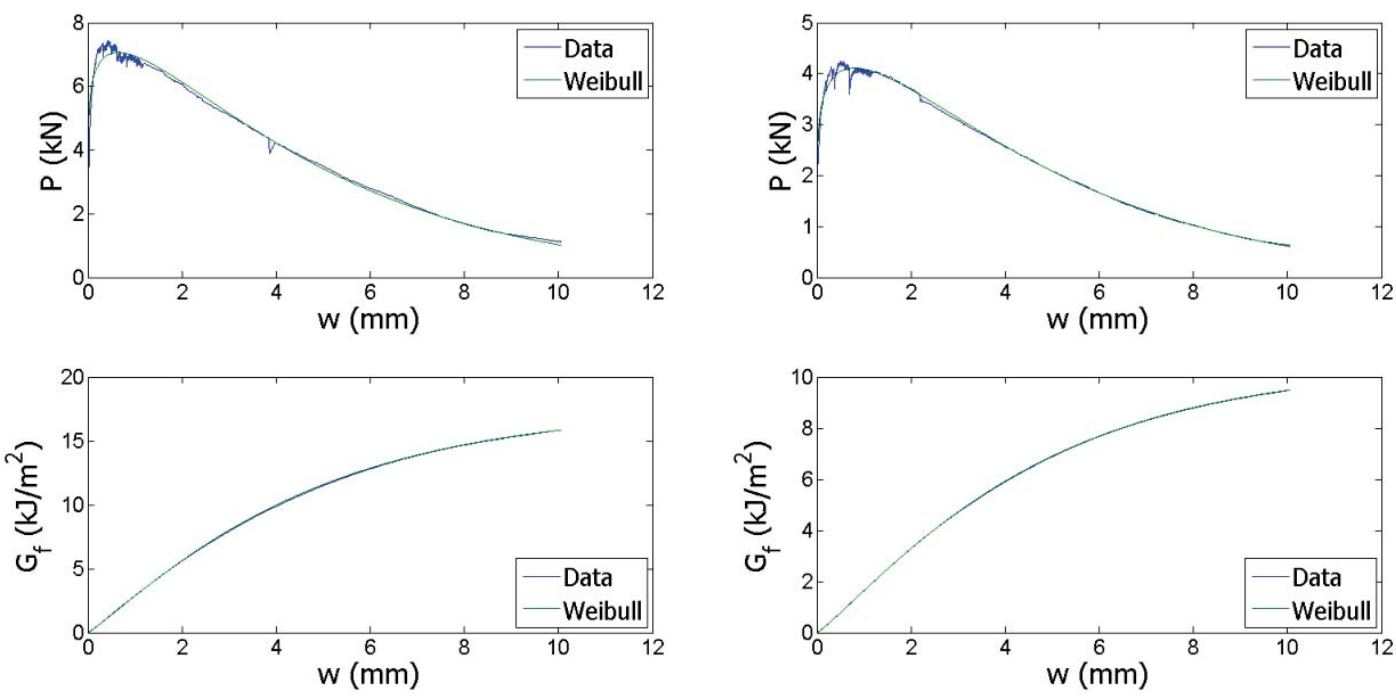

Figure E.19: NP-TT-7d-f1-2580-4.5 best fit (Left) and NP-TT-7d-f1-2580-9 best fit (Right)
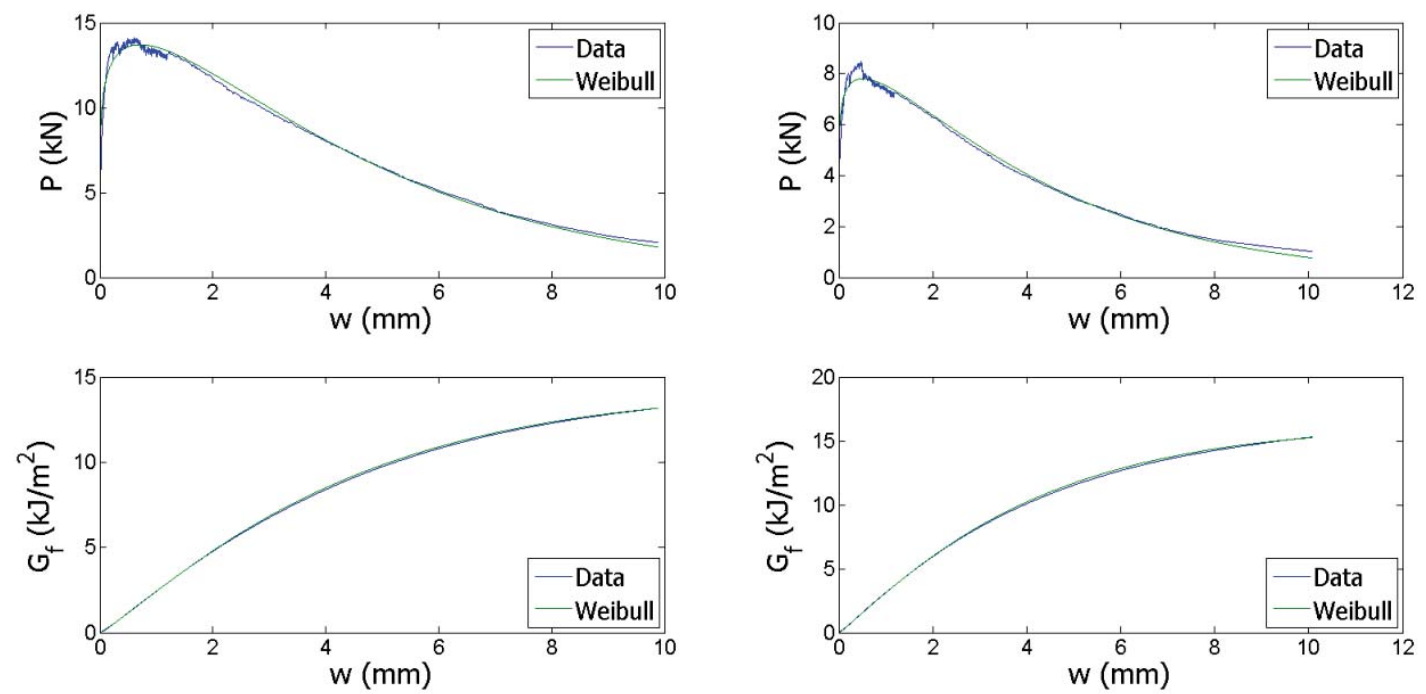

Figure E.20: NP-TT-7d-f1-5180-4.5 best fit (Left) and NP-TT-28d-f1-2580-4.5 best fit (Right) 

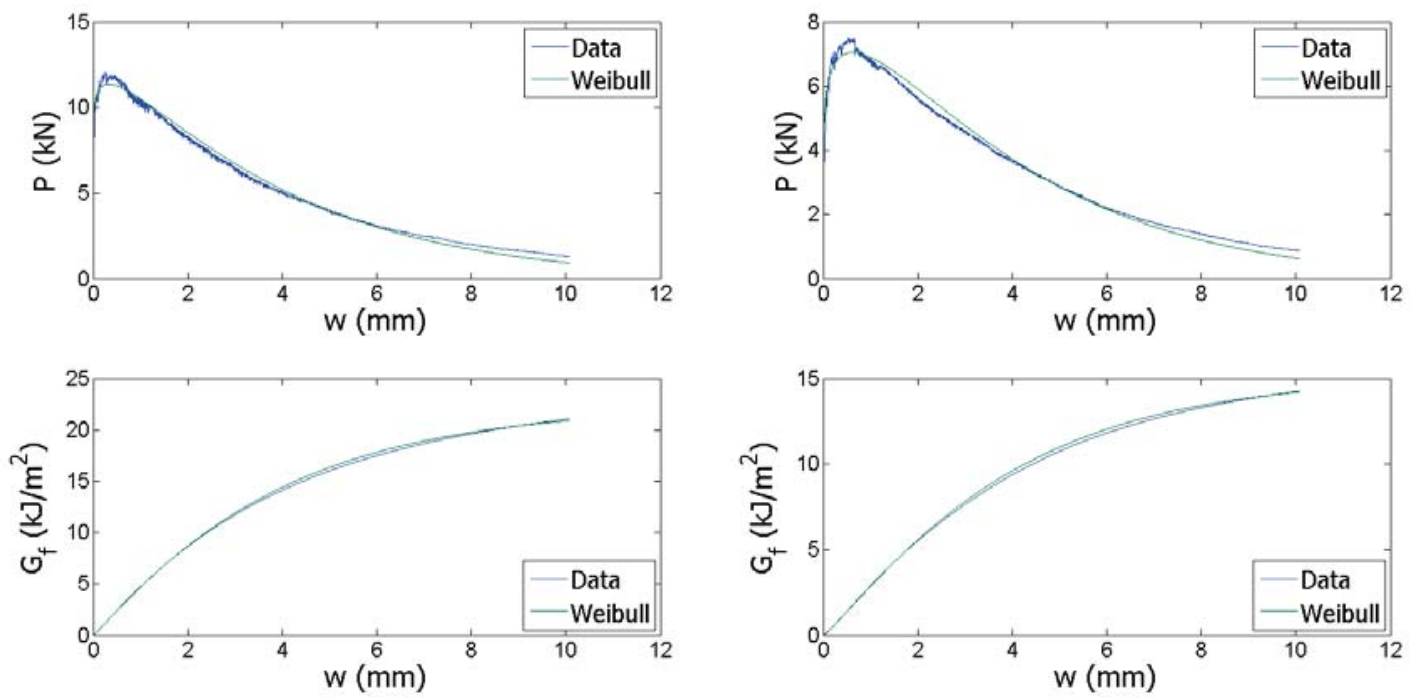

Figure E.21: NP-TT-7d-f2-2580-4.5 best fit (Left) and NP-TT-7d-f2-2580-6.75 best fit (Right)
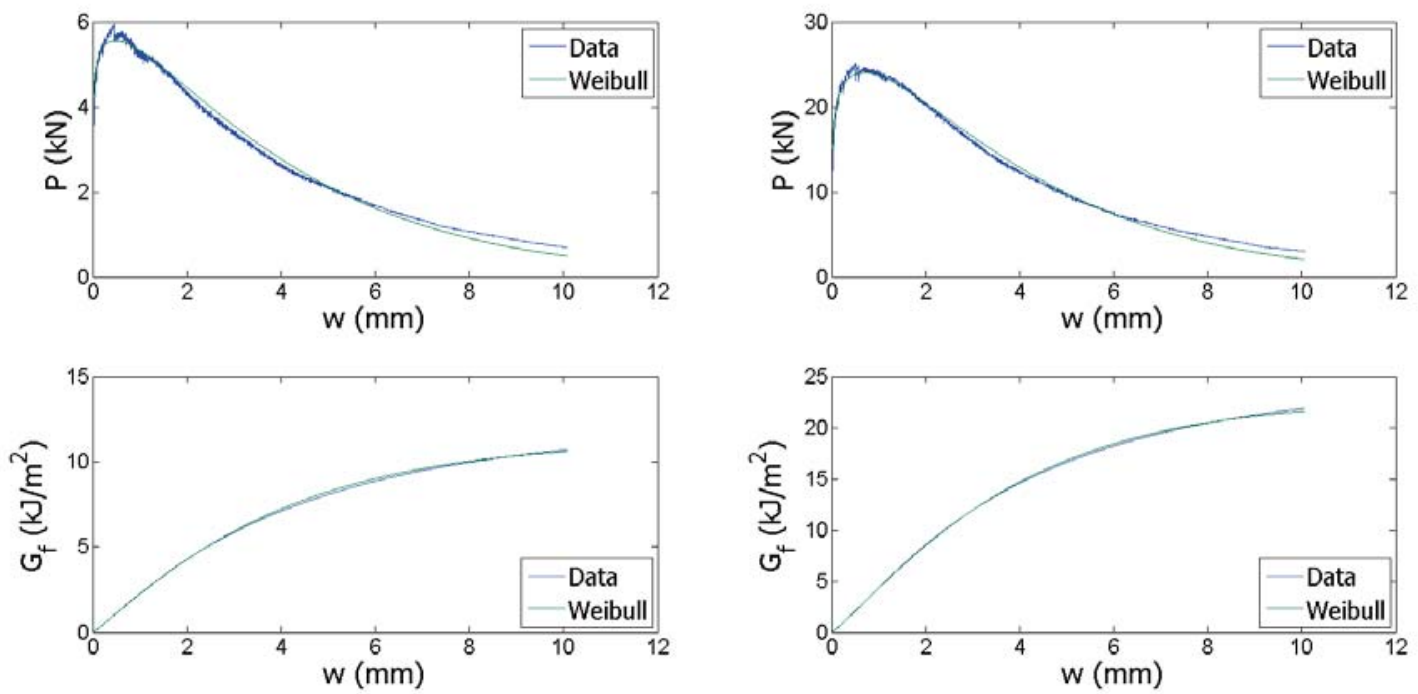

Figure E.22: NP-TT-7d-f2-2580-9 best fit (Left) and NP-TT-7d-f2-5180-4.5 best fit (Right) 

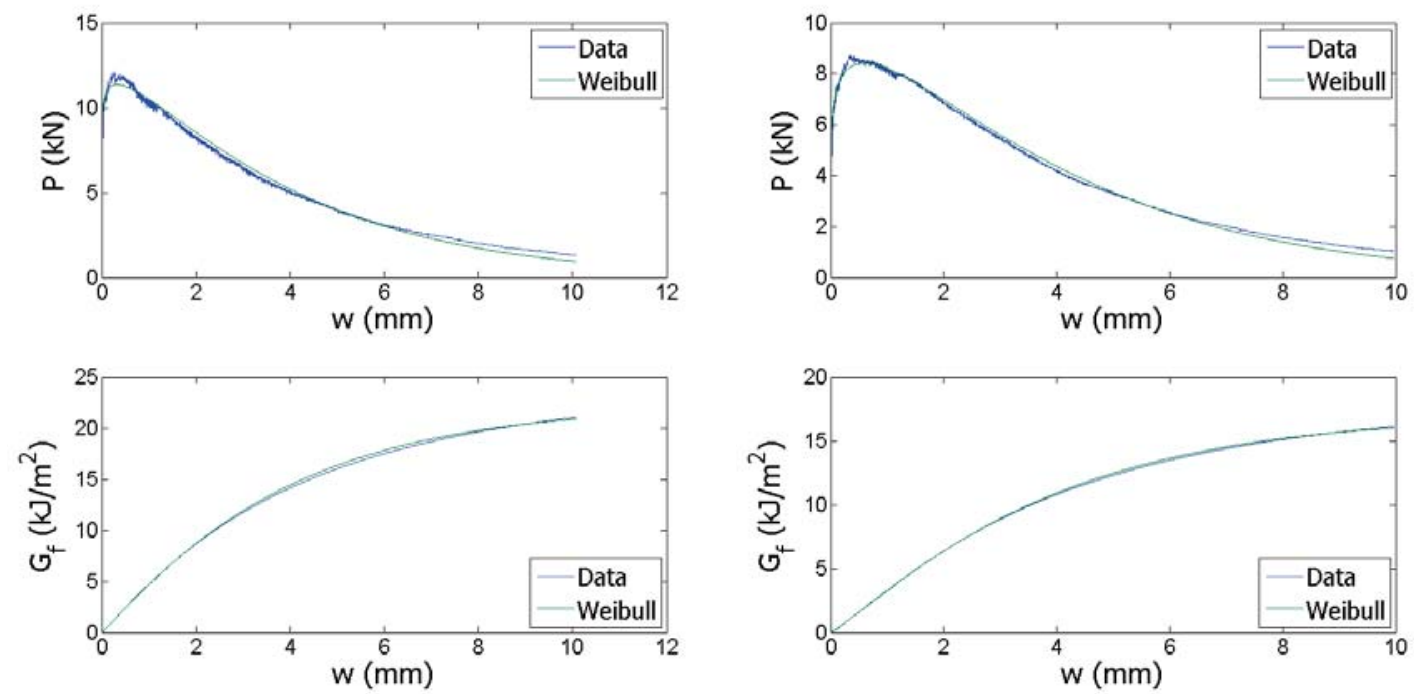

Figure E.23: NP-TT-28d-f2-2580-4.5 best fit (Left) and NP-TT-28d-f2-2580-6.75 best fit (Right)
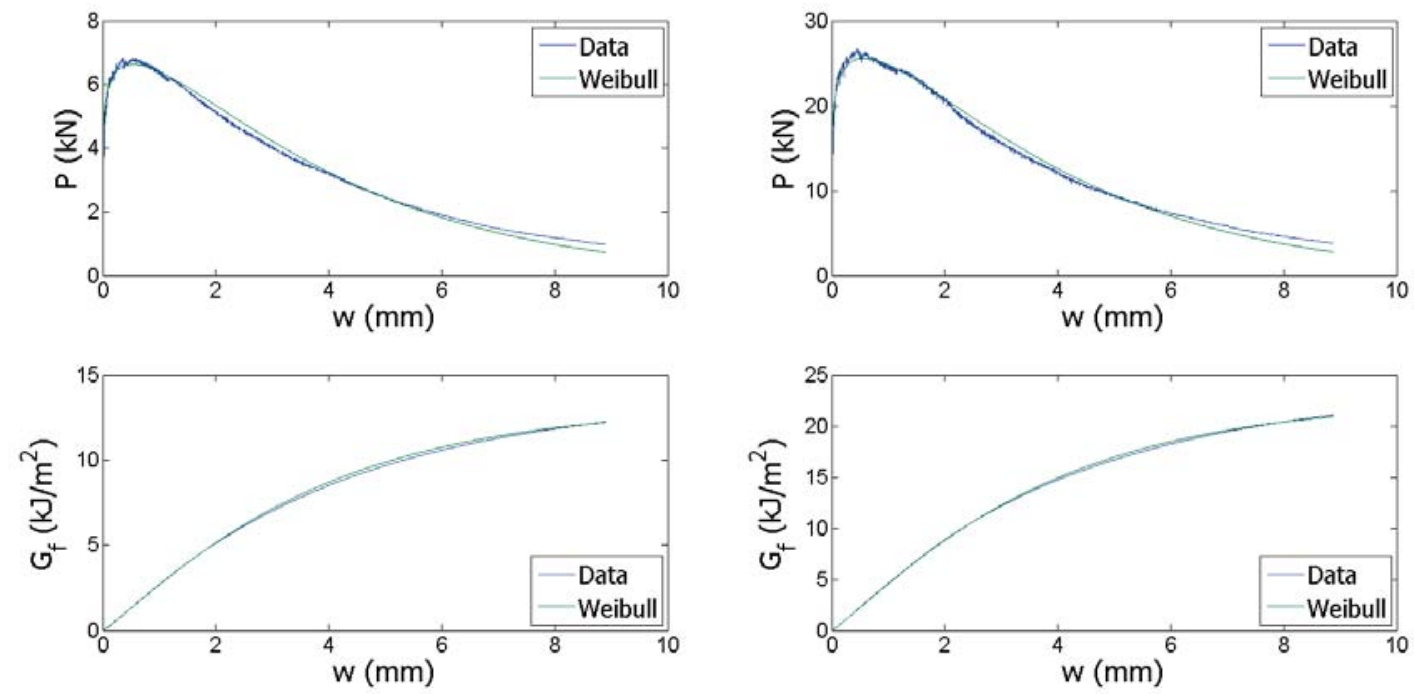

Figure E.24: NP-TT-28d-f2-2580-9 best fit (Left) and NP-TT-28d-f2-5180-4.5 best fit (Right) 

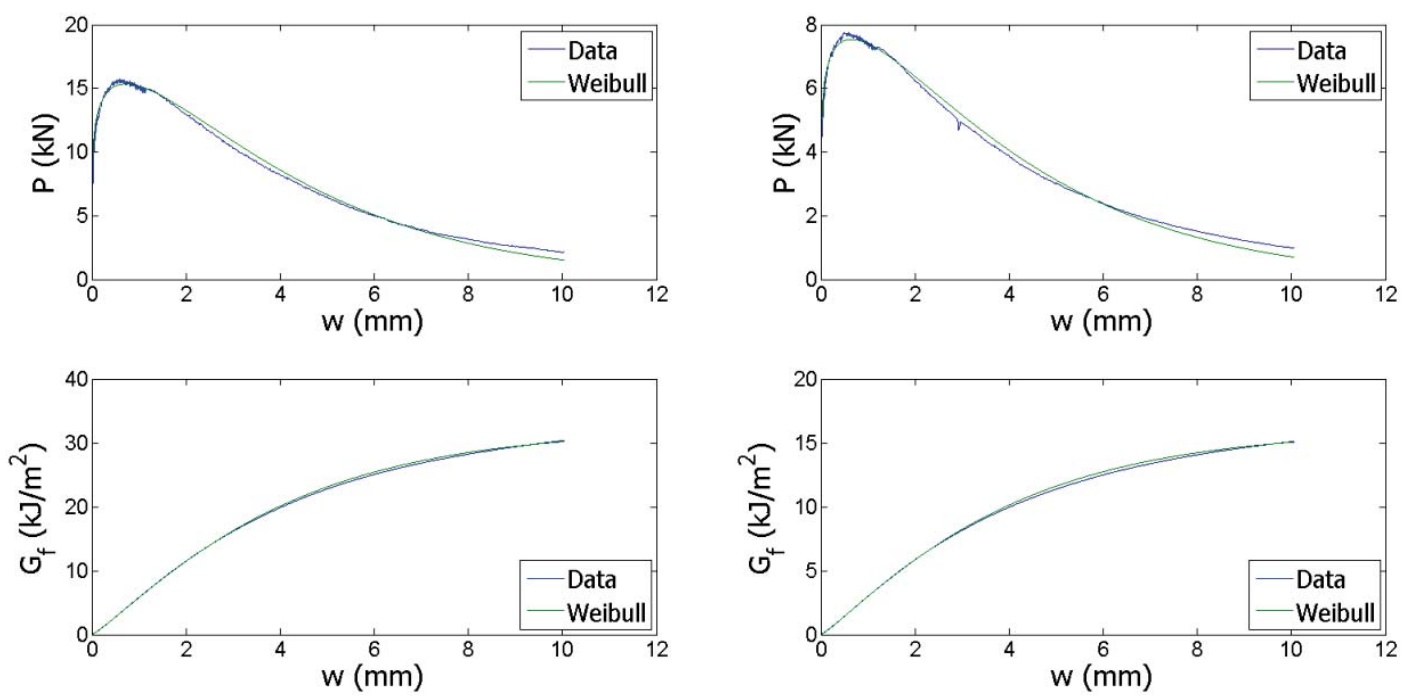

Figure E.25: NP-TT-7d-f3-2580-4.5 best fit (Left) and NP-TT-7d-f3-2580-9 best fit (Right)
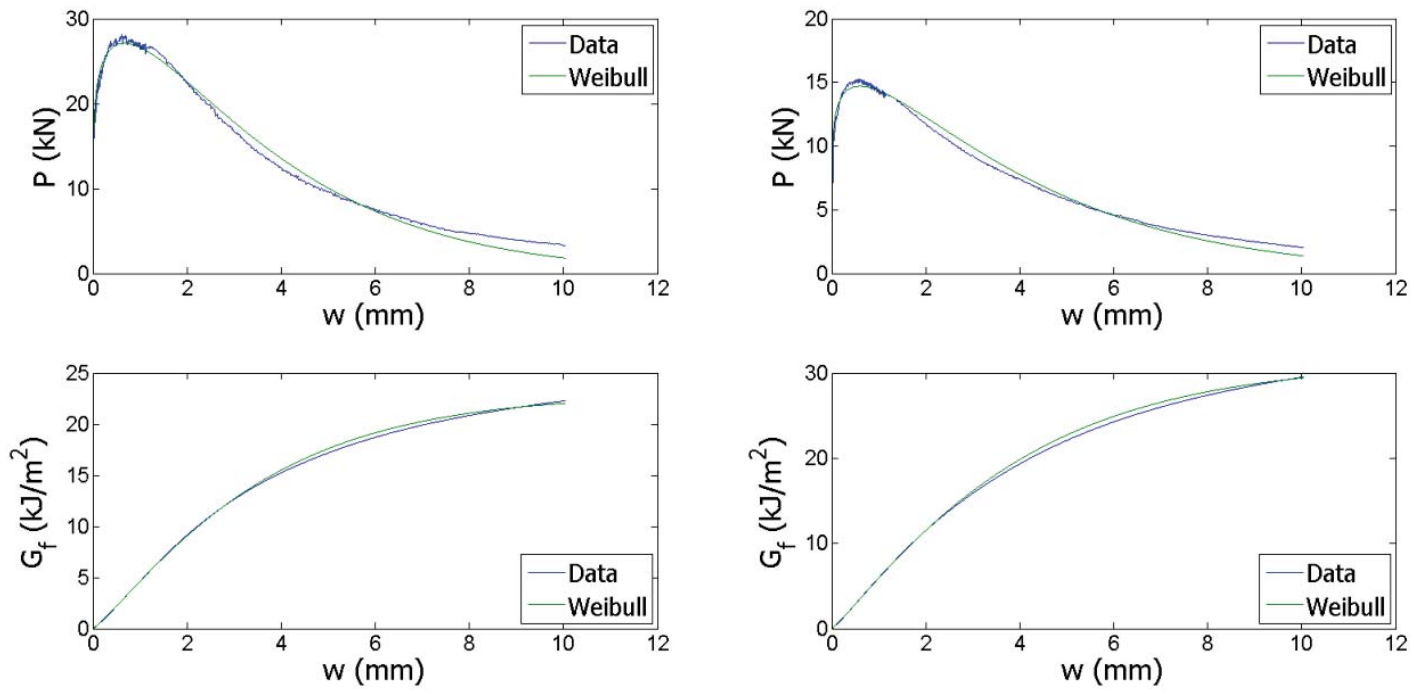

Figure E.26: NP-TT-7d-f3-5180-4.5 best fit (Left) and NP-TT-28d-f3-2580-4.5 best fit (Right) 

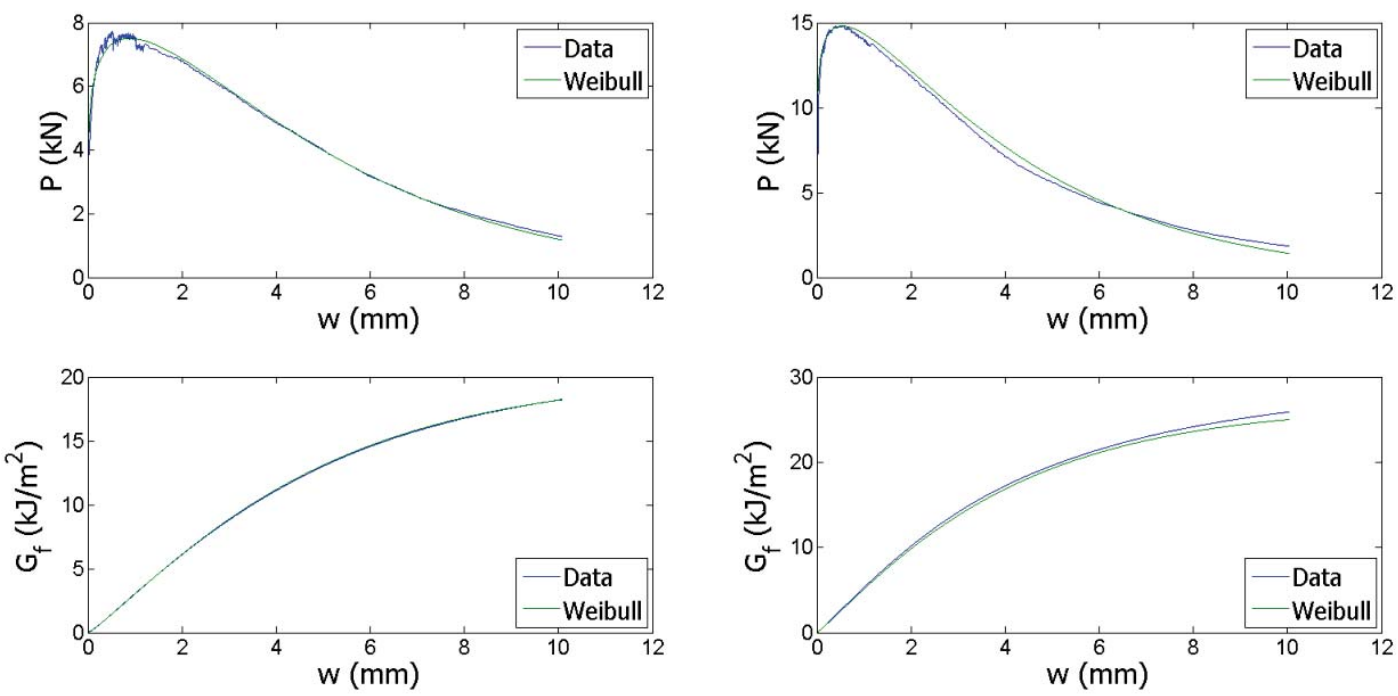

Figure E.27: NP-DTT-28d-f1-2580-4.5 best fit (Left) and NP-DTT-28d-f3-2580-4.5 best fit (Left)
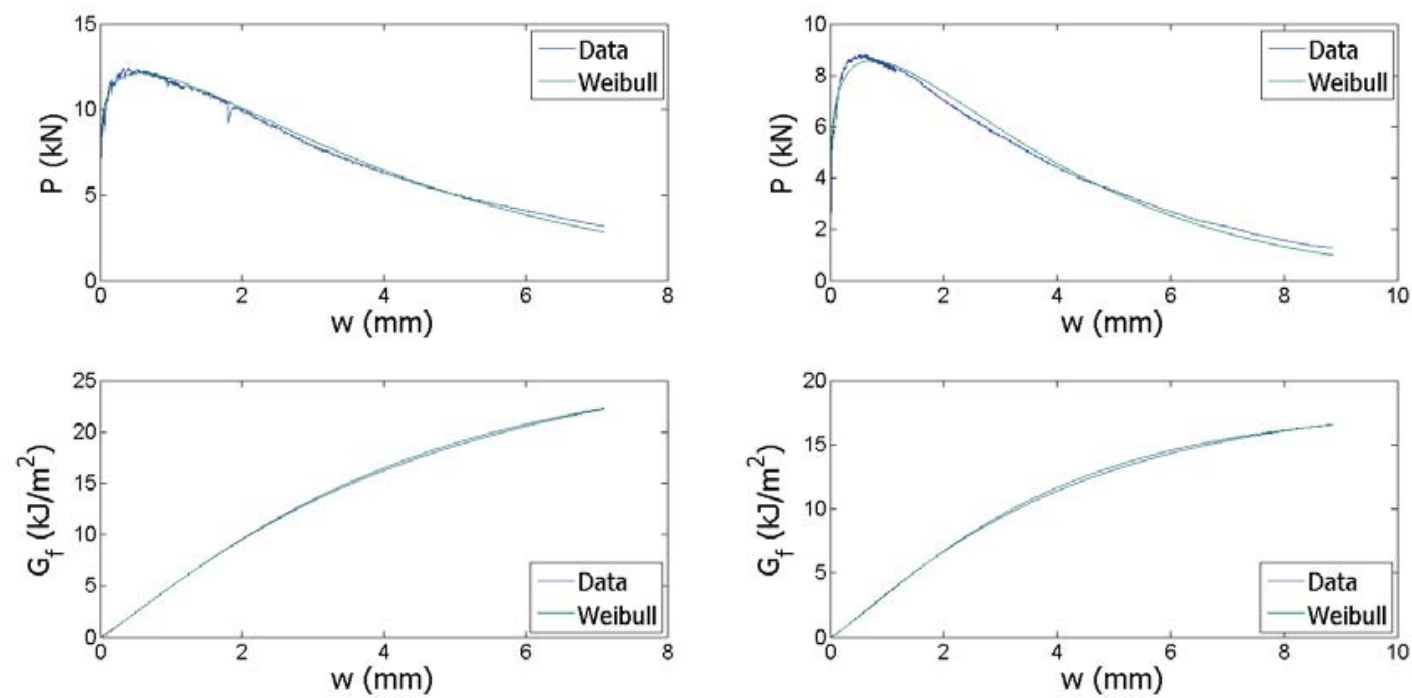

Figure E.28: NP-DTT-28d-f2-2580-4.5 best fit (Left) and NP-DTT-28d-f2-2580-6.75 best fit (Right) 

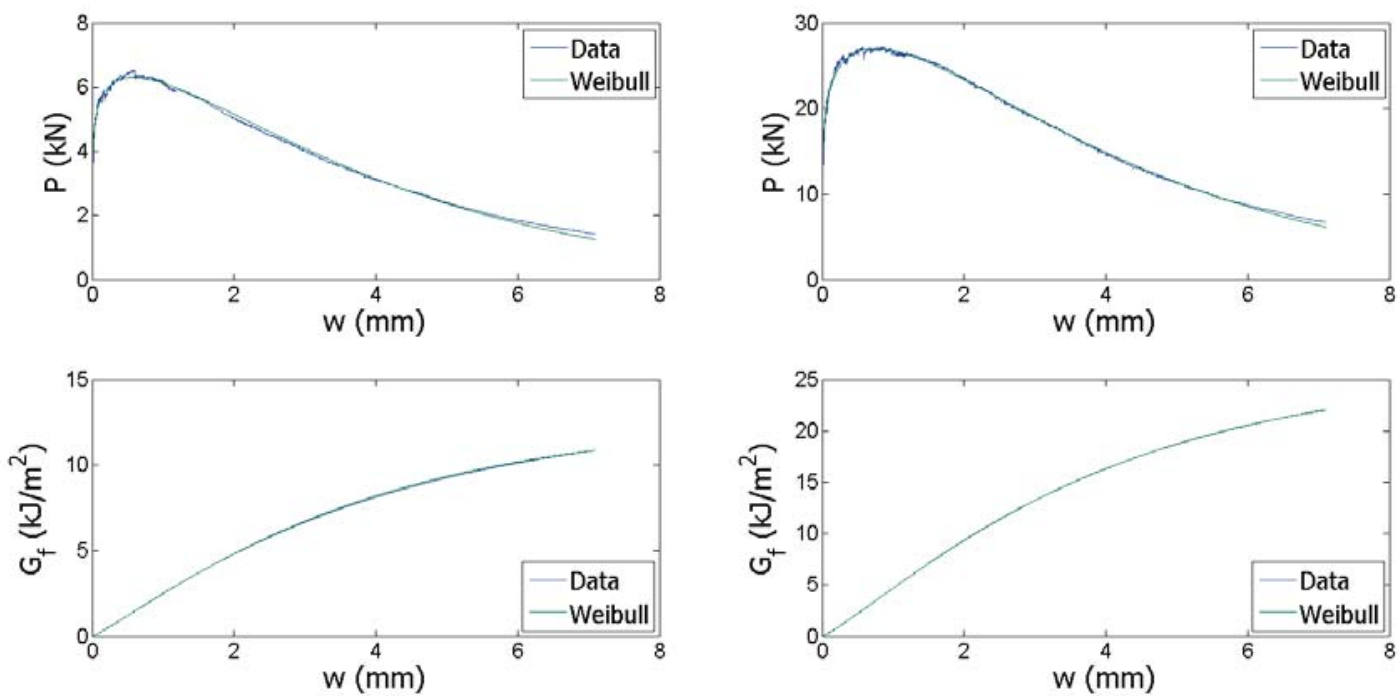

Figure E.29: NP-DTT-28d-f2-2580-9 best fit (Left) and NP-DTT-28d-f2-5180-4.5 best fit (Right) 